Portland State University

PDXScholar

\title{
Northwest Forest Plan The First 15 Years (1994-2008): Watershed Condition Status and Trend
}

Steven H. Lanigan

Sean N. Gordon

Portland State University, sean.gordon@pdx.edu

Peter Eldred

Mark Isley

Bureau of Land Management

Heidi Anderson

U.S. Department of Agriculture

Follow this and additional works at: https://pdxscholar.library.pdx.edu/iss_pub

Part of the Forest Management Commons, and the Water Resource Management Commons Let us know how access to this document benefits you.

\section{Citation Details}

Lanigan, S., Northwest Forest Plan, \& Pacific Northwest Research Station. (2012). Northwest Forest Plan, the first 15 years (1994-2008). Watershed condition status and trend (General technical report PNW ; 856). Portland, OR: U.S. Dept. of Agriculture, Forest Service, Pacific Northwest Research Station.

This Technical Report is brought to you for free and open access. It has been accepted for inclusion in Institute for Sustainable Solutions Publications and Presentations by an authorized administrator of PDXScholar. Please contact us if we can make this document more accessible: pdxscholar@pdx.edu. 


NORTHWEST
FOREST PLAN
The First 15 Years (1994-2008)

\section{Watershed Condition Status and Trend}

Steven H. Lanigan, Sean N. Gordon, Peter Eldred, Mark Isley, Steve Wilcox, Chris Moyer, and Heidi Andersen

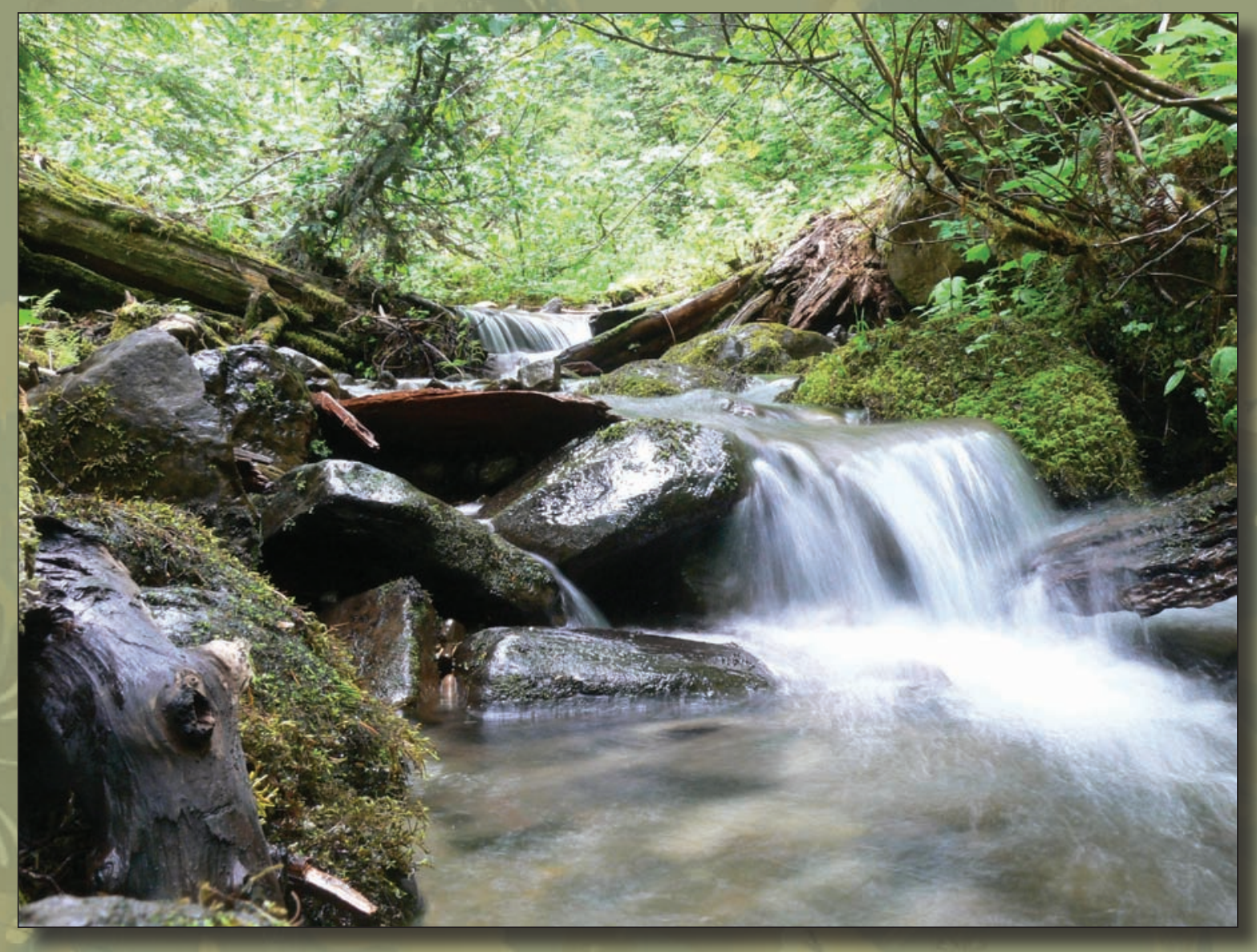

General Technical Report PNW-GTR-856 February 2012
USDA United States Department of Agriculture

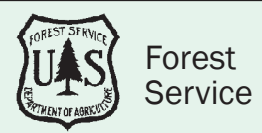


The Forest Service of the U.S. Department of Agriculture is dedicated to the principle of multiple use management of the Nation's forest resources for sustained yields of wood, water, forage, wildlife, and recreation. Through forestry research, cooperation with the States and private forest owners, and management of the national forests and national grasslands, it strives_-as directed by Congress—-to provide increasingly greater service to a growing Nation.

The U.S. Department of Agriculture (USDA) prohibits discrimination in all its programs and activities on the basis of race, color, national origin, age, disability, and where applicable, sex, marital status, familial status, parental status, religion, sexual orientation, genetic information, political beliefs, reprisal, or because all or part of an individual's income is derived from any public assistance program. (Not all prohibited bases apply to all programs.) Persons with disabilities who require alternative means for communication of program information (Braille, large print, audiotape, etc.) should contact USDA's TARGET Center at (202) 720-2600 (voice and TDD). To file a complaint of discrimination, write USDA, Director, Office of Civil Rights, Room 1400 Independence Avenue, SW, Washington, DC 20250-9410 or call (800) 795-3272 (voice) or (202) 720-6382 (TDD). USDA is an equal opportunity provider and employer.

\section{Authors}

Steven H. Lanigan is the module leader, Peter Eldred is the geographic information system (GIS) coordinator, Mark Isley is the database manager, Steve Wilcox is the GIS cartographer, and Heidi Andersen is a fish biologist for the Aquatic and Riparian Effectiveness Monitoring Program, U.S. Department of Agriculture, Forest Service, Pacific Northwest Region, 333 SW First Ave., Portland, OR 97204; Sean N. Gordon is a research associate with the Department of Forest Engineering, Resources and Management, Oregon State University, 333 SW First Ave., Portland, OR 97204; Chris Moyer is a fish biologist for the Aquatic and Riparian Effectiveness Monitoring Program, U.S. Department of the Interior, Bureau of Land Management, Oregon State Office, 4077 Research Way, Corvallis, OR 97333.

Cover photo by Steve Lanigan. 


\section{Abstract}

\section{Lanigan, Steven H.; Gordon, Sean N.; Eldred, Peter; Isley, Mark; Wilcox, Steve; Moyer, Chris; Andersen, Heidi. 2012. Northwest Forest Plan - the first 15 years (1994-2008): watershed condition status and trend. Gen. Tech. Rep. PNW-GTR-856. Portland, OR: U.S. Department of Agriculture, Forest Service, Pacific Northwest Research Station. 155 p.}

We used two data sets to evaluate stream and watershed condition for sixth-field watersheds in each aquatic province within the Northwest Forest Plan (NWFP) area: stream data and upslope data. The stream evaluation was based on inchannel data (e.g., substrate, pieces of large wood, water temperature, pool frequency, and macroinvertebrates) we sampled from 2002 to 2009 (193 watersheds) as part of a repeating sample design. We just completed our first round of sampling, so only current condition was calculated for this data set. When condition scores for the inchannel data were grouped into categories, relatively few fell into the low (10 percent) and very low (1 percent) categories. The majority of inchannel attribute scores fell into the moderate ( 35 percent) and high ( 41 percent) condition ranges, with relatively few (12 percent) in the very high category. For low-scoring watersheds, water temperature was often the most influential factor. Aquatic invertebrate scores also appeared influential in producing the low scores. An evaluation of upslope and riparian (watershed-wide) conditions for all 1,379 sixth-field watersheds in the NWFP area with significant federal ownership was based on mapped data, including road metrics from U.S. Forest Service and Bureau of Land Management geographic information system road layers and vegetation metrics derived from satellite imagery.

Watershed-wide condition scores were calculated for 1994 and 2008, and the difference between these scores was used to represent trend. Regarding status, the overall condition scores of the 1,379 watersheds mostly fell into the low (21 percent), moderate (27 percent), high ( 26 percent), and very high ( 22 percent) categories; relatively few watersheds scored in the very low (4 percent) category. The majority of watersheds (69 percent) had a positive change in condition scores (trend). Of those with larger positive changes, most were driven by both improvements in road (decommissioning) and vegetation (natural growth) scores. The greatest negative score changes were caused by the Biscuit Fire and other fires along the eastern side of the Cascades. Half of the fire-affected watersheds were in congressional reserves, 35 percent in late-successional reserves, and 15 percent in matrix (lands identified for timber production).

Keywords: Effectiveness monitoring, status and trend monitoring, aquatic ecosystems, riparian ecosystems, watersheds, decision-support models, Northwest Forest Plan, aquatic conservation strategy, Pacific Northwest. 


\section{Summary}

The watershed monitoring module (also known as the Aquatic and Riparian Effectiveness Monitoring Program) determines if the Northwest Forest Plan's (NWFP) aquatic conservation strategy is achieving the goals of maintaining and restoring the condition of watersheds. The NWFP area being evaluated includes USDA Forest Service (FS), USDI Bureau of Land Management (BLM), and USDI National Park Service lands. Only the federal portion of sixth-field watersheds was included when determining watershed condition status and trend because federal agency land managers have no jurisdiction over nonfederal lands.

We used two data sets to evaluate stream and watershed condition for each aquatic province within the NWFP: stream data and upslope data. The stream evaluation was based on inchannel data (e.g., substrate, pieces of large wood, water temperature, pool frequency, and macroinvertebrates) we sampled from 2002 to 2009 (193 watersheds) as part of a repeating sample design. We completed our first round of sampling in 2009, so only current condition was calculated for this data set. An evaluation of upslope and riparian (watershedwide) conditions for all 1,379 sixth-field watersheds in the NWFP area with significant federal ownership was based on mapped data, including road metrics from FS and BLM geographic information system road layers and vegetation metrics derived from satellite imagery. Watershed-wide condition scores were calculated for 1994 and 2008, and the difference in these scores was used to represent trend. Experts from six aquatic provinces decided which indicators to use, and how to evaluate and combine them into an overall condition index for each level. We used decision-support modeling software to calculate the index scores for each watershed to a standardized range between -1 ("poor") and +1 ("good").

When condition scores for the inchannel data were grouped into categories, relatively few fell into the low (10 percent) and very low (1 percent) categories. The majority of inchannel attribute scores fell into the moderate (35 percent) and high (41 percent) condition ranges, with relatively few (12 percent) in the very high category. For low-scoring watersheds, water temperature was often the most influential factor. In many of the provincial evaluation models, a poor water temperature score carried more weight than other attributes because it was only measured once for each watershed (at the lowest point), in contrast to the other attributes, which were averaged over six to eight sites. Aquatic invertebrate scores also appeared influential in producing the low scores.

Regarding status, the overall condition scores of the 1,379 watersheds were clustered in the center of the distribution and skewed slightly positive. Most fell into the low (21 percent), moderate ( 27 percent), high ( 26 percent), and very high ( 22 percent) categories; relatively few watersheds scored in the very low (4 percent) category. The spatial distribution of watershed scores showed some noticeable patterns. High scores were found in the central Olympic Peninsula (Olympic National Park), the north central Cascades, the Oregon Coast Range, and scattered pockets along the Klamath-Siskiyou mountain range (mostly corresponding to designated wilderness areas). Low condition scores were present in the southern Olympic region, eastern Klamath-Siskiyou, and along the eastern and western flanks of the Cascade Range in Oregon and Washington. These low-scoring areas are 
generally closer to existing development and lower in elevation and slope, making them historically more accessible to roading and timber harvest. Watershed condition was most positive for congressionally reserved lands, followed by late-successional reserves (LSR), and then matrix lands. Key watersheds, which provide high-quality habitat or refugia for aquatic- and riparian-dependent species, or would be able to after restoration, were in better condition than nonkey watersheds in both 1994 and 2008.

The majority of watersheds ( 69 percent) had a positive change in condition scores (trend). By far the largest trend category was score increases between 0 and +0.1 (55 percent). This trend was largely due to small increases in vegetation scores from natural tree growth moving acres out of early seral classes or into late seral classes. The second largest trend category was a minor decrease between 0 and -0.1 (18 percent). Because there has been little road building on federal lands, this trend was again due to vegetation, but in this case, decreases in average tree diameter or canopy cover. Positive trends in the +0.1 to +0.3 range were mostly due to road decommissioning (42 percent) but with a fair contribution from vegetation ( 30 percent) and landslide risk ( 28 percent). Reduced landslide risk was the dominant driver of improvement for the +0.3 level ( 54 percent), apparently from road decommissioning in landslide-prone areas, because road improvements contributed considerably more ( 38 percent) than vegetation ( 8 percent) at this level. The greatest negative score changes were caused by the Biscuit Fire and other fires along the eastern side of the Cascades. Half of the fire-affected watersheds were in congressional reserves, 35 percent in LSRs, and 15 percent in matrix (lands identified for timber production). Changes by land use allocations indicated that the reserved class actually declined slightly $(-0.01)$, while the LSR $(+0.05)$ and matrix $(+0.04)$ both showed slight increases on average. Considering that the reserved class is already generally in good condition with respect to roads and vegetation, it is not surprising that it did not increase, and as harvest and road building are not permitted in these areas, the main driver was vegetation losses from fires. 


\section{Contents}

1 Chapter 1: Introduction

1 Background

2 Overview of the Aquatic Conservation Strategy

3 Overview of the Aquatic and Riparian Effectiveness Monitoring Program

4 Monitoring Questions

5 Chapter 2: Methods

5 Study Area

7 Land Use Categories

8 Study Design

8 Definition of Watershed Condition

11 Assessment of Watershed Condition

11 Monitoring Questions

14 1. What Is the Status of Inchannel Conditions?

15 2. What Is the Status of Upslope and Riparian Conditions?

23 3. What is the Trend in Watershed Conditions?

24 Model Validation

25 Uniform Indicators

28 Upslope Versus Inchannel Conditions

29 Chapter 3: Results

29 1. What Is the Status of Inchannel Conditions?

31 Inchannel Status by Land Category

36 2. What Is the Status of Upslope and Riparian Conditions?

36 Watershed Status by Land Category

40 3. What is the Trend in Watershed Conditions?

50 Watershed Trend by Land Use Category

53 Model Validation

55 Road Density

57 Late-Successional Old Growth

61 Disturbance

65 Upslope/Riparian Versus Inchannel Conditions 
69 Chapter 4: Discussion

69 Watershed Trend

69 Upslope/Riparian and Inchannel Current Status

69 Model Validation

70 Evaluating Dynamic Processes and the Role of Fire

72 Management Implication

72 Improving the Assessment

75 Chapter 5: Emerging Issues

82 Metric Equivalents

82 Acknowledgments

83 References

91 Appendix 1: Objectives of the Aquatic Conservation Strategy

93 Appendix 2: Project-Scale Restoration Efforts

101 Appendix 3: Watersheds Selected for Inchannel Monitoring

113 Appendix 4: Model Structures, Evaluation Criteria, and Status and Trend Maps for Each of the Provincial Decision-Support Models

145 Appendix 5: Additional Information on Inchannel, Upslope, and Riparian Data

151 Appendix 6: Quality Assessment of Upslope/Riparian and Inchannel Data

155 Appendix 7: Contact Information 


\section{Chapter 1: Introduction}

In 1994, the Northwest Forest Plan (NWFP) Record of

Decision (ROD) amended 19 national forest and 7 Bureau of Land Management (BLM) resource plans within the range of the northern spotted owl (Strix occidentalis caurina) (USDA and USDI 1994). An interagency effectiveness monitoring framework was implemented to meet requirements for tracking status and trend for watershed condition, late and old forests, social and economic conditions, tribal relationships, and population and habitat for marbled murrelets (Brachyramphus marmoratus) and northern spotted owls. Monitoring results are evaluated and reported in 1and 5-year intervals. Monitoring results for the first 10 years are documented in a series of reports posted at http://www. reo.gov/monitoring/.

This "15-year report" evaluates the status of watershed condition and changes in condition under the NWFP aquatic conservation strategy (ACS) during years 1994-2008. Although this report was originally intended to evaluate 15 years of data, delays in producing this and other NWFP monitoring reports allowed us to include stream data from 2009 in our evaluation of stream condition status. Gallo et al. (2005) described the status of aquatic and riparian resources and changes in their condition for the first 10 years under the NWFP aquatic conservation strategy. That assessment was based on evaluating 250 randomly chosen watersheds throughout the NWFP area. Because of the limited number of watersheds, inference was appropriate only for the whole NWFP area. The Regional Interagency Executive Committee (RIEC) responded to the Gallo et al. (2005) assessment by asking Aquatic and Riparian Effectiveness Monitoring Program (AREMP) staff to develop a way to evaluate watershed condition at smaller scales than the entire NWFP area. The AREMP staff proposed a "GIS and field monitoring" option that the REIC supported (RIEC 2006). This option continued the sampling of inchannel attributes in 250 watersheds along with using a geographic information system (GIS) framework to evaluate all watersheds with at least 25 percent of the 1:100,000 stream layer within federal land ownership. This report describes the results of evaluating all watersheds that met this criterion.

\section{Background}

In the early 1990s, controversy over harvest in old-growth forests led to sweeping changes in management of federal forests in western Washington, Oregon, and northwest California. These changes were prompted by a series of lawsuits in the late 1980s and early 1990s that effectively shut down federal timber harvest in the Pacific Northwest. In response, President Clinton convened a summit in Portland, Oregon, in 1993, where he issued a mandate for federal land management and regulatory agencies to work together to develop a plan to resolve the conflict (Clinton and Gore 1993).

Immediately after the summit, a team of scientists and technical experts were convened to conduct an assessment of options (FEMAT 1993). This assessment provided the scientific basis for the environmental impact statement and ROD (USDA and USDI 1994) to amend Forest Service and BLM planning documents within the range of the northern spotted owl —otherwise known as the Northwest Forest Plan.

The ROD, covering 24 million ac of federal lands, put in place a new approach to federal land management. Key components of the ROD included a new set of land use allocations-late-successional reserves, matrix lands, riparian reserves, adaptive management areas, and key watersheds. The NWFP standards and guidelines provided direction regarding how these land use allocations were to be managed. In addition, the NWFP put in place a variety of strategies and processes to be implemented. These included adaptive management, an ACS, late-successional reserve and watershed assessments, a survey and manage program, an interagency executive organization, social and economic mitigation initiatives, and monitoring.

Monitoring provides a means to address the uncertainty of our predictions and compliance with forest management laws and policy. The ROD stated that monitoring is essential and required:

Monitoring is an essential component of the selected alternative. It ensures that management actions meet the prescribed standards and guidelines and that they comply with applicable laws and policies. 
Monitoring will provide information to determine if the standards and guidelines are being followed, verify if they are achieving the desired results, and determine if underlying assumptions are sound [USDA and USDI 1994].

Judge Dwyer reinforced the importance of monitoring in his 1994 decision declaring the NWFP legally acceptable: "Monitoring is central to the [NWFP's] validity. If it is not funded, or not done for any reason, the plan will have to be reconsidered" (Dwyer 1994).

The ROD monitoring plan provided a general framework to begin development of an interagency monitoring program. It identified key areas to monitor, initial sets of questions, types and scope of monitoring, the need for common protocols and quality assurance, and the need to develop a common design framework. In 1995, the effectiveness monitoring program plan (Mulder et al. 1995) and initial protocols for implementation monitoring (Alegria et al. 1995) were approved by the RIEC. Approval of the effectiveness monitoring plan led to the formation of technical teams to develop the overall program strategy and design (Mulder et al. 1999) and monitoring protocols for late-successional and old-growth forests (termed older forests) (Hemstrom et al. 1998), northern spotted owls (Lint et al. 1999), marbled murrelets (Madsen et al. 1999), tribal relations (Goodman et al. 2002), and watershed condition (Reeves et al. 2004). Periodic analysis and interpretation of monitoring data is essential to completing the monitoring task critical to completing the adaptive management cycle. This important step was described in the overall monitoring strategy (Mulder et al. 1999) and approved by the RIEC.

Gallo et al. (2005) completed one of a series of assessments describing current status and trends for the first 10 years of the NWFP, which also included northern spotted owls (Lint 2005), older forests (Moeur et al. 2005), marbled murrelets (Huff et al. 2006), socioeconomic conditions (Charnley 2006), tribal relations (Stewart and Martine 2006), and implementation or compliance monitoring (Baker et al. 2005). This series of reports was accompanied by a synthesis report by a panel of scientists and managers that integrates and interprets the findings from the status and trend reports and offers alternatives to policymakers (Haynes et al. 2006). These "10-year reports" were the first comprehensive analysis and interpretation of monitoring data since the ROD.

\section{Overview of the Aquatic Conservation Strategy}

ACS is a comprehensive, regionwide strategy designed to maintain, restore, and protect those processes and landforms that create good ecological conditions in watersheds, such as high-quality habitat for aquatic and riparian organisms and good water quality (FEMAT 1993, USDA and USDI 1994). The strategy contains nine objectives that describe general characteristics of functional aquatic and riparian ecosystems that are intended to maintain and restore good habitat in the context of ecological disturbance (see app. 1). This approach was intended to prevent further degradation of aquatic ecosystems and restore habitat over broad landscapes, as opposed to focusing on individual projects or species. Aquatic and riparian organisms evolved in a dynamic environment influenced by natural disturbance. The authors of the strategy believed that stewardship of aquatic resources is most likely to protect biological diversity and productivity when land use activities do not substantially alter the natural disturbance regime to which organisms are adapted. Therefore, the strategy used several tactics to try to maintain the natural disturbance regime in watersheds. The strategy also includes standards and guidelines that apply to management activities in riparian reserves and key watersheds. The four components of the strategy were intended to work in concert to maintain and restore the health of aquatic and riparian ecosystems:

- Watershed analysis - used to characterize watersheds and provide a basis (context) for making management decisions.

- $\quad$ Riparian reserves - used to enhance habitat for riparian-dependent organisms, to provide good water quality, to provide dispersal corridors for terrestrial species, and to provide connectivity within watersheds. 
- Key watersheds - provide high-quality habitat or refugia for aquatic- and riparian-dependent species, or would be able to after restoration.

- Watershed restoration - designed to recover degraded habitat and maintain existing good conditions.

Although late-successional reserves are not listed among the components of the strategy, they provide increased protection for aquatic and riparian ecosystems. Late-successional reserves contain areas of high-quality stream habitat that serve as refuge for aquatic and riparian organisms and as source areas from which organisms may move to recolonize formerly degraded areas (USDA and USDI 1994).

The ACS for the Forest Service in Region 6 (Oregon and Washington) has evolved to become known as the Aquatic and Riparian Conservation Strategy (ARCS). The ARCS integrates and refines three earlier aquatic strategies in the region: the ACS of the NWFP, PACFISH (USDA and USDI 1995), and INFISH (USDA FS 1995). It maintains and builds on the essential components of these earlier strategies including riparian management areas, key watersheds, watershed analysis, watershed restoration, and monitoring. It is based on the best available science, is ecologically sound, and complies with the requirements of federal law including the National Forest Management Act, Endangered Species Act, and Clean Water Act.

Specific refinements include better recognition that disturbance is integral to the resiliency of ecosystems, acknowledgment that climate change may have large effects on these resources, consideration of scale effects on ecosystem processes, better linkages between management intent and direction, and a more robust and transparent process for selecting key watersheds. In addition, the ARCS now includes a more explicit and strategic approach to executing forest watershed restoration programs.

Monitoring was included in the strategy to achieve three goals: ensure that management actions follow the standards and guidelines and comply with applicable laws and policies (implementation monitoring), determine the effectiveness of management practices at multiple spatial scales ranging from individual watersheds to the entire NWFP area (effectiveness monitoring), and determine whether the assumptions underlying the strategy are sound (validation monitoring). The first goal was accomplished through the implementation monitoring program (Baker et al. 2005). The aquatic and riparian effectiveness monitoring program was developed to reach the effectiveness monitoring goal.

\section{Overview of the Aquatic and Riparian Effectiveness Monitoring Program}

The AREMP is responsible for the effectiveness monitoring component of the ACS. Its purpose is to assess the effectiveness of the NWFP by periodically determining the status of watershed condition and using this information to track trends in the condition of watersheds through time. Watershed condition refers to a combination of aquatic, riparian, and upslope characteristics. The original intent of the AREMP was to combine all these characteristics into a single watershed evaluation (Reeves et al. 2004), but the evaluation process has evolved to consider stream condition separately from upslope and riparian ("watershed") condition. Stream condition is based on inchannel data, e.g., substrate, pieces of large wood, water temperature, pool frequency, and macroinvertebrates. Watershed condition is based on mapped data, e.g., road density and vegetation data.

Stream and watershed condition are determined by integrating biological and physical indicator information (Reeves et al. 2004). The results are assessed as a distribution of condition scores across the NWFP area. If the NWFP is effective, the distribution of conditions should either stay the same or improve over time (Reeves et al. 2004). Note that the authors of the ACS did not intend for each of the objectives to be monitored individually, nor did they expect that the objectives would be met in each watershed at all times (USDA and USDI 2003).

The AREMP was pilot tested in 2000 and 2001 to evaluate sampling protocols and determine the funding and crew structure needed to implement the monitoring program (fig. 1). Monitoring officially began in 2002, although funding was about half the amount identified as being needed to fully implement the program. As of fall 2009, 193 of an expected 250 watersheds had been sampled for inchannel attributes. 


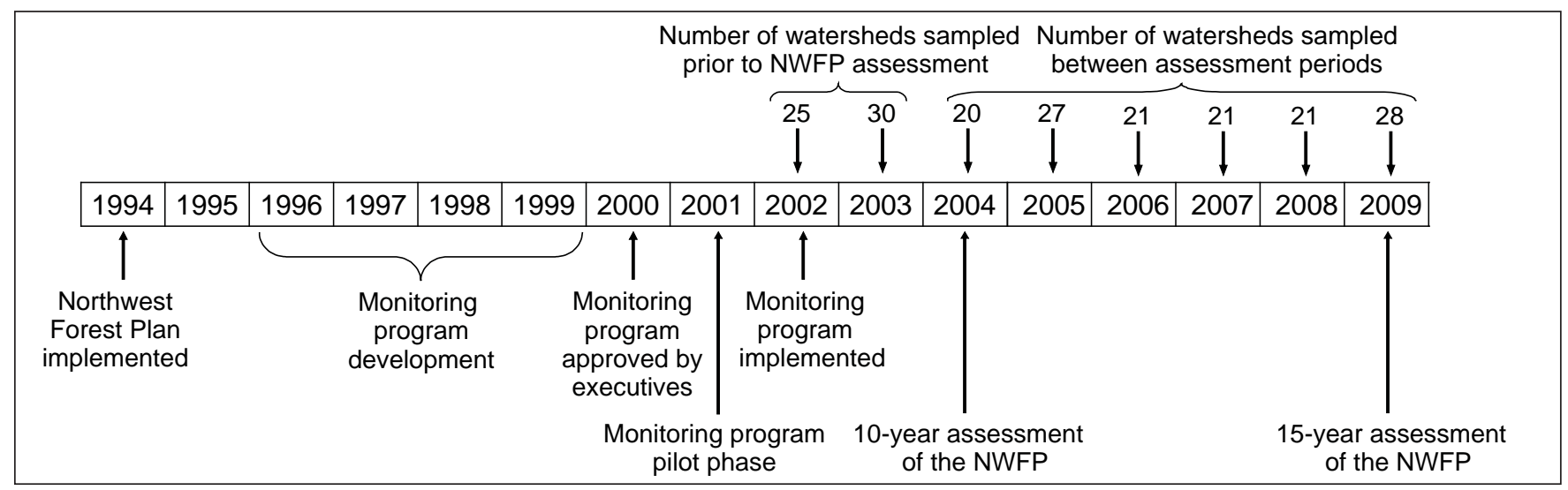

Figure 1-Timeline of the Northwest Forest Plan (NWFP) monitoring program development and implementation.

Evaluating the effectiveness of the ACS is based on measuring changes in the distribution of stream and watershed condition scores through time. Few details on the changes in individual watersheds are provided. The ACS does not describe the baseline condition of streams and watersheds, nor does it define a desired distribution. We infer that if the strategy has been effective in maintaining or improving the condition of watersheds, then the distribution of stream and watershed condition scores should shift in a direction that indicates improvement (Reeves et al. 2004). To spotlight some of the success local units have achieved with project-scale restoration, we describe several case studies in appendix 2. Some of the projects may have had immediate effects, such as opening up habitat to fish by replacing poorly designed culverts that previously blocked fish passage. But most restoration projects should be viewed as a critical first step in restoring natural watershed processes.

\section{Monitoring Questions}

The AREMP is charged with answering questions related to evaluating the effectiveness of the ACS in achieving its goal of maintaining and improving the condition of watersheds in the NWFP area (Reeves et al. 2004). This report focuses on responding to three questions, the answers to which provide insight for evaluating the success of the ACS:

1. What is the status of inchannel conditions?

2. What is the status of upslope and riparian conditions?

3. What is the trend in watershed conditions? 


\section{Chapter 2: Methods}

Each of the three principal monitoring questions is answered using somewhat different data sources and methods. First we describe the common elements of the study area and the conceptual model before moving onto sections providing more details on study designs, data sources, and analytical procedures for each of the four principal monitoring questions.

\section{Study Area}

The Northwest Forest Plan (NWFP) encompasses more than 24 million ac of federal lands in western Washington, western Oregon, and northwestern California and includes the entire geographic range of the northern spotted owl (Strix occidentalis caurina) (fig. 2). Stream and riparian habitat conditions differ greatly across the NWFP area because of natural and management-related factors. Geologic and climatic history influence topographic relief, landforms, channel patterns, and the dominant erosion processes.

Precipitation ranges from more than 200 in per year in some areas near the coast to less than 20 in on the east side of the Cascade Range. Riparian vegetation communities are structured by climate and the disturbance regime of the area, including hydrologic processes and disturbances such as forest fires (Benda et al. 1998, Naiman et al. 1992). Many of these critical components of landscape form and function are in distinctive combinations characteristic of each physiographic province in the region. Physiographic provinces incorporate physical, biological, and environmental factors that shape broad-scale landscapes and therefore reflect differences in responses such as soil development and plant community structure.

The evaluation of upslope and riparian conditions in watersheds was tailored to specific physiographic provinces. Although physiographic provinces are useful in describing both terrestrial and aquatic ecosystems, different processes dominate the functioning of these ecosystems. Consequently, the Forest Ecosystem Management Assessment Team or FEMAT (FEMAT 1993) used different physiographic province boundaries for aquatic and terrestrial ecosystems. The physiographic boundaries used in this analysis were developed from those used in the aquatic ecosystem assessment, and are based on broadly drawn precipitation and geologic zones, as well as political boundaries (state lines). These province boundaries differ from those used by the other effectiveness monitoring components (e.g., the late-successional old-growth and the northern spotted owl), which were delineated primarily by vegetation type and political boundaries. The aquatic province boundaries used by the FEMAT (1993) were not available in a digital format, so their province boundary lines were refined by using levelfour lines described by Omernik in Oregon and Washington (Bryce et al. 1999), Bailey ecological subsections lines in California (Bailey et al. 1994), and the Cascade crest derived from the Forest Service Pacific Northwest Region sixth-field watershed layer.

The NWFP area contains eight aquatic physiographic provinces including the Olympic Peninsula, North Cascades, Willamette-Puget Trough, West Cascades, Oregon Coast, High Cascades, Klamath-Siskiyou, and Franciscan. Land ownership in the Willamette-Puget Trough is predominantly private, and none of the watersheds in this province met the monitoring program minimum criterion of at least 25 percent of the 1:100,000 stream layer within federal land ownership. Consequently, this province is not included in the analysis. The Klamath-Siskiyou and Franciscan provinces were combined into one provincial area for this report, along with the California portion of what was formally part of the High Cascades. Descriptions of the provinces based largely on those presented by FEMAT (1993) are provided in Gallo et al. (2005).

The subwatershed (sixth-field hydrological unit, hereafter called watershed) was chosen as the basic geographic unit for monitoring, as recommended by Reeves et al.

(2004), because it was the smallest consistently delineated unit available at the time. These watersheds are 10,000 to $40,000 \mathrm{ac}$, and include both complete (contains all headwaters for a main stream) and composite (contains only part of the source waters) watersheds. Because the NWFP applies only to federally managed lands, watersheds must contain a minimum of 25 percent of the total length of the stream (1:100,000 National Hydrography Dataset stream layer) within federal ownership (USDA Forest Service [FS], USDI Bureau of Land Management [BLM], or USDI National Park Service [NPS]) to be considered for sampling 


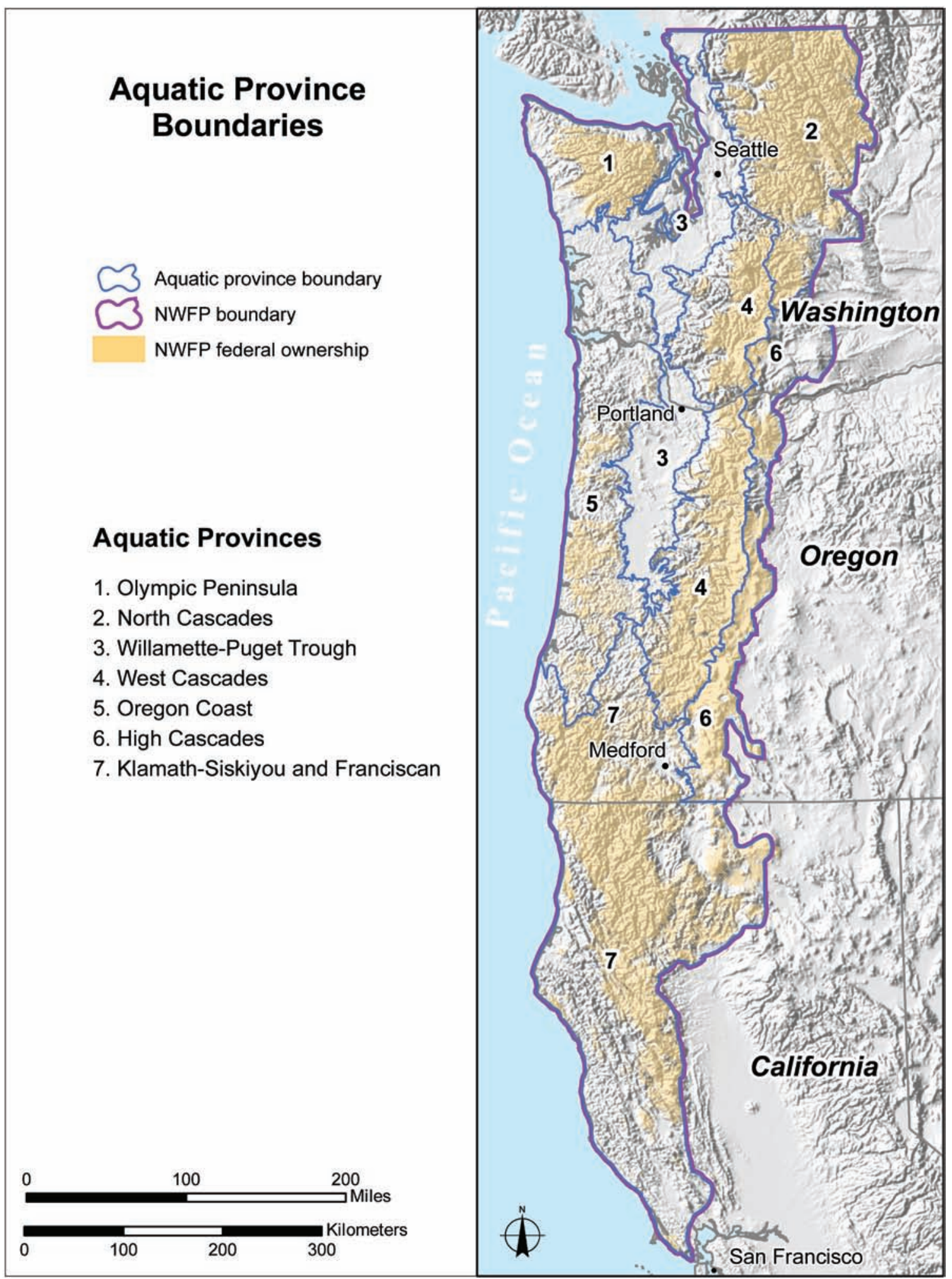

Figure 2-Aquatic provinces used to assess watershed condition in the Northwest Forest Plan (NWFP) area. The NWFP area extends from the U.S-Canada border to Point Reyes, California, and includes the eastern flank of the Cascade Mountain range and encompasses the range of the northern spotted owl. The NWFP area being evaluated includes USDA Forest Service, USDI Bureau of Land Management, and USDI National Park Service lands. 
and analysis in the monitoring program. The ownership criterion was recommended by Reeves et al. (2004) to gauge the influence of the strategy by sampling watersheds in which the strategy was implemented to varying degrees while avoiding sampling watersheds in which the contribution of federal lands to the condition of the watershed was insignificant. The NWFP area contains 2,657 watersheds, of which 2,151 contain some land that is federally owned, and 1,379 have at least 25 percent of stream channels in federal ownership. The ownership criterion excludes about 7 percent of the federal lands in the NWFP area from this analysis.

Only the federal portion of watersheds was included when determining watershed condition status and trend because federal agency land managers have no jurisdiction over management of nonfederal lands.

\section{Land Use Categories}

Land use categories provide a key spatial component of the NWFP by assigning different management guidelines and priorities to zones within the NWFP area. We review our three monitoring questions in the context of two types of land classification: the general NWFP land use allocations (congressionally reserved, late-successional reserve, matrix) and the NWFP aquatic conservation strategy (ACS) designations of key versus nonkey watersheds. We grouped some of the land use allocations that have similar guidelines for management (table 1). The land use allocation categories presented here are the same as those described by Tuchmann et al. (1996). Boundaries for land use categories did not follow watershed boundaries; consequently multiple land use categories may have been present in individual watersheds. Within each classification, each watershed was

Table 1-Land use and watershed categories used in this analysis

\begin{tabular}{|c|c|c|}
\hline Category & Number of watersheds & $\begin{array}{c}\text { Land use allocation }{ }^{a} \text { or aquatic } \\
\text { conservation strategy } \\
\text { designation }\end{array}$ \\
\hline \multirow[t]{2}{*}{ Congressional reserves } & 406 & Congressional reserves \\
\hline & & Administratively withdrawn areas \\
\hline \multirow[t]{5}{*}{ Late-successional reserves } & 464 & Late-successional reserve 1 \\
\hline & & Late-successional reserve 2 \\
\hline & & Late-successional reserve 3 \\
\hline & & Managed late-successional reserves \\
\hline & & $\begin{array}{l}\text { Adaptive management areas-late- } \\
\text { successional reserve }^{b}\end{array}$ \\
\hline \multirow[t]{3}{*}{ Matrix } & 509 & Matrix lands \\
\hline & & Riparian reserves \\
\hline & & $\begin{array}{l}\text { Adaptive management areas- } \\
\text { non-late-successional reserves }\end{array}$ \\
\hline \multirow[t]{3}{*}{ lotal } & 1,379 & \\
\hline & 469 & Tier 1 key watersheds \\
\hline & & Tier 2 key watersheds \\
\hline \multirow[t]{2}{*}{ Nonkey } & 910 & $\begin{array}{l}\text { All federal lands not designated as } \\
\text { key watershed }\end{array}$ \\
\hline & 1,379 & \\
\hline
\end{tabular}


assigned to the class covering the largest amount of its area. Table 1 shows the number of watersheds falling into each class. The following paragraphs briefly describe each allocation, and their spatial distribution is displayed in figure 3.

Congressional reserves (CR) include national parks and monuments, wilderness areas, wildlife refuges, and other areas reserved by the administrative unit or act of Congress. These lands are generally not managed for timber production.

Late-successional reserves (LSR) contain largely old-growth forest and were designated to provide habitat for old-growth-dependent species such as the northern spotted owl. Adaptive management areas managed under LSR guidelines were included in LSR (see below).

The matrix land use allocation includes all lands not included in one of the other allocations. Scheduled timber harvest activities may take place on matrix lands. For analysis and reporting purposes, we grouped some adaptive management with matrix (see below). Riparian reserves were not included as a separate land allocation because they have not been mapped; they are included as part of the matrix land allocation.

Adaptive management areas were identified to develop and test innovative management approaches to integrate and achieve ecological, economic, and other social and community objectives (USDA and USDI 1994). They are a mix of lands where timber production can occur and where timber production must follow LSR guidelines. For analysis and reporting purposes, we grouped watersheds in adaptive management areas into either matrix lands or LSR, depending on which allocation covered the largest amount of its area.

Key watersheds are one of the primary components of the ACS. They are intended to "serve as refugia for aquatic organisms, particularly in the short term for at-risk fish populations, to have the greatest potential for restoration, or to provide sources of high-quality water" (Haynes et al. 2006). Key watersheds were identified as part of the ACS and independent of the land use allocations in the NWFP, thus key and nonkey watershed designations overlay the other land use allocations. Key watershed delineation was begun prior to the development of the interagency standard fifth- and sixth-field watershed boundaries, so their boundaries are not always coincident. For this analysis, 469 of our 1,379 watersheds are considered key because they have $>50$ percent of the area designated as key watershed. The remaining 910 watersheds are considered as nonkey in this assessment.

\section{Study Design}

\section{Definition of Watershed Condition}

The definition of watershed condition developed by the monitoring program is based on the goals of the NWFP ACS (see app. 1) and on guidance provided by the aquatic monitoring plan (Reeves et al. 2004). The NWFP was designed to account for the complex and dynamic nature of aquatic ecosystems resulting from the wide range of physical characteristics, natural disturbance events, and climatic features of the region (Benda et al. 1998, Naiman et al. 1992). Monitoring these dynamic watershed processes is accomplished by linking them to measurable physical attributes (e.g., vegetation structure, road density, water temperature). Reeves et al. (2004) initially identified 90 potential attributes that represent key functions and processes in watersheds. This number of attributes was reduced based on criteria established by Noon et al. (1999). The monitoring program further removed some attributes that were found not to produce useful or consistent information (Lanigan et al. 2007). The remaining attributes represent upslope, riparian, and inchannel processes (table 2).

The condition of a watershed is defined as "good" if the state of these attributes support a high diversity and abundance of aquatic and riparian species. Many of the physical indicators are chosen for their relevance to native or desired fish species because of these species' roles in driving management policies (including the NWFP itself) and the availability of research related to their habitat needs. However, we attempt to assess indicators relative to the natural potential of the site to provide biotic habitat. A watershed that naturally does not support fish populations (because of elevation or other natural conditions) but has little vegetation disturbance, few roads, good pools, and wood should be evaluated positively. If this watershed loses significant vegetation, even from natural causes 


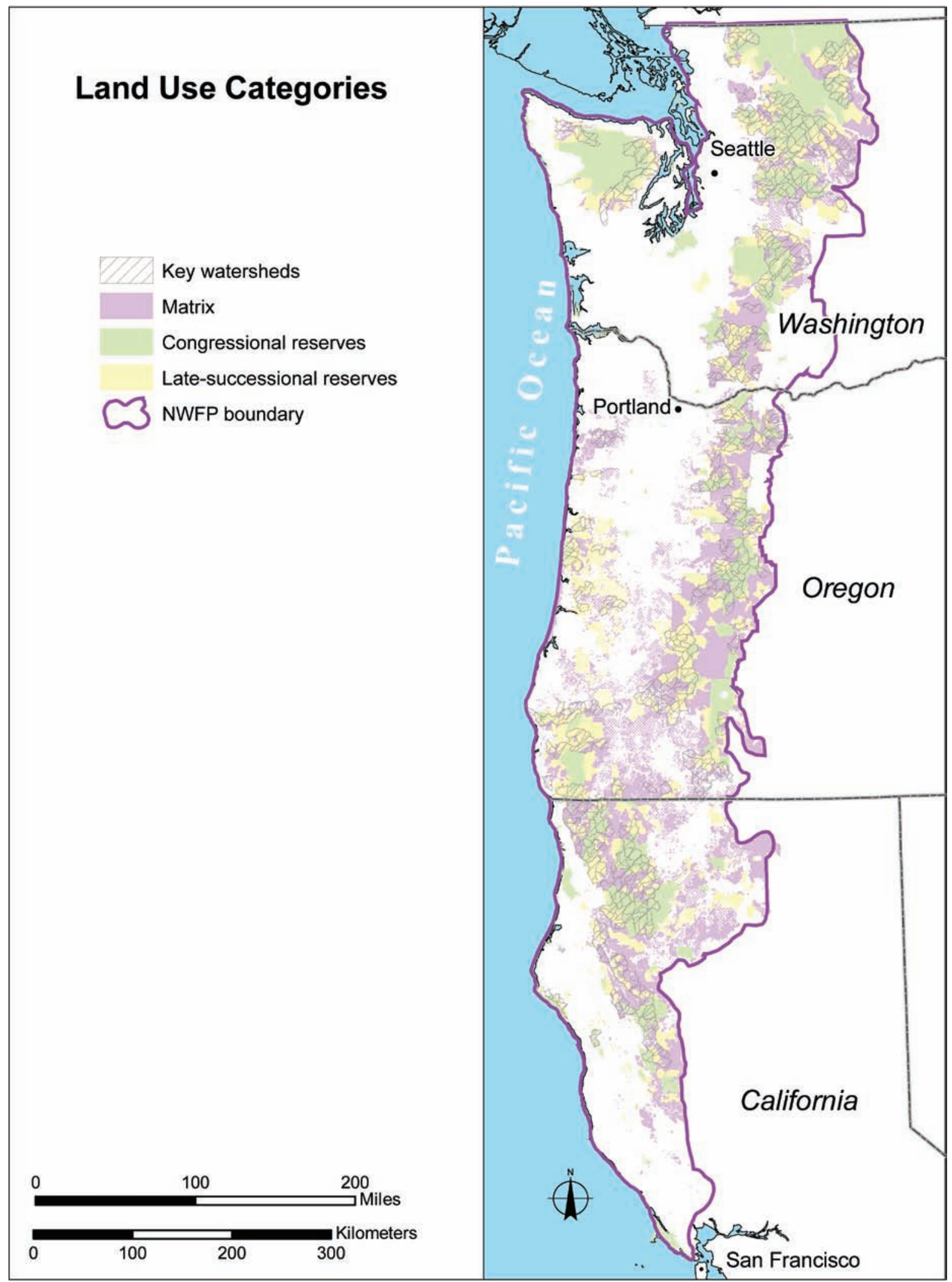

Figure 3-Land use allocations in the Northwest Forest Plan (NWFP) area. 
Table 2-Attributes included in the watershed condition assessments listed by ecological process

Ecological processes

\begin{tabular}{|c|c|c|}
\hline General process & Key process & Attributes assessed \\
\hline \multicolumn{3}{|l|}{ Upslope subsystem: } \\
\hline $\begin{array}{l}\text { Vegetative succession, growth, } \\
\text { and mortality }\end{array}$ & Wood production and transport & Vegetation seral stage \\
\hline Hydrologic cycle & Peak flow and timing/amount & $\begin{array}{l}\text { Vegetation hydrologic maturity } \\
\text { and road density }\end{array}$ \\
\hline Soil cycle & Sediment production and transport & $\begin{array}{l}\text { Road density, landslide risk, } \\
\text { vegetation seral stage }\end{array}$ \\
\hline \multicolumn{3}{|l|}{ Riparian subsystem: } \\
\hline $\begin{array}{l}\text { Vegetative succession, growth, } \\
\text { and mortality }\end{array}$ & Community structural development & Vegetation seral stage and association \\
\hline $\begin{array}{l}\text { Vegetative succession, growth, } \\
\text { and mortality }\end{array}$ & Wood delivery & $\begin{array}{l}\text { Vegetation seral stage, riparian road } \\
\text { density }\end{array}$ \\
\hline Soil cycle & Sediment production and transport & $\begin{array}{l}\text { Road density, off-highway vehicle } \\
\text { trail density, stream-crossing } \\
\text { density }\end{array}$ \\
\hline Hydrologic cycle & Flood-plain loss & Riparian road density \\
\hline Hydrologic cycle & Connectivity for fish and wood passage & Stream-crossing density \\
\hline \multicolumn{3}{|l|}{ Inchannel subsystem: } \\
\hline Hydrologic cycle & $\begin{array}{l}\text { Water storage and yield, off-channel } \\
\text { habitat }\end{array}$ & Channel connectivity with flood plain \\
\hline Channel structural dynamics & Sediment and wood delivery & $\begin{array}{l}\text { Bankfull width:depth ratio, channel } \\
\text { pools, wood, substrate composition }\end{array}$ \\
\hline Energy exchange & Heat delivery & Water temperature \\
\hline Chemical and nutrient turnover & Chemical and nutrient delivery & Water quality \\
\hline Biotic community dynamics & Biotic integrity & $\begin{array}{l}\text { Amphibians and macroinvertebrate } \\
\text { indices }\end{array}$ \\
\hline
\end{tabular}

Adapted from Reeves et al. 2004.

(e.g., fire), then the condition rating will go down (it is below its potential).

This simplified view of condition is a consequence of the fact that indicators taken at one point in time are imperfect measures for dynamic processes. Even a watershed with intact processes may not be in good condition in terms of providing quality fish habitat at any single assessment period. A fundamental principle underlying the monitoring program is that watersheds are naturally dynamic systems. Individual watersheds will cycle through conditions of high and low habitat quality, and not all watersheds can be expected to be in good condition at any one time (Naiman et al. 1992, Reeves et al. 1995). Therefore, the most important product of the monitoring program is the overall distribution of individual watershed ratings in the NWFP area. Implementing the ACS should result in an overall distribution of watershed condition scores that improves over time. 


\section{Assessment of Watershed Condition}

To assess watershed condition for the NWFP, Reeves et al. (2004) proposed a strategy that used the watershed concept as a unit of analysis, integrated multiple indicators, and provided a representative sample of the NWFP area. Because the multiple aspects related to watershed condition are diffuse and many of the relationships between them not yet quantified statistically, they recommended a knowledgebased systems methodology. This type of approach enables the integration of quantitative information and more qualitative expert knowledge into an explicit computer model, which then facilitates and documents the consistent and transparent application of a methodology for evaluation. An assessment of management options for federal lands in the interior Columbia River basin took a similar approach, supplementing an expert group approach (Sedell et al. 1997) with computer models that encapsulated expert knowledge and assessed each watershed unit in a consistent manner (Rieman et al. 2000, 2001).

To implement this knowledge-based systems approach, the Aquatic and Riparian Effectiveness Monitoring Program (AREMP) selected the Ecosystem Management Decision Support system (EMDS, http://www.institute.redlands. edu/emds/) as the modeling platform. EMDS integrates knowledge-based and decision-modeling components into the ArcGIS software (ESRI, http://www.esri.com). The AREMP assessments use the Netweaver component (Rules of Thumb Inc., http://rules-of-thumb.com/), which combines a basic multiattribute decision analysis framework with a variety of mathematical and logical operators. Multiple criteria evaluation is derived from multiattribute utility theory, which encompasses techniques for integrating multiple metrics into a combined decision or index value (Keeney and Raiffa 1976). These techniques are designed to address two basic problems with combining indicators: they are often (1) measured in different units and (2) of different importance to the overall evaluation objective. The sidebar "Overview of the Watershed Evaluation Modeling Process" (p. 12) provides details on how the individual indicators (or attributes) were normalized to a common scale and combined into an overall score.
For this assessment, models were developed for two scales, inchannel and upslope/riparian, following the process scales defined by the monitoring plan and the data sets available for the different scales. Upslope and riparian evaluations were combined in one model because they are based on the same data sources and sampling design. Each model comprises three basic elements: a list of measurable watershed attributes to evaluate, criteria for rating each attribute, and a model structure, which defines how the attribute scores are aggregated into an overall score. Data from each watershed are run through the appropriate provincial models (inchannel and upslope/riparian) to produce scores on a standardized scale from +1 to -1 , where +1 indicates excellent condition and -1 indicates poor condition.

For this assessment, decision-support models developed for each aquatic province $(n=6)$ for the 10 -year report (Gallo et al. 2005) were refined during workshops attended by local agency professionals (fig. 4). Separate models were built for each aquatic province (fig. 2) to account for the ecological differences between provinces. The workshops consisted of a semistructured group process through which participants reviewed the existing model structures, data attributes, and evaluation criteria, and came to consensus on changes needed. After the workshops, models were built and run and the results returned to the workshop participants. A second round of workshops was held to review the preliminary results. Participants compared the results of the models to their knowledge of the condition of the watersheds and suggested refinements to the models as necessary. These changes were made, resulting in the final models used. Generic model diagrams are presented in figure 5 to illustrate how individual indicators were aggregated into overall condition scores; actual model diagrams and evaluation criteria for each provincial model are provided in appendix 4.

\section{Monitoring Questions}

Data from two scales were used to answer the key monitoring questions, which led to differences in specific study designs and attributes evaluated. The inchannel status evaluation (question 1) was based on sampling of stream 


\section{Overview of the Watershed Evaluation Modeling Process}

Our watershed assessment process uses the Ecosystem Management Decision Support system (EMDS) to conduct consistent evaluations that integrate diverse kinds of data, such as vegetation and roads. EMDS is not a cause-and-effect statistical model; rather, it is a framework for integrating diverse sources of information (from statistical relationships to expert opinion) consistently across time and space.

Advantages of using such a decision-support model include:

- All aspects of the analysis process are shown; therefore, it is easy to explain to customers.

- Models can be developed to assess ecological condition at any spatial or temporal scale.

- As we learn more about how watersheds function, models can be refined and rerun on data from earlier periods to correct deficiencies.

The simplified model structure below illustrates how each watershed was scored using the EMDS process. The actual model structures we used are presented in appendix 4 .

Step 1: Each attribute (i.e., indicator) is scored to a common scale between +1.0 (for "good") and -1.0 (for "poor") by comparing it to a set of evaluation criteria.
Criteria are based on published literature, field data, and professional judgment. Usually one evaluation criterion value is selected for the +1 threshold, another for the -1 threshold, and intermediate values are scored based on a linear interpolation between these thresholds. Evaluation function examples are shown for the road components below.

Step 2: The evaluation scores for each of the attributes are aggregated together for each general model component (e.g., Roads) by using user-defined rules. Selection of the rules is based on experts' knowledge of the system and ecological processes. Rules can produce an aggregated score weighted toward the resource with either the highest or lowest attribute score, or use the average of scores (as shown in this example by “AVE”). An aggregated score can also be based on the weighted or unweighted average of the indicator evaluation scores, e.g., as shown in step 3.

Step 3: The component scores are further aggregated based on the model structure. In this model structure, the watershed condition is determined by using the weighted average of roads (60 percent) and vegetation (40 percent) scores. The watershed condition score will always range from -1.0 to +1.0 .

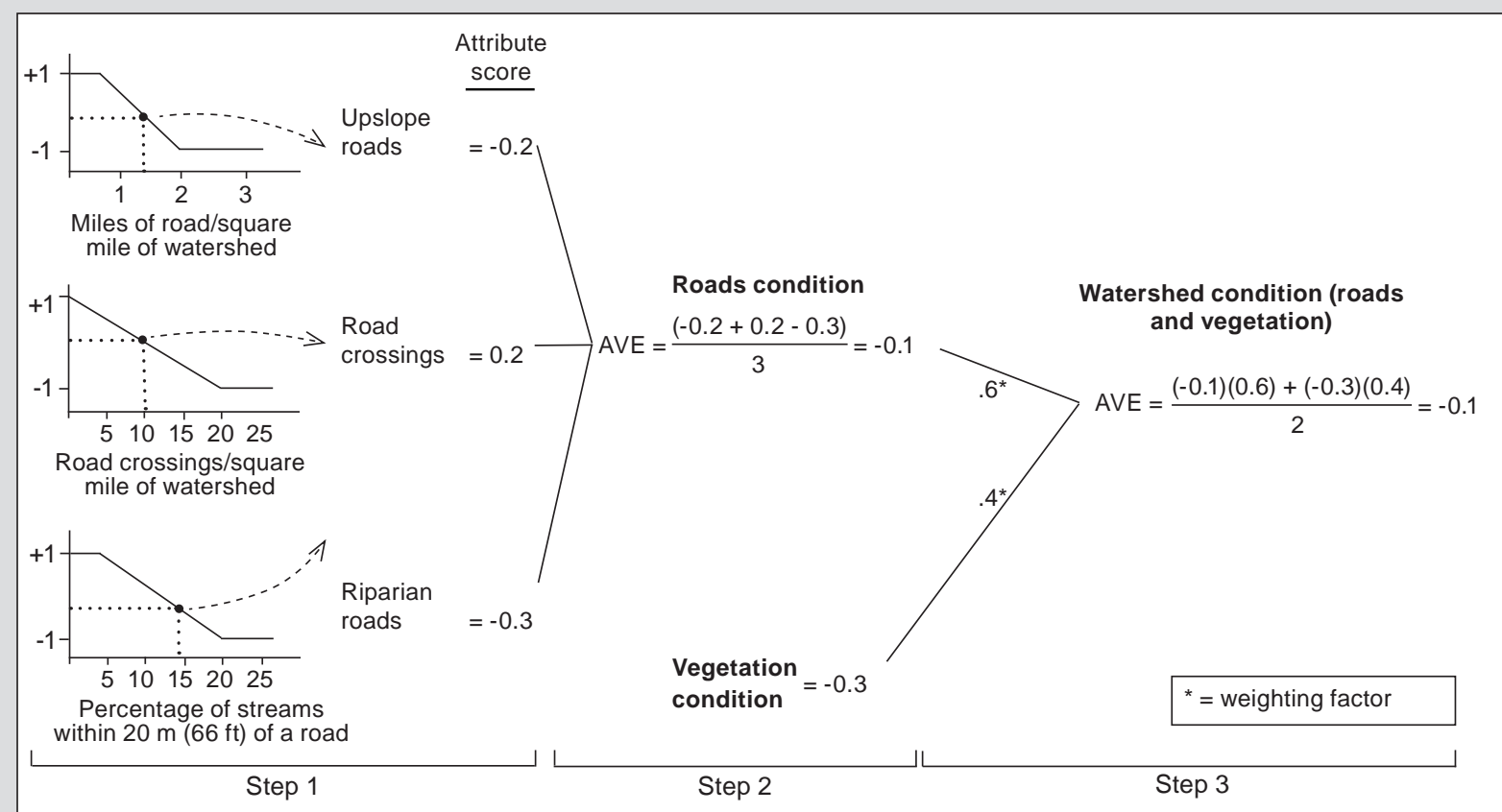

Example of a simplified decision-support model. In step 1, individual attributes are evaluated by using evaluation criteria. In steps 2 and 3, the evaluation scores of the attributes are aggregated to determine the overall watershed condition score. AVE = average of scores. Revised from Gallo et al. 2005. 

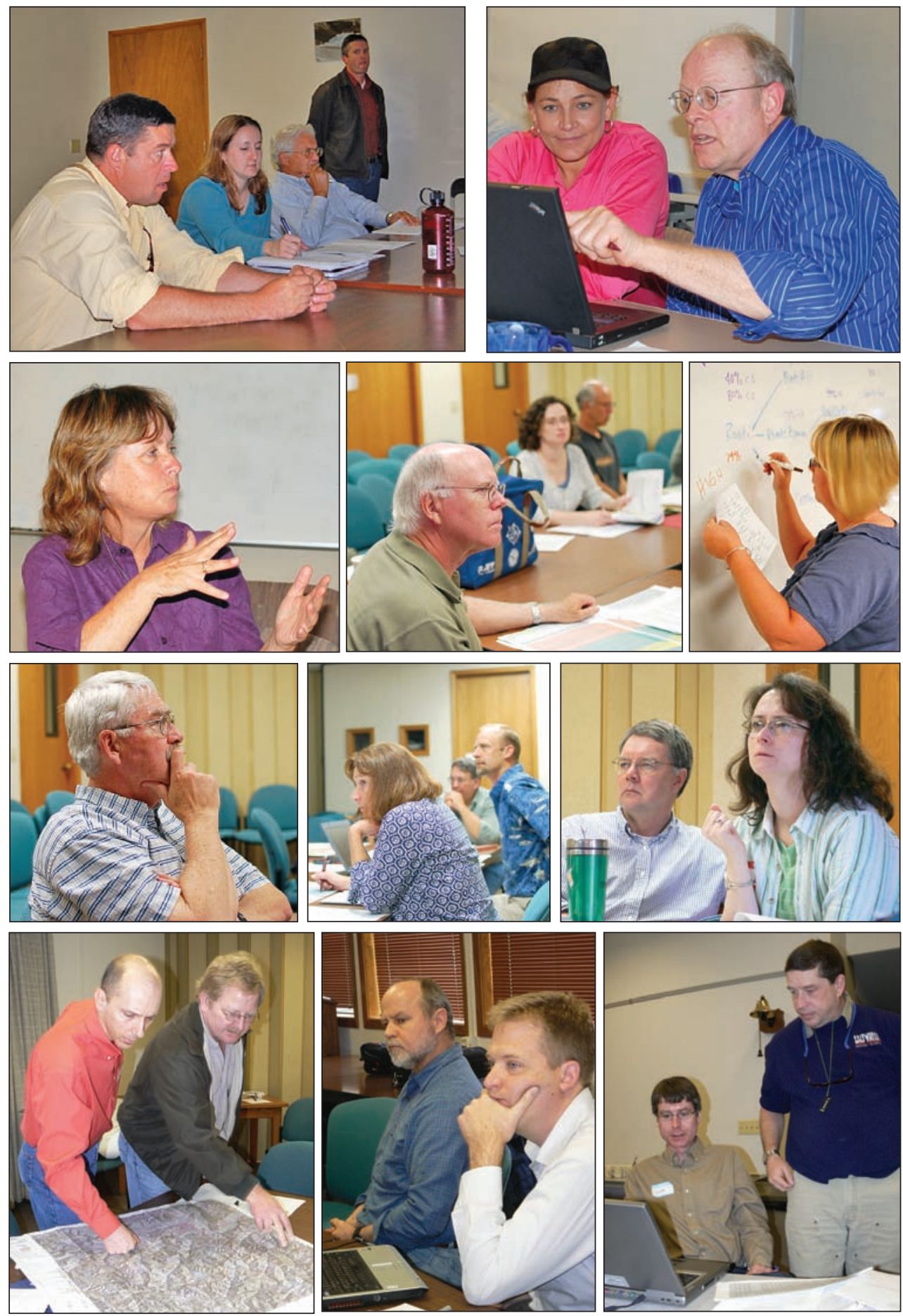

Figure 4-Program personnel from National Forest System; Bureau of Land Management; National Park Service; Pacific Northwest Research Station; Washington Department of Fish and Wildlife; Washington Department of Ecology; Washington Forest Practices Board Cooperative Monitoring, Evaluation, and Research Committee; Environmental Protection Agency; National Oceanic and Atmospheric Administration Fisheries; Oregon Fish and Wildlife; and California Fish and Game provided technical expertise and local knowledge for decision-support model refinement during a series of aquatic province workshops. Specialists also provided feedback on how well the output from refined models matched up with their perspective of "on-the-ground" conditions so the models could be further fine tuned. 


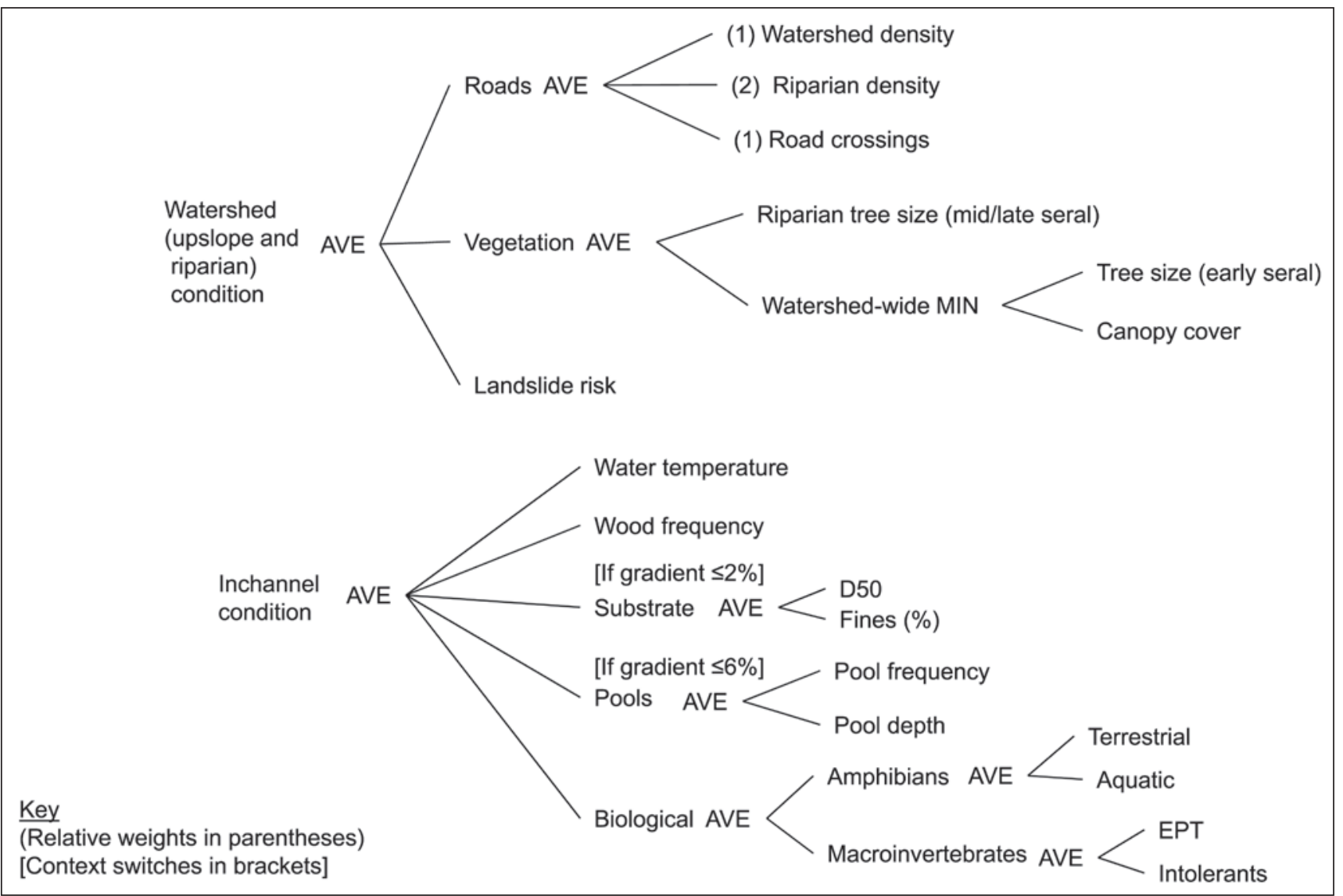

Figure 5-Illustrative model diagrams showing how indicators are combined into overall condition scores (actual structures for each province are detailed in app. 4). AVE = average of scores, MIN = minimum, D50 = median particle size, EPT = Ephemeroptera, Plecoptera, Tricoperta index. [ ] = Use the indicator if context switch is true.

data (e.g., water temperature, pool frequency, macroinvertebrates) collected in 193 watersheds by AREMP teams from 2002 to 2009. The assessments for questions 2 and 3 were based on watershed-wide mapped data (e.g., road density, canopy cover) derived from satellite imagery and other corporate data sets (circa 1994 and 2008, 1,379 watersheds). The following sections describe the specific study design and attributes evaluated for each of the monitoring questions.

\section{What Is the Status of Inchannel Conditions?}

\section{Study design-}

The AREMP study design identified 250 randomly selected watersheds (see app. 3) from the 1,379 watersheds in the sixth-field watershed coverage (version 1.1, dated 2002) for the NWFP area that met both the ownership criterion (i.e., more than 25 percent of the total stream length is located on federal land) and a set of criteria associated with safety and access concerns (see app. 5). Watersheds were selected using generalized random stratified tessellation survey, a process that guarantees a spatially balanced sample (Stevens and Olsen 2003, 2004). According to Reeves et al. (2004), 50 watersheds should be sampled each year for 5 years. On year 6 , the watersheds sampled the first year will be revisited. Because of funding limitations, we were only able to sample inchannel attributes in an average of 24 watersheds per year for a combined total of 193 watersheds in 2002 to 2009. Because no repeat sampling has yet occurred, the inchannel data from all years are used only to represent current status and not trend. Some indicators may 
be affected by natural year-to-year environmental variations (e.g., the effect of climate on water temperature), which is not accounted for in the current framework but may deserve consideration in future assessments.

Within each watershed selected, inchannel data were collected at multiple sites (stream segments referred to as reaches). These sites were selected by using generalized random stratified tessellation survey (Stevens and Olsen $2003,2004)$, the same procedure used to select watersheds. The 1:100,000 National Hydrography Dataset stream layer was clipped to the boundary of each watershed. Sample points were placed on the stream layer within the watershed boundary at random (fig. 6). These points represented the downstream starting point for the inchannel surveys. The length of the sample reach was determined as 20 times the average bankfull width, with minimum and maximum reach lengths of 175 and $525 \mathrm{yd}$, respectively. On average, six sites were sampled in each watershed, with a range from 4 to 10.

\section{Attributes-}

A list of suggested physical, biological, and chemical attributes of stream reaches used for the inchannel evaluation was initially suggested in Reeves et al. (2004) and subsequently refined in the provincial expert workshops. A list of attributes used in this assessment is provided in table 3; all of these attributes were based on data collected by AREMP field crews (figs. 7 through 9). Further details on the metrics used and evaluation criteria by province can be found in appendix 4 and details on data collection methods in appendix 5 and the AREMP field protocol (AREMP 2009)

\section{Data analysis -}

Inchannel data are presented using descriptive statistics and graphical displays of the decision-support model scores. Inferential statistics were used in two cases to test the reliability of generalizing from our sample to the overall population of stream reaches in the NWFP area. First, inchannel scores were tested to determine whether an equal proportion of watersheds fell into each of the five status categories by using a Pearson chi-squared test for goodness of fit (Maindonald and Braun 2003). Second, scores for the different land use categories were compared to determine if they differed significantly. Selecting the appropriate test was based on whether the classified scores met the assumption of homogeneity of variance between classes. Other test assumptions were accounted for owing to the large randomly selected sample (193 watersheds) with no classification of scores resulting in any one class containing a small percentage of the total scores. The Levene test was selected to determine homogeneity of variance as it is relatively insensitive to departures from normality within the classes (Sheskin 2004).

If the variances of the classified scores were determined to be homogenous, parametric tests were used to compare the mean scores. In these cases, the Student's t-test was employed to compare key and nonkey watersheds, and a one-way analysis of variance F-test was used to compare land use allocations. When a significant difference was found within the land use allocations, it was investigated further using a Tukey honest significant difference multicomparison test to identify which allocations had a significant probability of being different. In cases where the Levene test showed there was a significant chance that the variances of the classified scores were not homogeneous, nonparametric tests were used to test the classifications. Under these conditions, Wilcox rank sum tests were used to test for significant differences between key and nonkey watersheds, and a Kruskal-Wallis test was used to compare differences between land use allocations. When a significant probability of a difference between land use allocations was identified, Behrens-Fisher generalized p-values were used to determine which allocations were different. In interpreting test results, we chose a significance level of 10 percent (alpha $=0.10)$ as more appropriate than the commonly used 5 percent because of the high natural variability in stream habitats (Al-Chokhachy et al. 2010, Bryant et al. 2004). All analyses were conducted using the R statistical package (http://www.r-project.org).

\section{What Is the Status of Upslope and Riparian Conditions?}

\section{Study design-}

The upslope and riparian status assessment used the (sub) watershed as the basic unit of analysis (as described in the 


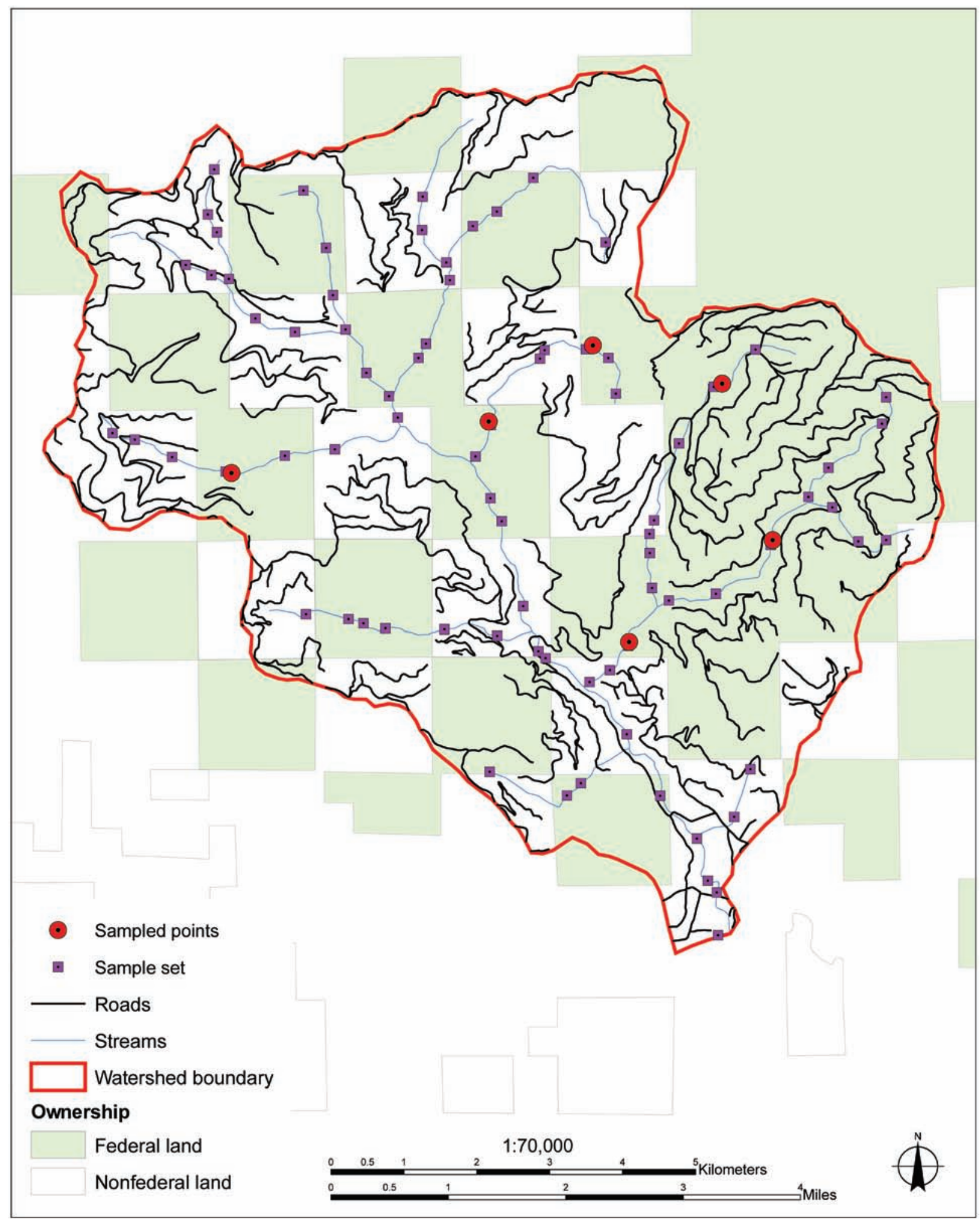

Figure 6-Example of randomly selected sample sites in a sixth-field watershed. The sampled stream reaches (red dots) were selected from 1:100,000 stream layers by using a generalized random stratified tessellation survey, a process that guarantees a spatially balanced sample (Stevens and Olsen 2004). 
Table 3-Inchannel attributes used in assessment and sources of metrics used

\begin{tabular}{ll}
\hline Attribute & Source of metric \\
\hline Bankfull width-to-depth ratio & Calculated from cross-sectional profiles (Peck et al. 1999) \\
Pool frequency & Calculated from longitudinal profiles (Peck et al. 1999) \\
Pool depth & Maximum pool depth (AREMP 2009: 29) \\
Flood-plain connectivity & Aquatic and Riparian Effectiveness Monitoring Program \\
& protocol (AREMP 2009: 31) \\
Wood frequency & From protocol developed by the Oregon Department of Fish \\
& and Wildlife (Moore et al. 1999) \\
Substrate fines (percentage of fine sediments) & From protocol developed by USDA Forest Service (1998) \\
Substrate D50 (median particle size) & Based on a modification of Peck et al. (1999) \\
Macroinvertebrates & See "Macroinvertebrate Metric" sidebar (p 18) \\
Terrestrial and aquatic amphibians & See "Amphibian Metric" sidebar (p 19) \\
Dissolved oxygen & Data were collected with either a YSI Professional or YSI 556 MPS \\
Water temperature & Data were collected with either a YSI Professional or YSI 556 MPS \\
& by using Onset tidbits
\end{tabular}

${ }^{a}$ The use of trade or firm names in this publication is for reader information and does not imply endorsement by the U.S. Department of Agriculture of any product or service.

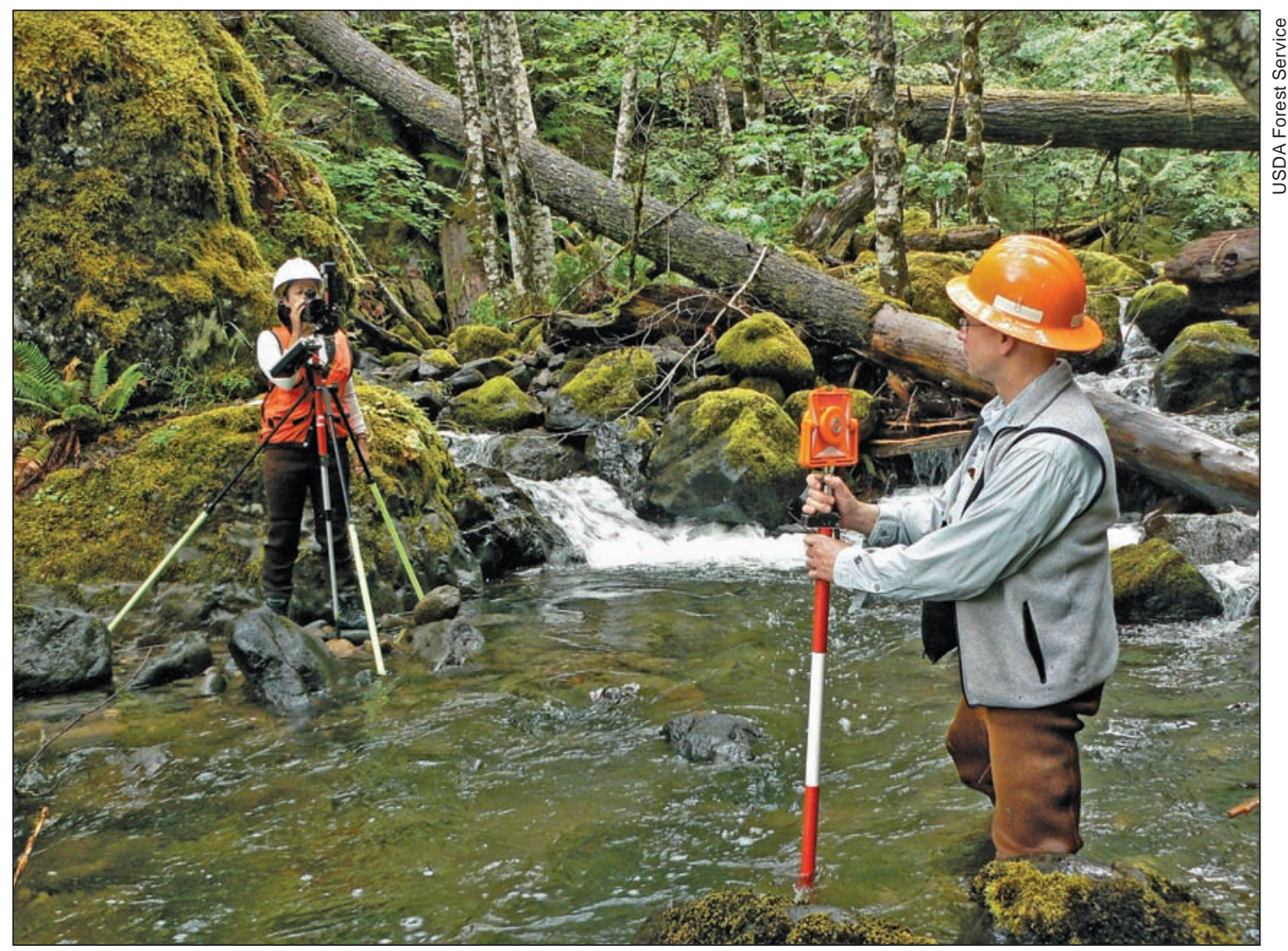

Figure 7-Bankfull width-to-depth ratios were calculated from cross-sectional profiles. 


\section{Macroinvertebrate Metric}

An evaluation of aquatic macroinvertebrates was added into the decision-support model (DSM) for this report. The diversity and environmental sensitivity of macroinvertebrates make them useful indicators of stream condition, and they respond predictably to anthropogenic disturbances on the landscape or in the stream (Karr and Chu 1999). To determine which macroinvertebrate metrics to include in the DSM, we engaged the assistance of Alan Herlihy, an Oregon State University scientist who had used data from the Environmental Protection Agency's Environmental Monitoring and Assessment Program (EMAP) to develop indixes of biotic integrity for macroinvertebrates. We analyzed Aquatic and Riparian Effectiveness Monitoring Program data and EMAP data collected within the Northwest Forest Plan (NWFP) area independently to select macroinvertebrate metrics that are sensitive to management in the NWFP area and eliminate redundant metrics. The EMAP data were included to increase sample size and because the data set includes forested lands that are not federally owned, which increased the range of environmental conditions.

Three metrics were selected for inclusion in the DSM. The first attribute, proportion of the macroinvertebrate taxa in the orders of Ephemeroptera (mayflies),

Tricoptera (caddisflies), and Plecoptera (stoneflies), is a community composition index that focuses on species known to exist in cold, high-quality waters (Merritt and Cummins 1996). The second metric, the proportion of the macroinvertebrate taxa that are intolerant, can be used to detect nutrient enrichment, high sediment load, high water temperature, and organic pollution (Hilsenhoff 1988). The final measure, proportion of the macroinvertebrate taxa that are climbers, is an indicator of habit. These taxa tend to live in structurally complex habitats, such as those with high-quality spawning gravel or cover for juvenile fish (Karr and Chu 1999).

Determination of evaluation criteria for each metric was conducted by distinguishing sample locations that were in minimally disturbed or "reference" condition

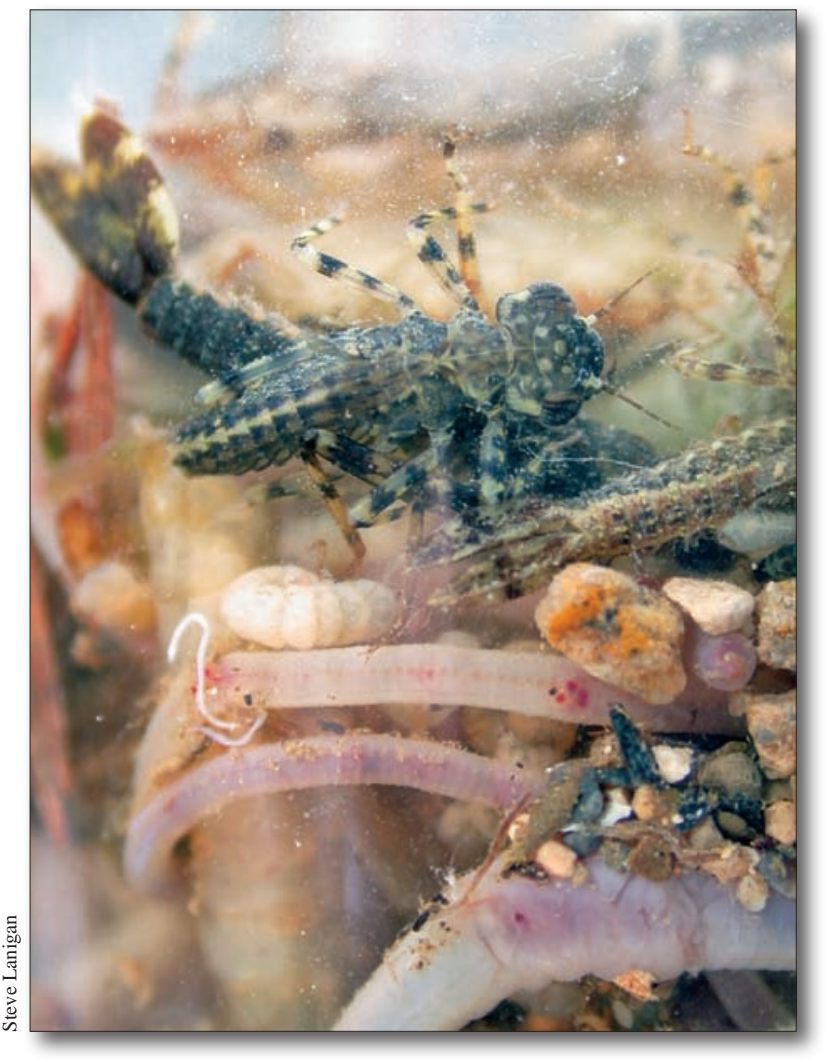

Three metrics were used in the decision-support model for macroinvertebrate data: (1) a community composition index that focuses on species known to exist in cold, highquality waters; (2) the proportion of the macroinvertebrate taxa that are intolerant to detect nutrient enrichment, high sediment load, high water temperature, and organic pollution; and (3) the proportion of the macroinvertebrate taxa that are climbers.

from those in poor condition, then looking at the range of metric values to distinguish the two types of locations. The median data value of the "reference" sites was designated as the +1 evaluation criterion and the median value of the poor sites was designated as the -1 criterion. 


\section{Amphibian Metric}

An evaluation of terrestrial and aquatic amphibians was added into the decision-support model (DSM) for this report. Amphibians have characteristics that make them useful for monitoring watershed health including their association with riparian areas (Olson et al. 2007), their sensitivity to environmental stressors (Blaustein et al. 1994), and their low cost to sample (relative to many other field attributes). Linkages between inchannel impacts of management practices and amphibians in aquatic life stages (Dicamptodon spp. and larval Ascaphus truei) have been demonstrated in the literature (Olson et al. 2007).

The amphibian data came from two survey protocols: time-constrained searches for terrestrial amphibians done in a splash zone (within $2 \mathrm{~m}$ [6 ft] of the wetted edge), and single-pass electrofishing, without block nets, done throughout the survey reach. ${ }^{1}$ Because the two different protocols were not optimal in their ability to capture animals for a variety of reasons (including

${ }^{1}$ Aquatic amphibian data were available from 2002 to 2007 . Electrofishing was discontinued after 2007.

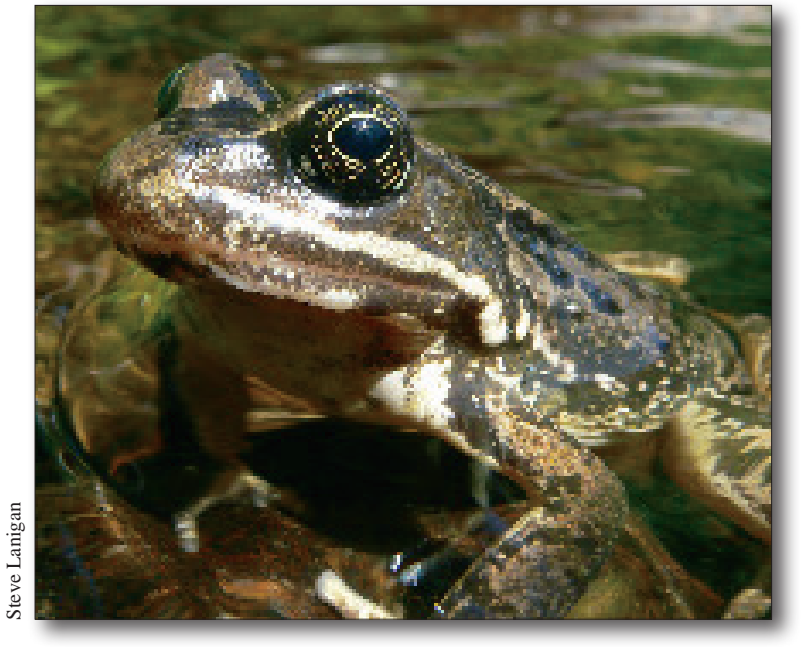

Aquatic and terrestrial amphibians were included in our assessment of stream reach condition.

time of year and moisture conditions), the lower range of the DSM score was truncated to 0 . This resulted in giving positive credit to the watershed score if animals are captured, while not penalizing the score when we failed to find any amphibians.

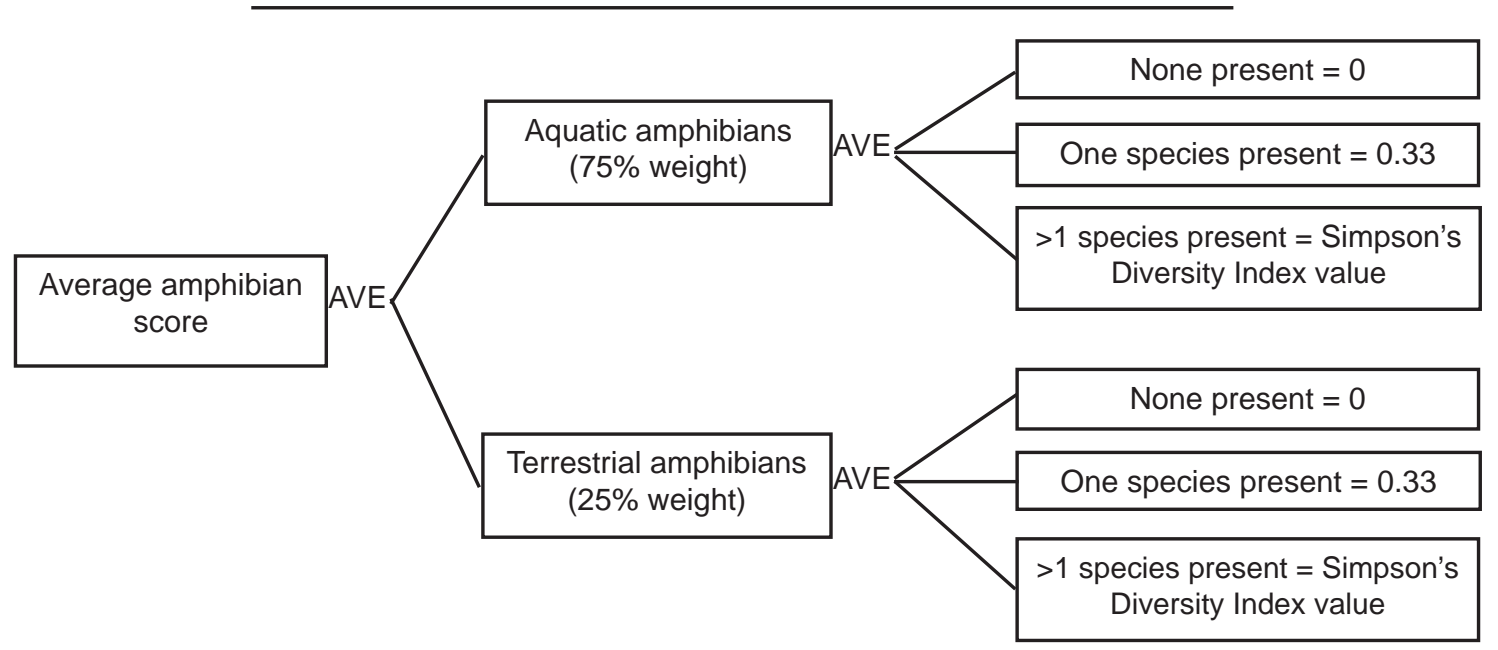

A Simpson's Index of species richness was used to convert the captures of each of the aquatic amphibians and the terrestrial amphibians to a 0 to +1 scale. There are three possible outcomes for generating a decision-support model (DSM) score for each branch of the amphibians model: (1) If no aquatic amphibians are found at a site, then the aquatic amphibian score is zero. (2) If only one species of aquatic amphibian is captured (approximately 58 percent of the sites with aquatic amphibian captures and 41 percent of the sites with terrestrial amphibian captures had only one species present) or the Simpson's Index value is $<0.33$, then the DSM score is arbitrarily changed to a value of 0.33. (3) If more than one species of aquatic amphibian is present and the Simpson's Index value is $\geq 0.33$, then the Simpson's Index value is used as the DSM score. ${ }^{2}$ The two DSM scores-aquatic and terrestrial-were averaged with a weight of 0.75 and 0.25 (see footnote 2 ), respectively, for the overall site amphibian score.

${ }^{2}$ Olson, D.H. 2010. Personal communication. Research ecologist, Pacific Northwest Research Station, 3200 SW Research Way, Corvallis, OR 97331. 


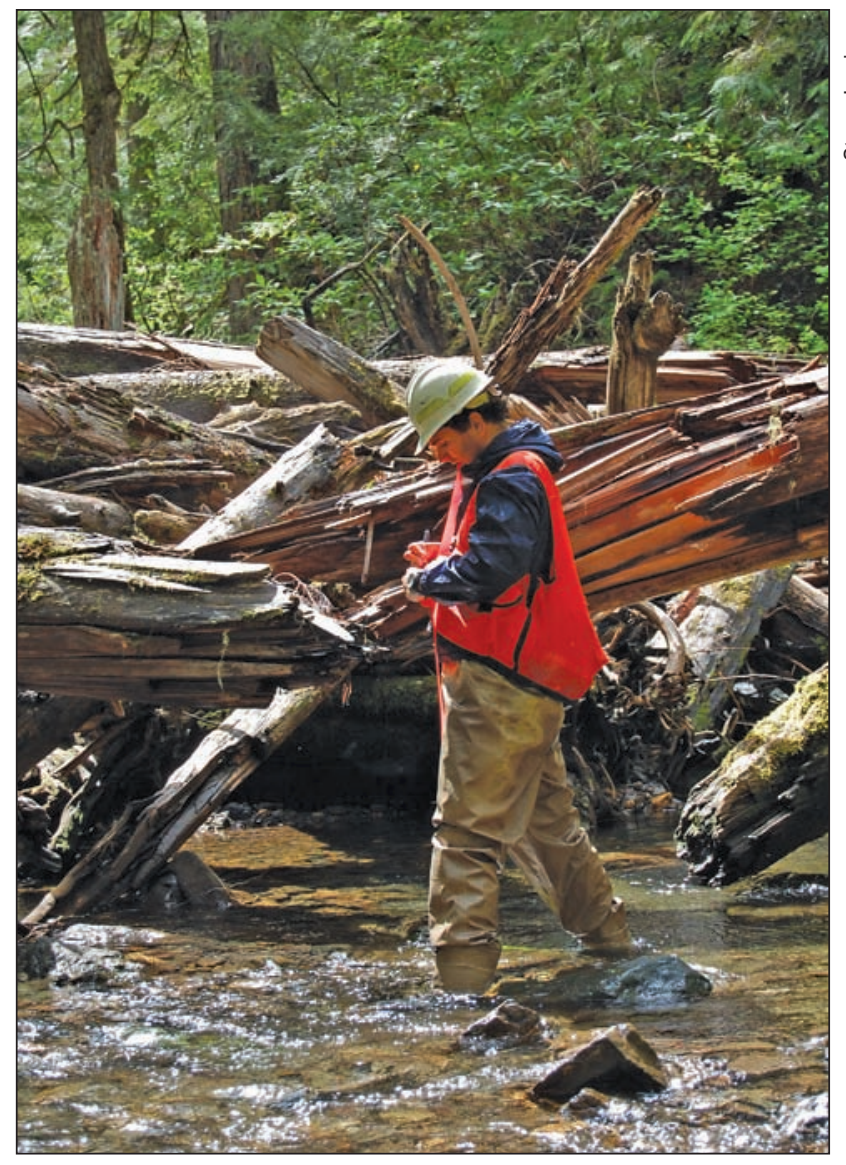

Figure 8-Large pieces of wood in the stream channel were counted in each sampled stream reach.

"Study Area" section). The NWFP area contains 1,379 watersheds that met the sampling criteria of at least 25 percent of stream channels along the 1:100,000 stream layer in federal ownership.

Riparian reserves were defined in the NWFP to have variable widths based on a combination of 100-year flood plains, breaks in slope, riparian vegetation, and site potential trees (USDA and USDI 1994), but these boundaries have yet to be delineated. Therefore, riparian areas for road, vegetation, and landslide risk assessments were based on fixed-width buffers that were placed on the stream layer (see following sections for details). Upslope attributes (also referred to as "watershed-wide" attributes) were calculated for the entire federal portion of the watershed, including the riparian area. Although this approach may count riparian areas twice, the upslope and riparian attributes are assessed

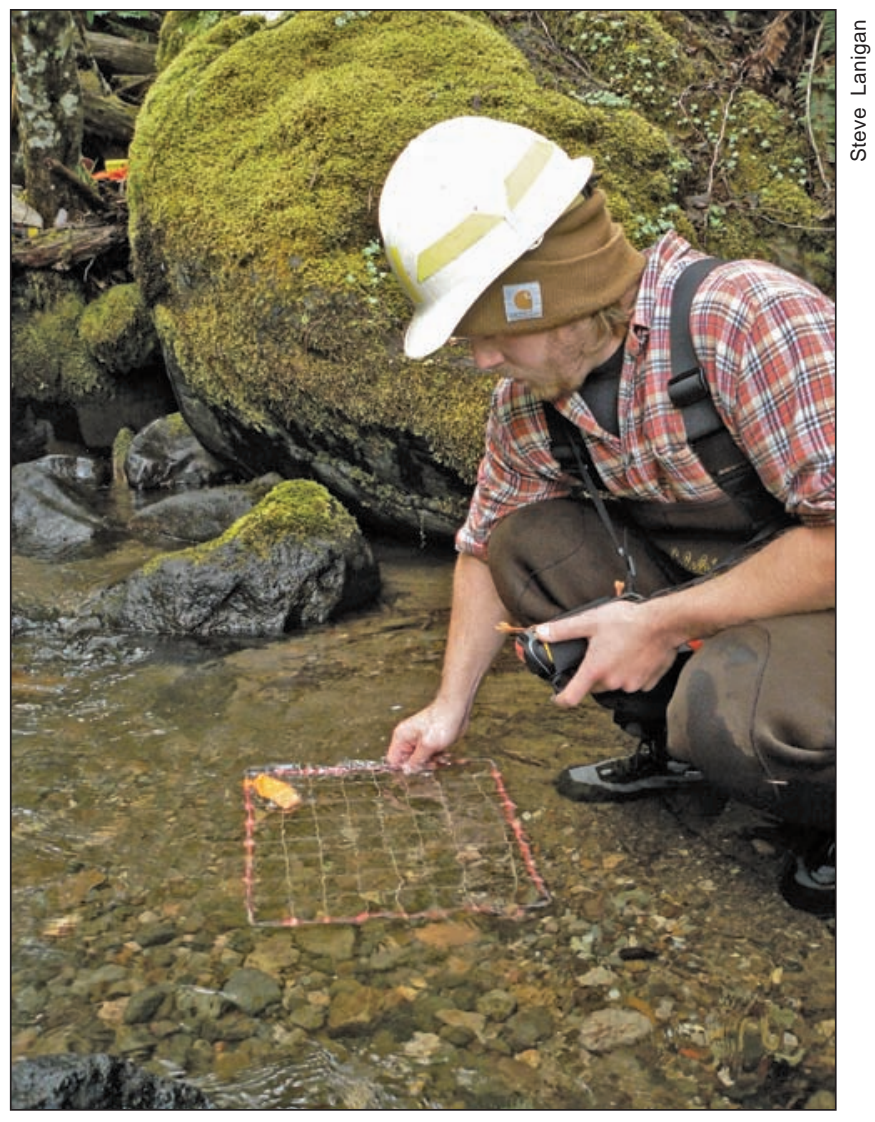

Figure 9-Fine sediment was measured at pool tail crests.

as proxies for different processes, and multicollinearity is not an issue because we are not statistically estimating the influence of explanatory factors. Watershed-wide metrics also avoid the problem of wide variation in the amount of nonriparian areas in watersheds, and they tend to be consistent with available studies on watershed impacts (e.g., road density is typically measured as total watershed density).

\section{Attributes-}

Each province used a somewhat different set of attributes and model structure to evaluate upslope and riparian conditions (see app. 4 for details); however, all the attributes fell into three basic categories: roads, vegetation, and landslide risk. Attributes were calculated for the federal portion of each watershed based on data from geographic information systems (GIS) and remote sensing data sets. The GIS layers used in the analyses were collected from various sources, 
including the FS, BLM, and NPS, and other state and federal agencies. Further details on the layers used in the analyses are provided in appendix 5.

Roads - The road layer comprises 2008 data from a variety of sources (see app. 5 for details). Road density in upslope and riparian areas and the frequency of road-stream crossings were determined for all the federal watersheds, except for the Oregon Coast province, which dropped road-stream crossings because of concerns about the effects of the variation in stream mapping density among watersheds (see "Road Data Challenges" sidebar on page 77). All data were based exclusively on the GIS layers, with no field verification. For these analyses, road and 1:24,000 stream layers were clipped to watershed boundaries. A fixed buffer was placed over streams in the watershed to determine riparian area. The width of the buffer was determined during the decision-support model workshops and differed across the provinces. The buffer widths were based on what the participants believed was the relevant area for the riparian process of interest. For example, a narrow buffer was used in evaluating the extent that stream channels were constricted by the presence of a road. Wider buffers were used for evaluating wood and sediment input into streams. For riparian road density analyses, the road layer was laid over the riparian buffer, and miles of road inside the buffer were summarized by watershed. The number of road-stream crossings was calculated by performing a GIS intersection between the road and stream layers.

Vegetation - The analysis used GIS vegetation layers developed by the Interagency Mapping and Assessment Project (IMAP) in California, Oregon, and Washington to assess vegetation characteristics (Moeur et al. 2011). Layers were built by using Landsat Thematic Mapper remote sensing data and forest inventory plot data using a gradient nearest neighbor approach (Ohmann and Gregory 2002). In this method, the closest matching plot data are assigned to each map pixel, enabling a wide variety of vegetation attributes to be calculated. Expert groups from the different aquatic provinces chose somewhat different vegetation attributes, but most chose some combination of canopy cover and mean tree diameter metrics assessed for the whole watershed and for riparian corridors (see app. 4). In each of the federal watersheds, the vegetation layer and the 1:24,000 stream layer were clipped to the federal ownership boundary. A fixed-width buffer, which differed by province, was applied to the stream layer to designate the riparian area (app. 4).

Landslide risk - As part of the natural disturbance regime, landslides play an important long-term role in the production and renewal of habitat conditions for salmonids (fig. 10) (Reeves et al. 1995). However, timber harvesting and road construction can increase the amount of landslide activity beyond natural levels, overwhelming river systems and negatively affecting aquatic organism populations (Montgomery et al. 2000, Reeves et al. 1995, Swanson and Dyrness 1975). The AREMP landslide risk attribute was based on an empirical model developed for the Oregon Coast Range (Miller and Burnett 2007, 2008) and expanded to the NWFP area using landslide data derived from aerial photographs in 14 AREMP sixth-field watersheds. The model used widely available digital elevation model (DEM) and land-cover data (10-m [33-ft] DEMs and 25-m [82-ft] satellite imagery) and found landslide frequencies differed by topography, forest cover, and proximity to roads: landslide frequency was 48 percent higher in areas with early seral vegetation (average diameter $<4$ in) and 170 percent higher in areas within $50 \mathrm{~m}$ (164 ft) of roads (Miller 2006). The AREMP landslide risk attribute evaluates the effect of management activities on landslide susceptibility by comparing the "current" landslide susceptibility with "baseline" susceptibility by sixth-field watershed. Baseline susceptibility was determined using the DEMs and forest cover class, assuming that trees with a greater than 4 in diameter were growing in all areas capable of supporting tree growth. We determined susceptibility in each cell in the DEM grid and then calculated the average susceptibility rating across all cells in the sixth-field watershed. This measurement was considered the best approximation of a watershed's natural or baseline susceptibility for landsliding, although we recognize that we are underestimating susceptibility because we do not account for loss of trees owing to natural processes. The "current" susceptibility rating was 


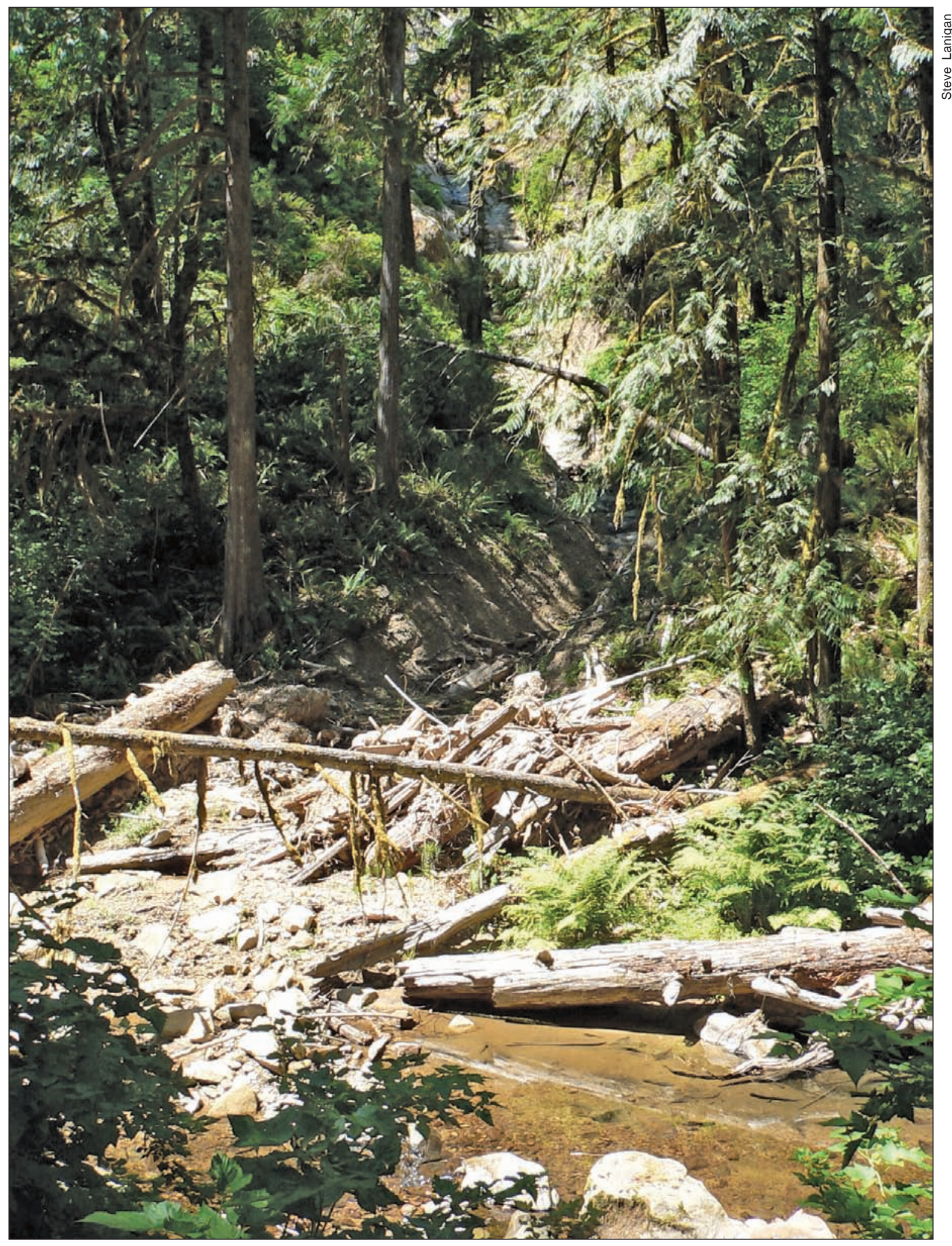

Figure 10-Naturally occurring landslides provide large wood and spawning gravels to rivers. However, excessive landslides caused by management activities can overwhelm river systems and negatively impact aquatic organisms. 
determined by multiplying the baseline rate of each cell in early seral areas by a factor of 1.48 and areas within $50 \mathrm{~m}$ $(164 \mathrm{ft})$ of a road by a factor of 2.7. The effect of management on landslide susceptibility was calculated as a ratio of the current susceptibility to the baseline. Landslide risk was included for all aquatic provinces except the KlamathSiskiyou and Franciscan provinces because model results did not match up well with a locally derived model, so we are continuing to work with local provincial experts to refine this attribute before including it in the decision-support model.

\section{Data analysis -}

The condition of upslope and riparian processes was estimated for the federal portion of each sixth-field watershed in the NWFP area having greater than 25 percent federal ownership along the 1:100,000 stream layer. Condition scores were calculated by evaluation models designed for each aquatic province. The models aggregate a number of attributes (principally road and vegetation) derived from GIS and remote sensing data (see "Methods" section and app. 4). The normalized watershed condition scores range from -1 to +1 and are positively related with the condition of watersheds: watersheds in good condition have higher scores than those in poor condition. Because data on every watershed in the target population were analyzed, inferential statistics are not needed to test the reliability of generalizing results from a sample to a larger population. All differences are effectively statistically significant, so what remains for judgment is whether differences are meaningful in terms of biology or management.

\section{What Is the Trend in Watershed Conditions?}

\section{Study design-}

Because no repeat sampling has yet occurred for the inchannel data, it was only possible to use the upslope and riparian data set to calculate trend. The same 1,379 watersheds used for question 2 are used here. Assessment of trend estimates watershed condition status in 1994 and again in 2008 based on upslope and riparian process attributes.

\section{Attributes-}

Attributes used for the trend analysis are the same as those described above under the status of upslope and riparian condition. Additional information related to the calculation of these metrics related to the two periods is provided below (with further details in app. 5).

Roads - Information on road building and decommissioning conducted since the NWFP was implemented is spotty and incomplete. Although most of the federal road layers contain attributes that describe whether specific road segments were decommissioned, dates of decommissioning and road building on Forest Service land were not available. Historical roads layers (e.g., from 1994 when the NWFP was implemented) also were not available. Therefore, to obtain road density data from 1994 (time 1) and 2008 (time 2) to analyze change, we used total road miles (existing + decommissioned) as the time 1 data point and the existing roads as the time 2 data point. We assumed that all the roads were decommissioned later than 1994. The Forest Service and the BLM rarely decommissioned roads before 1990 (Erkert 2003). Although analyzing just the miles of roads that have been decommissioned may seem more straightforward than looking at miles of roads in time 1 and time 2, this approach would not allow us to use the decisionsupport model and determine the distribution of watershed conditions across the NWFP area in the two periods. For simplicity, we refer to the range of dates as 1994 to 2008 in subsequent figures to match our 15-year reporting period.

Vegetation - For change analysis, vegetation layers for the NWFP area were developed (as described above under question 2) for two dates: 1996 and 2006 in Washington and Oregon, and 1994 and 2007 in California. The temporal consistency of the vegetation models was enhanced by using Landsat imagery that had been geometrically rectified and radiometrically normalized through time (i.e., "temporally normalized") using the LandTrendr algorithms (Kennedy et al. 2010) and by using a single pool of inventory plots for 
model development for both dates (Moeur et al. 2011). For simplicity, we refer to the range of dates as 1994 to 2008 in subsequent figures to match our 15 -year reporting period.

Landslide risk - Because landslide risk is based on the intersection of roads and early seral vegetation with topographic risk, it was simply calculated for time 1 (1994) and time 2 (2008) based on the roads and vegetation layers developed for each period as described above. The underlying topographic risk factor did not change between the two periods.

\section{Data analysis-}

The results were based on the amount of change that occurred; i.e., trends in watershed condition were calculated by comparing the 2008 to the 1994 upslope/riparian scores. Trend scores are simply the 2008 score minus the 1994 score, which results in a possible range between -2 and +2 (given that the maximum theoretical change is from a -1 score in 1994 to a +1 score in 2008 , or vice-versa). Positive trend scores indicate an improvement in condition and negative scores a decline. No statistical tests were needed to compare scores because trend was assessed based on a complete data set of the population of interest rather than a sample of a larger population.

Nevertheless, there is measurement error in the underlying data attributes. Of particular importance to the trend calculation is the fact that slight pixel-level differences in the Landsat imagery between dates can result in a change in the vegetation plot (and associated attributes) assigned to a pixel. Although both plot assignments generally approximate on-the-ground conditions, the switch will cause slight changes in attributes resulting in "noisiness" in the model scores beyond what has occurred on the ground; however, the magnitude of this noise is unknown at the current time (see Moeur et al., 2011 for further discussion). As a simple way to reduce the effect of these fluctuations and provide a conservative bound for estimated changes, we also calculated the percentage of watersheds trending up or down using an arbitrary minimum change threshold of greater than 5 percent ( \pm 0.1 in model score).
To further understand what was driving the trends, we developed a method to assess the relative contributions from the roads, vegetation, and landslide risk components. Watersheds were divided into seven bins by their overall trend scores ( -2 to $-0.3,-0.3$ to $-0.1,-0.1$ to $<0,0,>0$ to $0.1,0.1$ to $0.3,0.3$ to 2 ). For each watershed, the relative contributions were calculated using the following formula:

$$
\frac{\left(\text { AttributeScore }_{i}-\text { BinBoundary }\right)^{3}}{\left.\sum_{i}^{3} \text { AttributeScore }_{i}-\text { BinBoundary }\right)^{\text {BinBound }}}
$$

where:

AttributeScore $_{\mathrm{i}}=$ trend subscores $(-2$ to +2$)$ for roads, vegetation, and landslide risk.

BinBoundary $=$ boundary of the bin range closest to zero.

The percentage contribution of attribute subscores for each bin was calculated by taking the average of the individual watershed contributions.

\section{Model Validation}

The reliability of our watershed condition assessments depends on the validity of the evaluation models used. Model validation, as understood in the natural sciences, means testing to see if a model produces empirically accurate results with respect to independent, real world observations (Oreskes et al. 1994). However, expert-based systems, such as used here, are often built for situations in which such empirical tests are neither possible nor affordable — watershed condition is more of a concept than a measureable attribute in the environment. For this reason, validation in the expert systems sense is often done by comparing model processes and results back to the judgments of experts (Turban and Aronson 2001). We accomplished this type of validation by checking preliminary results with the provincial expert groups, identifying and researching discrepancies between results and expert opinions, and adjusting the models to better reflect their judgments.

We also employed two data-based analyses as a check on model results. First, we compared watershed model results to a few simple indicators measured consistently across the NWFP area, and, second, we compared inchannel to upslope and riparian results. 


\section{Uniform Indicators}

The watershed evaluation models used for questions 2 and 3 differ somewhat by aquatic province. Attributes used in the watershed condition models for the different aquatic provinces were similar in nature (roads, vegetation, landslide risk), but the specific metrics (e.g., tree size, width of riparian buffers) and evaluation criteria differed by province. The rules for integrating the attributes into overall condition scores also differed. As an alternative view and general check on these results, this analysis looked at a few key indicators individually and in a consistent fashion across all provinces.

\section{Study design-}

The same set of 1,379 watersheds used for questions 2 and 3 were evaluated for the same periods, 1994 and 2008.

\section{Attributes-}

Road density - Road density has often been used in watershed assessments because of documented effects on a number of stream attributes, broadly including patterns of water and sediment delivery (Gucinski et al. 2001, Lee et al. 1997, Reid and Dunne 1984, Reiman et al. 2001). Road density was chosen as an indicator for most of the AREMP provincial models. The metric used was watershed road density, expressed as the number of road miles per square mile of watershed area, and it was calculated the same as described above under upslope and riparian status attributes. Figure 11 illustrates road density for a single watershed.

Late-seral vegetation - A number of the provincial models incorporated indicators of the amount of the watershed or riparian area in mid- to late-seral stages, as approximated by average tree diameter and canopy cover metrics (fig. 12). As an alternative indicator for comparison to our watershed scores, we adopted the late-successional old-growth (LSOG) metric used by the NWFP Vegetation Monitoring Program, which was an average conifer diameter $\geq 20$ in and conifer canopy cover $\geq 10$ percent (Moeur et al. 2011). The metric was derived from the same data sets used for vegetation attributes for questions 2 and 3 (see app. 5).
Vegetation disturbance-The loss of natural vegetation cover can also be a major influence on water and sediment delivery (Grant et al. 2008, Reid 1993). A number of AREMP provincial models included indicators of early seral conditions as a proxy for disturbance (fig. 13). For our alternative "check" metric, we made use of a new approach to extracting vegetation disturbance information from satellite data, called LandTrendr, developed in conjunction with the NWFP late-successional old-growth monitoring module (Cohen et al. 2010, Kennedy et al. 2010). LandTrendr classifies disturbance into long- and short-duration events. Longduration events were attributed to insect and disease agents. Short-duration events were attributed to fire and harvest. Fire-caused losses were identified by matching LandTrendr disturbance areas with digitized fire polygons from the national interagency fire database, Monitoring Trends in Burn Severity (MTBS). Harvest was defined as any shortduration disturbance not characterized as caused by fires recorded in the MTBS fire layer. This harvest metric also includes blowdown and small fires not captured in MTBS.

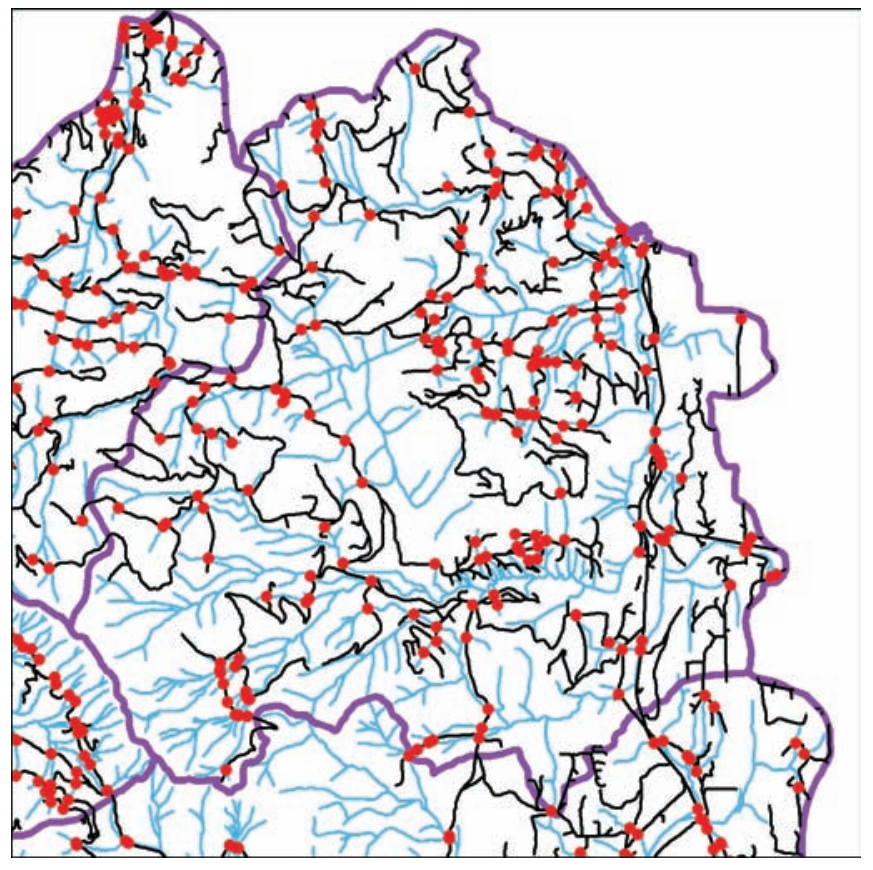

Figure 11-Road density (miles per square mile of watershed) was used as an indicator of watershed condition. In this example of a sixth-field watershed (purple line), the black lines are roads, blue lines are streams, and red dots are road-stream crossings. 


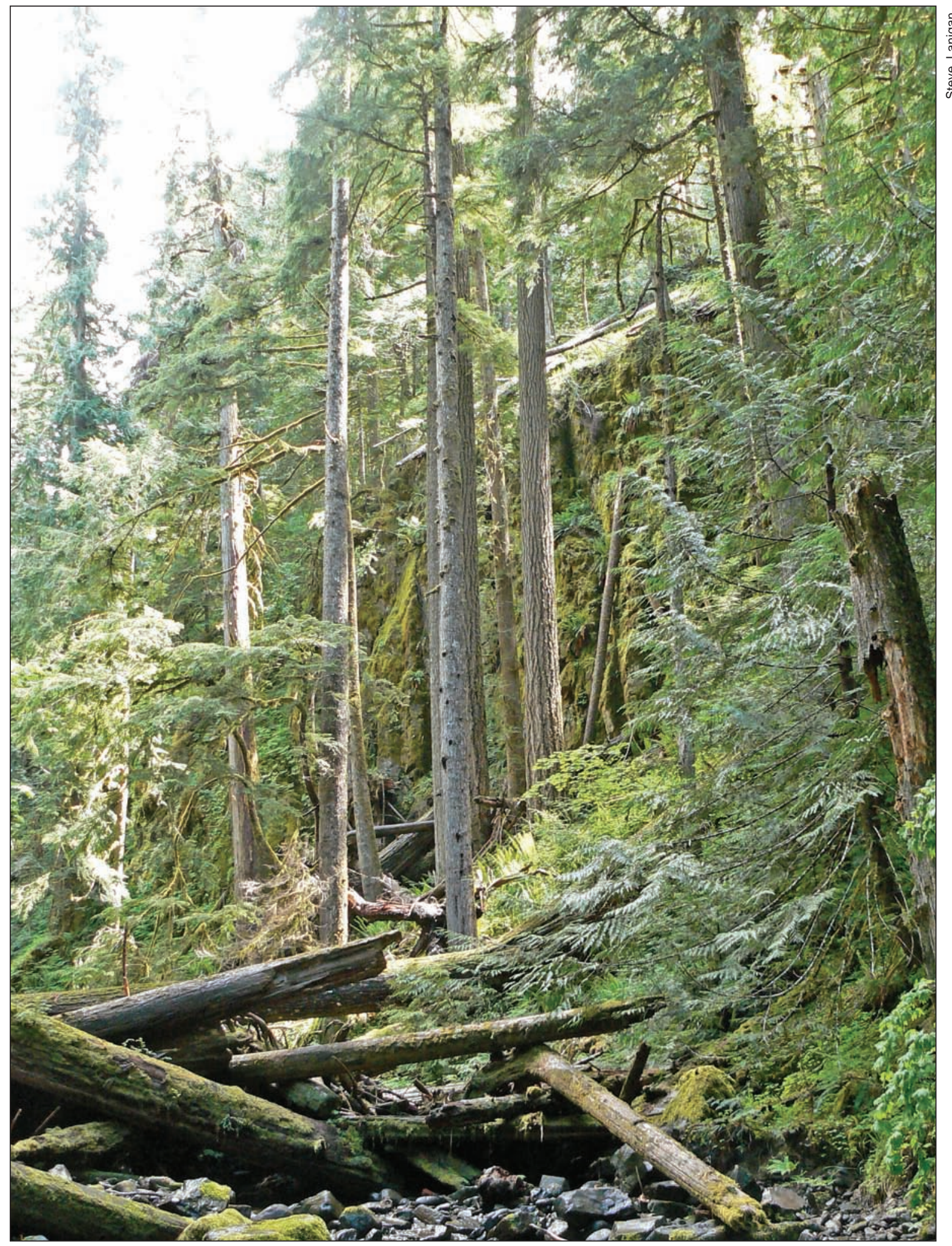

Figure 12-Watershed condition evaluations included metrics of average tree diameter and percentage canopy cover in riparian and upslope areas. 


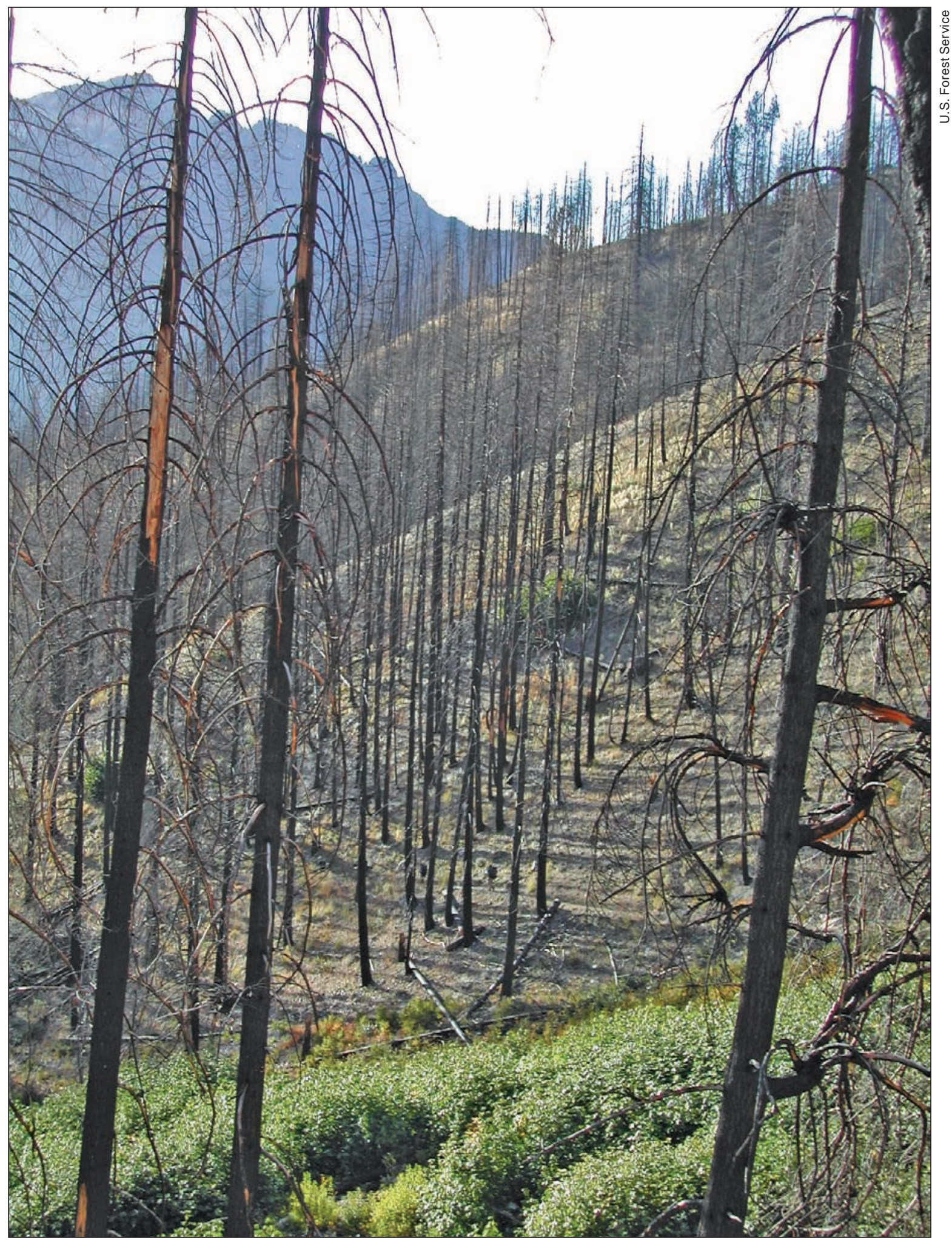

Figure 13-Disturbance from fire and harvest was used as an alternative "check" metric for assessing accuracy of watershed condition derived from models. 
For the alternative vegetation disturbance "check" metric, percentage of equivalent disturbed area was derived from the LandTrendr disturbance layer. All LandTrendr disturbances have a magnitude value of 15 (minimum detection threshold) to 100 percent, so the equivalent acres were calculated by multiplying the magnitude by the disturbance area. Percentage of areas disturbed for each year were summed into five periods, 1985-1989, 1990-1994, 19951999, 2000-2004, and 2005-2008. Note that it is possible for an area to be more than 100 percent disturbed if it has multiple disturbances within a 5-year period. For example, if a watershed burned completely (100 percent) twice in a 5-year period, it would receive an aggregate fire disturbance value of 200 percent. The vegetation disturbance from insects and disease was less than 0.3 percent of the NWFP area over the 1994 to 2008 period and so was ignored for this analysis.

\section{Data analysis-}

These alternative "check" indicators were analyzed individually using descriptive statistics and graphical displays of the original indicator units (e.g., miles per square mile) as opposed to scaled model scores. Again, no statistical tests are needed, given that the data are a complete census of the population of interest.

\section{Upslope Versus Inchannel Conditions}

In the 2004 monitoring report (Gallo et al. 2005), we combined the upslope-riparian and inchannel scores to derive an overall watershed score. We chose not to make this combination for this iteration for a number of reasons. First, only 193 watersheds have been sampled for inchannel attributes, whereas we were able to generate upslope and riparian data for all 1,379 watersheds in the NWFP areas. Second, we lack trend data for the inchannel attributes. Third, the separation emphasizes the fact that they provide different information about watershed condition. Inchannel scores are our best estimate at current conditions for fish and other aquatic biota, whereas watershed-wide conditions represent more of a risk assessment: What is the likely impact of upslope and riparian conditions on the future state of aquatic organisms? Instead of combining the scores, we report them separately. We also decided to look for correlation between the scores, in order to understand the extent to which they are measuring directly related aspects of watershed condition.

To assess correlation between the two data sources, we paired the inchannel model scores from the 193 watersheds (2002-2009) to a set of upslope-riparian model status scores (2006-2008) for the same watersheds. We performed a simple linear regression on these paired data and tested against the null hypothesis that the slope of the linear relationship was zero based on a standard t-test. 


\section{Chapter 3: Results}

Results are presented for each of the key monitoring questions, whose answers provide insight for evaluating the success of the aquatic conservation strategy in the entire Northwest Forest Plan (NWFP) area and by land use allocation. As described in the "Methods" section, standardized condition model scores range from -1 to +1 , with watersheds in good condition having higher scores than those in poor condition. For much of the following display and analysis, we have grouped scores into the five equal condition categories: very high $(>0.6)$, high $(>0.2$ and $\leq 0.6)$, moderate $(\leq 0.2$ and $\geq-0.2)$, low $(<-0.2$ and $\geq-0.6)$, and very low $(<-0.6)$.

\section{What Is the Status of Inchannel Conditions?}

The distribution of scores for the 193 subwatersheds with inchannel data ranged from -0.76 to +1.0 , with a mean score of +0.2 . Grouping scores into categories shows that relatively few fell into the low (10 percent) and very low (1 percent) categories (fig. 14). The majority of inchannel attribute scores fell into the moderate (35 percent) and high (41 percent) ranges, with relatively few (12 percent) in the very high category. The number of watersheds in each category was compared to a theoretical uniform discrete distribution in which each category had an equal number.
The actual distribution of scores is different from the equal distribution (Pearson chi-squared, p-value $<0.0001$ ) indicating that the number of scores in each category is not similar to the result of random effects.

For the low- and very low-scoring subwatersheds (scores $<-0.2$ ), water temperature was usually the most influential factor (mean temperature score $=-0.77$ ). In many of the provincial evaluation models, a poor water temperature score carried more weight than other attributes because it was only measured once for each subwatershed (at the lowest elevation on federal land), in contrast to the other attributes, which were averaged over six to eight sites. Aquatic invertebrate scores (mean $=-0.6$ ) also appeared influential in producing the low scores.

Looking at the distributions of individual attribute scores, one can see that pools, substrate, and invertebrates all had median positive scores and were skewed with a long negative tail, whereas wood was more evenly distributed with a median near zero (fig. 15). Temperature actually fell into a bimodal distribution with many scores at the extremes ( -1 and +1 , causing the lack of "whiskers" on the box-whisker chart) owing to temperatures either above or below the evaluation criteria range.

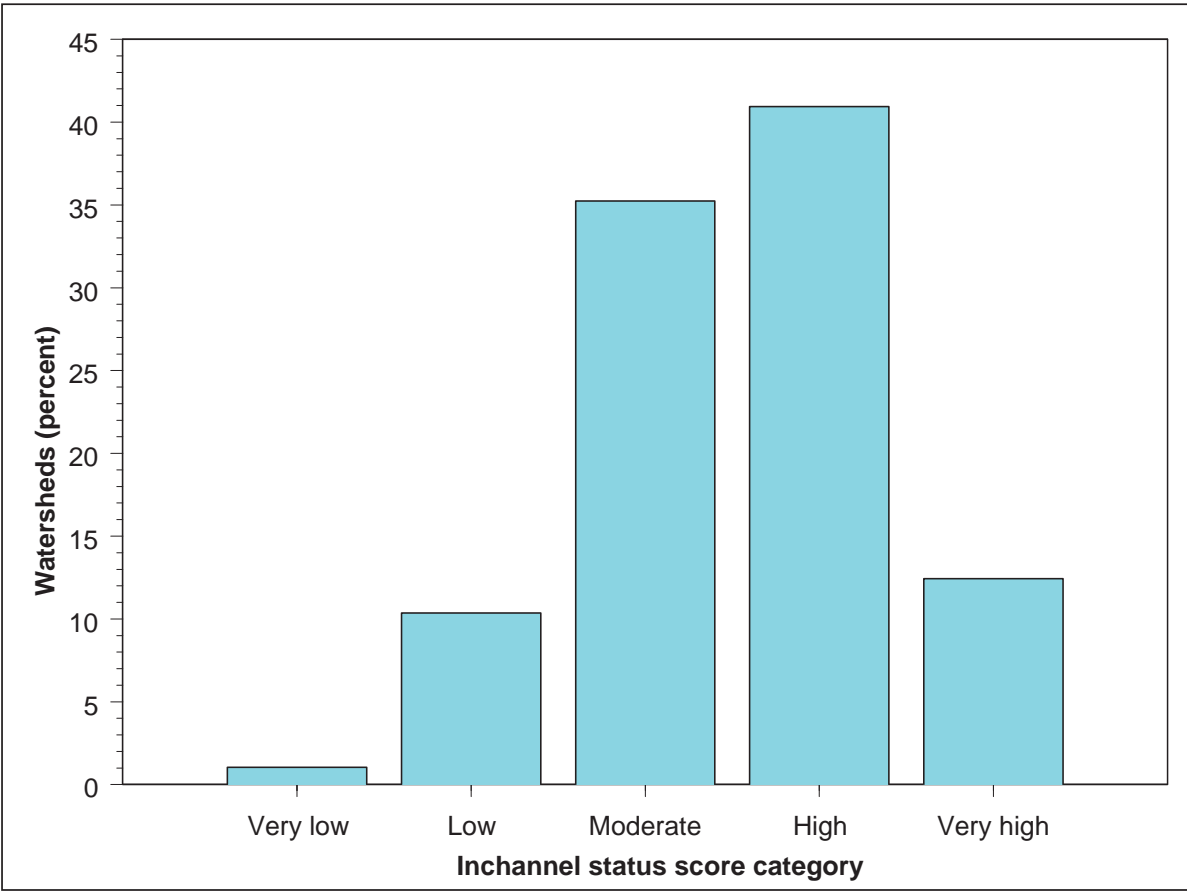

Figure 14-Inchannel condition scores by status category for the 193 randomly selected watersheds in the Northwest Forest Plan area that have been sampled for inchannel attributes as of 2009. 


\section{Distribution Functions}

This report makes use of three types of distribution graphs: box plots (A), histograms (B), and frequency of occurence graphs (C). Box plots break the data into four groups each representing a quarter of the range of data values or observations. The box represents the middle 50 percent of the data called the second and third quartiles, and the lines outside the box represent the first and fourth quartiles. The line inside the box represents the median value. In the plots showing inchannel data, which are samples of all watersheds, the shaded area represents possible variation in the median value. The median does not vary for watershed condition scores because the scores are based on upslope and riparian data for all watersheds, i.e., a census.

Histograms and frequency of occurence graphs represent the distribution of a data set in a similar way. The $\mathrm{x}$-axis represents the range of values within the data set, and the $y$-axis represents the number of observations that occur at different places within the range. In a histogram, the total range of values is segmented into smaller groups called bins. The $\mathrm{x}$-axis represents the bins and the y-axis represents how many observations fall into each bin. Because the data are grouped together, the size of the bin affects the shape of the histogram. Smaller bins provide a closer approximation of the shape of the distribution for continuous data such as watershed and attribute scores.

Frequency of occurence graphs also display the range of the data on the $x$-axis. However, the $y$-axis represents the relative number of watersheds that are in the vicinity of a line vertical to the $x$-axis. The relative amount is determined using bins as in the histograms. Instead of counting the occurrences of observations in each bin, the count is compared to the rest of the observations in a mathematical interpolation function. Interpolation infers observations in places where no data are present, making it possible to display a continuous representation of the data. In the case of density graphs, this creates a line describing the shape of the data where higher counts of observations result in higher relative amount. Because the line is continuous, it provides insight into the shape of the distribution that cannot be derived from a histogram.

To interpret a frequency of occurence graph, consider the height, slope, and features of the line. The higher on the $\mathrm{y}$-axis the more observations around the $\mathrm{x}$-axis value, steeper line slopes identify larger increases or decreases in the number of observations around the $\mathrm{x}$-axis value, and peaks represent high concentrations of observations. With overlaid graphs, at any point along the $\mathrm{x}$-axis the top line has more observations than the bottom line. When frequency of occurence graphs are used to represent the same attribute at different times, shifts along the $\mathrm{x}$-axis of features such as peaks implies a concentration of observations has increased or decreased its highest frequency $\mathrm{x}$-axis value.
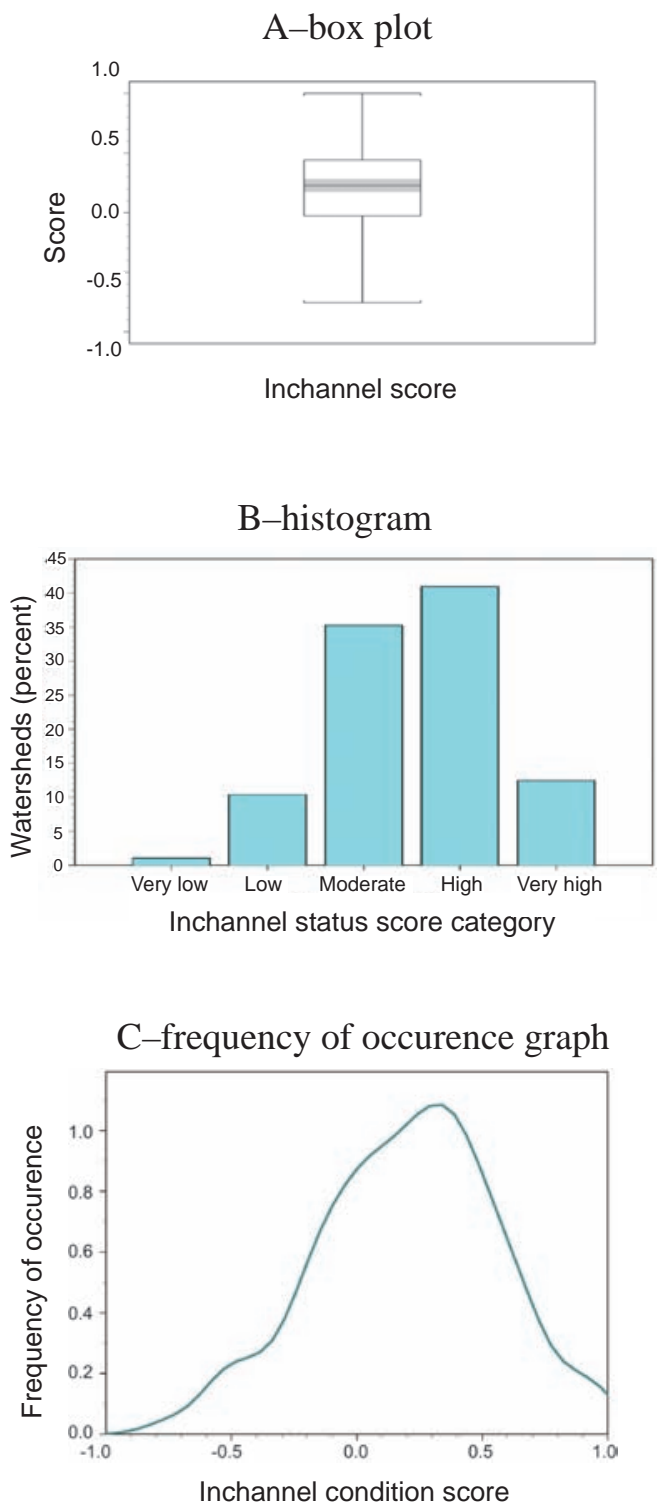


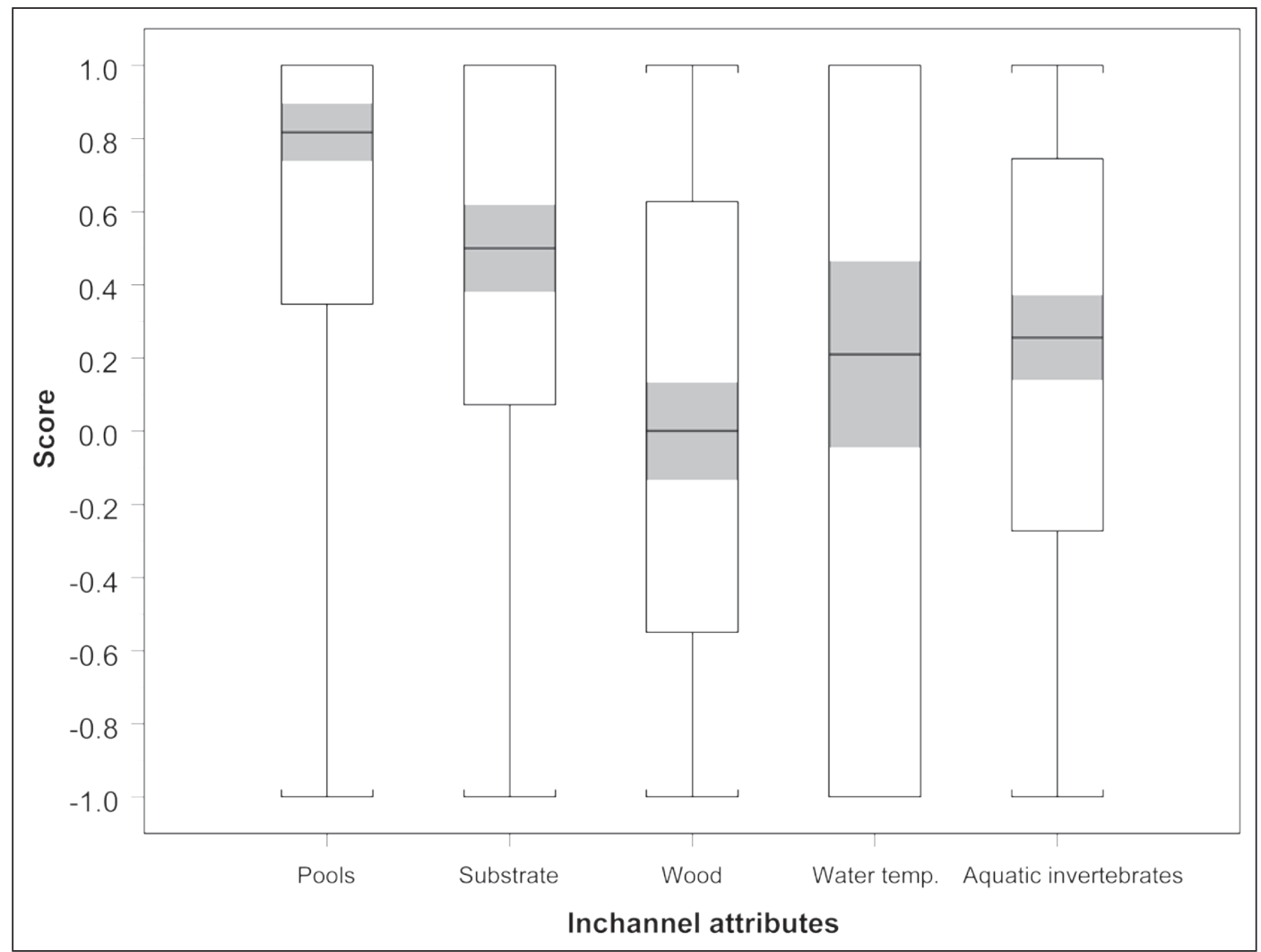

Figure 15-Distribution of attribute scores for aquatic pools, substrate, wood, temperature, and aquatic invertebrates and for the 193 randomly selected watersheds in the Northwest Forest Plan area that were sampled for inchannel attributes as of 2009.

Figure 16 shows the spatial distribution of inchannel scores. Low scores are found only in the southern half of the NWFP area, with over 70 percent of watersheds in the low and very low categories occurring in the Klamath-Siskiyou and Franciscan provinces.

\section{Inchannel Status by Land Category}

Examining overall inchannel score results in the context of land use allocations (fig. 17) shows that congressionally reserved lands have the highest scores (mean +0.31 , median +0.31 ), followed by late-successional reserve (LSR) (mean +0.21 , median +0.22 ) and matrix (mean +0.14 , median +0.16 ). Statistical analysis showed that the difference between median scores for congressionally reserved lands and matrix lands is significant (Behrens-Fisher generalized $\mathrm{p}$-value $=0.036)$, whereas the difference between LSR lands and the other two land use allocations is not significant (LSR-matrix generalized $p$-value $=0.649$, LSR-reserved generalized $p$-value $=0.230$ ). The reserved class had the least variability, followed by increasing distribution ranges for LSR and matrix lands. There was a significant difference between the means of the key and nonkey categories (Student's t-test, $\mathrm{p}$-value $=0.042$ ), with key watersheds scoring higher (mean +0.27 , median +0.29 ) than nonkey watersheds $(+0.16$, median +0.15$)$. Their distribution ranges were also different, with the range of key watershed scores more concentrated than scores for nonkey.

The distributions of individual attribute scores were more variable in regard to land use categories (fig. 18). Statistically significant differences between attribute scores by land use category are summarized in table 4 . Pool scores were high across all land use allocations, and the median 


\section{Stream Scores}

\section{Status scores}

\begin{tabular}{|c|c|}
\hline+0.61 to +1.0 & Very high \\
\hline+0.21 to +0.6 & High \\
\hline-0.2 to +0.2 & Moderate \\
\hline-0.21 to -0.6 & Low \\
\hline-0.61 to -1.0 & Very low \\
\hline
\end{tabular}

\section{Aquatic Provinces}

1. Olympic Peninsula

2. North Cascades

3. Willamette-Puget Trough

4. West Cascades

5. Oregon Coast

6. High Cascades

7. Klamath-Siskiyou and Franciscan

0

100 200 Miles

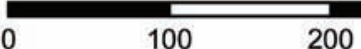

Kilometers

300

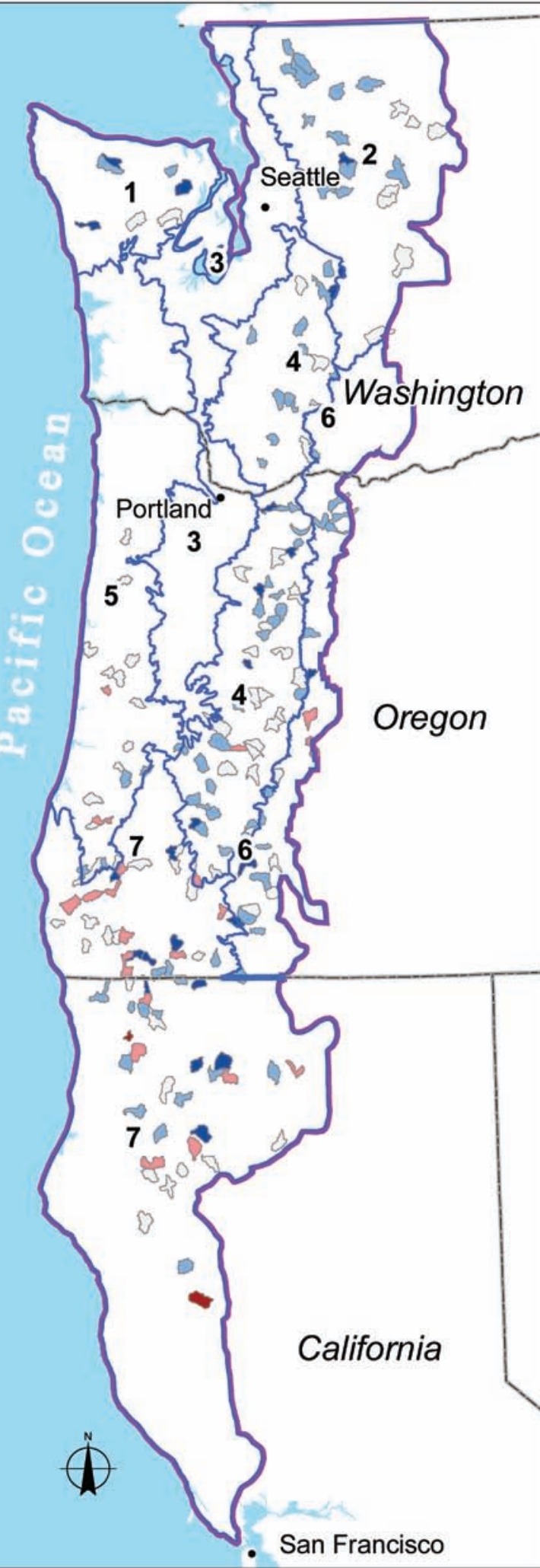

Figure 16-Distribution of inchannel condition scores for the 193 randomly selected watersheds in the Northwest Forest Plan (NWFP) area that have been sampled for inchannel attributes as of 2009. 

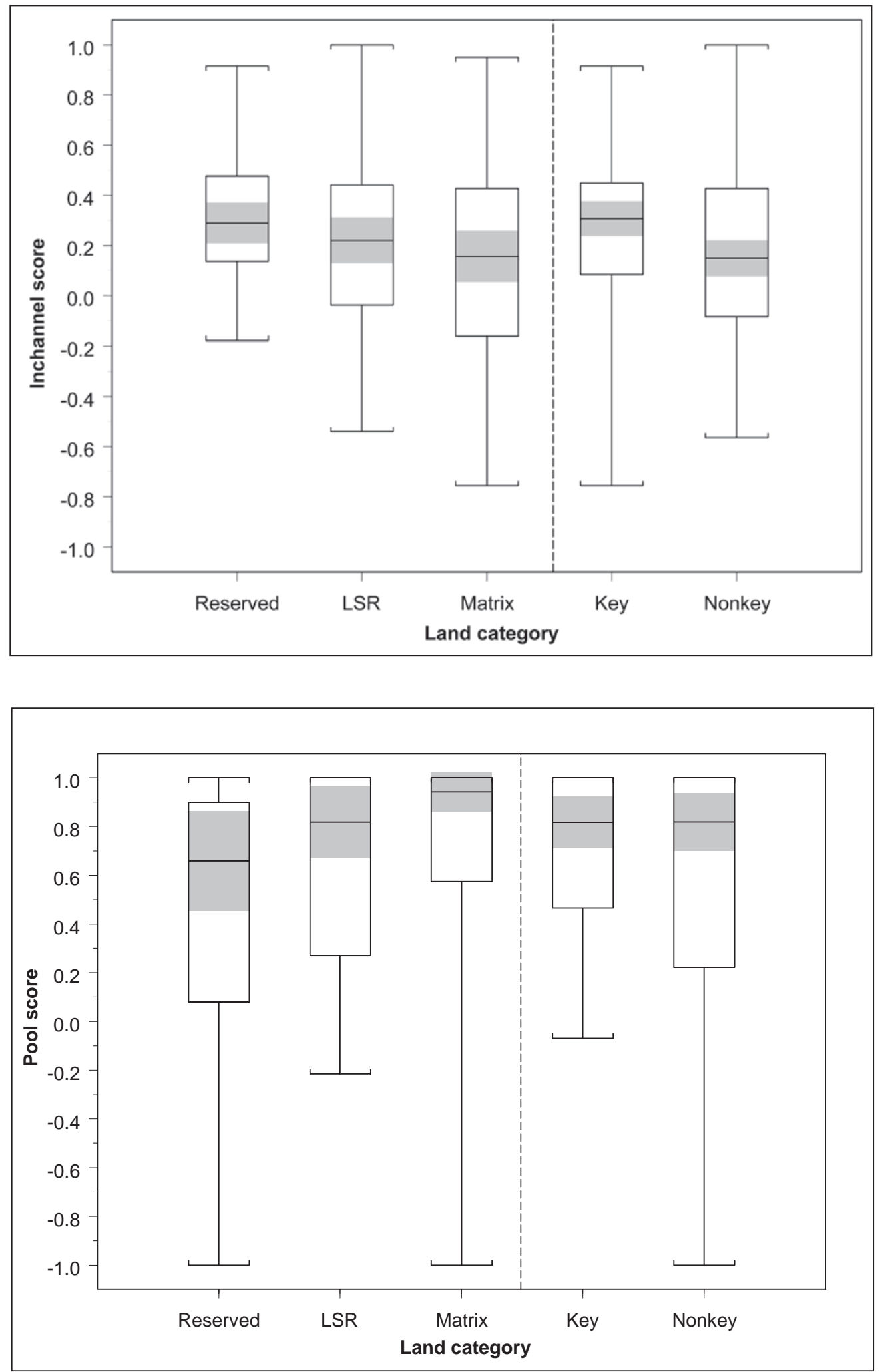

Figure 18-Distribution of inchannel attribute scores by land use category (reserved = congressional reserves, $\mathrm{LSR}=$ late-successional reserves).
Figure 17-Distribution of overall inchannel scores by land use category for the 193 randomly selected watersheds in the Northwest Forest Plan area that were sampled for inchannel attributes as of 2009 (reserved $=$ congressional reserves, LSR = late-successional reserves). 


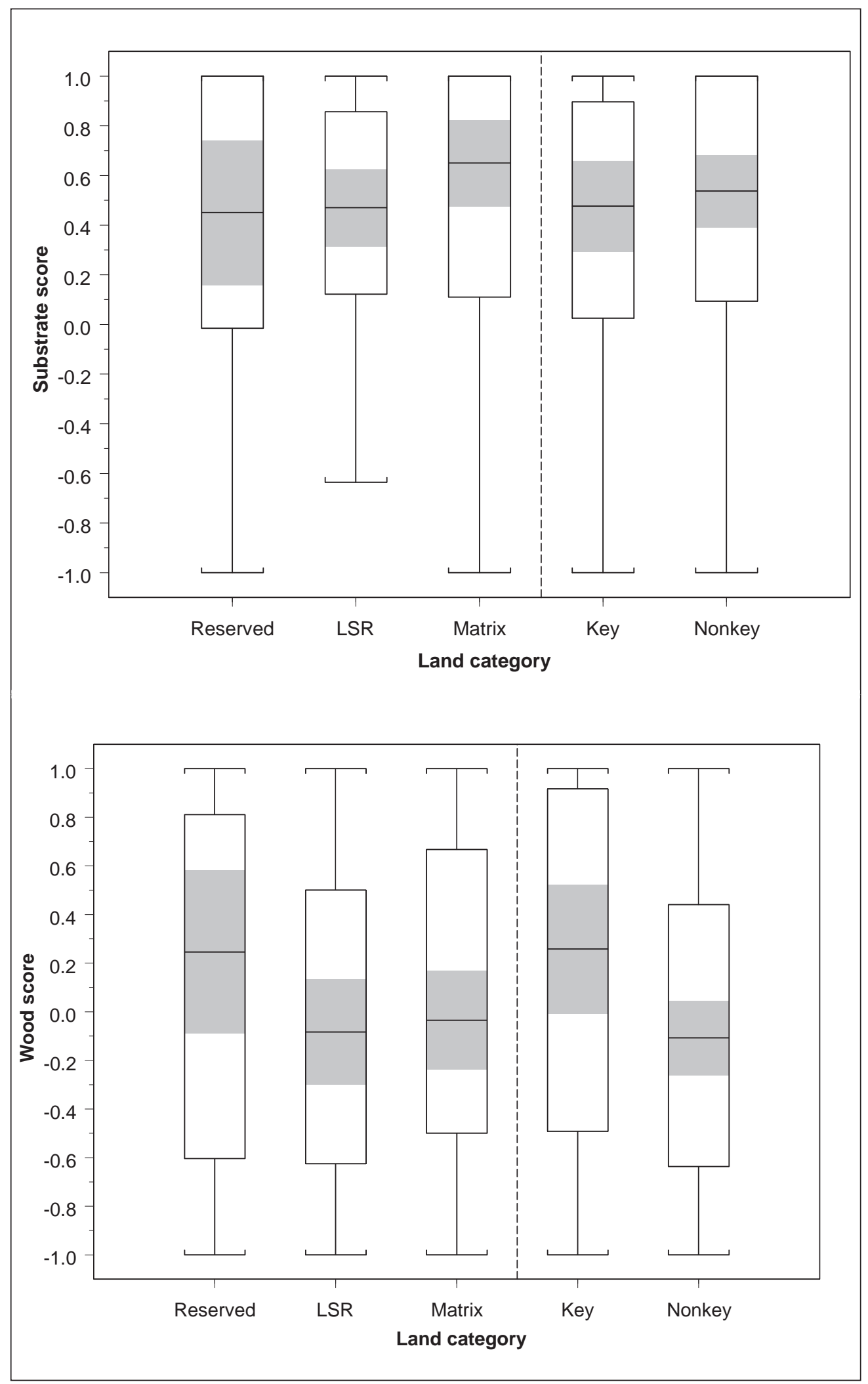

Figure 18-continued. 


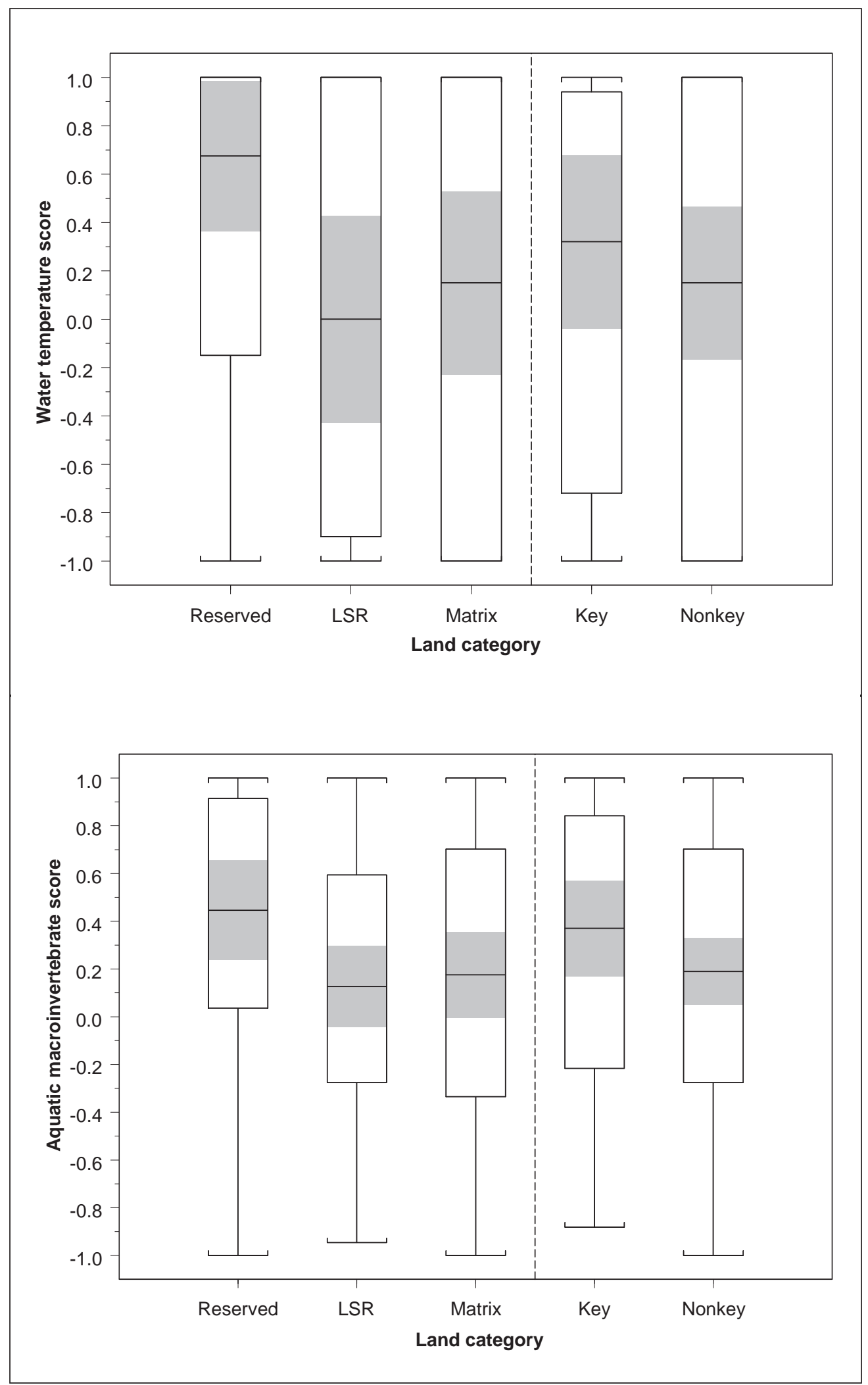

Figure 18-continued. 
Table 4-Inchannel attribute scores by land use category

\begin{tabular}{llcccccccc}
\hline Attribute & Statistic & CR & LSR & Matrix & p-value & Statistic & Key & Nonkey & p-value \\
\hline Inchannel score & Median & $+\mathbf{0 . 3 1}$ & +0.22 & $\mathbf{+ 0 . 1 6}$ & 0.04 & Mean & $+\mathbf{0 . 2 7}$ & $+\mathbf{0 . 1 5}$ & 0.04 \\
Pools & Median & $+\mathbf{0 . 6 6}$ & +0.82 & $+\mathbf{0 . 9 4}$ & 0.02 & Median & +0.82 & +0.82 & 0.13 \\
Substrate & Median & +0.45 & +0.47 & +0.65 & 0.69 & Mean & +0.43 & +0.39 & 0.65 \\
Wood & Mean & +0.10 & -0.02 & +0.02 & 0.67 & Median & $+\mathbf{0 . 2 6}$ & $\mathbf{- 0 . 1 1}$ & 0.03 \\
Temperature & Mean & +0.31 & +0.05 & -0.01 & 0.17 & Median & +0.32 & +0.15 & 0.94 \\
Invertebrates & Mean & $+\mathbf{0 . 3 8}$ & $\mathbf{+ 0 . 1 3}$ & $\mathbf{+ 0 . 1 3}$ & 0.08 & Mean & +0.25 & +0.15 & 0.28
\end{tabular}

Key: bold indicates significant differences between italicized and nonitalicized bold values in the row. $\mathrm{CR}=$ congressional reserves, $\mathrm{LSR}=1$ atesuccessional reserves.

score on matrix lands was found to be significantly greater than on congressionally reserved lands (Behrens-Fisher generalized $\mathrm{p}$-value $=0.02)$; no difference was found between key and nonkey watersheds (Wilcox rank sum p-value $=0.13$ ). In contrast, inchannel wood scores were found to be higher in key than nonkey watersheds, but no differences were confirmed for the reserved/LSR/matrix categories. Examining the distribution of aquatic invertebrate scores by land use allocation showed that congressionally reserved lands had a higher mean value than matrix and LSR lands. No statistically significant differences were found for substrate or temperature scores. Although the mean temperature score on reserved lands appeared considerably higher than on LSR or matrix lands, the difference was not statistically significant owing to the high dispersion in scores across all allocations (min -1.0, max 1.0 for all three allocations).

\section{What Is the Status of Upslope and Riparian Conditions?}

The conditions of upslope and riparian processes are estimated by scoring and integrating a variety of road and vegetation attributes derived from remote sensing and other mapped data sets (see "Methods" section and app. 4 for details). Data on every watershed in the target population were analyzed; therefore, inferential statistics are not needed to test the reliability of results. Measurement error inherent in the attributes is still an issue; however, it has not yet been fully quantified and propagated through the assessment models (see "Discussion" section and app. 6).

Overall watershed condition scores of the 1,379 watersheds ranged from a low of -0.99 to a high of +1 , with a mean score of +0.17 . Scores are clustered in the center of the distribution and skewed slightly positive, with 50 percent falling between approximately -0.25 and +0.5 . Figure 19 presents a view of the distribution of scores by status category. The largest percentage fell into the moderate category (29 percent), followed by the high category (25 percent). Comparable amounts were classified as very high (22 percent) and low (21 percent), but relatively few watersheds scored in the very low (4 percent) category.

The spatial distribution of watershed scores shows some noticeable patterns (fig. 20). High scores are found in the central Olympic Peninsula (Olympic National Park), the north central Cascades, the Oregon Coast Range, and scattered pockets along the Klamath-Siskiyou mountain range (mostly corresponding to designated wilderness areas). Low condition scores can be seen in the southern Olympic region, eastern Klamath-Siskiyou, and along the eastern and western flanks of the Cascade Range in Oregon and Washington. Breaking these scores down by aquatic province reveals some notable patterns (table 5). First, no watersheds were rated low in the Oregon Coast or High Cascades, and very few in the Olympic and Klamath-Siskiyou and Franciscan. The Western Cascades had both the largest percentage in the very low category and the lowest distribution overall. In contrast, the Oregon Coast, North Cascades, and Olympic all had the highest percentage of their watersheds in the very high category.

\section{Watershed Status by Land Category}

Figure 21 presents the summary of watershed scores (using upslope and riparian data) by land category. Reserved lands had the highest scores (mean +0.56 , median +0.62 ), 


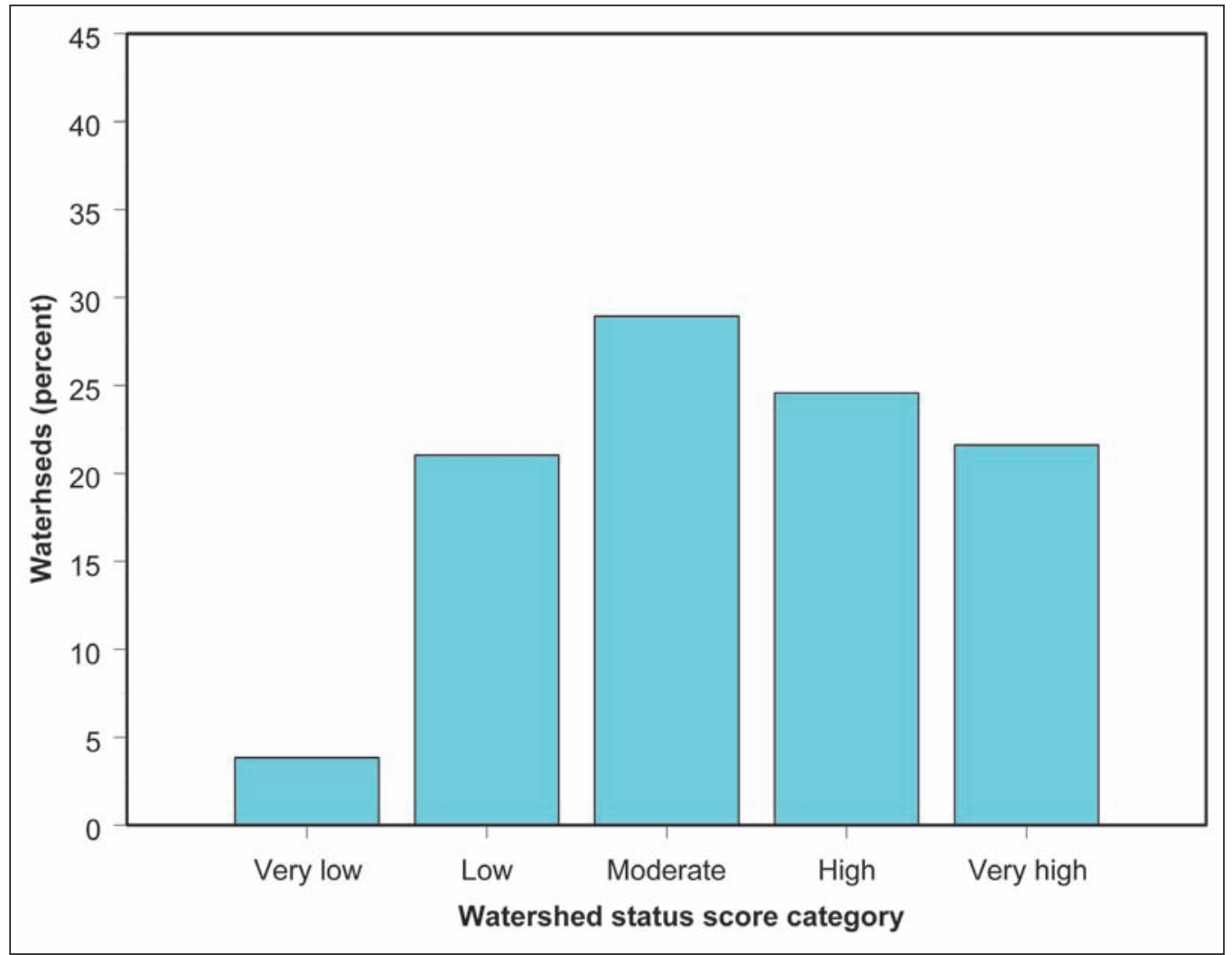

Figure 19-Watershed condition scores (2008) in the Northwest Forest Plan area by status category. 


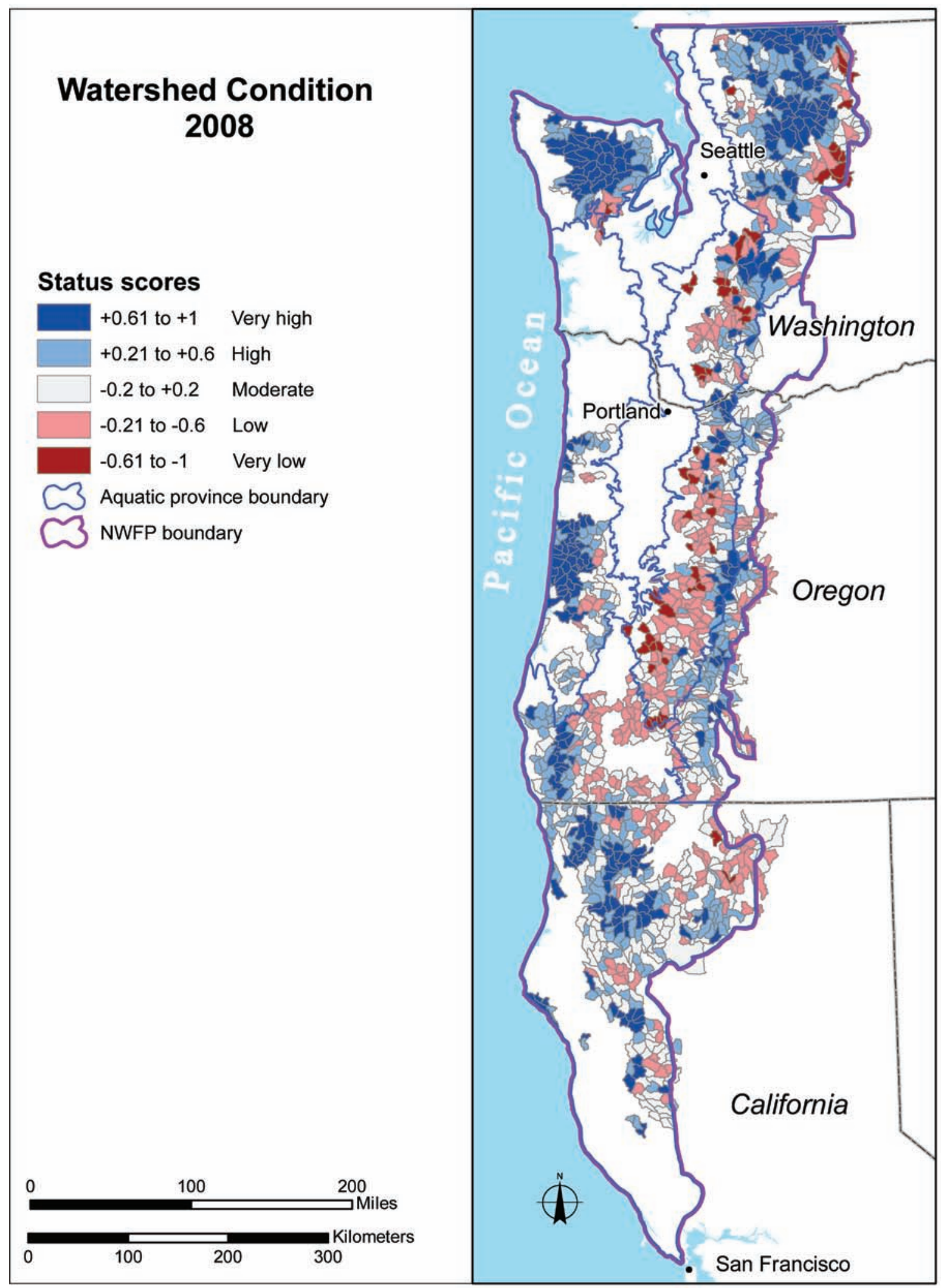

Figure 20-Watershed condition status scores (2008) in the Northwest Forest Plan (NWFP) area. 
Table 5 -Watersheds $(n=1,379)$ falling within each status condition class by aquatic province, 2008

\begin{tabular}{|c|c|c|c|c|c|}
\hline Province & $\begin{array}{l}\text { Very } \\
\text { low }\end{array}$ & Low & Moderate & High & $\begin{array}{l}\text { Very } \\
\text { high }\end{array}$ \\
\hline & & & Percent & & \\
\hline High Cascades & & 21 & 36 & 32 & 12 \\
\hline $\begin{array}{l}\text { Klamath-Siskiyou } \\
\text { and Franciscan }\end{array}$ & $<1$ & 23 & 31 & 27 & 18 \\
\hline North Cascades & 5 & 11 & 20 & 27 & 37 \\
\hline Olympic & 2 & 8 & 5 & 30 & 56 \\
\hline Oregon Coast & & 8 & 25 & 32 & 35 \\
\hline West Cascades & 13 & 34 & 27 & 17 & 9 \\
\hline
\end{tabular}

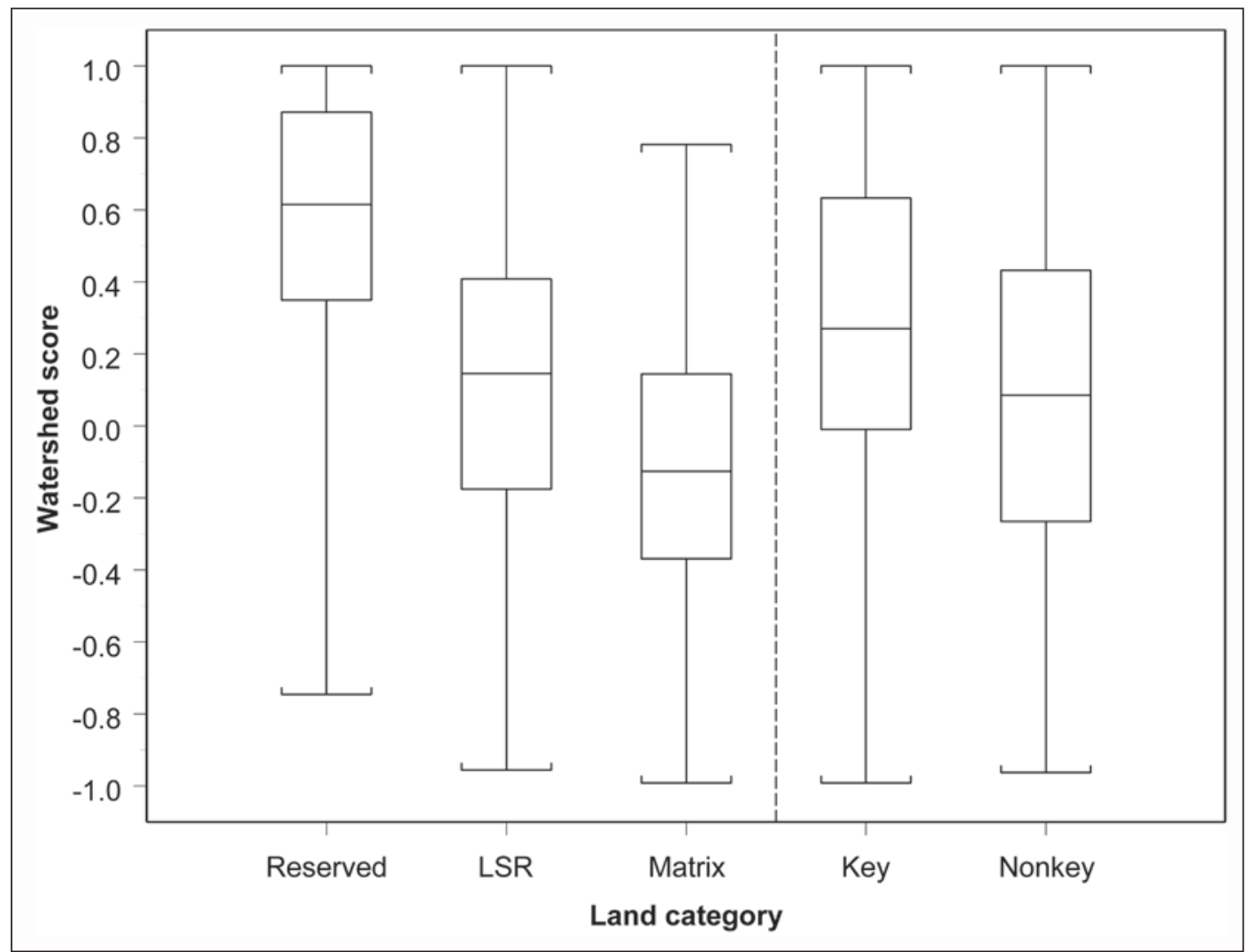

Figure 21-Distribution of watershed condition status scores (2008) by land use allocation (reserved = congressional reserves, LSR = late-successional reserves). 
followed by LSR (mean +0.14 , median +0.15 ) and matrix (-0.12, median -0.13). No watershed that was predominately reserved land received the minimum score (-1). Conversely no watersheds in the matrix category received a perfect score (+1). Although the distributions of the aquatic conservation strategy categories had similar ranges, key watersheds generally scored higher (mean +0.27 , median +0.27 ) than nonkey watersheds (mean +0.11 , median +0.09 ).

Figure 22 shows the frequency of score occurrences by land category, and it reveals a distinct distribution for each category. A preponderance of matrix scores are in the middle range $(-0.4$ to +0.4$)$, with very few greater than +0.5 . The greatest frequency of scores in the LSR category also occurs in the middle range $(+0.15)$, but there is a greater frequency of higher scores across the range and especially at the upper end. The reserved class shows very few watersheds at the lower end and a steadily increasing number of higher scores, until a small dropoff just before +1 . Differences between key and nonkey watersheds are less pronounced (fig. 23). Both distributions have their maximum frequencies around +0.25 , but nonkey watersheds have a greater frequency of scores below this value, whereas key watersheds have greater frequencies above it.

Looking at the spatial distribution of watershed scores in the various categories (fig. 24), an obvious pattern is that many of the higher scoring watersheds on congressionally reserved lands lie near the Cascade Crest, where higher elevation lands are naturally less amenable to human activities. The contiguous nature of the Olympic National Park, which makes up a significant portion of reserved lands, also may help to explain the high watershed quality on these lands. The spatial distribution of scores by key and nonkey watersheds does not reveal any further patterns by this designation (fig. 25).

\section{What Is the Trend in Watershed Conditions?}

Overall, there was a positive change in watershed scores, from a mean score of +0.14 in 1994 to +0.17 in 2008. Scores increased for 69 percent of watersheds versus 23 percent showing declines. As a portion of these shifts was likely due to errors inherent in the satellite imagery classification process, we also calculated a more conservative estimate looking at only condition score changes of greater than 5 percent $( \pm 0.1)$; using this threshold, 10 percent of watersheds increased versus the 4 percent that decreased (table 6).

Figure 26 shows a general increase in scores (a shift to the right), especially for watersheds in the low (centered around -0.75$)$ and mid to high ( +0.25 to 0.75$)$ ranges. The number of watersheds in the very high range $(+0.9)$ actually decreased slightly, primarily as a result of fire on reserved lands.

Figure 27 and table 7 examine the watershed condition score changes in more detail. Figure 27 reveals that most score changes ( 81 percent) were relatively small $( \pm 0.1$ in model score or 5 percent of possible change from -1 to +1 ). Fifty-five percent of the watersheds had score increases between 0 and +0.1 ; increases in vegetation scores were the dominant driver (66 percent) for this range, but with some contribution from roads ( 24 percent) and landslide risk (11 percent; table 7). Scores declined by 0.1 or less in 18 percent of watersheds, and in this portion of the distribution the relative influence of vegetation scores ( 83 percent) to road scores (2 percent) was much greater. The landslide risk contribution remained comparable (15 percent), but it was likely driven more by vegetation changes in landslideprone areas than road changes. Eight percent of watersheds showed no change in score (dot on fig. 27). There were two reasons why a score might not change: either (1) there were no changes in any of the underlying attributes between the sampling dates or (2) an increase in one or more attributes was cancelled out by declines in others (generally these increases/decreases were quite small).

The proportion of changes in watershed scores owing to roads, vegetation, and landslide risk diverges further between the positive and negative tails of the distribution. Vegetation losses (and associated landslide risk increases) were responsible for all of the negative trend scores beyond -0.3 . Five watersheds decreased by more than -0.5 ; all were located in the Klamath-Siskiyou and Franciscan provinces and experienced heavy vegetation losses from the 2002 Biscuit Fire. Positive trends in the +0.1 to +0.3 range were mostly due to road decommissioning (42 percent) but with a fair contribution from vegetation (30 percent) and landslide 


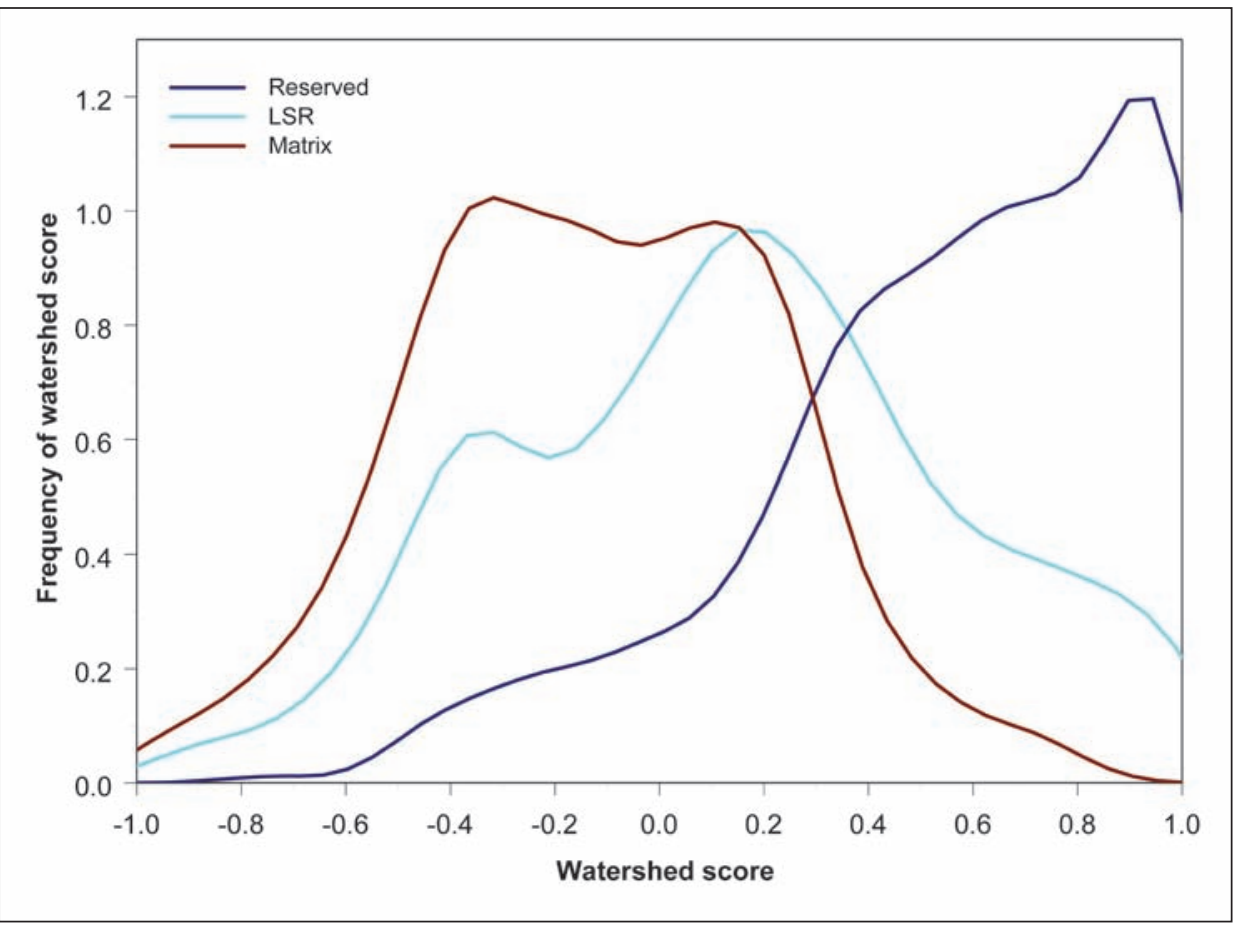

Figure 22-Frequency of watershed condition scores (2008) by land use allocation (reserved $=$ congressional reserves, $\mathrm{LSR}=$ late-successional reserves). These curves show the data in a continuous manner rather than by data bins (i.e., histograms).

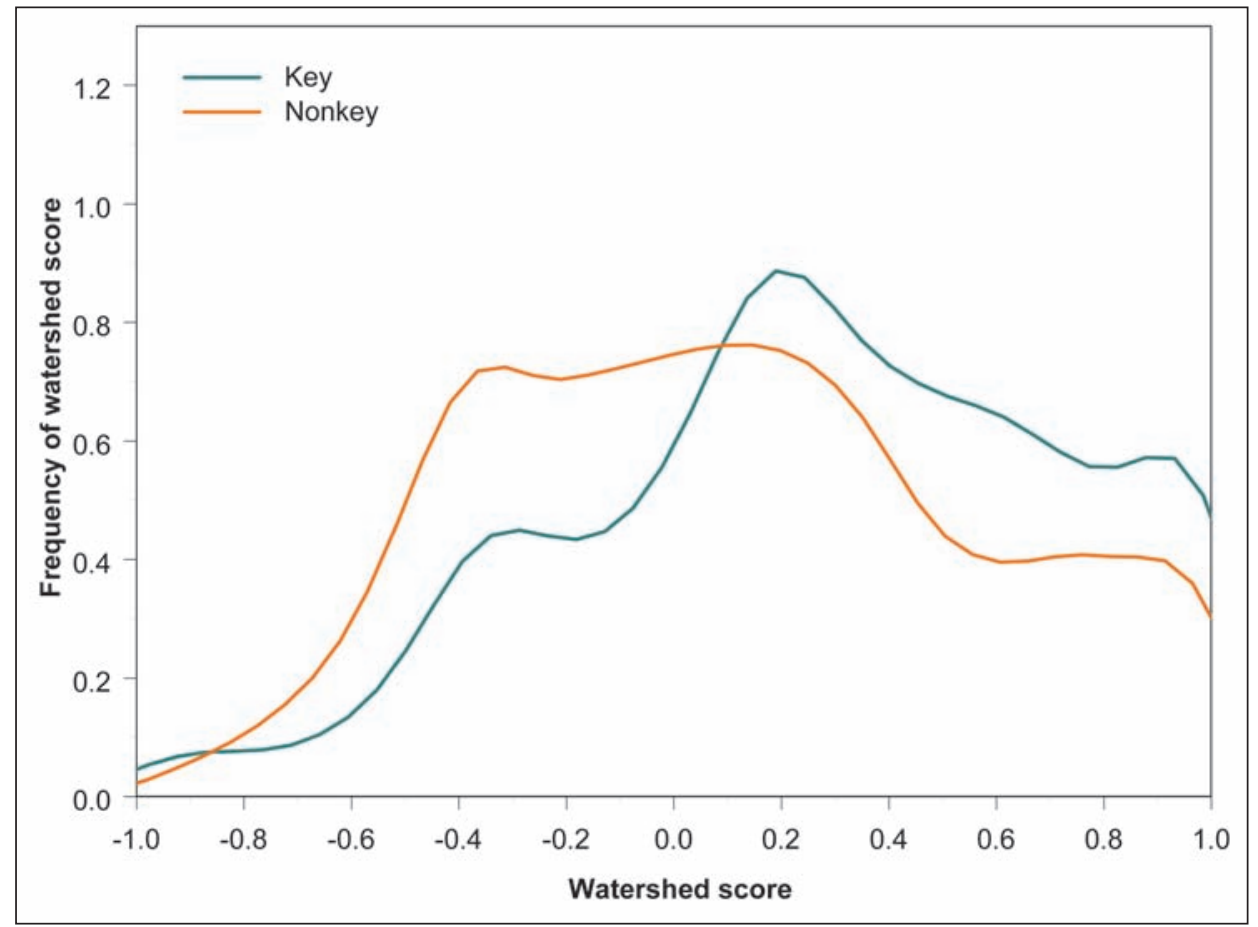

Figure 23-Frequency of watershed condition scores (2008) for key and nonkey watersheds. These curves show the data in a continuous manner rather than by data bins (i.e., histograms). 


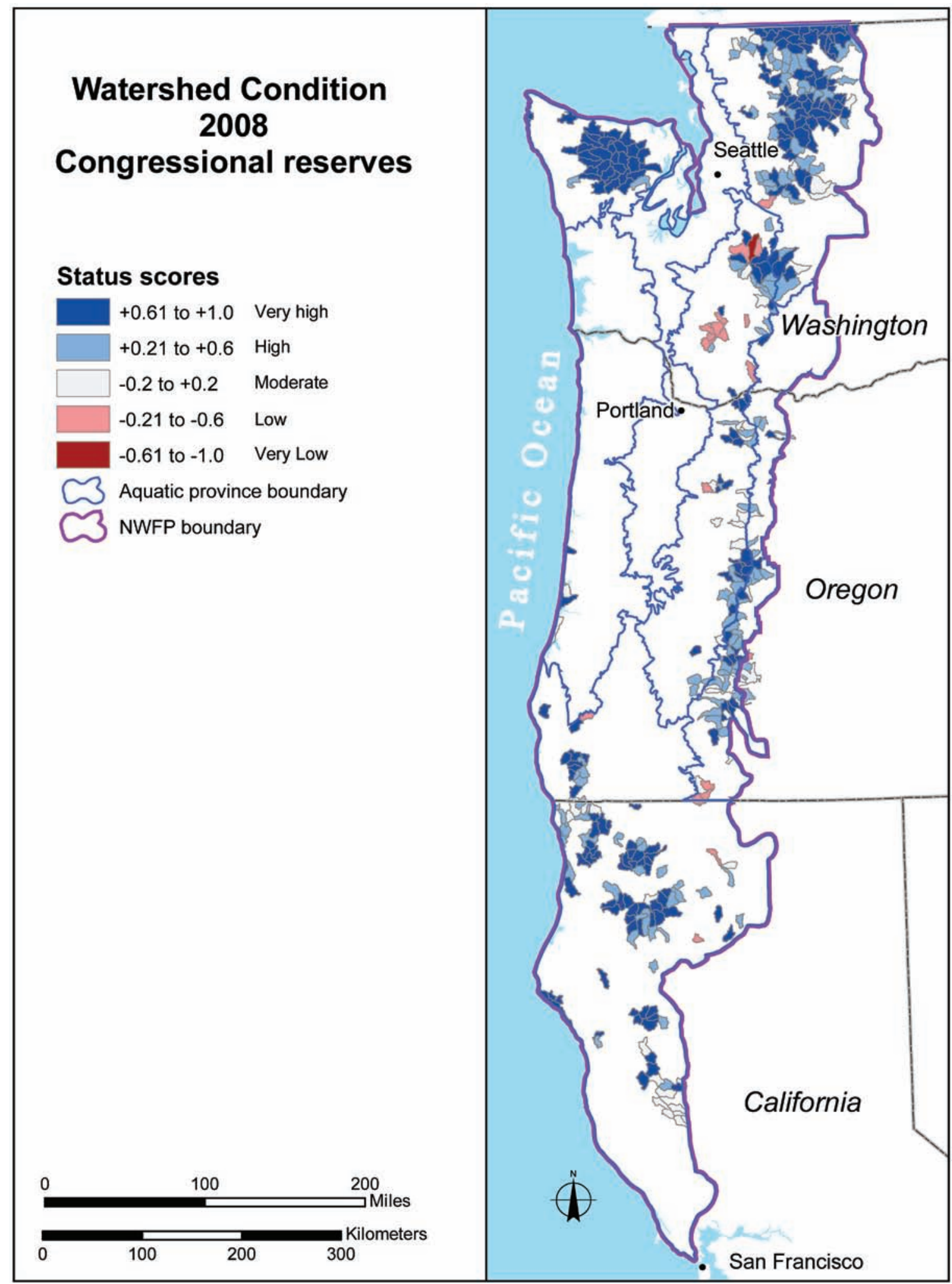

Figure 24-Watershed condition status (2008) by land use allocation in the Northwest Forest Plan (NWFP) area. 


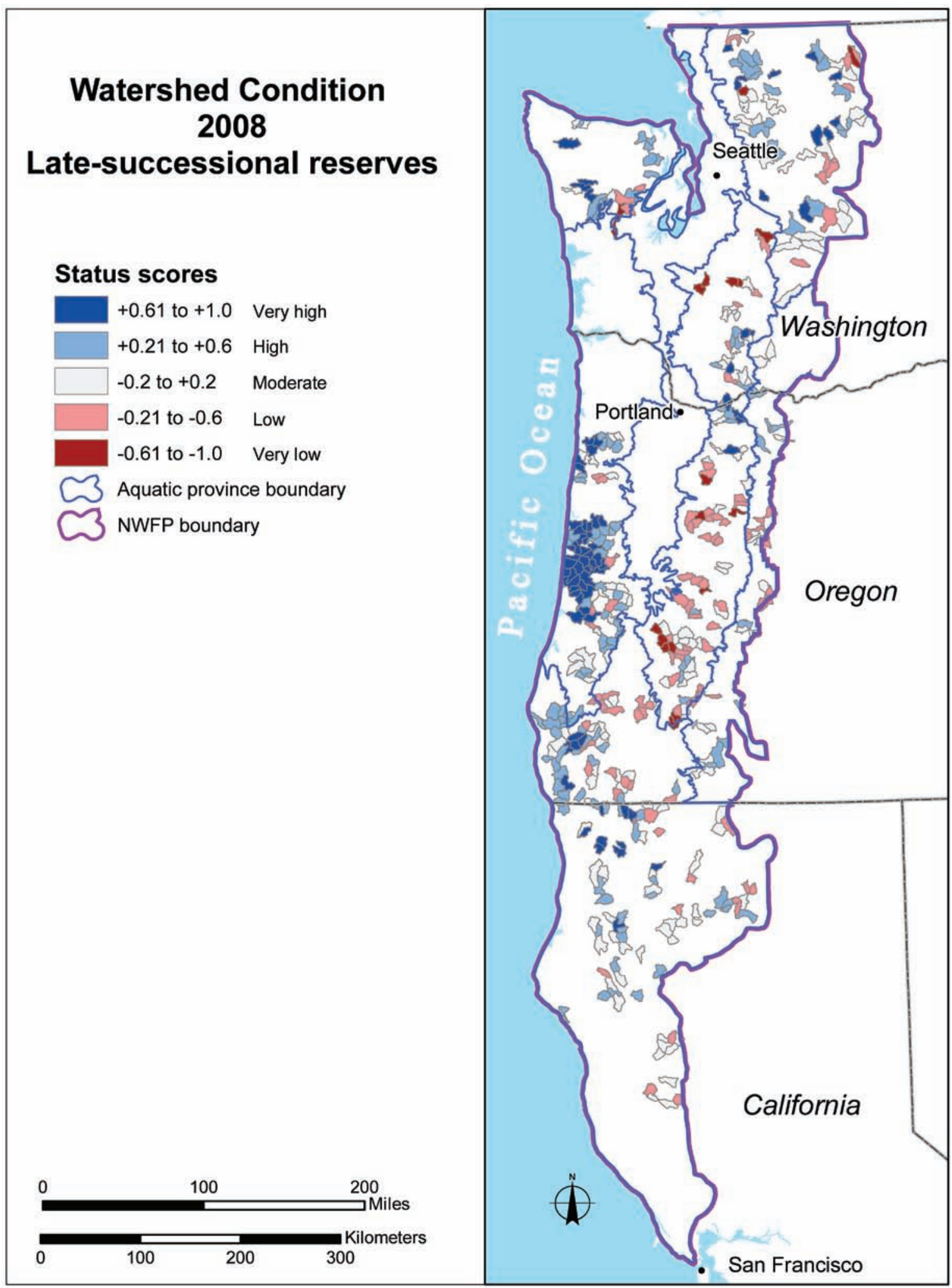

Figure 24-Continued. 


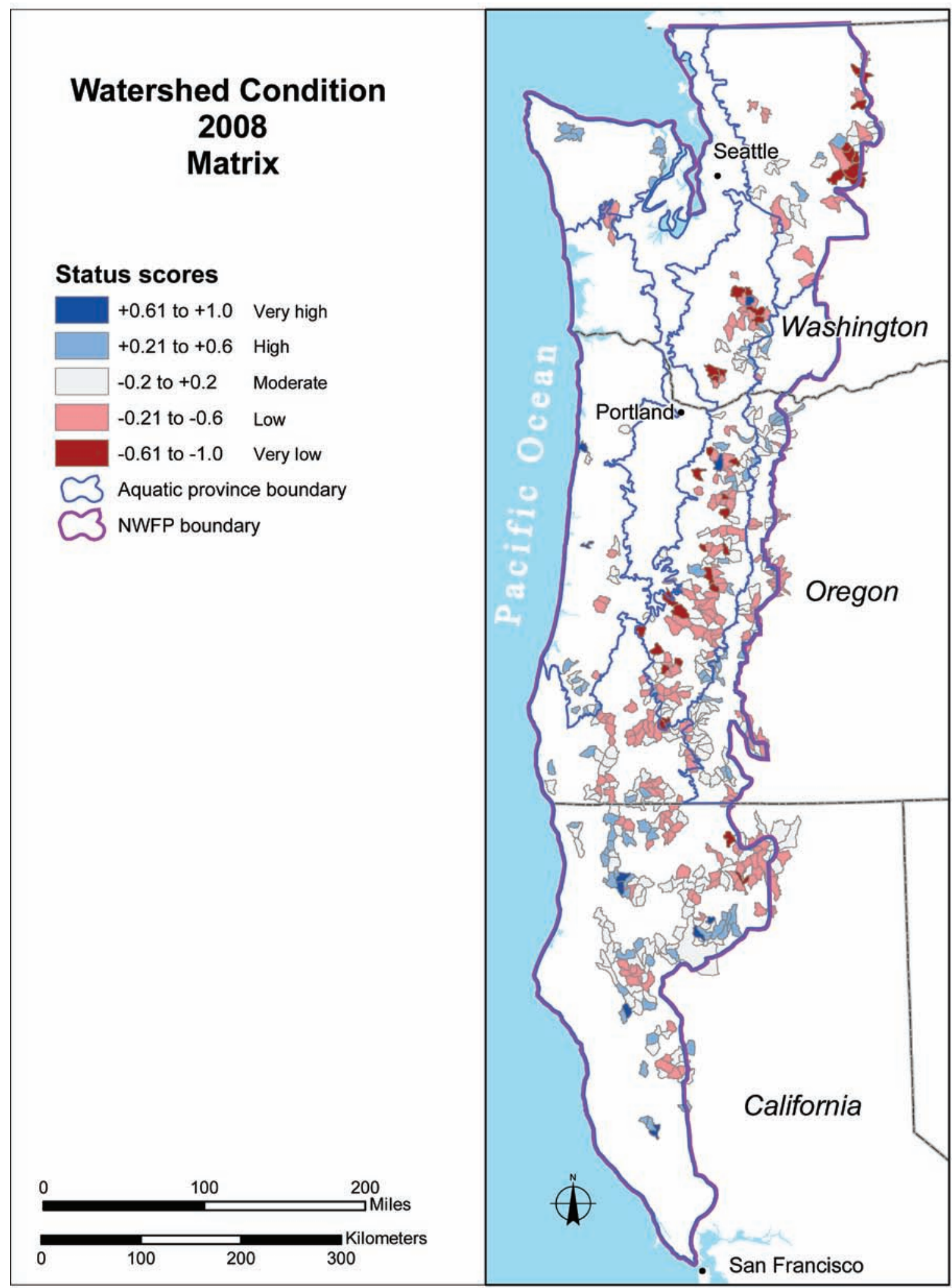

Figure 24-Continued. 


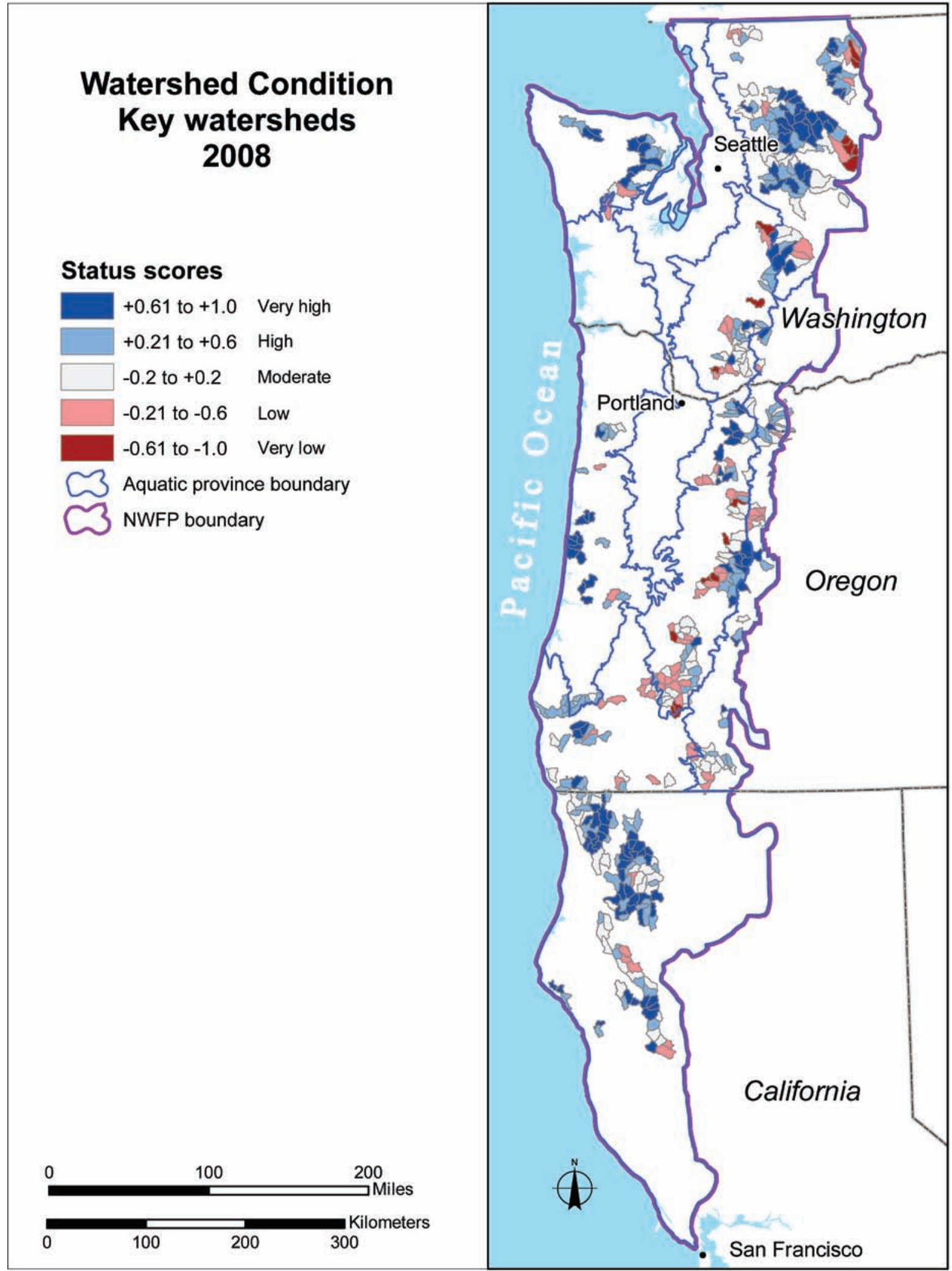

Figure 25-Watershed condition status (2008) for key and nonkey watersheds in the Northwest Forest Plan (NWFP) area. 


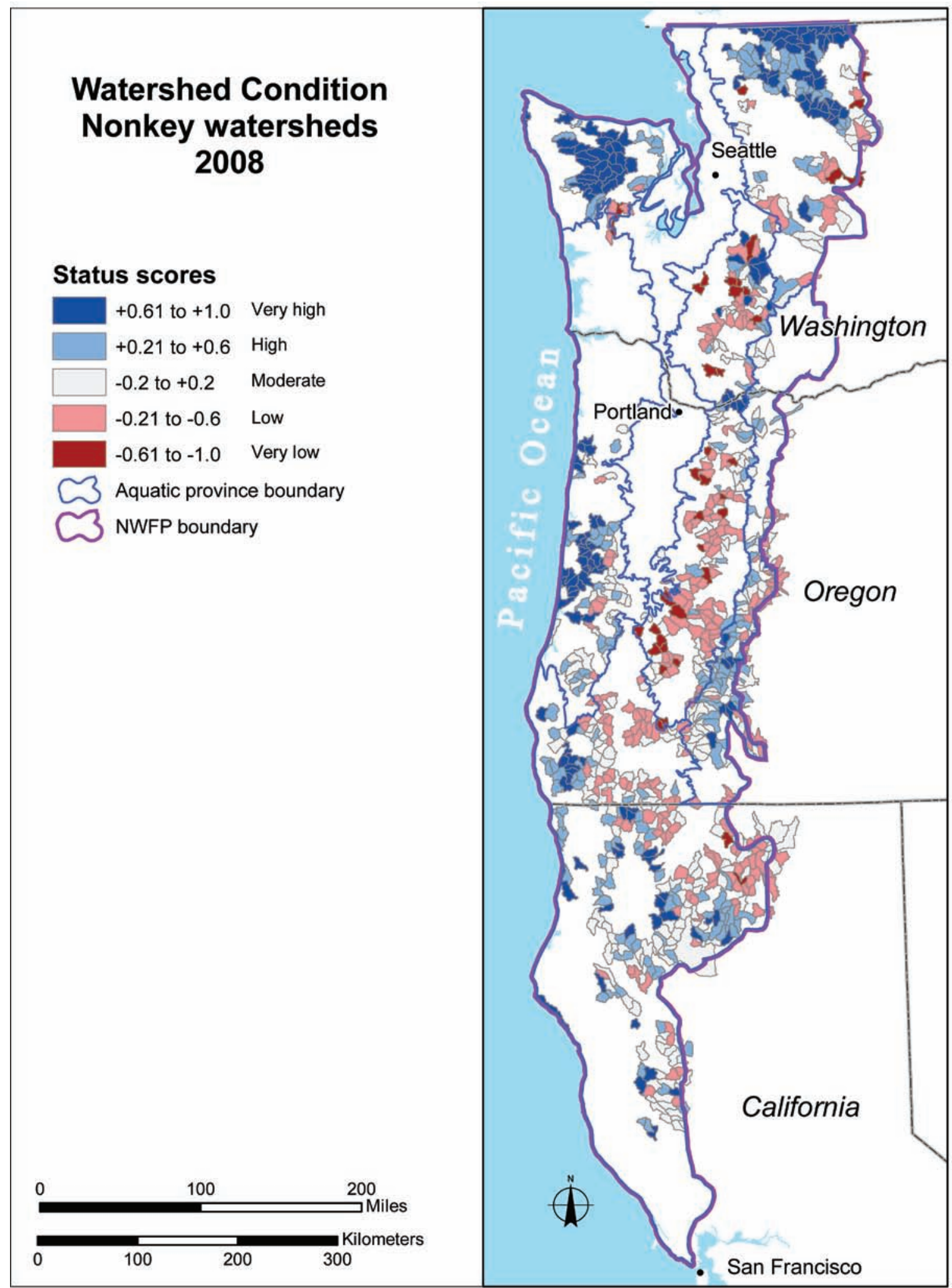

Figure 25-Continued. 
Table 6 -Watersheds $(n=1,379)$ that decreased, increased, or had no change in watershed scores between 1994 and 2008

\begin{tabular}{ccc}
\hline Decrease & No change & Increase \\
\hline & Percent &
\end{tabular}

All watersheds

No min. threshold ${ }^{a}$

\pm 0.1 min. threshold ${ }^{b}$

23

8

69

Congressional reserve ${ }^{\mathrm{c}}$

4

86

10

Late-successional reserve

38

19

43

Matrix

17

3

80

Key

16

3

81

Nonkey

23

23

9

68

${ }^{a}$ This categorization was based on any amount of change in a watershed's score and therefore includes some changes likely due to data imprecision; it is intended as an upper-bounding estimate of the amount of change.

${ }^{b}$ Only score changes greater that \pm 0.1 are counted as change in this categorization; it is intended as a lower-bounding estimate of the amount of change.

${ }^{c}$ Changes by land use categories were based on the no-minimum-threshold approach.

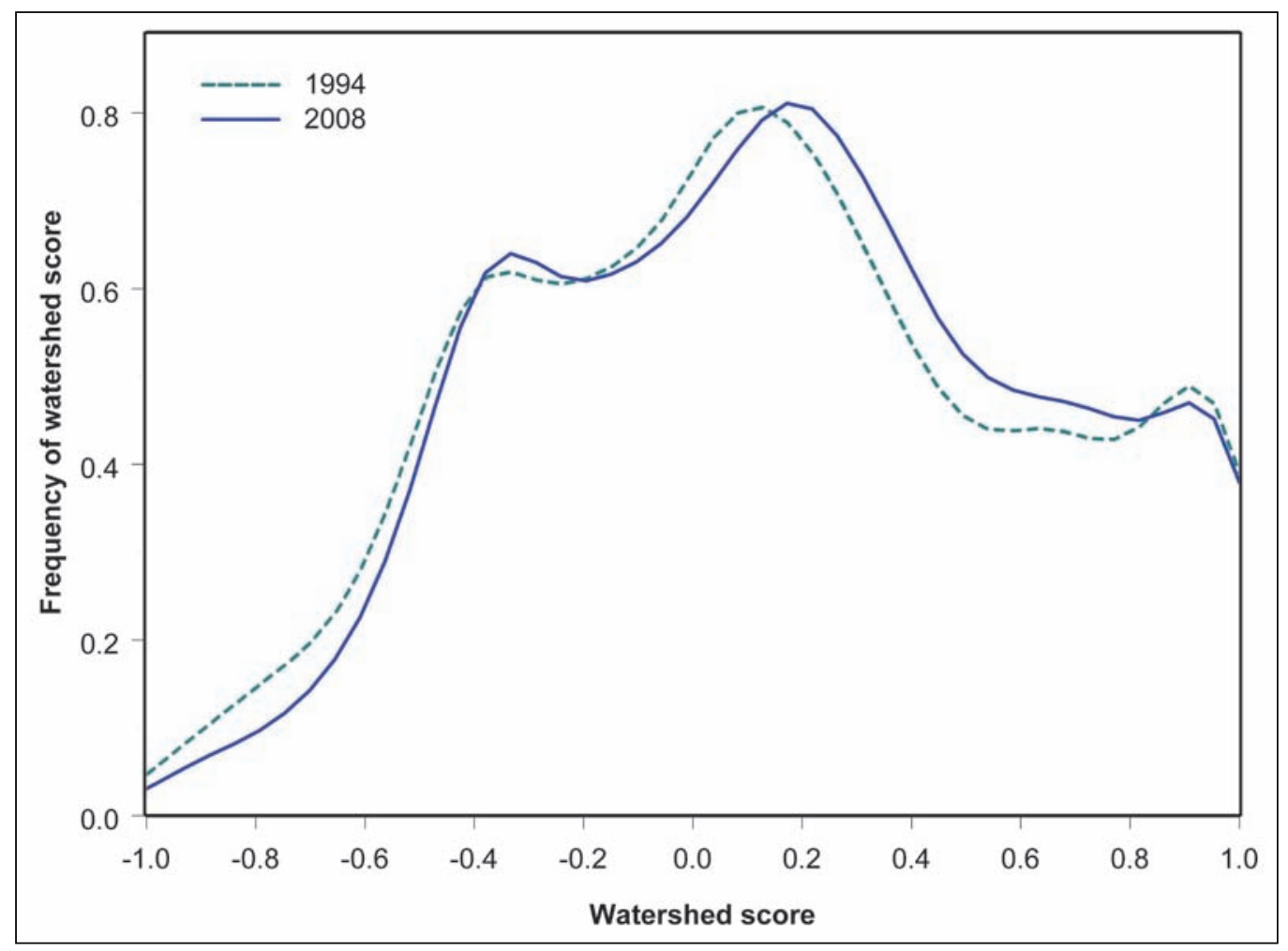

Figure 26-Frequency of watershed condition scores in 1994 and 2008. These curves show the data in a continuous manner rather than by data bins (i.e., histograms). 


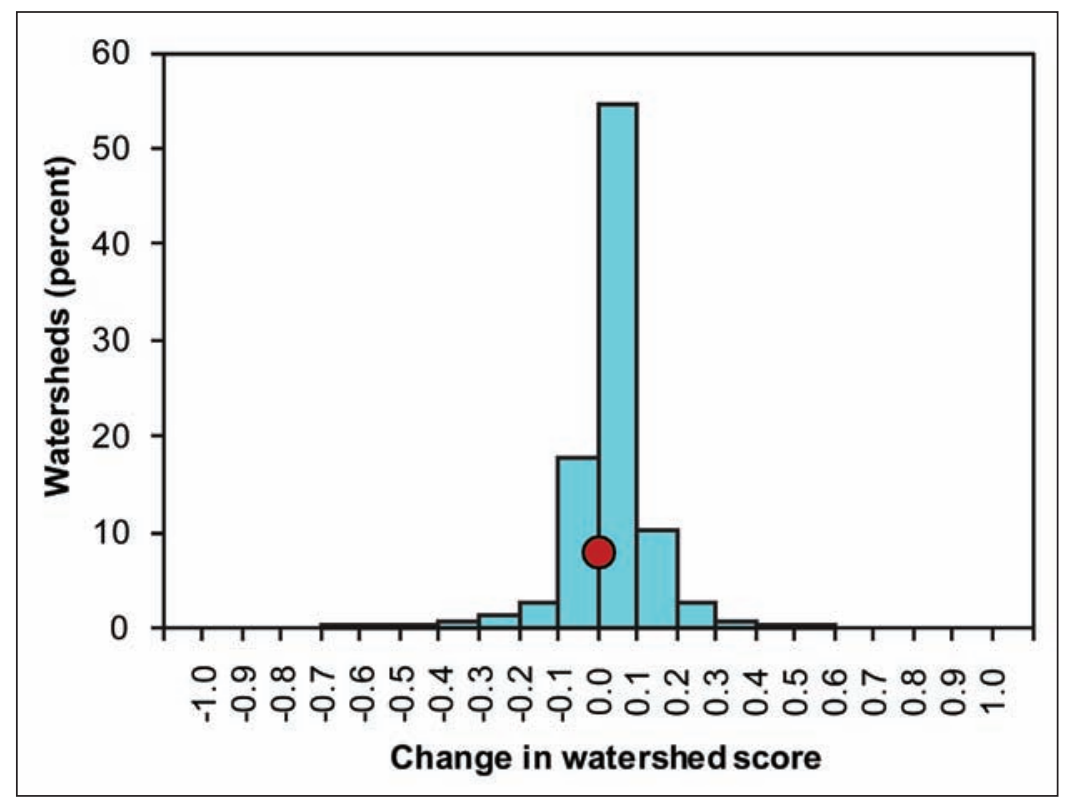

Figure 27-Distribution of changes in watershed condition scores between 1994 and 2008. Circle shows percentage of watersheds with no change in score.

Table 7-Watershed score trend changes (1994 to 2008) owing to changes in roads, vegetation, and landslide risk attributes

\begin{tabular}{lccccc}
\hline $\begin{array}{l}\text { Score change } \\
\text { categories }\end{array}$ & Roads & Vegetation & $\begin{array}{c}\text { Landslide } \\
\text { risk }\end{array}$ & \multicolumn{2}{c}{$\begin{array}{c}\text { All watersheds } \\
\text { (n= 1,379) }\end{array}$} \\
\hline & & Corcent & & & Percentage \\
\hline-2 to -0.3 & 0 & 94 & 6 & 18 & Percent \\
-0.3 to -0.1 & 0 & 84 & 16 & 52 & 1 \\
-0.1 to $<0$ & 2 & 83 & 15 & 246 & 18 \\
0 & & & & 108 & 8 \\
$>0$ to 0.1 & 24 & 66 & 11 & 753 & 55 \\
0.1 to 0.3 & 42 & 30 & 28 & 175 & 13 \\
0.3 to 2 & 38 & 8 & 54 & 27 & 2 \\
\hline
\end{tabular}


risk (28 percent). Reduced landslide risk was the dominant driver of improvement about the +0.3 level ( 54 percent), apparently because of road decommissioning in landslideprone areas, as road improvements contributed considerably more (38 percent) than vegetation ( 8 percent) at this level. Only four watersheds increased by 0.5 or more, and three of these four were driven primarily by road decommissioning. Fish Creek in the western Cascades had over $100 \mathrm{mi}$ of road decommissioned and realized the largest score increase overall (+1.5). In contrast, the increase in the Olympic province's Deep Creek $(+0.5)$ was entirely due to vegetation and its associated effects on landslide risk.

For simplification and display, we have again grouped scores into categories. Figure 28 shows the change in the distribution of watersheds by category. Most notable are the decline in watersheds in the very low category and an increase in the high category.

A display of these changes by status categories in 1994 and 2008 (fig. 29), shows that most changes occurred in the middle score categories (low, moderate, high) and that these changes were predominantly positive. Some watersheds from all three of these classes improved to the very high category, demonstrating that large changes appear possible in a relatively short period (15 years). The categories at the extremes (very low and very high) showed the least amount of change. This lower mobility was likely due to many of their indicator values being either considerably above or below the evaluation thresholds, so even moderate changes in the indicator values would not change the indicator scores (e.g., a change in road density from 6 to $4 \mathrm{mi} / \mathrm{mi}^{2}$ would not change the evaluated score from -1).

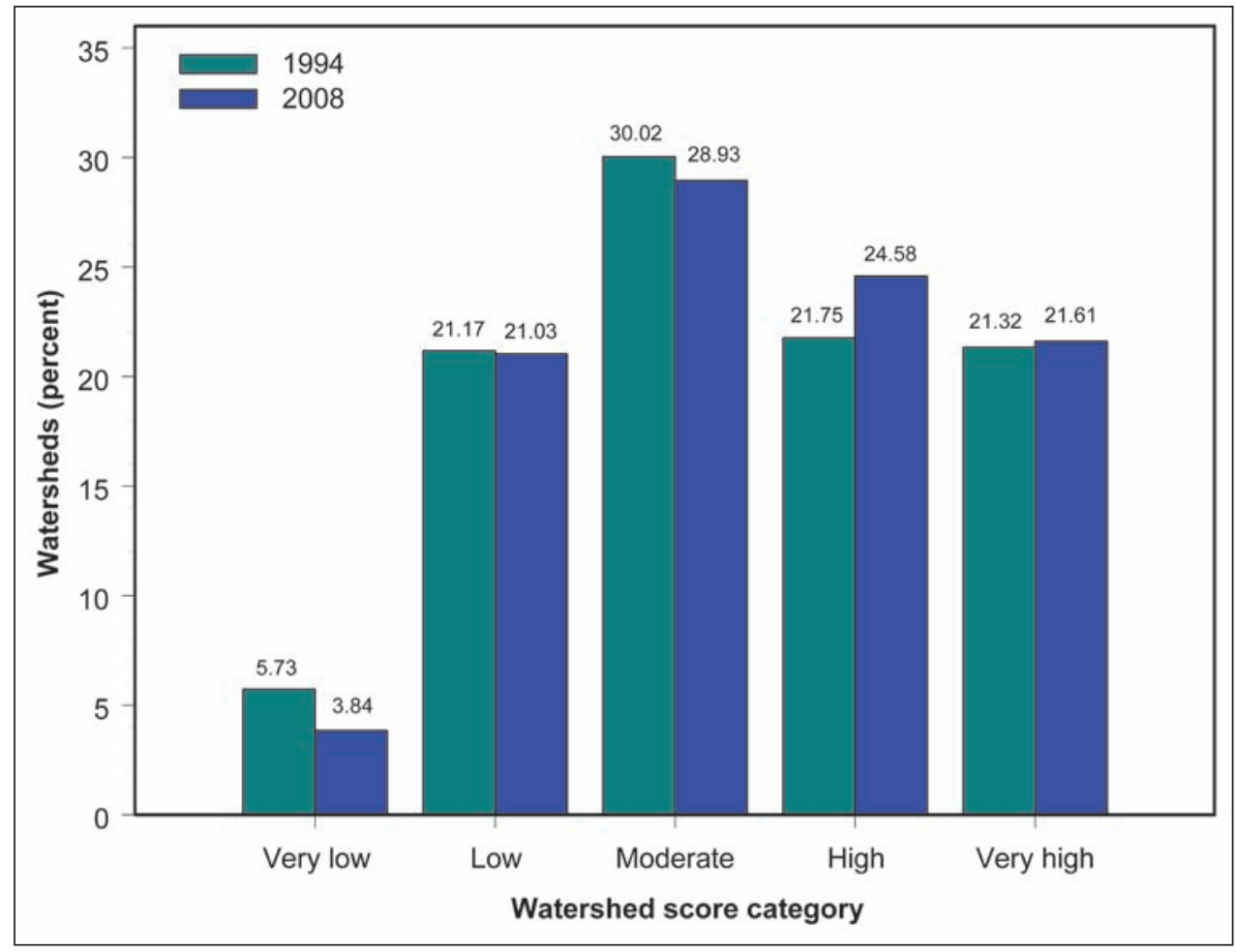

Figure 28-Watershed condition scores by status category in 2008 . 


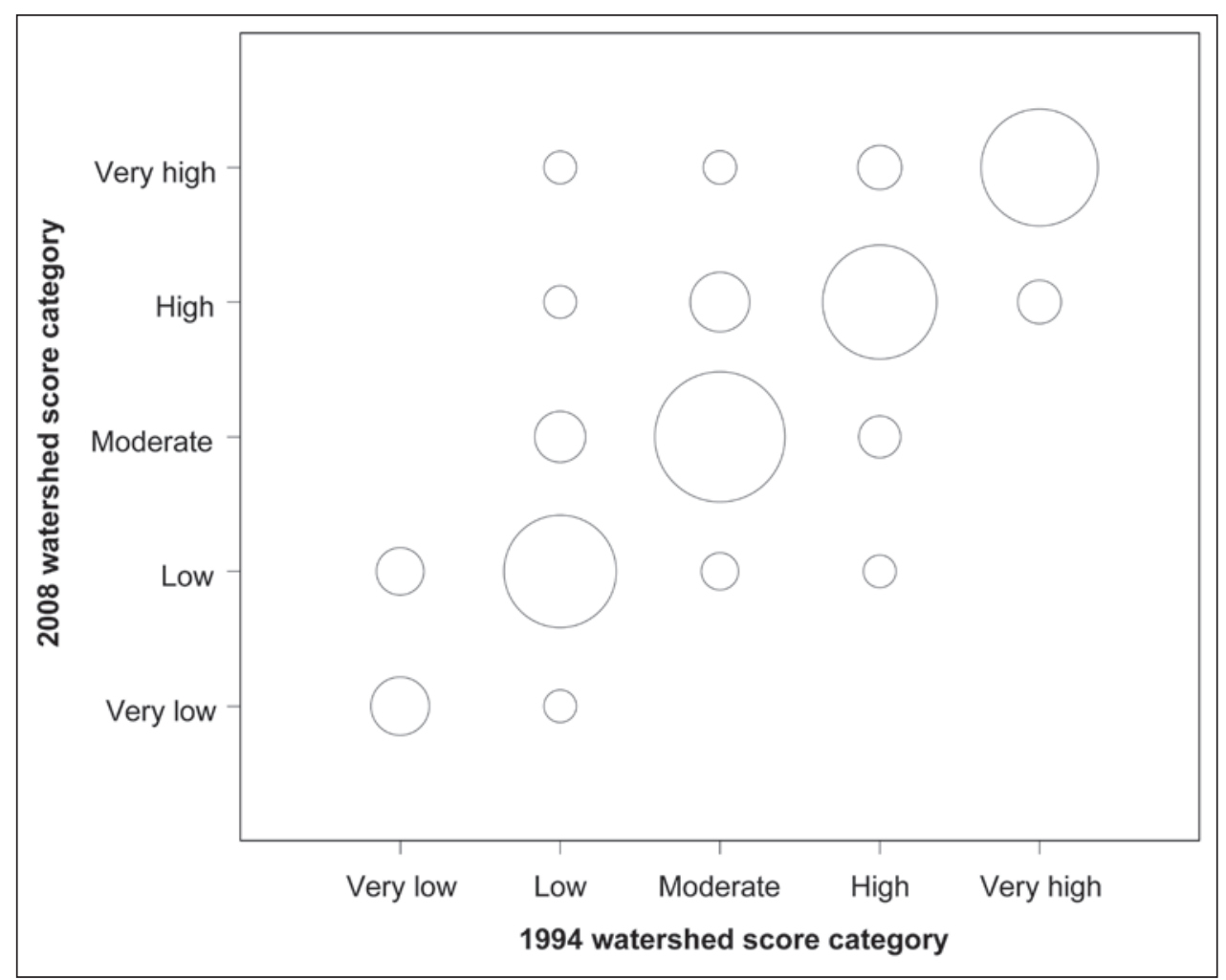

Figure 29-Number of watersheds with category scores from 1994 and 2008. The bubble sizes range from few watersheds (smallest bubbles) to many watersheds (largest bubbles).

The watershed condition trend map (fig. 30) uses seven categories instead of five, and the central categories also have a smaller interval (0.2) than the extremes (0.5) for better discrimination because changes in scores tended to be more tightly grouped than the status scores. The largest negative changes can be seen in southwest Oregon and are due to loss of vegetation from the Biscuit Fire. Other declines can be seen scattered mostly along the east side of the Cascade crest, again principally because of large fires.

\section{Watershed Trend by Land Use Category}

All land use categories had more watersheds with score increases than decreases between 1994 and 2008 (table 6). The proportion of increases to decreases was much higher (almost double) in LSR and matrix lands than in congressional reserves. The mean score of the reserved class actually declined slightly (-0.01), whereas the LSR (+0.05) and matrix $(+0.04)$ both showed slight increases on average. Key and nonkey watersheds both had approximately three times more watersheds with score increases than with decreases. There was also little difference in the average trend between the key (mean +0.04$)$ versus nonkey $(+0.03)$ watersheds.

The magnitude of changes did differ somewhat by land use allocation (fig. 31). Although the majority of changes were small $(< \pm 0.1)$ for all categories, the LSR experienced more of the larger positive changes $(>+0.1)$ than the other two classes. Figure 32 shows where in the overall score distributions the largest changes occurred. Matrix watersheds had the most positive score changes in the lower $(-0.9$ to -0.6$)$ and middle-upper ( +0.2 to +0.6$)$ ranges. Changes in the LSR category were similarly distributed at the lower end and more broadly at the middle-upper range $(-0.2$ to +0.7$)$. The reserved category showed a shift from the upper end $(+0.8$ to +1.0$)$ to slightly lower scores $(+0.5$ to +0.8$)$.

Differences between key and nonkey watersheds were less pronounced. There was little difference in the average trend between the key (mean +0.04$)$ versus nonkey $(+0.03)$ watersheds. The change magnitude distributions were quite 


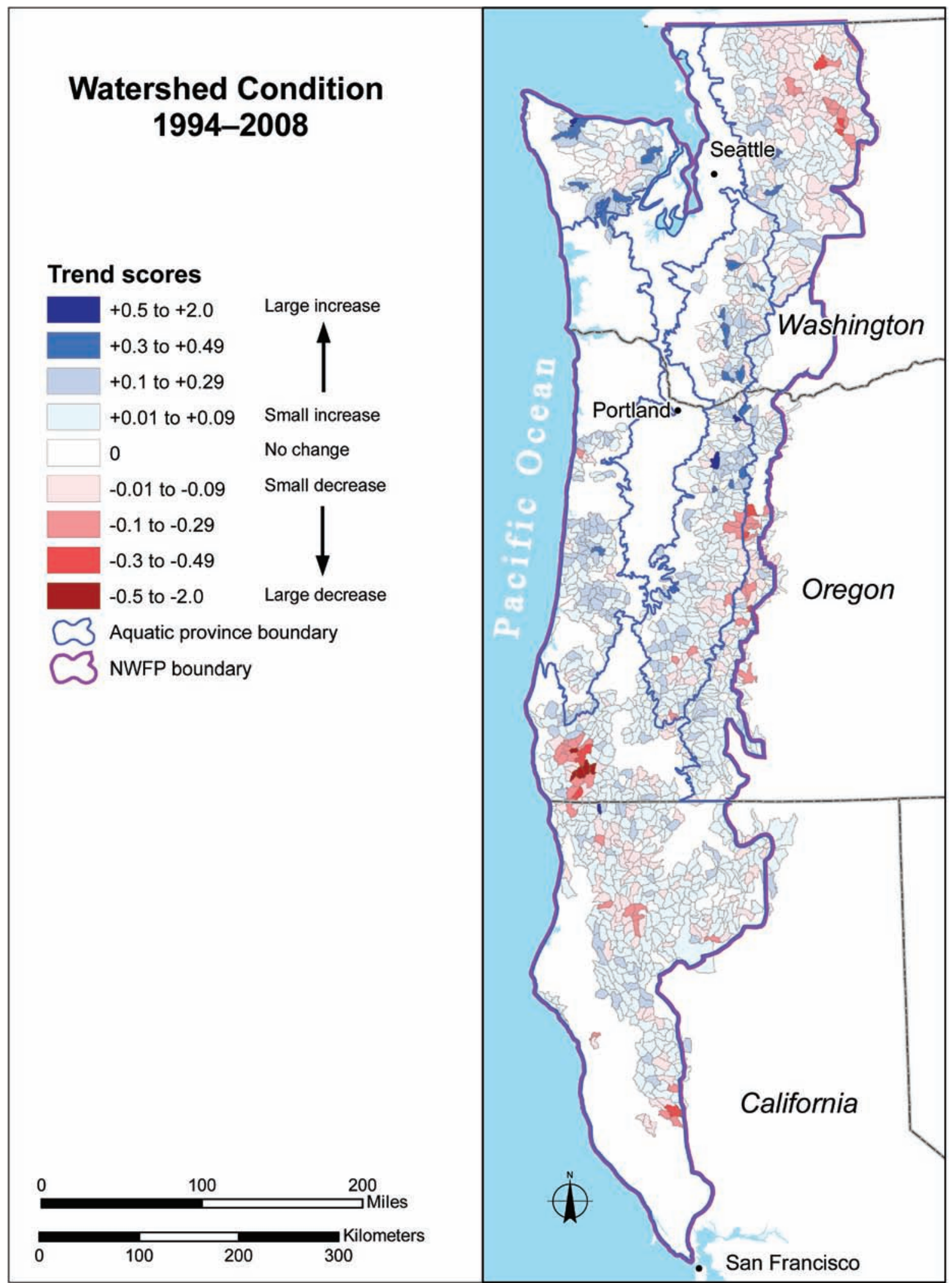

Figure 30-Change in watershed condition score, 1994 to 2008. 


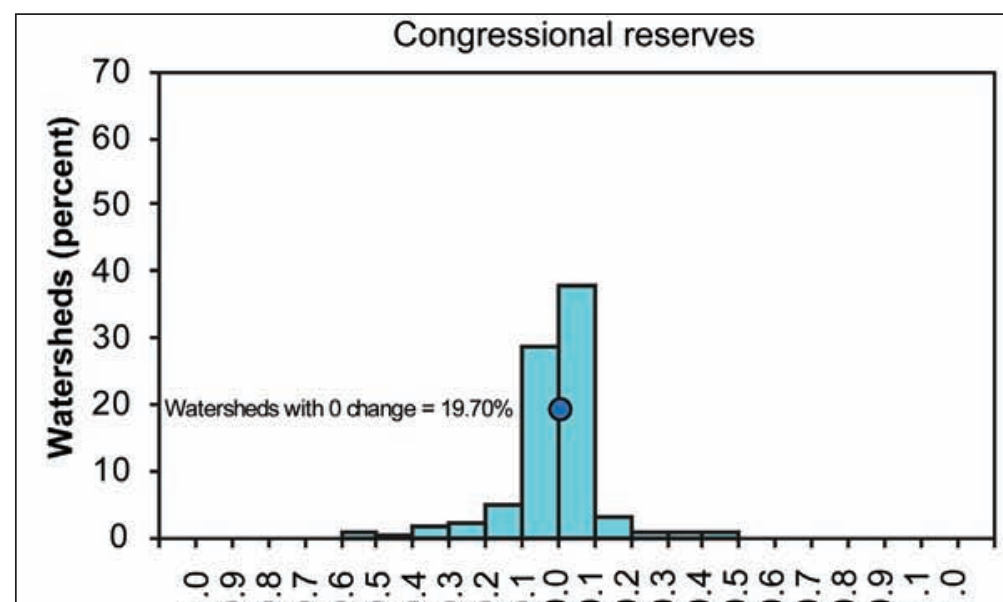

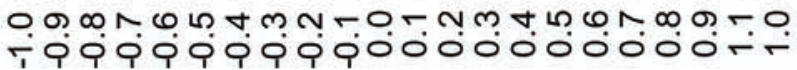

Change in watershed score

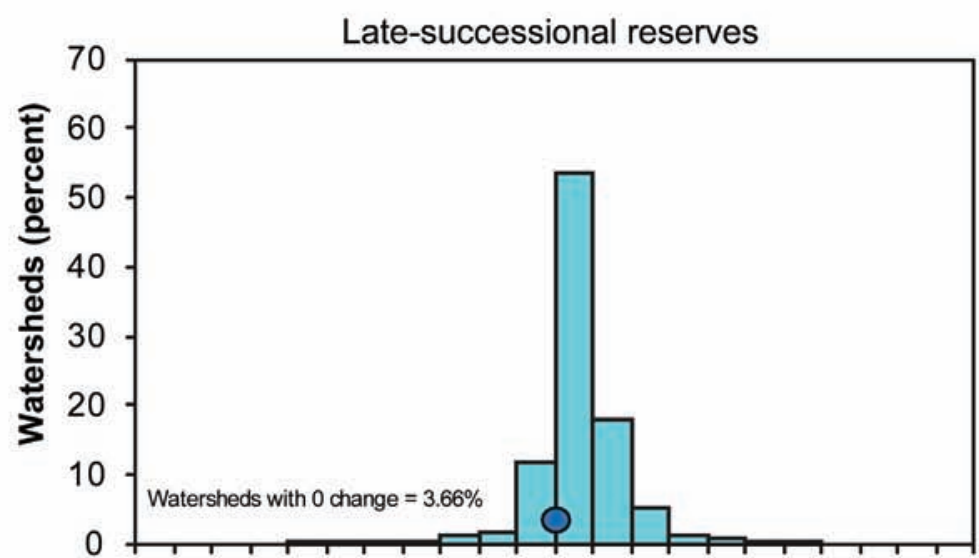

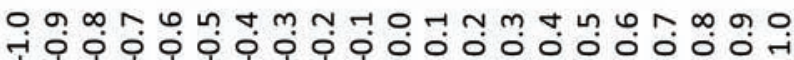

Change in watershed score

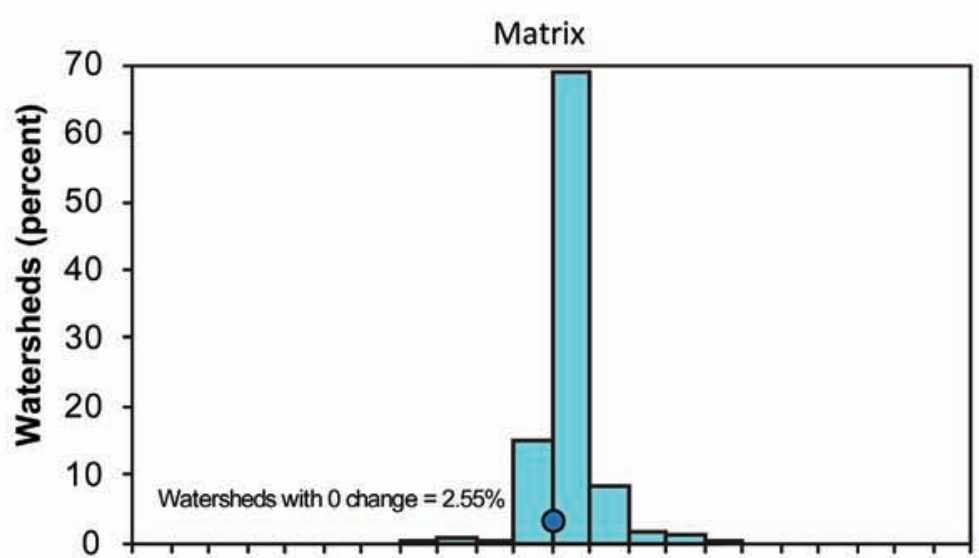

0 $\infty$ ต

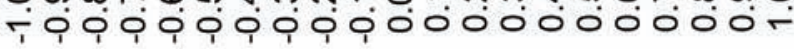

Figure 31-Distribution of changes in watershed condition scores from 1994 to 2008 by land use allocation. Circle shows percentage of watersheds with no change in score. 


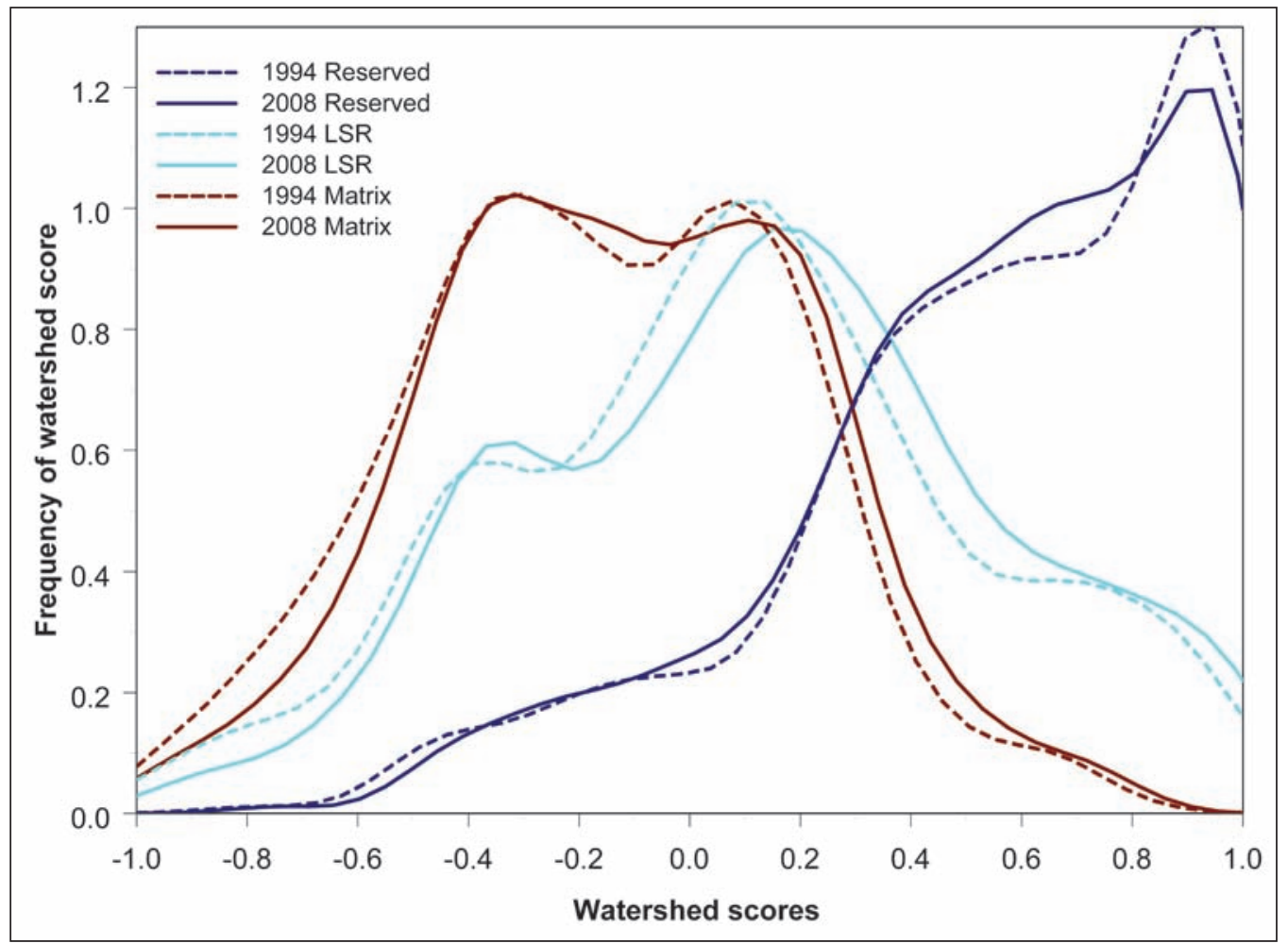

Figure 32-Frequency of 1994 and 2008 watershed scores by land use allocation. These curves show the data in a continuous manner rather than by data bins (i.e., histograms) (reserved = congressional reserves, LSR = late-successional reserves).

similar in form, and again the majority of changes were small $(< \pm 0.1)$ for both categories (fig. 33). For the continuous score distributions (fig. 32), both categories had positive score changes in the lower (-0.9 to -0.6) and middle-upper $(+0.1$ to +0.6$)$ ranges (fig. 34). Key watersheds experienced more positive changes in the middle range $(-0.2$ to +0.2$)$.

On average, more roads were decommissioned in key watersheds (4.1 $\mathrm{mi})$ than in nonkey $(1.6 \mathrm{mi})$; however, in terms of watershed road density (miles of road per square mile of watershed) the difference in changes are smaller: an average of $-0.14 \mathrm{mi} / \mathrm{mi}^{2}$ in key and $-0.07 \mathrm{mi} / \mathrm{mi}^{2}$ in nonkey watersheds. Given that the evaluation criteria thresholds for road density ranged from 0.5 ( +1 score ) to $4 \mathrm{mi} / \mathrm{mi}^{2}(-1$ score), a decline in density on the order of $-0.14 \mathrm{mi} / \mathrm{mi}^{2}$ would not have a large effect on the overall score. Two examples show the possible range of effects. Lower Fish Creek in the western Cascades had the largest mileage of roads decommissioned (118 $\mathrm{mi}$ ) and the highest decline in road density $\left(-2.5 \mathrm{mi} / \mathrm{mi}^{2}\right)$, which dropped road density from $3.3 \mathrm{mi} / \mathrm{mi}^{2}$ in 1994 to $0.8 \mathrm{mi} / \mathrm{mi}^{2}$ in 2008 with a high corresponding score change from -0.9 to +0.8 . In contrast, the lower South Fork Skokomish River in the Olympic province had the second highest decline in road density (-1.6 $\mathrm{mi} / \mathrm{mi}^{2}$ ), which dropped road density from $4.6 \mathrm{mi} / \mathrm{mi}^{2}$ in 1994 to $3.0 \mathrm{mi} / \mathrm{mi}^{2}$ in 2008 but produced no score change because it was still at or above the evaluation criteria of 3 $\mathrm{mi} / \mathrm{mi}^{2}$ that defines poor condition.

\section{Model Validation}

The watershed evaluation models used to address questions 1 through 3 are complex in that they integrate a number of different indicators and do so somewhat differently for each province. For an alternative view and check on our results, we looked at three single indicators measured consistently 


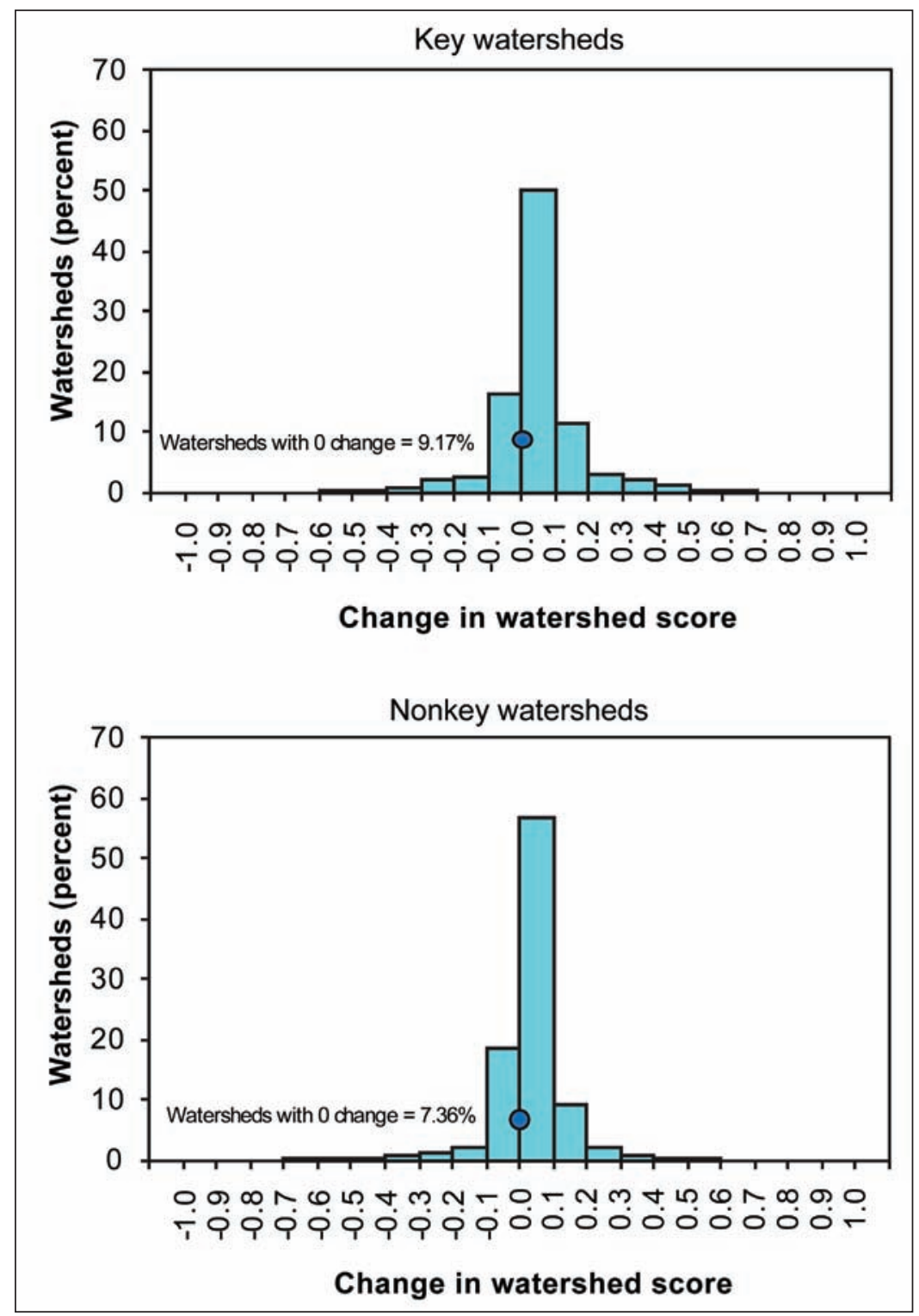

Figure 33-Distribution of changes in watershed condition scores from 1994 to 2008 for key and nonkey watersheds. Circle shows percentage of watersheds with no change in score. 


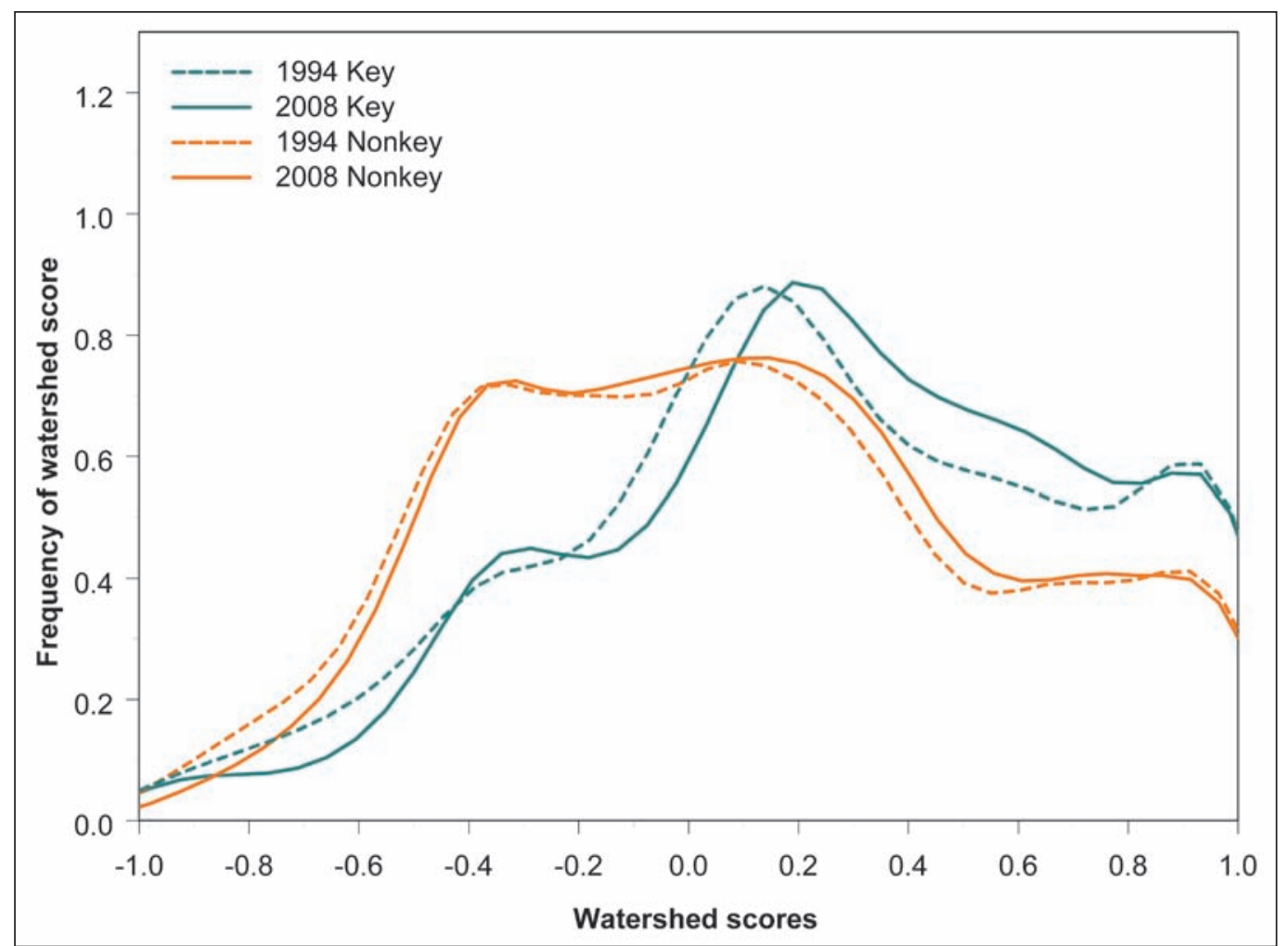

Figure 34-Frequency of 1994 and 2008 watershed condition scores for key and nonkey watersheds. These curves show the data in a continuous manner rather than by data bins (i.e., histograms).

across the NWFP area: road density, the percentage of area in large trees, and the amount of disturbance from harvest and fires.

\section{Road Density}

The density of roads in watersheds ranges from 0 to $7.1 \mathrm{mi} /$ $\mathrm{mi}^{2}$ in 1994 and from 0 to $6.8 \mathrm{mi} / \mathrm{mi}^{2}$ in 2008 . Our data set registered 3,406 mi of roads decommissioned between 1994 and 2008. However, the effect of this removal on the overall distribution of road densities was small, from a median of $2.42 \mathrm{mi} / \mathrm{mi}^{2}$ (mean of 2.35 ) in 1994 to $2.31 \mathrm{mi} / \mathrm{mi}^{2}$ (mean of 2.25) in 2008 (fig. 35). Looking at the distribution of changes reveals that only 5 percent of watersheds showed any increase in road density, 45 percent had no change, and 50 percent decreased (fig. 36). Increases were small, a maximum of $0.2 \mathrm{mi} / \mathrm{mi}^{2}$, and decreases ranged to the -2.5 $\mathrm{mi} / \mathrm{mi}^{2}$ in Fish Creek in the western Cascades.

For context, the watershed model evaluation criteria for most of the provinces rate less than 0.5 to $1 \mathrm{mi} / \mathrm{mi}^{2}$ of watershed as good condition and from 2.4 to $4 \mathrm{mi} / \mathrm{mi}^{2}$ as poor condition. Using these rough guides and looking at figure 35 , one can see that approximately 25 to 50 percent of watersheds (the top half and whisker in the box charts) would be rated as poor condition using this single indicator. This result is considerably lower than the distribution of our model evaluation scores under question 1 , where only 4 percent of the watersheds fell into the poor category. However, these results are roughly consistent with what happens inside the evaluation model, with roads often scoring poorly but with vegetation scoring well, bringing up the overall scores. The result is also consistent with discussions in our evaluation workshops, where experts have identified road density as the major problem in many watersheds.

\section{By land use category -}

Road density distributions by land use category (fig. 37) are consistent with the overall watershed model results (fig. 21). The lowest road densities were found in congressionally 


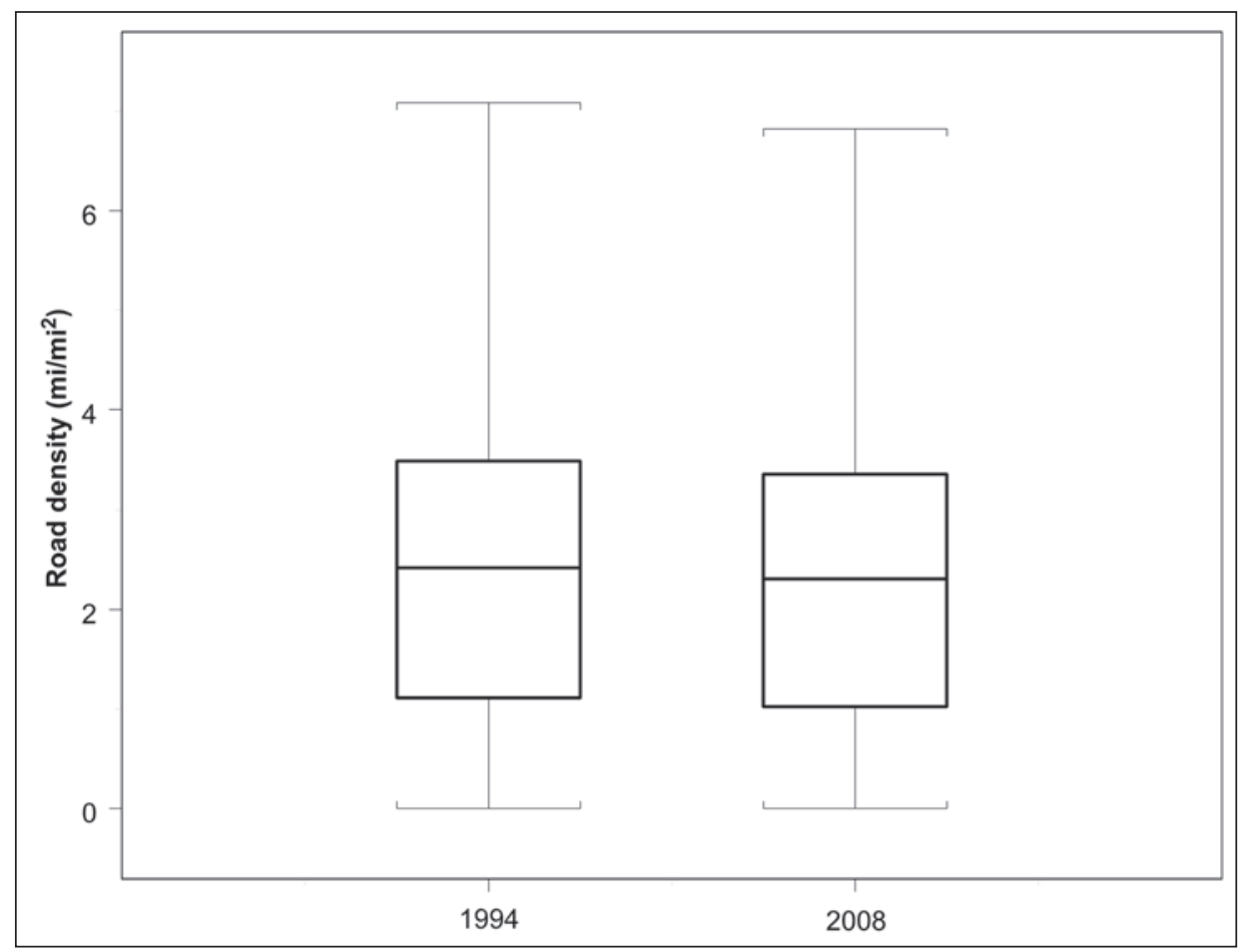

Figure 35-Watershed road density in 1994 and 2008.

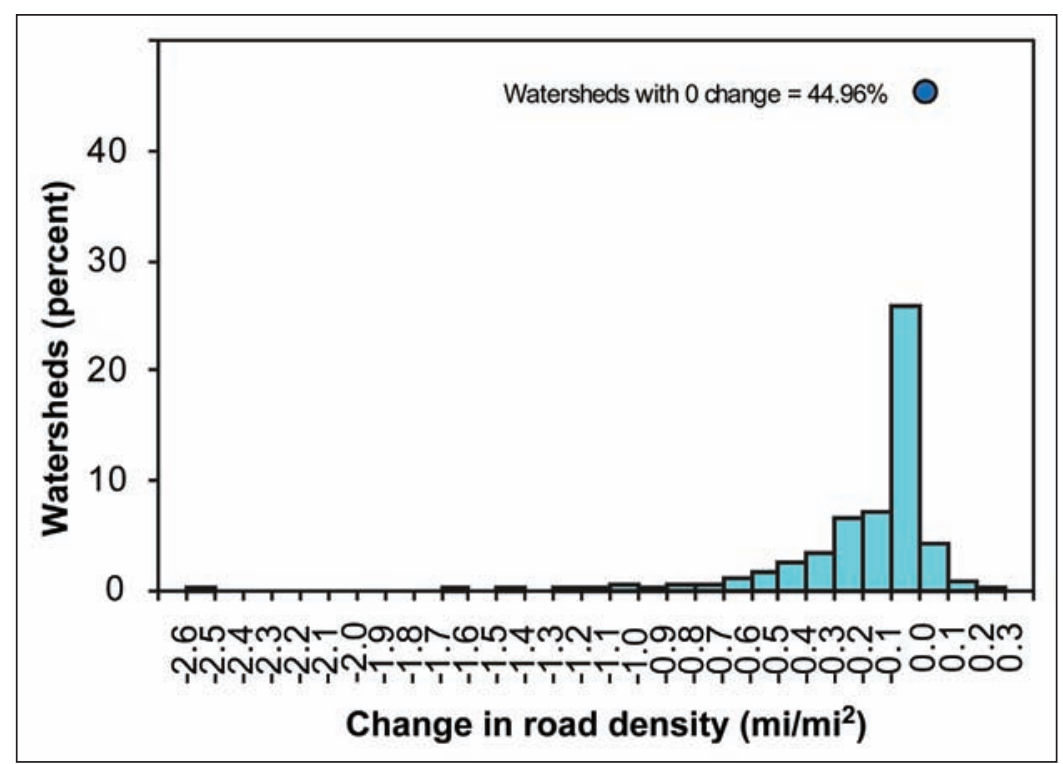

Figure 36-Changes in watershed road density from 1994 to 2008. Circle shows percentage of watersheds with no change in score. 


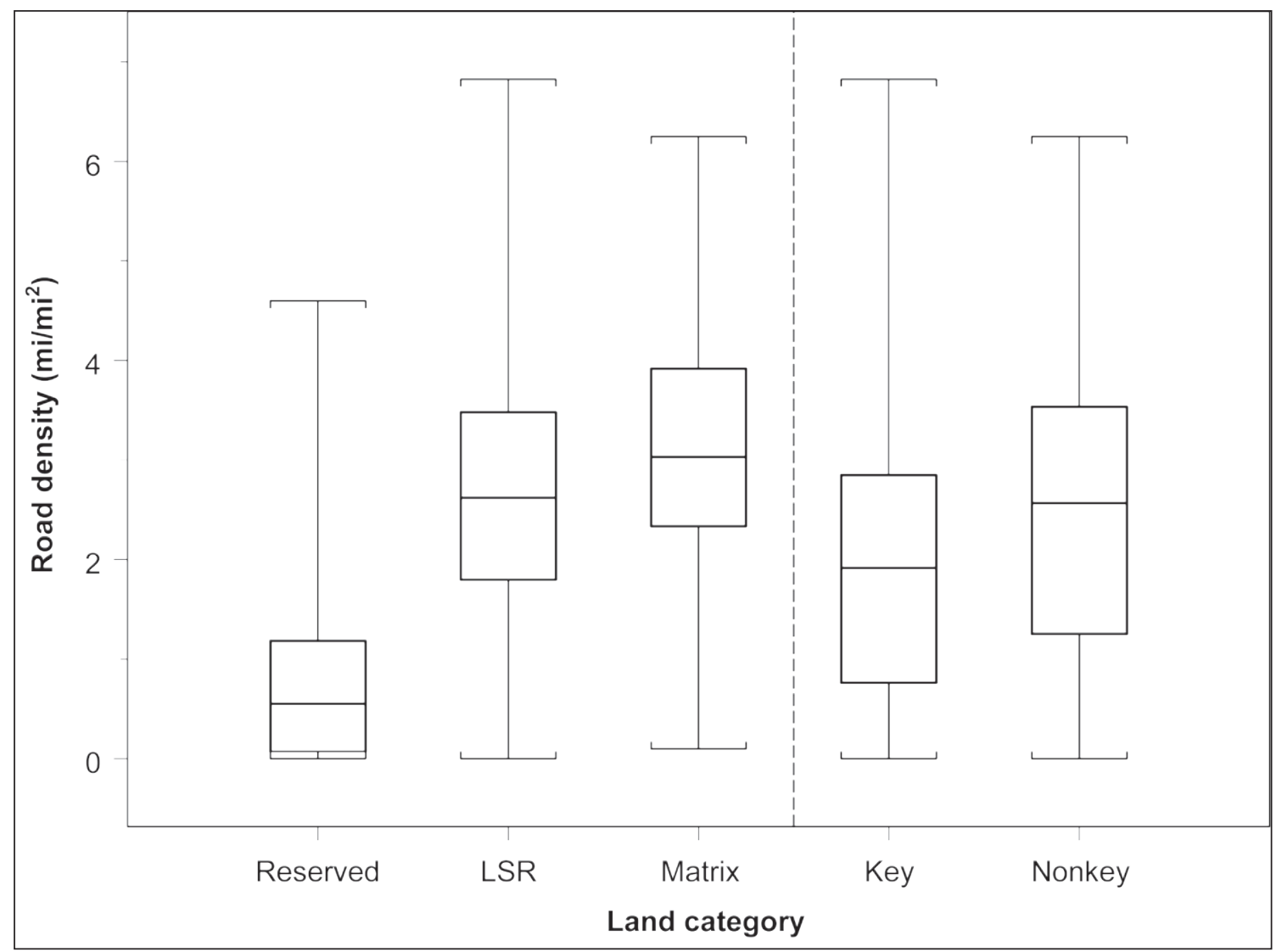

Figure 37-Road density by land category, 2008 (reserved = congressional reserves, LSR = late-successional reserves).

reserved lands (mean $0.76 \mathrm{mi} / \mathrm{mi}^{2}$ ), higher densities in the LSR category (mean $2.6 \mathrm{mi} / \mathrm{mi}^{2}$ ), and the highest densities on matrix lands (mean $3.1 \mathrm{mi} / \mathrm{mi}^{2}$ ). Although road building is generally prohibited on congressionally reserved lands, some contain legacy roads, and our classification by entire watershed means that nonreserved lands will often be included in watersheds classified as reserved. Key watersheds also tend to have lower densities (mean $1.9 \mathrm{mi} / \mathrm{mi}^{2}$ ) than nonkey watersheds (mean $2.4 \mathrm{mi} / \mathrm{mi}^{2}$ ) (fig. 37).

In terms of trend, the LSR category had a larger average reduction in density (mean $-0.15 \mathrm{mi} / \mathrm{mi}^{2}$ ) than the matrix (mean $-0.10 \mathrm{mi} / \mathrm{mi}^{2}$ ) or reserved (mean $-0.03 \mathrm{mi} /$ $\mathrm{mi}^{2}$ ) categories. Road density reduction in key watersheds (mean $-0.15 \mathrm{mi} / \mathrm{mi}^{2}$ ) averaged about double that in nonkey watersheds (mean $-0.07 \mathrm{mi} / \mathrm{mi}^{2}$ ). Small reductions (between
0 and $0.1 \mathrm{mi} / \mathrm{mi}^{2}$ ) were the most frequent, occurring in 20 to 30 percent of watersheds across all categories (fig. 38).

\section{Late-Successional Old Growth}

A number of the provincial models incorporate indicators of the amount of the watershed and riparian area in different seral stages, as approximated by average tree diameter and canopy cover metrics. For a simple, uniform comparison metric, we used percentage of watershed area in latesuccessional old-growth (LSOG) vegetation, as defined by the NWFP Vegetation Monitoring Program (average tree diameter $\geq 20$ in and canopy cover $\geq 10$ percent).

The percentage of watershed area meeting this large tree definition ranges from 0 to 89 percent over the 1,379 watersheds, and this range remained constant from 1994 to 2008 . The mean percentage decreased from 30.1 to 29.5 


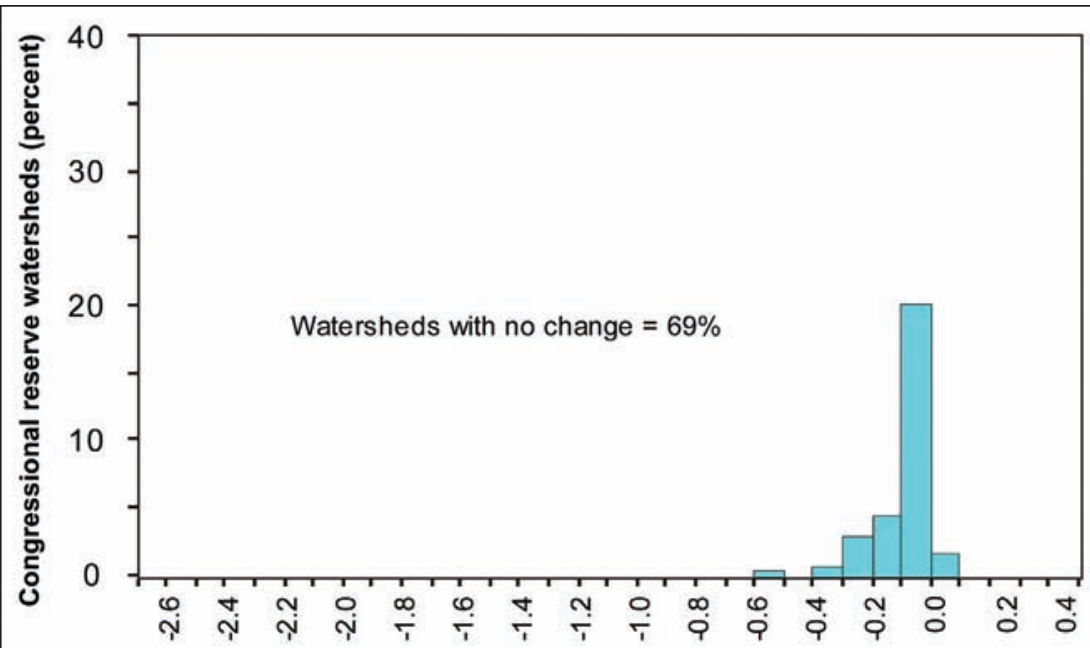

Change in road density 1994 to $2008\left(\mathrm{mi} / \mathrm{mi}^{2}\right)$
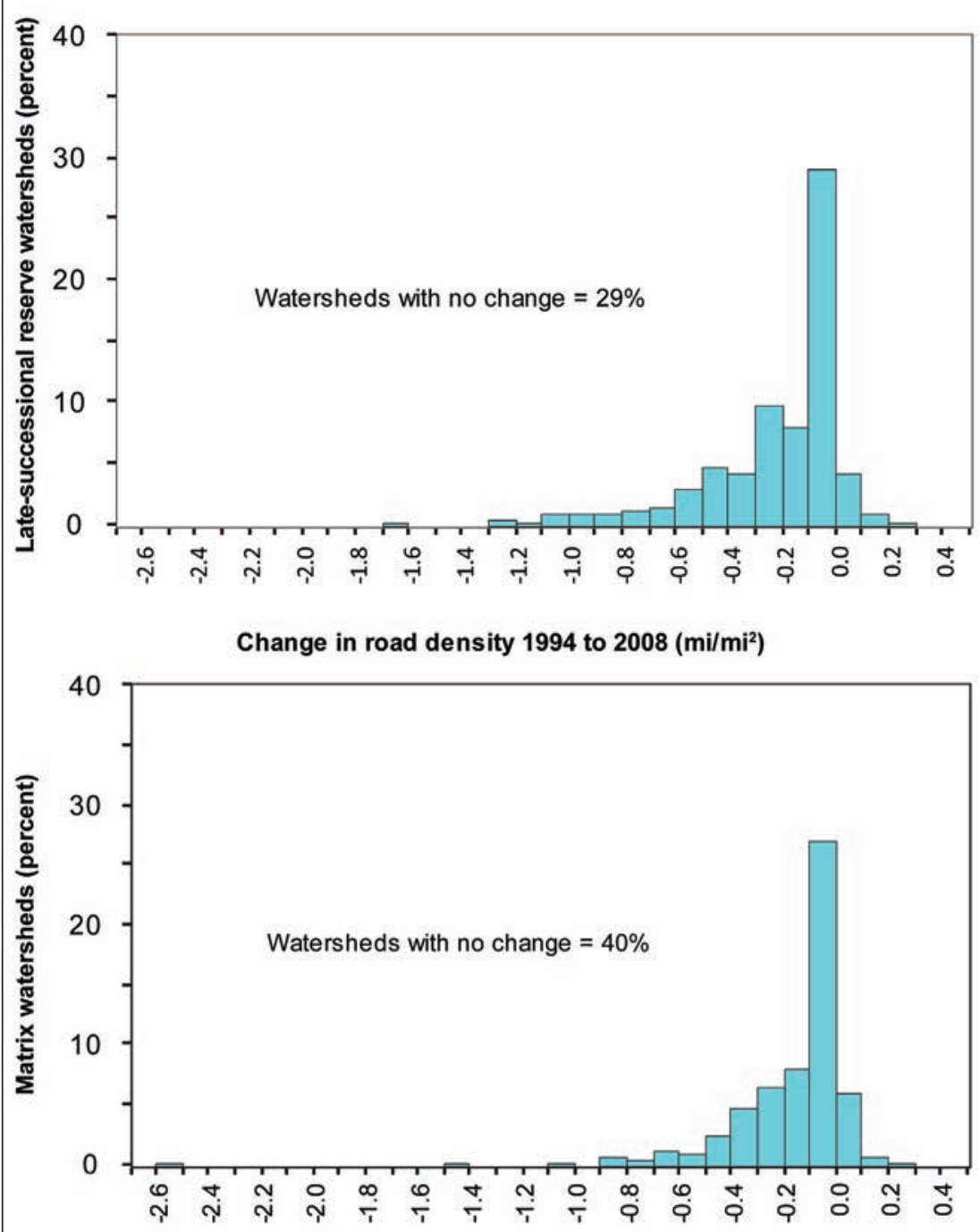

Change in road density 1994 to $2008\left(\mathrm{mi} / \mathrm{mi}^{2}\right)$

Figure 38-Change in road density by land use category, 1994 to 2008 . 


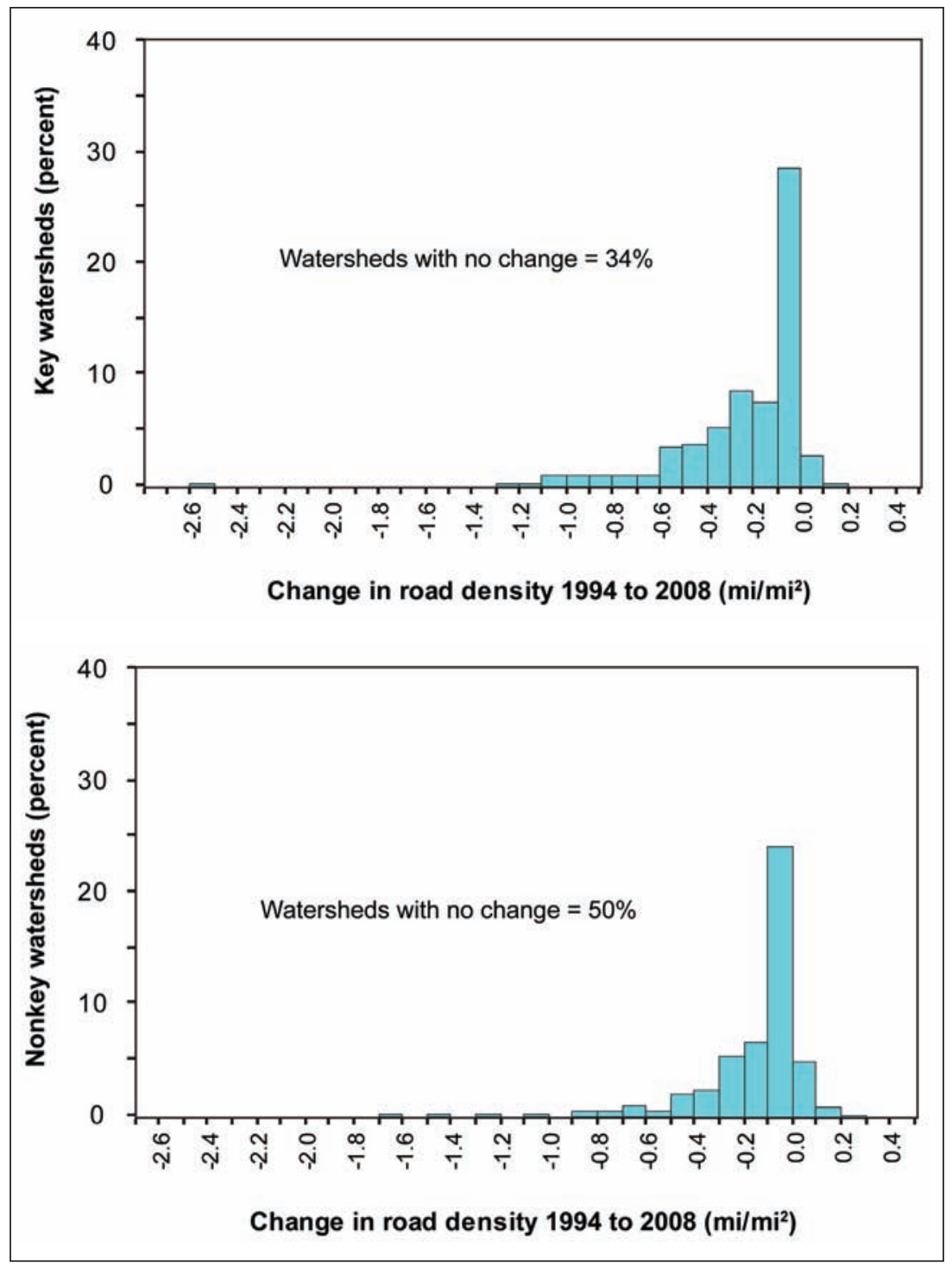

Figure 38-Continued.

in this period, and the median also dropped from 30 to 29.7 (fig. 39). Large tree coverage between 1994 and 2008 decreased in more watersheds (57 percent) than it increased (42 percent) (fig. 40). Changes were generally small, and therefore somewhat uncertain, given the classification error inherent in the satellite data. Only 1.3 percent of watersheds experienced an increase of greater than 5 percent in LSOG, and 4.3 percent of watersheds showed a loss in LSOG of greater than 5 percent.

Comparing these LSOG results to vegetation scores from our watershed models is problematic because the watershed vegetation metrics differ considerably between and even within provinces. The variations in the watershed models are designed to adjust for local growth potential, as influenced by factors such as high elevations and low precipitation regimes. For example, the High Cascades model has both riparian and upslope vegetation evaluations. In the riparian zone, the metric is the percentage of the watershed where average tree diameter is $\geq 14$ in, except in lodgepole pine (Pinus contorta spp.)-dominated areas where $a \geq 8$-in diameter threshold is used. The metric is scored by comparing it to a target range of 30 percent (-1 model score) to 70 percent ( +1 score). The upslope evaluation uses the area where average tree diameter is $\geq 8$ in and canopy cover 


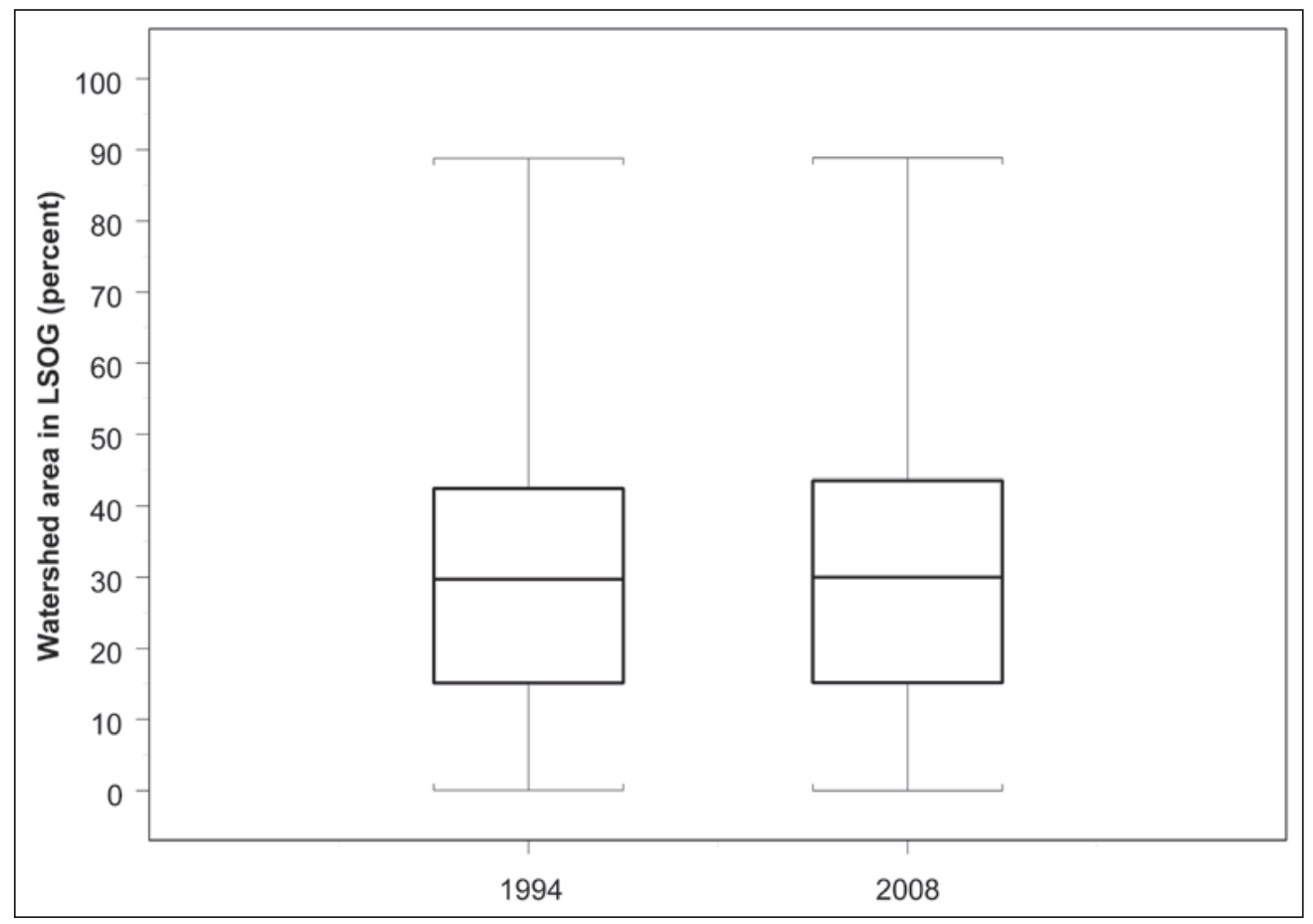

Figure 39-Watershed area in late-successional old-growth vegetation (LSOG) in 1994 and 2008. (LSOG has conifer quadratic mean diameter $\geq 20$ in and canopy cover $\geq 10$ percent.)

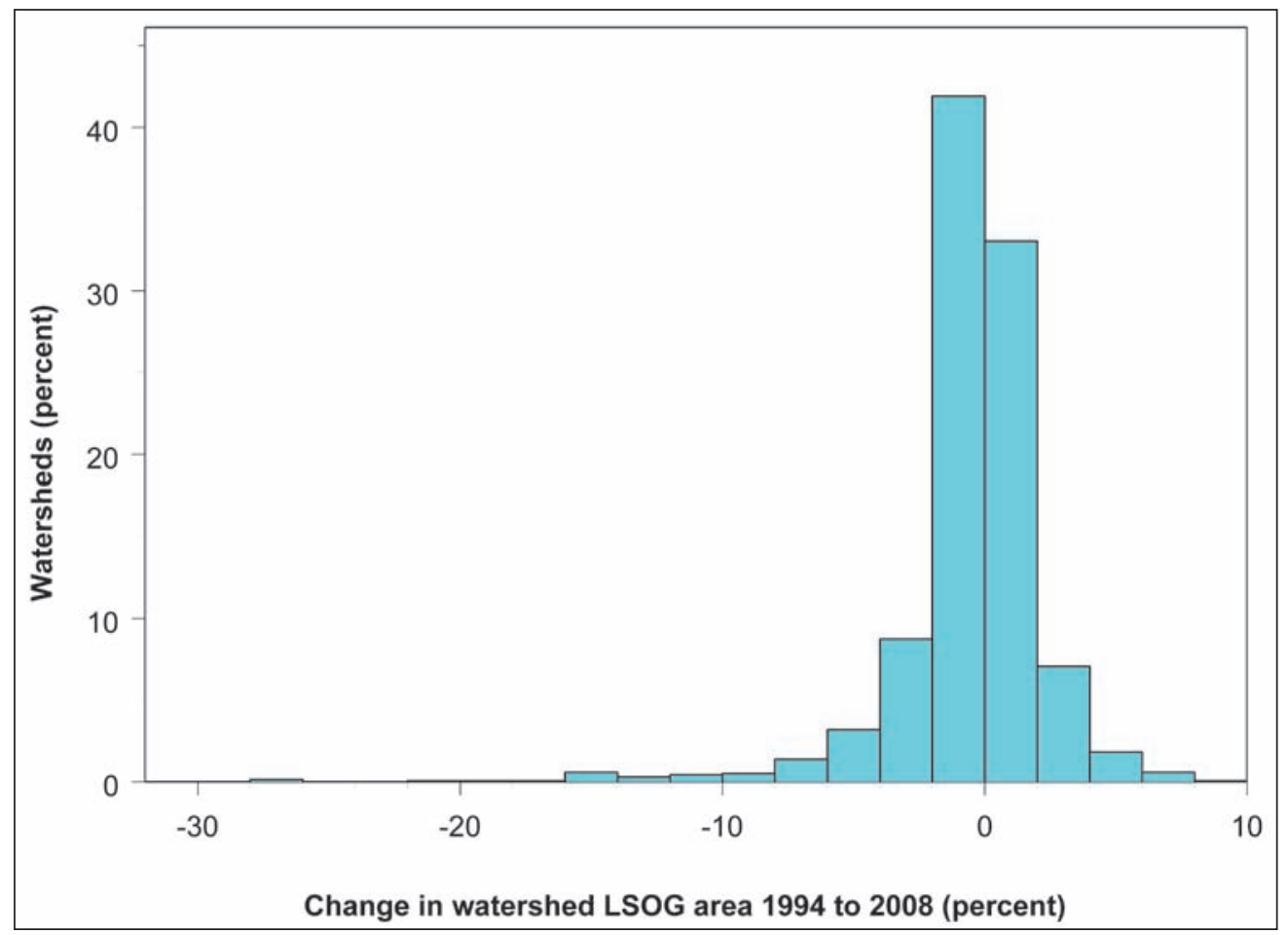

Figure 40-Change in percentage of watershed area in late-successional old-growth vegetation (LSOG) from 1994 to 2008. Four watersheds had no change. (LSOG has conifer quadratic mean diameter $\geq 20$ in and canopy cover $\geq 10$ percent.) 
is $\geq 40$ percent. Target ranges differ, depending on whether the watershed falls within the rain-on-snow zone or not (see app. 4 for model details by province).

Despite these differences, a comparison of trend results between the watershed model vegetation scores and the simpler LSOG metric should help in understanding both measures. The overall distributions of the two metrics moved in opposite directions. In contrast to the declines in LSOG area, as described above, our watershed condition model vegetation scores increased in more watersheds (58 percent) than decreased ( 28 percent). There were also larger changes in the model scores $(>5$ percent or $<-5$ percent, equivalent to \pm 0.1 in model score), and more of these changes were positive than negative (19 versus 12 percent). No overall pattern to these differences between LSOG and watershed model vegetation scores was evident; watersheds with divergent trends were scattered across all provinces. Reasons for the disparities differed by province and by individual watershed attribute. Some of the most divergent scores occurred in the High Cascades in the area of the 2003 B\&B Fire, where modeled vegetation scores trended down sharply but LSOG scores actually increased. These watersheds had very little vegetation ( $<3$ percent) classified as LSOG to begin with, so small increases in LSOG area translated into relatively large gains when measured as a percentage change. The fixed minimum and maximum area targets used to derive the watershed vegetation scores (e.g., 30 to 70 percent for riparian vegetation) are more robust to such differences in areas. High trend differences between LSOG and watershed vegetation scores also appear in burned areas of the Klamath-Siskiyou and Franciscan provinces. In those watersheds, however, both LSOG and model metrics declined, but LSOG fell much more sharply. The divergence was due to the fact that this provincial evaluation model used indicators based on canopy cover and early seral ( $<5$-in diameter) area, both of which rebound much more quickly after severe fires than the LSOG largetree metric.

\section{By land use category-}

The distribution of LSOG by land use category (fig. 41) does not follow the same pattern as the watershed condition model results (fig. 21). In particular, congressionally reserved lands had a lower average of area in large trees (mean 28 percent) than LSR (36 percent) and only slightly higher than matrix lands (26 percent). This lower average is likely due to the fact that a large proportion of congressionally reserved watersheds are in higher elevations where the natural vegetation is less likely to attain an average tree diameter of 20 in (ideally we would stratify size expectations by site vegetation potential, a task we have prioritized for future development - see chapter 5 "Emerging Issues"). The key watershed classification does not appear to have this same elevation correlation, so key watersheds exhibit the expected pattern having more large-tree area than nonkey watersheds.

The average trend change in LSOG for all land categories was slightly negative (1 percent or less), except for a slight increase ( +0.1 percent) on matrix lands. Trend distributions by land category were similar; however, matrix watersheds were more tightly clustered around zero and did not have the long negative tails present in the other categories (fig. 42).

\section{Disturbance}

An alternative to judging vegetation by its current condition, and one that avoids the need for setting "natural" size or cover thresholds, is to look at the amount of vegetation disturbance in a watershed. A new disturbance data set for the full NWFP area based on satellite imagery changes only recently became available (Kennedy et al. 2010), so none of the provincial models currently incorporate disturbance metrics. The attributes we derived for this analysis are the percentage of watershed area disturbed by harvest and fire, summed over 5-year periods and averaged over the 1,379 watersheds (because the latest data available were from 2008 , the last period comprises only 4 years; see "Methods" section for further details).

By individual watershed, the cumulative percentage area disturbed during the periods ranged from 0 to 22 percent for fire and 0 to 18 percent for harvest. Because disturbance area in most watersheds was zero or very low, the average area disturbed over all 1,379 watersheds was 


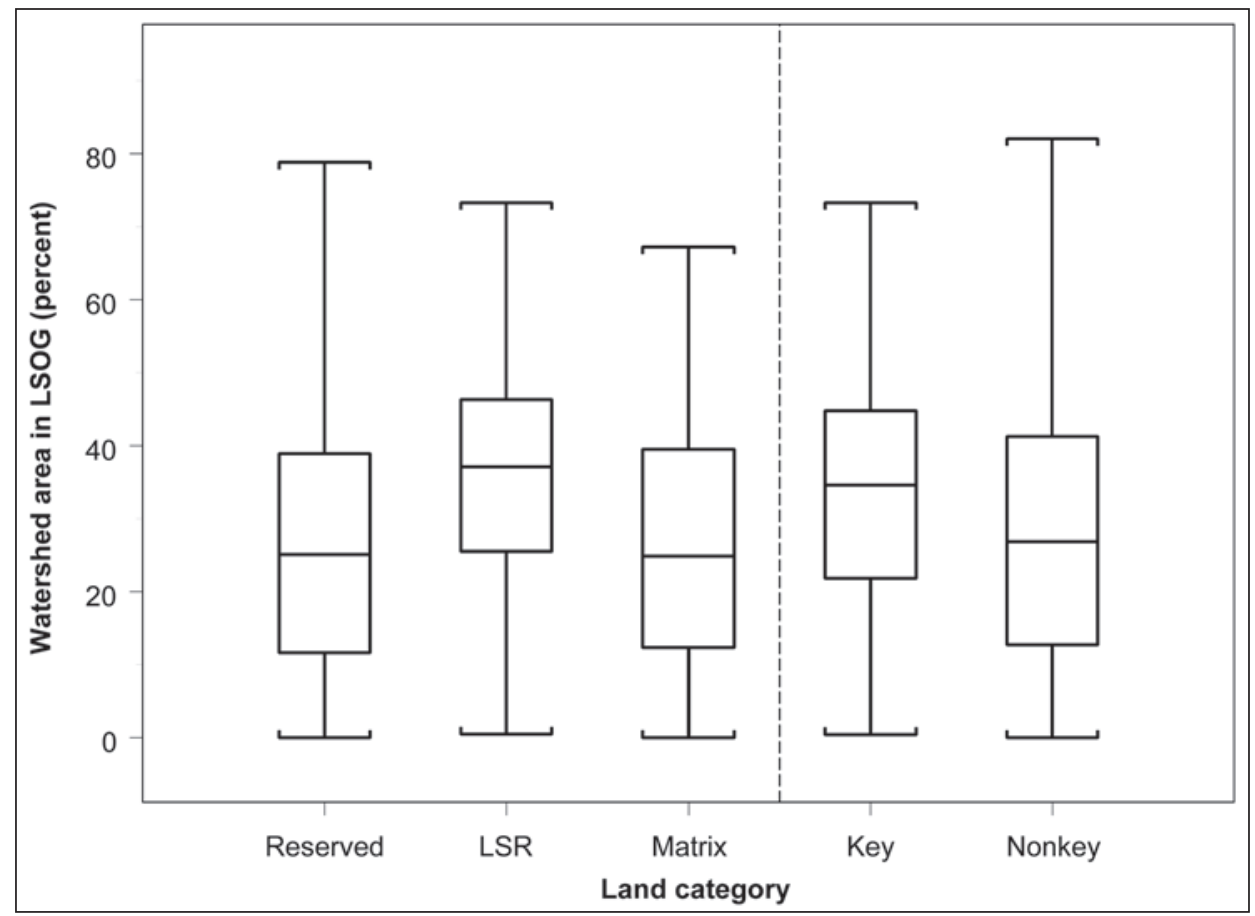

Figure 41-Watershed area in late-successional old-growth (LSOG) by land use allocation, 2008. (LSOG has conifer quadratic mean diameter at breast height $\geq 20$ in and canopy cover $\geq 10$ percent. Reserved $=$ Congressional reserves, LSR $=$ late-successional reserves.)

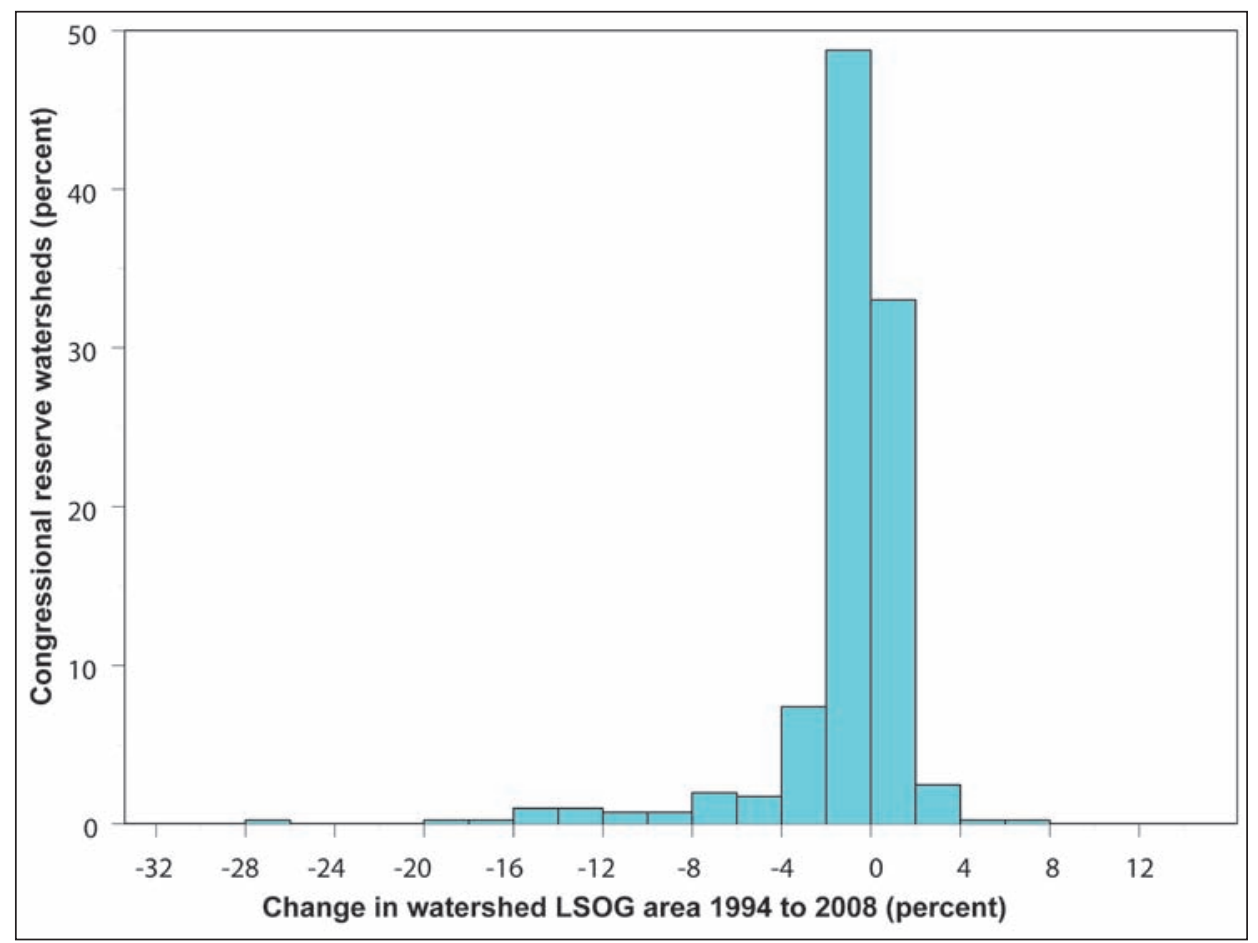

Figure 42-Change in percentage of watershed in late-successional old-growth (LSOG) from 1994 to 2008 by land category. (LSOG has conifer quadratic mean diameter at breast height $\geq 20$ in and canopy cover $\geq 10$ percent.) 

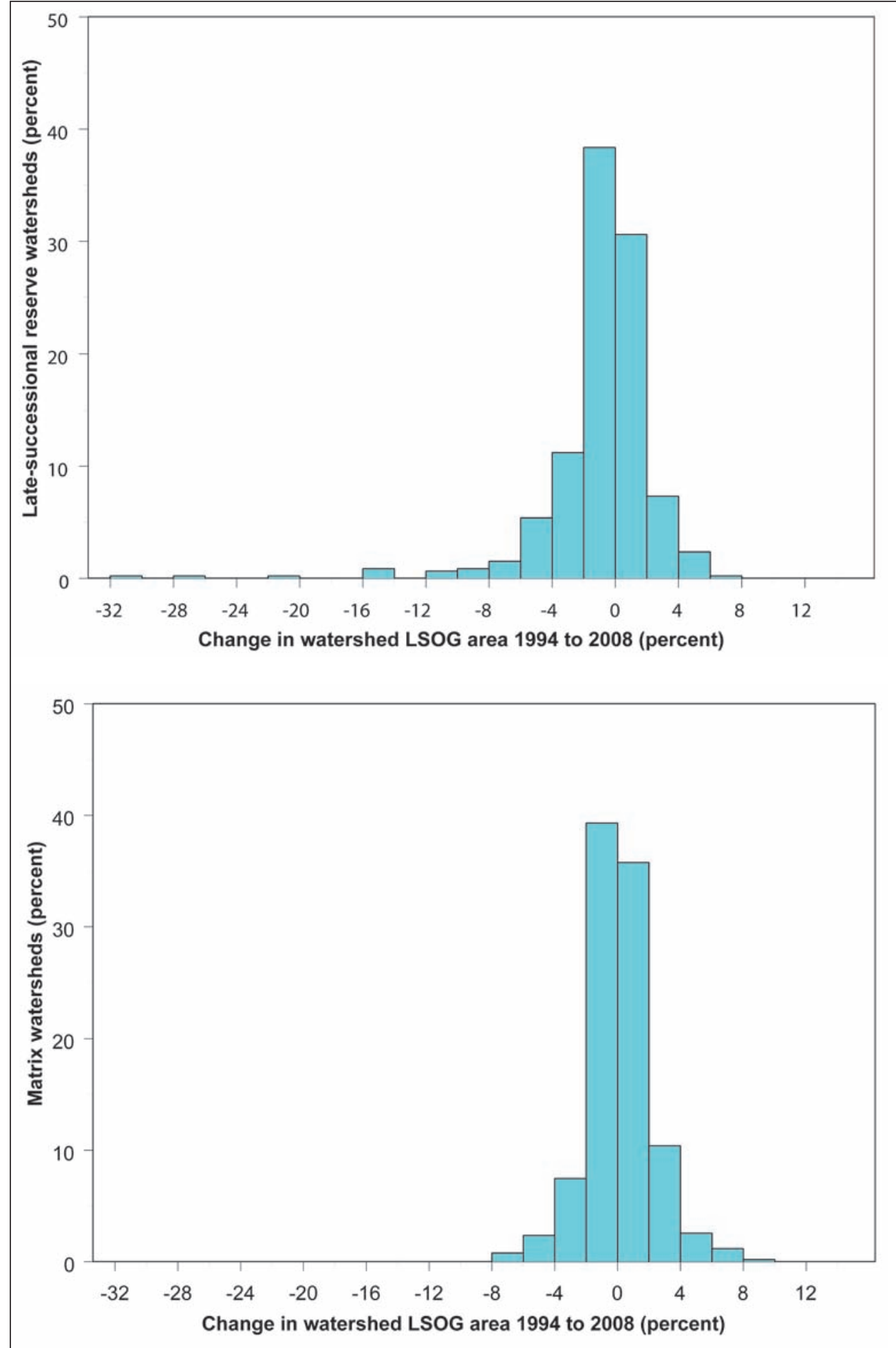

Figure 42-Continued. 


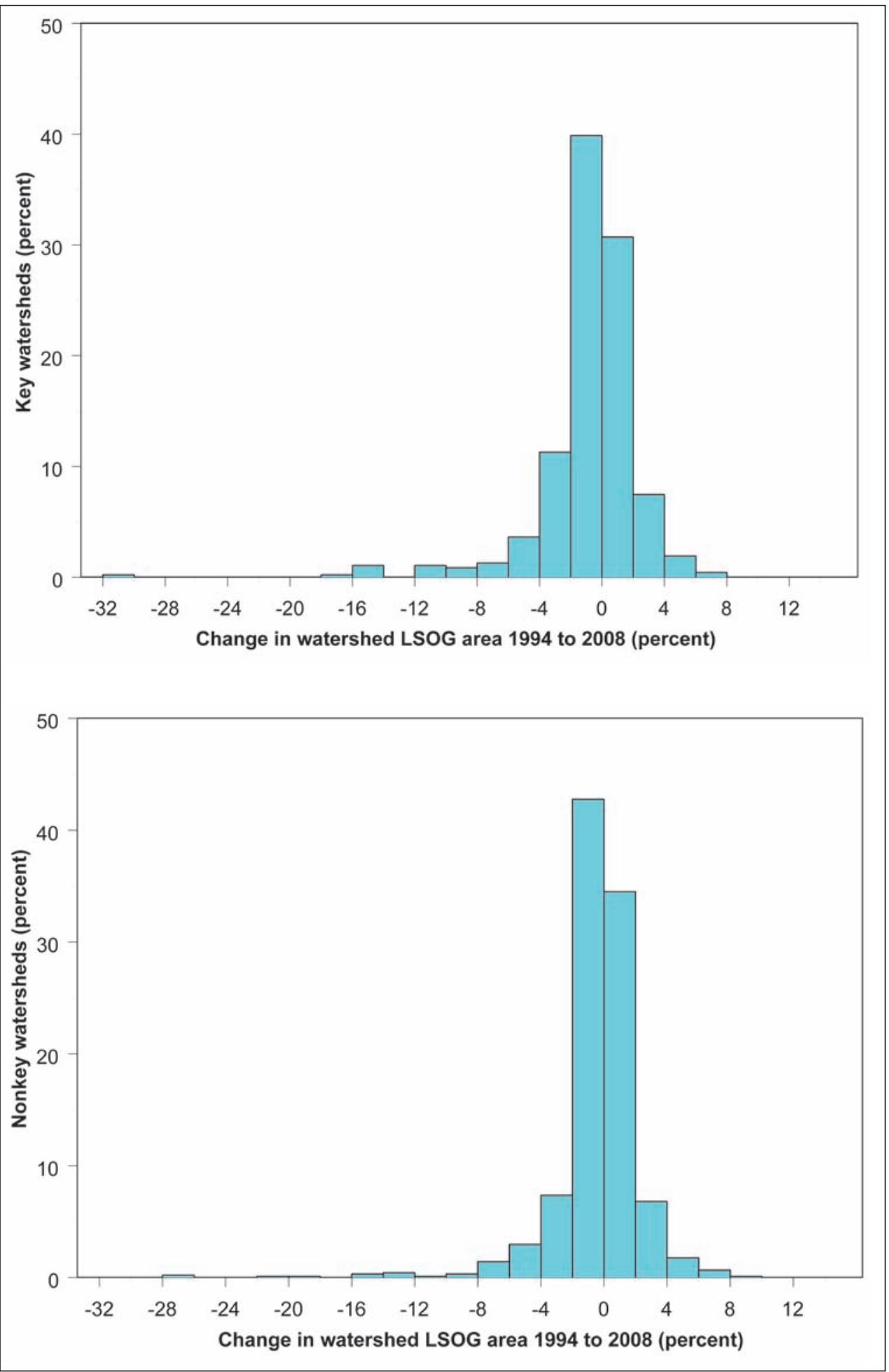

Figure 42-Continued. 
considerably smaller: 0.03 to 1.79 percent for fire and 0.21 to 1.41 percent for harvest (fig. 43). As a regional average, harvest declined dramatically from the first period (1985-1989) to the second (1990-1994), even before the NWFP initiation. There was a moderate uptick to 0.41 percent harvested in the latest period (2004-2008); however, the level is less than one-third of the first period. Fire was more variable. A smaller average percentage was lost to fire than harvest in the first two periods, whereas fire losses exceeded harvest in periods three and four (with a notable jump in period four owing to the Biscuit Fire and others).

For comparison, the watershed evaluation models of a number of the provinces use a measure of percentage of forest land in early seral stage (as represented by average tree diameter less than 5 in) to approximate disturbance. The evaluation criteria in these models rate 5 percent or less disturbance as good condition and greater than 25 percent as poor. Comparing these thresholds to the sum of harvest and fire disturbance percentages shows that only 45 watersheds (3 percent) experienced a greater than 5 percent disturbance and only 11 watersheds ( 0.8 percent) would score in the very low category (model score $\leq-0.6$ ). In contrast to road density and large-tree alternative metrics, evaluating this disturbance metric using the thresholds in our watershed models would produce a considerably more positive distribution of condition scores than was produced by the vegetation component of our provincial watershed evaluation models, where 6 percent of the watersheds fell into the poor category.

\section{By land use category-}

Disturbance levels, averaged over all watersheds, show some distinct patterns by land use class (fig. 44). On a per-watershed basis, pre-NWFP (prior to 1994) vegetation losses were primarily due to harvest on matrix (timber production) lands. In contrast, the greatest post-NWFP losses have been mainly due to fire and mostly on congressionally reserved lands and LSRs. Note that harvest associated with reserved watersheds does not indicate harvest in reserved areas, as the harvest category includes small fires and blowdown, and watersheds classified as reserve may have portions of nonreserve lands (see "Methods" section for further details). Average harvest levels are low in both periods in the reserved category, but decline dramatically on the LSR class and somewhat less on matrix lands. Sharp declines are also seen on key and nonkey watersheds, but the difference between the two is slight. Average losses from fire went up in all land categories from the pre-NWFP to post-NWFP period, but the increase was noticeably less on matrix lands.

\section{Upslope/Riparian Versus Inchannel Conditions}

The shapes of the overall score distributions for upslope/ riparian and inchannel conditions are shown in figure 45 . The majority of watersheds scored in the moderate and high condition categories. Inchannel scores were more tightly grouped around the center of the distribution, with fewer scores in the very low, low, and very high categories.

Figure 46 displays the inchannel values paired with the corresponding upslope/riparian scores by watershed, along with the best fit regression line. The test of whether the slope of the line was zero had a two-sided p-value of 0.12 , indicating a possible relationship, but the strength of this relationship was extremely weak $\left(\mathrm{R}^{2}=0.01\right)$. 


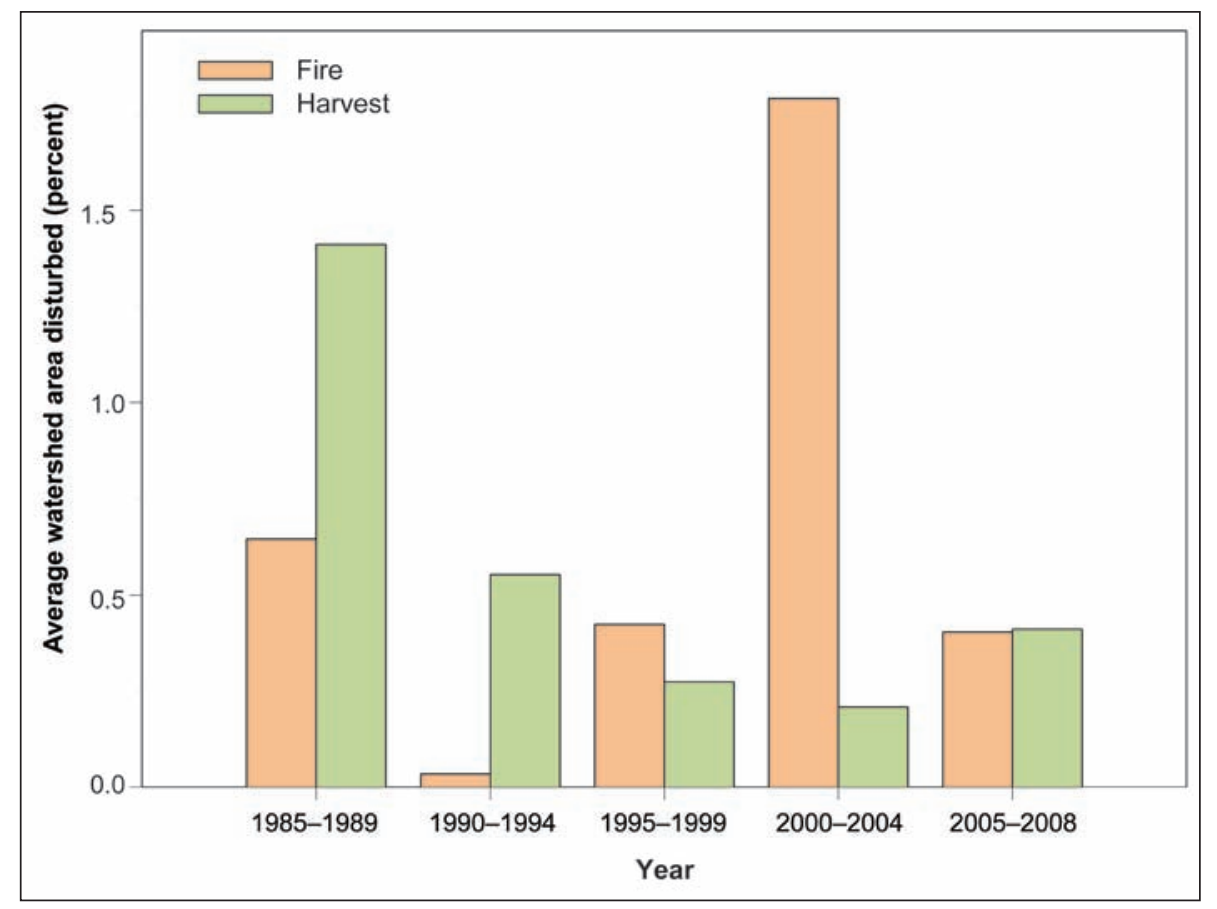

Figure 43-Watershed area affected by harvest and fire disturbances, 1985 to 2008.

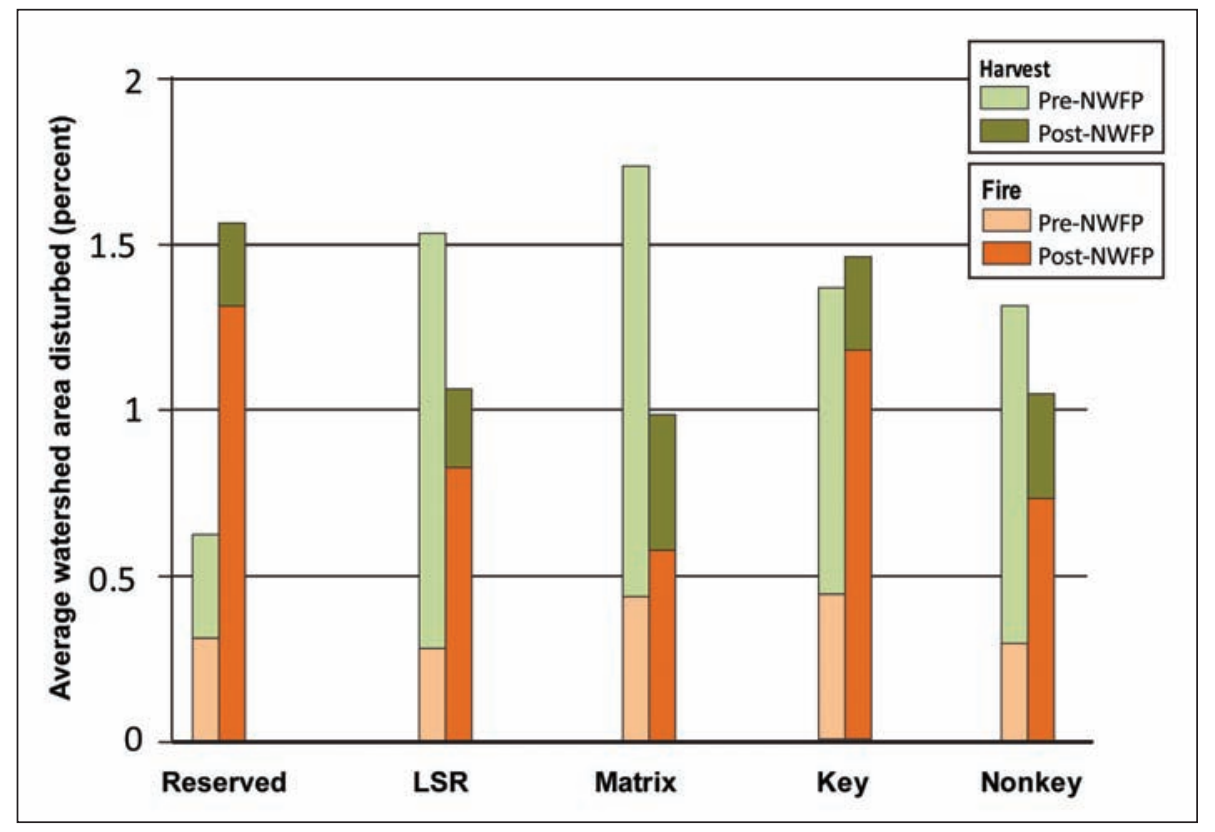

Figure 44-Average yearly fire and harvest disturbance levels before and after Northwest Forest Plan (NWFP) by land use allocation, and for key and nonkey watersheds (Reserved = congressionally reserved, LSR = late-successional reserve.) 


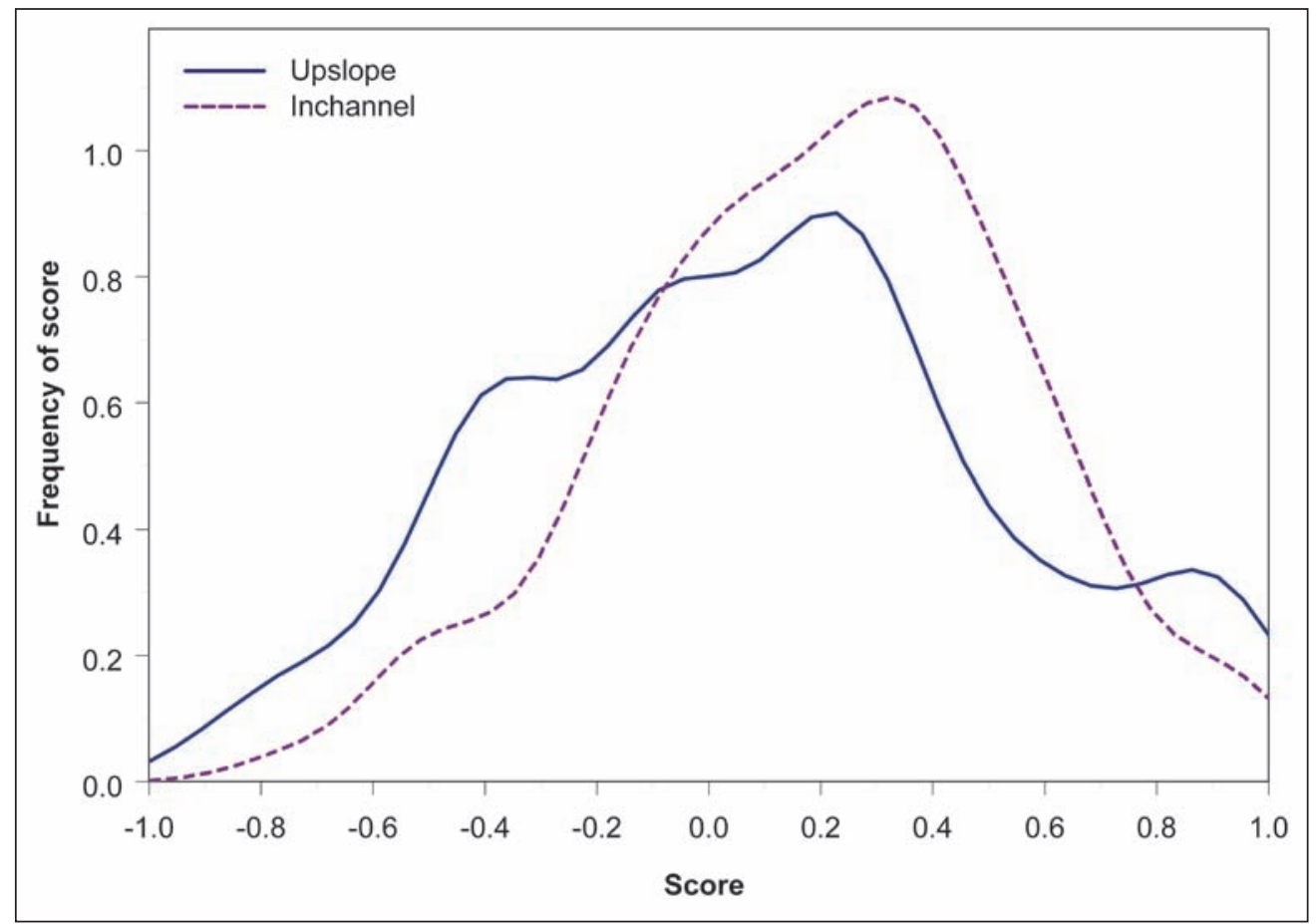

Figure 45-Watershed versus inchannel current condition scores. These curves show the data in a continuous manner rather than by data bins (i.e., histograms).

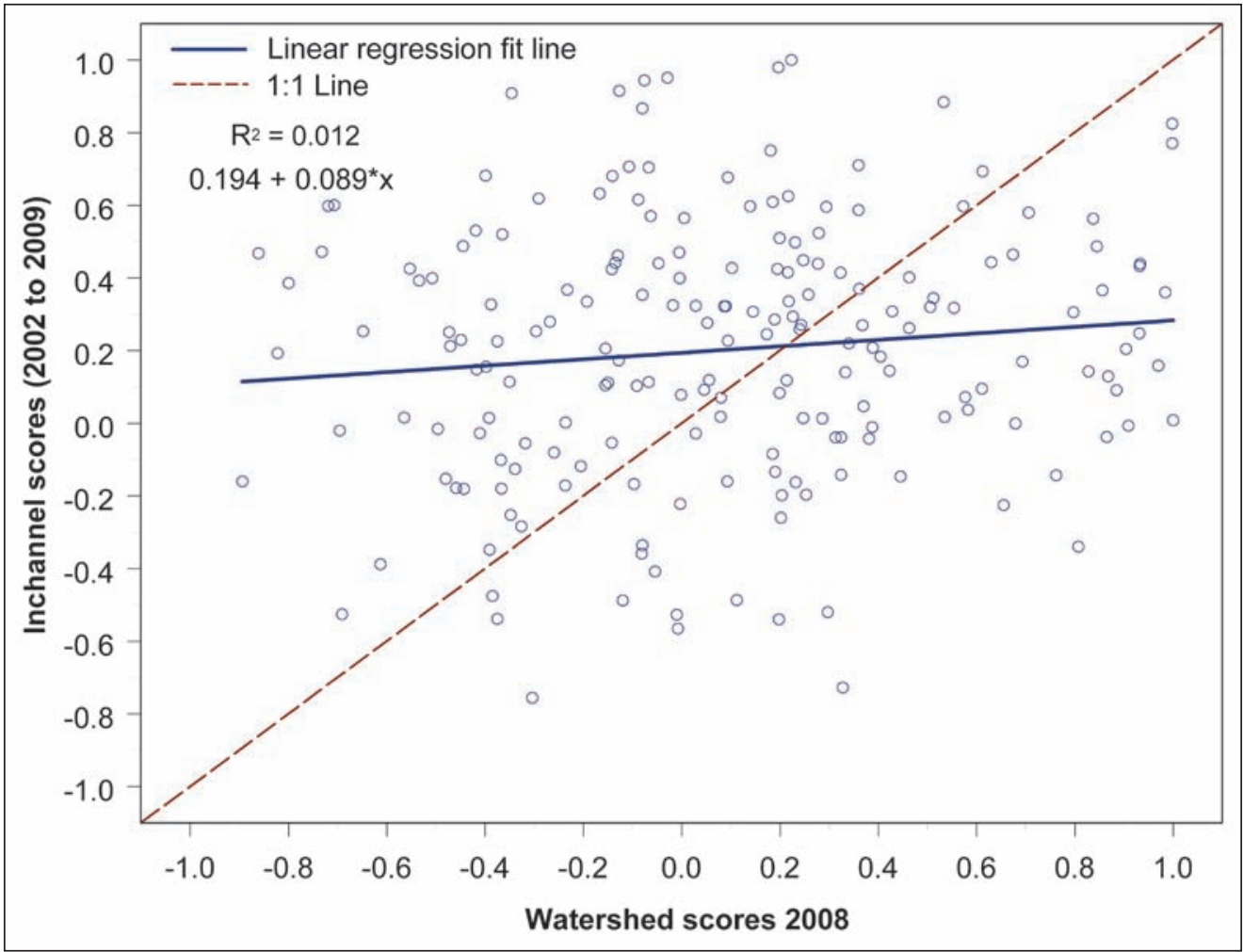

Figure 46-Upslope/riparian versus inchannel current condition scores for 193 watersheds with both data types available. 


\section{Chapter 4: Discussion}

\section{Watershed Trend}

Did the Northwest Forest Plan (NWFP) succeed in maintaining and improving watershed condition? Examining the trend data expressed either as a continuous distribution (fig. 27) or as score categories (fig. 29) the answer seems to be yes. The overall trend was clearly positive with 69 percent of watersheds trending up versus 23 percent showing declines (table 6). Although a portion of these shifts was likely due to errors inherent in the satellite imagery classification process, a more conservative estimate still showed a similarly positive ratio, with 10 percent of watersheds increasing more than this threshold versus 4 percent decreasing. In most cases, these larger positive changes depended on the combined effects of natural vegetation growth and road decommissioning efforts, and especially road decommissioning in landslide-prone areas.

A greater proportion of the positive changes in watershed condition occurred on late-successional reserve (LSR) and matrix lands than on congressionally reserved lands, and the mean score for reserved lands actually declined slightly. Considering that the reserved class is already generally in good condition with respect to roads and vegetation, it is not surprising that the larger increases were found in the other allocations. Our analysis of contributing factors revealed that declining watershed condition scores were driven almost exclusively by vegetation losses, and our alternative disturbance indicator showed that fire was the main driver of these losses. Parallel to a similar finding in the late-successional old-growth (LSOG) monitoring report (Moeur et al. 2011), vegetation losses from fire were much higher on reserved lands and on key watersheds than on the other land use categories. These disproportionate vegetation losses were one reason average improvement on key watersheds was only slightly greater than on nonkey watersheds. Another reason key watersheds did not show more improvement was that, although more roads were decommissioned on key watersheds, these numbers were often too small in terms of overall density to raise condition scores.

\section{Upslope/Riparian and Inchannel Current Status}

In addition to the satellite vegetation classification and geographic information system (GIS)-based road data used to evaluate upslope and riparian condition, this report also assessed current watershed condition status using field sampling of multiple inchannel attributes. The shapes of the overall distributions of these scores (fig. 45), showed the majority of watersheds scoring in the moderate and high condition categories. In terms of land use categories, both upslope and instream condition scores generally followed a pattern consistent with the amount of allowable management (i.e., timber harvest). Matrix lands had the lowest upslope/riparian and inchannel scores. The LSR scores were higher, followed by congressionally reserved lands with the highest scores. Key watersheds also were in considerably better condition on average than nonkey watersheds.

\section{Model Validation}

We looked at a number of simple metrics, i.e., road density, LSOG, and vegetation disturbance, to provide an alternative view and partial check on our results. None of these metrics closely matched the results from our more complex provincial evaluation models, but this was not unexpected given that each metric provides only a partial picture of watershed influences and does not account for the natural variability in conditions across the broad monitoring area. Nevertheless, these metrics provided some additional insights relevant to watershed conditions.

When viewed as a regional aggregate, road density has changed little over the life of the NWFP. However, dramatic changes have been accomplished in targeted watersheds, e.g., Lower Fish Creek in the western Cascades dropped road density from $3.3 \mathrm{mi} / \mathrm{mi}^{2}$ in 1994 to $0.8 \mathrm{mi} / \mathrm{mi}^{2}$ in 2008 through decommissioning $118 \mathrm{mi}$ of roads. This targeting of road decommissioning appeared to follow the intent of the aquatic conservation strategy in that the rate in key watersheds was double that in nonkey watersheds. Similarly, in broad aggregate, the area in LSOG has changed little over the 15-year period, although the latest estimates suggest a 
slight decline in area (Moeur et al. 2011). In contrast, the Aquatic and Riparian Effectiveness Monitoring Program (AREMP) model vegetation attributes scores generally increased; however, this was not inconsistent because many of the AREMP indicators were based on earlier seral stages. The utility of LSOG as a metric for aquatic monitoring appeared low because of this mismatch in seral stage and the natural variability of vegetation potential across the NWFP area. In contrast, the vegetation disturbance metric showed considerable promise for contributing to aquatic assessment. Many of the expert groups wished to assess disturbance but had to rely on simple mean tree diameter metrics (cover, quadratic mean diameter) as proxies, and these measures are difficult to calibrate to the variability in natural vegetation potential. The disturbance metric also revealed that average losses from fire went up in all land categories from the pre-NWFP to post-NWFP period, especially in congressionally reserved lands and key watersheds. Average timber harvest levels declined sharply from pre-NWFP levels on both key and nonkey watersheds, but the decline in both classes was similar, suggesting that the key watershed designation did not have a major influence on harvest levels at the regional scale.

Reeves et al. (2004: 6) stated, "To be meaningful, a monitoring program should provide insights into causeand-effect relations between environmental stressors and anticipated ecosystem responses." Although the shapes of the upslope and inchannel score distributions looked similar (fig. 45), we found little correspondence at the individual watershed level (fig. 46). Reid and Furniss (1998) summarized a number of past efforts that illustrate the difficulty of showing strong relationships based on a short period:

Gilbert (1917), for example, demonstrated that the aggradational front for sediment from longdiscontinued hydraulic mining in the Sierra Nevada foothills was still progressing through the Central Valley. Similarly, Trimble (1983) found that the form of low-order channels in the Coon Creek watershed of Wisconsin responded quickly to agricultural impacts of the last century, while downstream channels are still adjusting today. In Redwood
Creek, California, logging-related impacts on channel morphology only became evident when major storms occurred, and parts of the channel are only now responding to sediment introduced by the 1964 flood (Madej and Ozaki 1996). Similarly, Frissell et al. (1997) note that it may take another major flood to allow channel morphology to recover, even if upslope practices have indeed improved to the point that recovery is possible.

Other reasons for difficulty in finding relationships between stressors and response are a lack of direct upslopeinchannel links, and upstream influences (see sidebar "Modeling Inchannel Variables from landscape conditions," page 71). However, a few recent studies have found statistical relationships between a few simple measures of upslope/ riparian conditions and corresponding inchannel attributes. Lee et al. (1997) found a relationship between road density and the status of resident salmonids in the interior Columbia River basin. Kaufmann and Hughes (2006) were able to factor out major natural landscape differences (basin size, stream gradient, lithology) and found relationships between road density, riparian condition, and an index of stream macroinvertebrates. Al-Chokhachy et al. (2010) have further developed statistical methods for filtering out natural landscape variability, and they found a relationship between upslope road density and an index of inchannel physical conditions.

\section{Evaluating Dynamic Processes and the Role of Fire}

Fire has surpassed timber harvest as a dominant influence on vegetation on federal lands in the NWFP area (fig. 44) (Healy et al. 2008; Moeur et al. 2011). The NWFP watershed condition models currently do not distinguish between vegetative disturbances: fire and harvest (and other disturbances) affect condition simply through their impacts on canopy cover and average tree size metrics. Reviewers of this report have argued that fire, as a natural process, should not be considered in the same way, and we acknowledge that different types of disturbances have different associated effects and ecological legacies. New metrics based on disturbance types (Kennedy et al. 2010) rather than vegetation 


\section{Modeling Inchannel Variables From Landscape Conditions}

Aquatic and Riparian Effectiveness Monitoring Program (AREMP) staff contracted with Kelly Burnett (Pacific Northwest Research Station [PNW]), Ken Vance-Borland (Oregon State University [OSU]), Rebecca Flitcroft (PNW), and Lisa Ganio (OSU) to to develop statistical models to explore relationships between inchannel variables and landscape conditions (geographic information system [GIS] and satellite imagry data).

Numerous landscape conditions were explored as independent variables. One of these, contributing area $\left(\mathrm{km}^{2}\right)$, was determined for the entire catchment upstream of each sampled reach. All other landscape conditions were summarized in 100-m (328-ft) buffers and 2-km (1.2-mi) catchments for each sampled reach. For modeling each inchannel variable, a core set of six landscape conditions (see below) was considered. Contributing area $\left(\mathrm{km}^{2}\right)$, reach gradient, and mean annual precipitation $(\mathrm{cm})$ were selected as influencing stream power and thus numerous biophysical characteristics of fluvial systems (e.g., Knighton 1999, Standford 1998). Road density $\left(\mathrm{km} / \mathrm{km}^{2}\right)$, percentage of area harvested 1972-2002, and percentage of area with $>65$ percent hardwood cover were selected as indicators of riparian and stream disturbance (e.g., Lee et al. 1997, Pabst and Spies 1999). Inchannel data used included pool frequency (number of pools per meter), frequency of key ( $0.6 \mathrm{~m}$ by $15 \mathrm{~m}$ [2 by $50 \mathrm{ft}])$ large wood pieces (number per $\mathrm{m}$ ), frequency of all large $(0.3 \mathrm{~m}$ by 3 $\mathrm{m}$ [1 by $10 \mathrm{ft}]$ ) wood pieces (number per $\mathrm{m}$ ), and aquatic macroinvertebrate species richness (number of Ephemeroptera species in the reach).

Statistical models indicated that inchannel variables were generally more strongly related to landscape conditions describing topography, lithology, or climate than those considered to be sensitive to human activities. The relatively weak relationship observed between inchannel variables and landscape conditions sensitive to human activities may stem from several sources, including use of probability sampled data, among-reach variability that was relatively low for land use but high for characteristics unrelated to management, and a legacy of splash-damming effects in streams.

Although the current AREMP probability sample design was considered useful for collecting inchannel data to assess status and monitor trends in streams, a modified sampling design may be more conducive for developing models to explain these trends or to predict inchannel data in nonsampled watersheds from GIS and remote-sensing data.

Landscape conditions that were considered in developing final models for each inchannel variable

\begin{tabular}{|c|c|c|c|c|c|c|}
\hline & Landscape condition & $\begin{array}{c}\text { Pool } \\
\text { frequency }\end{array}$ & $\begin{array}{l}\text { Key wood } \\
\text { frequency }\end{array}$ & $\begin{array}{l}\text { All large wood } \\
\text { frequency }\end{array}$ & $\begin{array}{l}\text { Macroinvert. } \\
\text { family richness }\end{array}$ & $\begin{array}{l}\text { Ephemeroptera } \\
\text { species richness }\end{array}$ \\
\hline \multirow[t]{6}{*}{ Core set } & Contributing area $\left(\mathrm{km}^{2}\right)$ & $\mathrm{X}$ & $\mathrm{X}$ & $\mathrm{X}$ & $\mathrm{X}$ & $\mathrm{X}$ \\
\hline & Reach gradient (\%) & $\mathrm{X}$ & $\mathrm{X}$ & $\mathrm{X}$ & $\mathrm{X}$ & $\mathrm{X}$ \\
\hline & Mean annual precipitation (cm) & $\mathrm{X}$ & $\mathrm{X}$ & $\mathrm{X}$ & $\mathrm{X}$ & $\mathrm{X}$ \\
\hline & Road density $\left(\mathrm{km} / \mathrm{km}^{2}\right)$ & $\mathrm{X}$ & $\mathrm{X}$ & $\mathrm{X}$ & $\mathrm{X}$ & $\mathrm{X}$ \\
\hline & \% area harvested 1972 to 2002 & $\mathrm{X}$ & $\mathrm{X}$ & $\mathrm{X}$ & $\mathrm{X}$ & $\mathrm{X}$ \\
\hline & $\%$ area with $>65 \%$ hardwood cover & $\mathrm{X}$ & $\mathrm{X}$ & $\mathrm{X}$ & $\mathrm{X}$ & $\mathrm{X}$ \\
\hline \multirow[t]{4}{*}{ Disturbance } & $\%$ area with urban cover & $\mathrm{X}$ & & & & $\mathrm{X}$ \\
\hline & $\begin{array}{l}\text { Average quadratic mean diameter (QMD) of } \\
\text { coniferous trees }(\mathrm{cm})\end{array}$ & $\mathrm{X}$ & & & & $\mathrm{X}$ \\
\hline & $\begin{array}{l}\text { \% area with conifer QMD } 10.2 \text { to }-25.4 \mathrm{~cm} \\
\text { (4 to } 10 \text { in) }\end{array}$ & & & & $\mathrm{X}$ & \\
\hline & $\%$ area with conifer QMD > 50.8 cm (20 in) & & $\mathrm{X}$ & $\mathrm{X}$ & & \\
\hline \multirow[t]{5}{*}{ Topography } & $\%$ area with hillslope 3 to $6 \%$ & & & & & $\mathrm{X}$ \\
\hline & $\%$ area with hillslope 20 to $44 \%$ & $\mathrm{X}$ & $\mathrm{X}$ & $\mathrm{X}$ & $\mathrm{X}$ & \\
\hline & Mean elevation (m) & $\mathrm{X}$ & & & $\mathrm{X}$ & \\
\hline & $\%$ area with elevation < $198.1 \mathrm{~m}(650 \mathrm{ft})$ & & & & & $\mathrm{X}$ \\
\hline & $\%$ area with elevation $<609.6 \mathrm{~m}(2,000 \mathrm{ft})$ & & $\mathrm{X}$ & $\mathrm{X}$ & & \\
\hline \multirow[t]{2}{*}{ Lithology } & $\%$ area with unconsolidated deposits & & & & $\mathrm{X}$ & $\mathrm{X}$ \\
\hline & $\%$ area with weak rock & & $\mathrm{X}$ & $\mathrm{X}$ & $\mathrm{X}$ & \\
\hline
\end{tabular}


status may enable further distinction among disturbances in future assessments. Fire does often have short- to mediumterm negative impacts on fish habitat from increases in mass wasting, sedimentation, solar radiation, and water temperatures (Burton 2005, Dunham et al. 2003), although it also plays a longer term role in renewing habitat attributes (Reeves et al. 1995). Given the possibility of a changing climate, along with changes in disturbance regimes (Dale et al. 2001), we believe it is important to capture all disturbance effects on watershed conditions, rather than to assume that some are natural and therefore just part of a natural baseline or reference condition.

\section{Management Implications}

We can draw some management implications from this type of broad-scale monitoring and assessment, but it must be realized that restoration actions are planned and implemented with finer grained information that is much more sensitive to the local context. At the regional level under current management practices, watershed condition appears to be improving, with widespread, small score increases owing to maturing vegetation and larger but localized increases from restoration actions. According to our assessment methods, road decommissioning in landslide-prone areas is the most effective action for raising watershed scores. Such decommissioning has the dual benefit of reducing more direct road impacts, such as altered hydrology and erosion, as well as the indirect effect on reducing landslide risks. Removing roads in riparian buffers, especially those with associated stream crossings, is another strategy that yields dual benefits. Reducing overall road density, even in lower risk areas, can be effective, as roads are weighted more heavily than vegetation in a number of the provincial expert models. However, because these models incorporate certain thresholds, changes in density that remain above the upper threshold (which ranges by province from 2.4 to $4 \mathrm{mi} / \mathrm{mi}^{2}$ ) will not affect evaluation scores. Based on this evaluation technique, there is an advantage to targeting restoration in watersheds at or below the threshold, where each mile removed will benefit scores, rather than those watersheds that are the most heavily roaded.
Similar management implications can be drawn from the assessment relative to vegetation. Riparian areas are generally accorded more weight in the models, so restoration activities in these areas will have greater positive effects on evaluation scores. Thinning in riparian reserves is one restoration strategy (Chan et al. 2004), and, if targeted to smaller diameter trees, it will increase scores by raising the mean tree diameter. However, two of the provinces also include riparian canopy cover metrics, and reducing cover below these thresholds could have a corresponding negative effect. Although upslope vegetation generally carries less weight, it also tends to have lower thresholds in terms of mean tree diameter expectations. Thus revegetating burned or harvested areas can yield results more quickly than in riparian areas, again especially in landslide-prone areas. Reducing stand-replacing fires, via fuel treatments or suppression, will also have positive effects under our evaluation approach; however, suppression alone can have negative effects by reducing mean tree diameters and can increase longer term risks of more severe fires. Finally, similar to the concern expressed in Moeur et al. (2011) about old-growth reserves, the unpredictable nature and dynamic role of fire may have implications for the static reserves approach that lies behind the designated set of key watersheds.

\section{Improving the Assessment}

We anticipate working on the following issues to improve confidence in these assessment models: improving the data and error estimates, improving the validity of the evaluation criteria, and making comparisons to results of other assessments.

Improving data quality and quantity and better understanding and communicating measurement error are fundamental to advancing these assessments. We continue to work on obtaining attributes important to salmonid habitat, such as fish passage barriers, and broader aquatic processes, which are currently missing from these models owing to lack of regional data sets (see chapter 5 "Emerging Issues"). Quantifying and communicating the effect of measurement errors on watershed condition estimates is also needed. Appendix 6 presents information on data quality estimates for a number of attributes, but more detail 
is clearly desirable, especially for the upslope indicators. Estimating uncertainty levels in the results of this type of multimetric, nonstatistical model is challenging, but there are feasible methods. One such method is a Monte Carlo approach, which runs the model multiple times drawing inputs from the expected distributions of the attribute values each time (Refsgaard et al. 2007).

Evaluation criteria, the standards against which the input data are judged, are perhaps the most critical and sensitive piece of the assessment process. The criteria used are derived from and validated by expert workshops. It is often challenging to link these criteria back to specific empirical studies, but future work in this area would help to improve model validity (Gordon and Gallo 2011). Reeves and Duncan (2009) cautioned against using fixed standards because of natural variability owing to environmental gradients even within sites in the same ecological space. The NWFP models include broad-scale criteria adjustments by ecological province and some finer scale gradients; however, a more empirical approach would be desirable. As discussed above, a few recent studies have factored in environmental gradients by using multiple regression techniques (Al-Chokhachy et al. 2010, Kaufmann and Hughes 2006).

Comparison to results from other assessments also provides an opportunity for further validation. New biotic indexes, which combine both abundance and diversity measures, show promise, and there are a number of available data sets in the Pacific Northwest with the necessary information (Hubler 2008, Hughes et al. 2004, Whittier et al. 2007). Other recent assessments have used these biotic indexes, although they have not attempted correlations with the other biophysical indicators (Hubler et al. 2009, Mulvey et al. 2009, Oregon DEQ 2004). Testing for relationships between our expert-based watershed assessments and these biotic data sets is another potential approach to better model validation. 
GENERAL TECHNICAL REPORT PNW-GTR-856 


\section{Chapter 5: Emerging Issues}

New issues related to the condition of watersheds continue to emerge as our understanding of processes affecting watershed condition evolves. These issues will be incorporated into future iterations of decision-support models as needed information becomes available. The following paragraphs highlight a number of such emerging issues.

- Fish passage-Millions of dollars have been spent by the Forest Service (FS) and Bureau of Land Management (BLM) over the past 15 years restoring fish passage where it was blocked by culverts at road stream crossings. The FS spent $\$ 2,090,000$ in 2009 alone for improving fish passage in Oregon and Washington (USDA FS 2010b). However we had no way to consider the effect of blocked fish passage on watershed condition, or improved watershed conditions when fish passage was improved or restored, because fish passage assessment data were unavailable (see "Fish Passage at Culverts" sidebar page 76). When culvert locations and culvert fish passage assessment data become available, we intend to use the amount of fish habitat available to fish as part of our watershed condition assessment.

- Complete road layer-Road data are currently stored separately by the FS and BLM. The two agencies manage their road information with different data structures and attributes, which makes combining the data very challenging. Also, nonsystem roads on federal lands are often not included, and private lands have very poor road information (see sidebar page 77). Although roads are known to have a major effect on watershed condition (see Daigle 2010), it will remain difficult to analyze watershed conditions across ownership boundaries until agencies use more compatible information systems.

- All lands approach-Recent FS policy statements have emphasized looking at agency actions in the context of the broader landscape (Tidwell 2010). The use of geographic information system and satellite imagery should eventually allow for a consistent assessment of watershed condition across all land ownerships. For example, vegetation data are now consistent for all ownerships through the use of satellite imagery. However, road data are not consistent, and including nonfederal lands could affect watershed condition scores in two ways-with opposite results:

- If nonfederal lands within a mixed ownership watershed have a high road density this could result in an overall low (poor) watershed condition score even if the majority of the watershed consists of federal lands with few or no roads (fig. 47).

- Nonfederal land road layers are known to underrepresent the number of roads in watersheds. Gallo et al. (2005) found that 37 percent of the roads on nonfederal lands were missing on the agency layer used, compared to 10 percent on BLM lands and 15 percent on FS lands. If a large number of roads on nonfederal lands are missing on a watershed's road layer, the watershed could receive an artificially high (good) watershed condition score.

- Inadequate flow-Dams and irrigation practices have altered flow regimes in many watersheds. Altered flow regimes include changes in timing and magnitude of peak flow and dewatering that result in insufficient flow during summer (Gallo et al. 2005).

- Invasive aquatic species-The effects of invasive and exotic aquatic species on the aquatic biotic community are usually detrimental to native species. However, an overall, accurate assessment of invasive species distributions is currently unavailable. Although invasive species databases currently exist for Oregon, Washington, California, U.S. Geological Services, U.S. Fish and Wildlife Service, National Park Service, and Forest Service, the ability to easily and quickly share data among agencies is still being developed.

- Fire-Fire condition class, which identifies how vegetation conditions have deviated from historical fire conditions, could be included in our watershed condition models. However, the effect of fire suppression and stand-replacing burns on vegetation and stream reach conditions is still largely unknown, 


\section{Fish Passage at Culverts}

When culvert fish-passage data become available, decision-support models can reflect improved conditions as fish passage barriers are removed.

Forest Service - An initial culvert assessment was done by forests in 2002-2003 that covered almost all streams within the range of anadromy and 80 percent of the streams with resident fishes. ${ }^{1}$ However, culvert location data are known to have spatial errors that need to be corrected. An effort is underway by the Forest Service (FS) to compile and update all of their culvert location data for where fish are present. Documentation of actions to correct fish-passage problems are also incomplete; the FS corporate database only tracks work funded out of the regional office (about 75 percent of the culvertrelated projects). Additional culvert improvement/ removal projects funded at the forest level, e.g.,

\footnotetext{
${ }^{1}$ D. Heller. 2010. Personal communication. Regional fish biologist, retired, USDA Forest Service, Pacific Northwest Region, 333 SW First Ave., Portland, OR 97204.
}

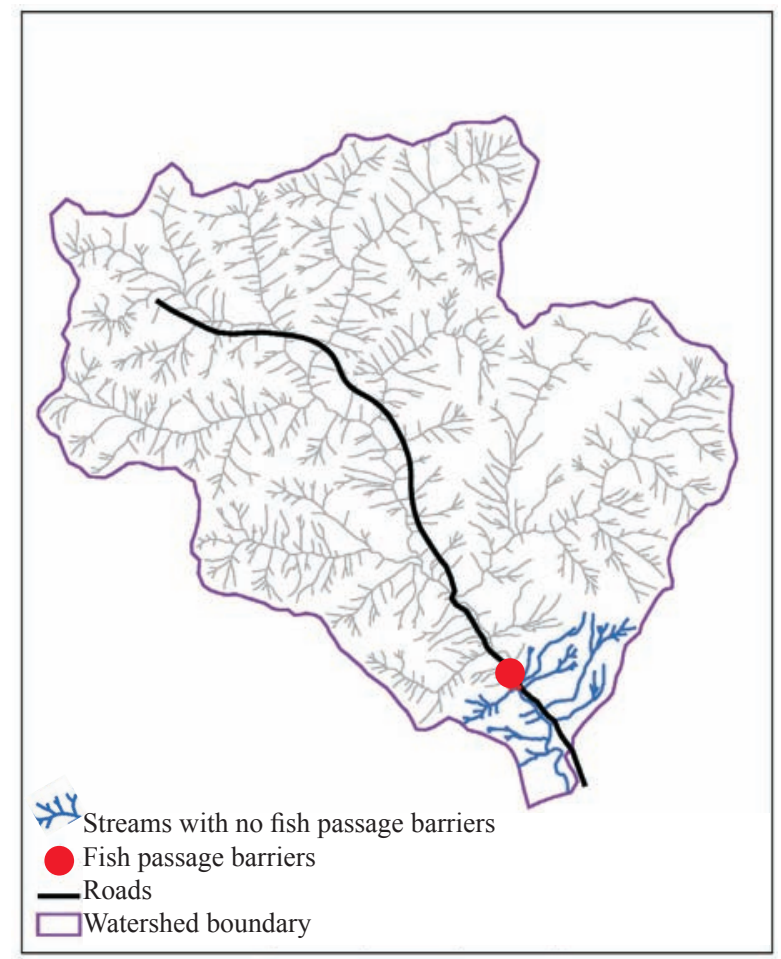

Knutson-Vandenberg Act funds, Burned Area Emergency Response, partnership funding, Emergency Relief for Federally Owned Roads, and Highway Trust Funds used for county and state roads are not being tracked.

Bureau of Land Management- Bureau of Land Management (BLM) culvert data varies in its quality, consistency, and completeness. Working in concert with BLM, Oregon Department of Fish and Wildlife has converted a substantial quantity of BLM culvert/ barrier data into the Oregon Fish Passage Barrier Data Standard. As of April 2009, a total of 3,981 barrier records from five western Oregon BLM districts were "standardized," with several thousand still to be evaluated. Culverts constitute the majority of the barriers that will be tracked by the data set, but dams, diversions, tidegates, weirs, falls, and cascades/gradient barriers are also included. Data collected from BLM units starting in 1999 for aquatic restoration project data, including culvert removal, replacement, and upgrade, are stored in a corporate geographic information system data warehouse.

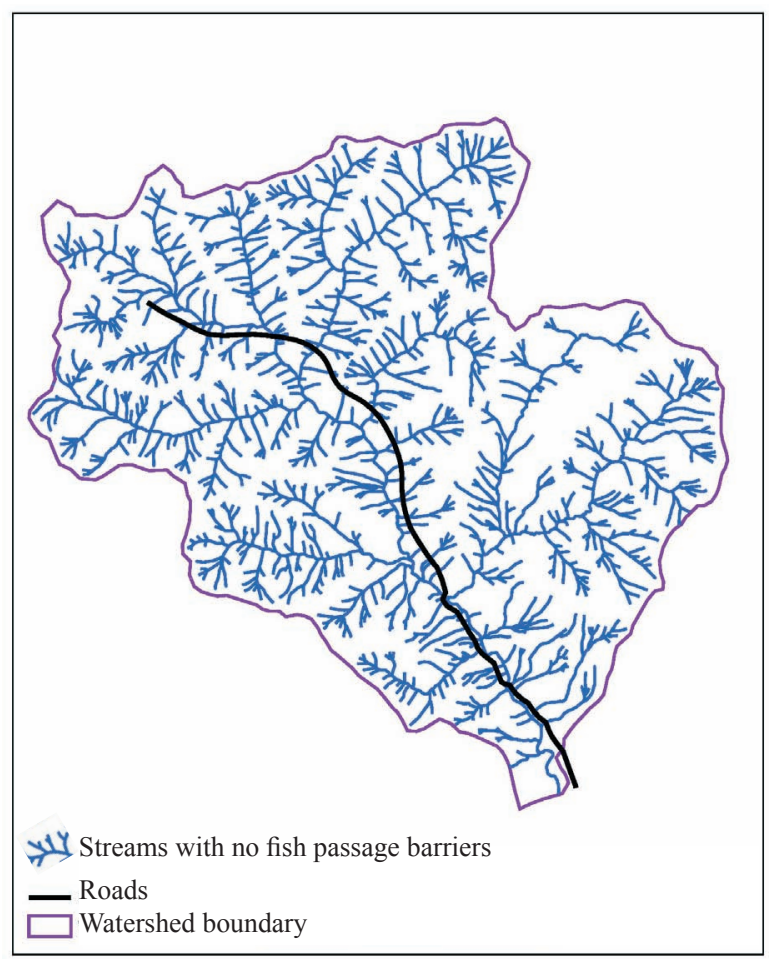

Without barrier data, these two watersheds would have received the same watershed condition score, despite the fact that the watershed on the left is almost entirely blocked to fish passage. When culvert locations and culvert fish passage assessment data become available, we intend to use the amount of fish habitat available to fish as part of our watershed condition assessment. 


\section{Road Data Challenges}

Roads are a major part of our evaluation models; however, there are a number of issues with available road data.

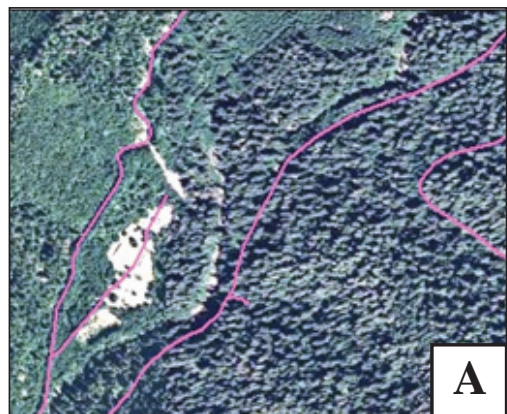

$\sim$ Willamette NF roads LIDAR-derived roads

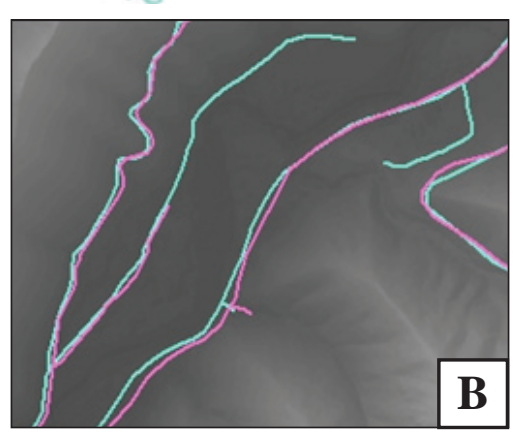

B

\section{Not all roads on federal lands are digitized in existing} geographic information system (GIS) layers-Figure A is a digital orthoquad with an overlay of the existing Willamette National Forest (NF) roads layer. Road locations are not exact, and some roads seen in the orthoquad are not included in the Forest Service (FS) roads layer. This is because the FS does not track "nonsystem" roads, even though they may affect hydrological processes. These are usually smaller spur roads built for timber sales. Gallo et al. (2005) found that the Bureau of Land Management (BLM) and FS underrepresented roads by 10 and 15 percent, respectively. Roads on nonfederal lands were underrepresented by 37 percent.

Figure B shows the same area with a surface derived from LIDAR (Light Detection and Ranging). LIDAR is a remote sensing data collection system that collects topographic information using aircraft-mounted lasers. A road layer derived from LIDAR imagery has more accurate road locations and includes roads that are not part of existing GIS road layers. Specifically, roads not included in the FS roads layer, but visible on the orthoquad and roads that were "hidden" under the canopy show up in LIDAR imagery. Complete LIDAR coverage of the Northwest Forest Plan area is not available now, but is expected to become available as more areas are flown and agencies share their data. However, LIDAR can only provide road locations and gradient. The BLM and FS road databases will still be needed to provide information about the roads, such as maintenance level and surface type.

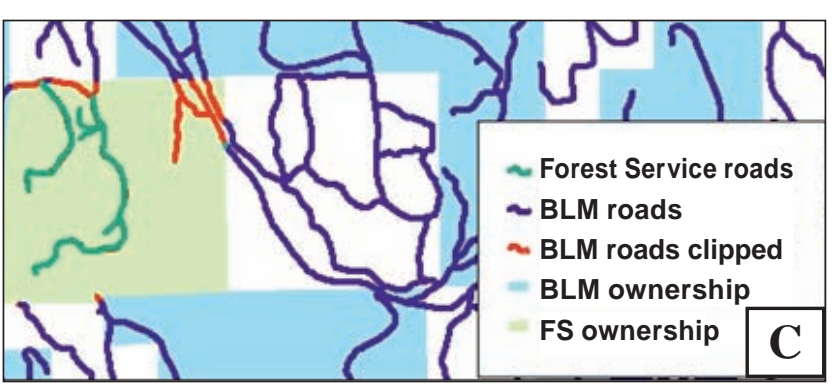

BLM and FS have separate road layers-We derived our current road layer by putting the BLM ground transportation layer together with the FS Infra travel route transportation data. However, because the two agencies manage their road information in different data structures and have different road attributes, the data did not go together easily.

We clipped each agency's data to their ownership to avoid overlap when combining road layers (fig. C). However, this potentially caused roads or their attributes to be clipped off if they were not contained in the databases of both agencies. Evaluating road attributes that could affect watershed condition, such as surface type and maintenance levels, will continue to be very challenging unless the FS and BLM manage their road data cooperatively.

Better tracking of road improvements is needed-We currently evaluate the effect of roads on watershed condition by using a rather simplistic approach because of the lack of corporate road data. The only road information available is whether a road is present or it has been decommissioned (and is therefore assumed to be benign with respect to sediment delivery to streams). Therefore, decommissioned roads are the only "road improvements" tracked in federal agency databases. However, the term "decommissioned" can be applied to a road that has been closed by a gate or a tank trap, or to a road that has been obliterated. Because other road condition improvements (e.g., outsloping, water bars, drivable fords, hardening surfaces) can also reduce sediment delivery, we recommend that additional road attributes should be tracked in federal agency databases. Availability of these data will allow future decision-support models to better reflect the effects of roads on watersheds and allow managers to take credit for those improvements. 


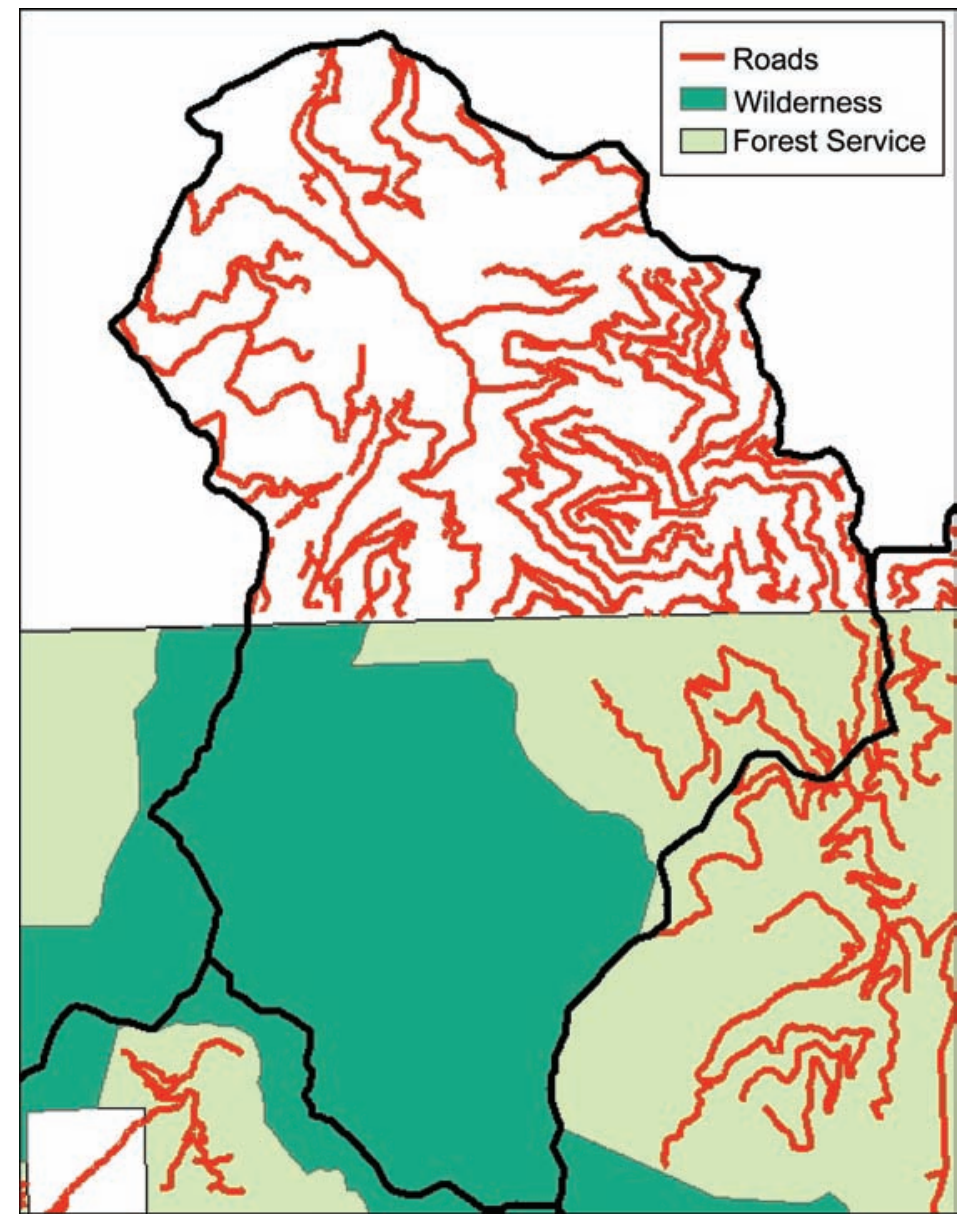

especially for forests that tend to have catastrophic fires several centuries apart (Franklin and Dyrness 1973), which is common throughout the Northwest Forest Plan (NWFP) area. Fire condition class is currently being mapped for all federal lands in the NWFP area.

- Climate change-Climate change is likely to affect our measures of watershed condition in a number of ways, from stream temperatures to morphology changes from increased storms to vegetation changes. Further thought and discussion are needed to decide whether the program should attempt to distinguish between direct management and climate change effects in the future.

- Restoration projects-A link between restoration projects and the monitoring program has yet to be established. For example, the decision-support
Figure 47-Federal lands in the headwaters of the Clearwater River watershed (Mount Baker-Snoqualmie National Forest) are within a wilderness. Nonfederal lands in the upper half of the same watershed are managed for timber production, and that area is heavily roaded. Including the nonfederal lands would misrepresent the watershed score if the watershed is classified as a federal watershed.

models are sensitive only to road decommissioning, because road improvements are not tracked consistently in a database. Assigning and tracking other road attributes (such as water bar installation and culvert replacement) is needed to better reflect how roads affect the condition of watersheds (Gallo et al. 2005).

- Unified model-Aquatic province watershed condition models are similar in the attributes being evaluated, but their model structures differ (see app. 4). A "unified model structure" may be possible that would still allow evaluation criteria to differ based on contextual information, e.g., geology, precipitation zone, elevation. This would have the advantage of simplifying the effort needed to keep track of different model structures. 
- Distribution of watershed condition scores-The desired distribution of watershed condition scores was not identified by the strategy. This information would allow field unit specialists to determine if planned disturbances will move watershed conditions outside the range of natural variation (Gallo et al. 2005).

- Model validation and links between upslope, inchannel, and biological indicators - The alternative metrics we looked at in this report do not appear well-suited for validating our models. New biotic indexes, which combine both abundance and diversity measures, show promise, and there are a number of available data sets in the Pacific Northwest with the necessary information (Hubler 2008, Hughes et al. 2004, Whittier et al. 2007). Testing for relationships between our expert-based watershed assessments and these biotic data sets could be a more promising approach to model validation and linking upslope and inchannel models.

- National watershed condition assessment coordination-The FS is developing a consistent national process for watershed condition assessment to improve the system for rating watershed condition. The Aquatic and Riparian Effectiveness Monitoring Program (AREMP) already evaluates some, but not all, of the indicators proposed for use in a national assessment (USDA FS 2010b). One option being considered is to have AREMP include additional attributes identified in national assessment guidelines as part of regional watershed condition assessments.
- Management review-An AREMP management review is proposed for 2011 to determine if any changes are appropriate after 10 years of implementing the program. Suggested questions to be addressed include:

- What are the relevant management questions today?

- The watershed condition monitoring program uses a fairly sophisticated decision-support tool; is it a good fit?

- Is the ongoing amount of effort still needed to answer the current management questions of status and trend? Is it too rigorous?

- What new technologies exist that can help answer management questions (e.g., satellite imagery, and LIDAR)? Can these be used instead of instream sampling (to reduce program costs and safety risks to field crews)?

- What are AREMP's strengths and weaknesses?

- What can or do we use AREMP information for in addition to NWFP monitoring questions (e.g., project support, forest plan revisions, Endangered Species Act consultation, impaired water listings, watershed assessments, watershed condition framework [FS new national effort], and Survey and Manage riparian species detection)?

- What are program costs and what is the current staffing level? 


\section{Support to Local Units}

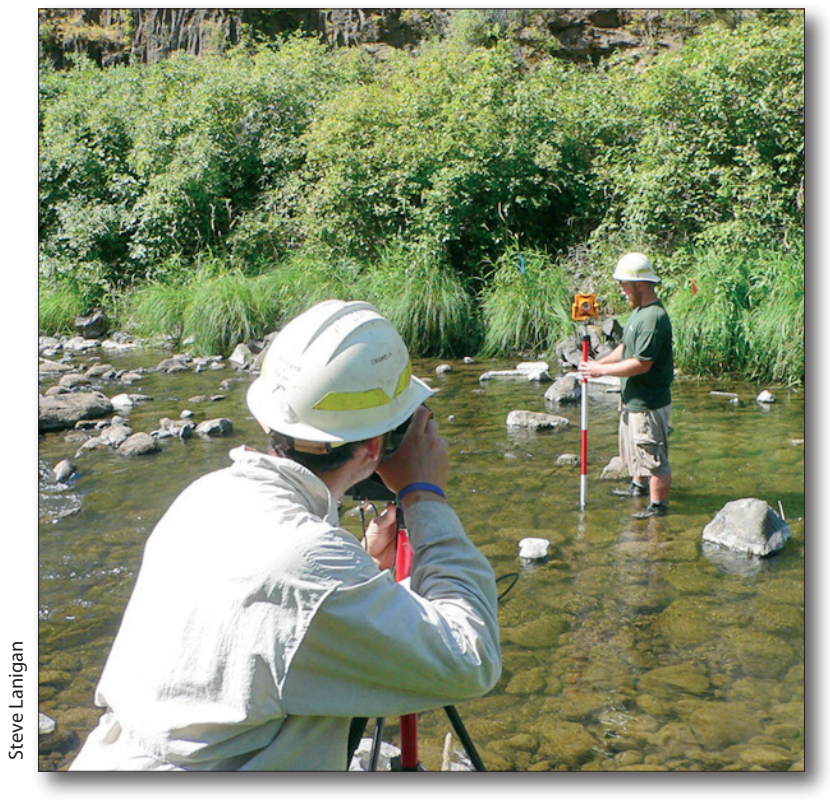

Protocol comparison test-Aquatic and Riparian Effectiveness Monitoring Program staff helped initiate and coordinate an interagency side-by-by-side protocol test in the John Day Basin (eastern-central Oregon). The goal of this effort was to assess the performance and compatibility of measurements obtained from seven monitoring groups that all use different monitoring protocols to assess stream habitat throughout the Pacific Northwest. The following were examined: (1) consistency of measurements within a monitoring group, (2) the ability of each monitoring protocol to detect environmental heterogeneity, (3) the compatibility of measurements between monitoring groups, and (4) the relationship of measurements to more intensive stream measurements that may better describe the true character of stream habitat. Understanding how the results of different monitoring programs are related to each other may foster improvement in the quality of stream habitat data, increase the sharing of data across monitoring groups, and increase statistical power to detect environmental trends (Roper et al. 2010).

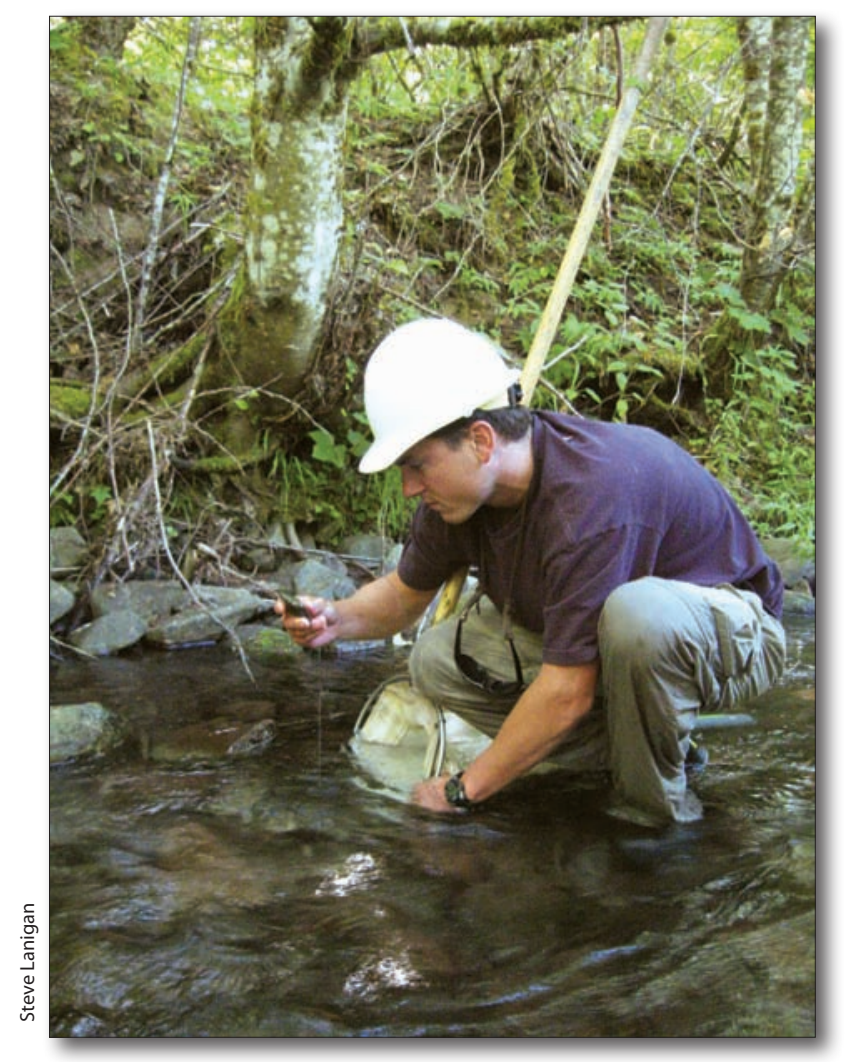

Aquatic invasive species surveys-Aquatic and Riparian Effectiveness Monitoring Program staff participated in a pilot regional survey effort to locate aquatic invasive species on federal lands. Training and field protocols we developed with Oregon State University Sea Grant College Program personnel were used to survey for 23 aquatic plants and animals identified as threats to northwest watersheds. We are continuing to work with regional invasive species coordinators to develop a process for alerting agency managers when aquatic invasives occur on lands they manage, so appropriate control and eradication efforts can be made (Andersen and Lanigan 2009). 


\section{Support to Local Units}

Forest plan revisions-Program personnel worked with specialists on the Okanogan-Wenatchee and Colville National Forests, the Forest Service (FS) Pacific Northwest Regional Office, and forests in the Blue Mountains (Umatilla, Malheur, and Wallowa-Whitman) to apply decision-support models in their forest plan revisions. The Aquatic and Riparian Effectiveness Monitoring Program (AREMP) watershed condition model is being used by these forests as part of the key watershed designation process and to evaluate the contribution of the FS.

Assessment of temperature problems-AREMP personnel initiated and provided a summary of hydrograph temperature data AREMP crews collected to Bureau of Land Management and FS regional water quality coordinators. These data will be shared with the Oregon Department of Environmental Quality and Washington Department of Ecology for assessment of temperature total maximum daily load.

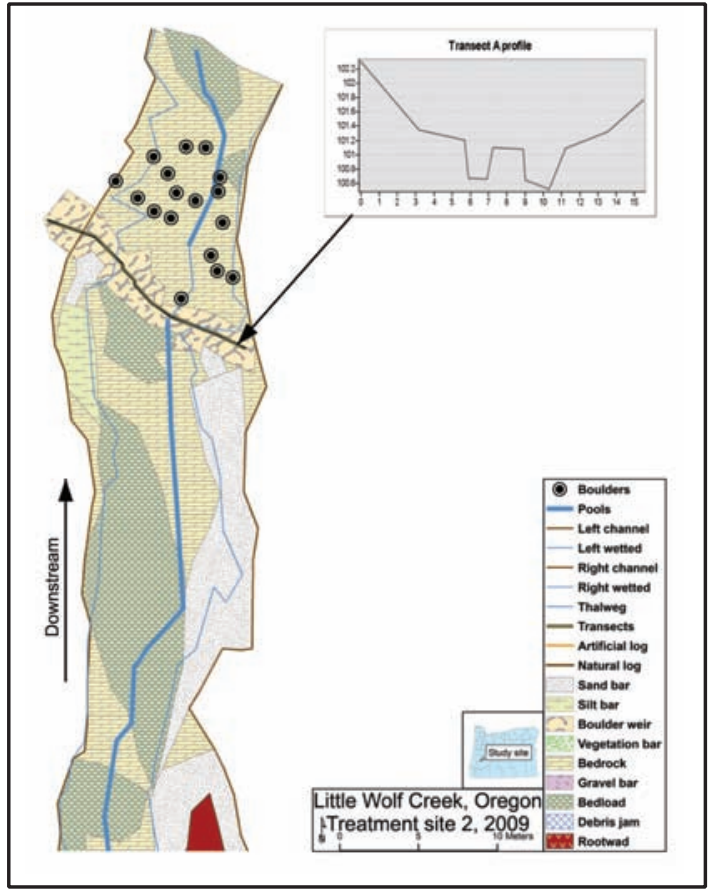

Restoration project survey support-Aquatic and Riparian Effectiveness Monitoring Program personnel, assisted the Fisheries and Hydrology staff of the Roseburg Bureau of Land Management district on a project to map existing channel configuration at the beginning of a restoration project so that changes could be measured through time. Six sites (in two watersheds) totaling approximately $6,000 \mathrm{ft}$ were intensively mapped to document the existing channel and habitat features. Mapped habitat features included different types of substrate bar classifications (distinguished from bed load material), wood (both natural and placed), exposed bedrock sheets, and information about the existing pools. The AREMP resurveyed the same sites after the project was in place to detect differences in substrate as the result of a winter flood.

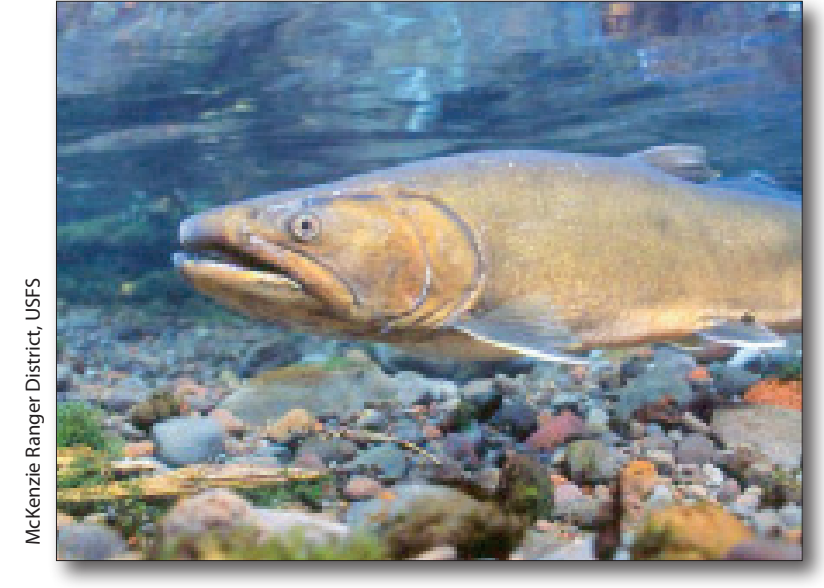

Bull trout reintroduction-The Mount Hood National Forest is working with the U.S. Fish and Wildlife Service, Oregon Department of Fish and Wildlife, and researchers from the U.S. Geological Survey to reintroduce bull trout into the Clackamas River. Aquatic and Riparian Effectiveness Monitoring Program personnel consulted on the project and built a decision-support model to document the decision process used to determine the suitability of an area for reintroduction and the likelihood of success. The model can be used for reintroduction of any species in any ecosystem. It evaluates data related to historical occupation of the species in the ecosystem, likelihood that the species is still present, natural recolonization potential, potential of habitat to support the reintroduction, threats, and impacts to donor stocks (Dunham and Gallo 2008). 


\section{Acknowledgments}

The Aquatic and Riparian Effectiveness Monitoring Program is an interagency effort resulting from the contributions of the USDA Forest Service (FS), USDI Bureau of Land Management (BLM), U.S. Environmental Protection Agency (EPA), National Oceanic and Atmospheric Administration (NOAA) Fisheries, U.S. Fish and Wildlife Service (USFWS), USDI National Park Service (NPS), California Indian Forestry and Fire Management Council, Northwest Indian Fisheries Commission, Intertribal Timber Council, and U.S. Army Corps of Engineers. Funding was provided by FS Pacific Northwest Region (R6) and Pacific Southwest Region (R5), BLM Oregon State Office, NOAA Fisheries, NPS, U.S. Geological Survey (USGS), USDA FS Pacific Northwest Research Station (PNW), and U.S. EPA.

Program support and direction was provided by Shawne Mohoric, Phil Mattson, Jon Martin, and Lisa Freedman (FS R6), Kim Titus and Nancy Molina (BLM), Tom Quigley (FS PNW), Dave Powers (EPA), Mike Crouse (NOAA), John Gabrielson (EPA), and Becky Gravenmier (FS PNW).

The program benefited greatly from contributions from Kirsten Gallo (NPS), Gordie Reeves and Kelly Burnett (PNW), Phil Larsen (EPA), and Brett Roper (FS-WO).

Phil Larsen (EPA), Tony Olsen (EPA), Jim Alegria (BLM) and Tom Kincaid (Dynamac Corp.) provided statistical advice.

This manuscript was much improved thanks to reviews by Ann Shlisky (FS), Al Doelker (BLM), Brett Roper (FSWO), Chester Novak (BLM), Gordie Reeves (PNW), Jim Alegria (BLM), Ken MacDonald (FS) and Shawne Mohoric (FS). Lynn Sullivan (PNW) provided a much appreciated editorial review.

Russ Chapman (BLM), Dan VanSlyke (BLM), John Schuyler (FS), Corrine Black (FS), Jack Sleeper (FS), and Gene Shull (FS) provided restoration project summaries.

Sean Gordon, Kirsten Gallo, Steve Lanigan, and Peter Eldred coordinated provincial watershed condition workshops. Participants included Jeff Dose, Umpqua National Forest; Marc Wilcox, Deschutes National Forest; Johann Hogovorst, Willamette National Forest; Becky Flitcroft, PNW; Bob Ruediger, Salem BLM; Ivars Steinbloom, Mt.
Hood National Forest; Ruth Tracy, Gifford Pinchot National Forest; Dave Fuller, BLM California State Office; Juan de la Fuente and Gregg Bousfield, Klamath National Forest; Christine Mai, Shasta Trinity National Forest; Don "Flick" Flickenger, NOAA; Robin Mowery, Sam Gygli, and Erica Helton, Mendocino National Forest; Julie Perrochet, Klamath National Forest; Angie Bell, Klamath National Forest; Scott Downie, California Department of Fish and Game; Joseph Furnish, R5; Cameron Thomas and Pierre Dawson, Wenatchee National Forest; Dick Miller, Cooperative Monitoring, Evaluation, and Research Committee; Bob Cusimono, Washington Department of Ecology; Kirk Krueger, Washington Department of Fish and Wildlife; Peter Kiffney, NOAA Fisheries; Bob Metzger, Robin Stoddard, and Bill Shelmerdine, Olympic National Forest; Al Doelker, BLM; Kami Ellingson, Siuslaw National Forest, Gordie Reeves and Kelly Burnett, PNW; Alan Herlihy, OSU/EPA; and Phil Kaufmann, EPA.

And finally, thanks to all the field crew members who collected the 2001-2009 inchannel data used in this report.

\section{Metric Equivalents}

\section{Metric Equivalents}

\begin{tabular}{lcl} 
When you know: & Multiply by: & To find: \\
\hline Inches (in) & 2.54 & Centimeters \\
Feet (ft) & 0.305 & Meters \\
Acres (ac) & 0.405 & Hectares \\
Yards (yd) & 0.914 & Meters \\
Miles (mi) & 1.609 & Kilometers \\
Square miles $\left(\mathrm{mi}^{2}\right)$ & 2.59 & Square kilometers \\
Trees per acre & 2.47 & Trees per hectare \\
Degrees Fahrenheit & $0.55(\mathrm{~F}-32)$ & Degrees Celsius
\end{tabular}

\section{English Equivalents}

\begin{tabular}{lll} 
When you know: & Multiply by: & To find: \\
\hline Millimeters (mm) & 0.0394 & Inches \\
Centimeters $(\mathrm{cm})$ & 0.394 & Inches \\
Meters $(\mathrm{m})$ & 3.28 & Feet \\
Kilometers $(\mathrm{km})$ & 0.621 & Miles \\
Hectares (ha) & 2.47 & Acres \\
Square kilometers $\left(\mathrm{km}^{2}\right)$ & 0.386 & Square miles \\
Trees per hectare & 0.405 & Trees per acre \\
$\begin{array}{l}\text { Degrees Celsius }(\mathrm{C}) \\
\text { Milligrams per liter }\end{array}$ & $1.8 \mathrm{C}+32$ & Degrees \\
$\quad$ & & Fahrenheit \\
(mg/L) & & Parts per Million
\end{tabular}




\section{References}

Al-Chokhachy, R.; Roper, B.B.; Archer, E.K. 2010.

Evaluating the status and trends of physical stream habitat in headwater streams within the interior Columbia River and upper Missouri River basins using an index approach. Transactions of the American Fisheries Society. 139(4): 1041-1059.

Alegria, J.; Hyzer, M.; Mulder, B.; Schnoes, B.; Tolle, T. 1995. Guidance for implementation monitoring for management of habitat for late-successional and oldgrowth related species within the range of the northern spotted owl. Draft. On file at: Regional Ecosystem Office, 333 SW First Avenue, Portland, OR 97208.

Andersen, H.; Lanigan, S.H. 2009. Aquatic and riparian invasive species survey. http://www. reo.gov/monitoring/ reports/watershed-reports-publications.shtml.

(October 25, 2010).

\section{Aquatic and Riparian Effectiveness Monitoring} Program [AREMP]. 2009. Field protocol manual: Aquatic and Riparian Monitoring Program. http://www. reo.gov/monitoring/reports/watershed/2009FieldProtocol Final.pdf. (January 10, 2010).

Bailey, R.G.; Avers, P.E.; King, T.; McNab, W.H., eds. 1994. Ecoregions and subregions of the United States [map 1:7,500,000]. With supplementary table of map unit descriptions by McNab, W.H.; Bailey, R.G., comps., eds. Washington, DC: U.S. Department of Agriculture, Forest Service.

Baker, D.; Ferguson, G.; Palmer, C.; Tolle, T. 2005. Northwest Forest Plan — the first 10 years (1994-2003): implementation monitoring, summary of regional interagency monitoring results. R6-RPM-TP-04-2005. Portland, OR: U.S. Department of Agriculture, Forest Service, Pacific Northwest Region. 24 p.

Benda, L.E.; Miller, D.J.; Dunne, T.; Reeves, G.H.; Agee, J.K. 1998. Dynamic landscape systems. In: Naiman, R.J.; Bilby, R.E., eds. River ecology and management: lessons from the Pacific coastal ecoregion. New York: Springer-Verlag: 261-288.
Blaustein, A.R.; Wake, D.B.; Sousa, W.P. 1994. Amphibian declines: judging stability, persistence, and susceptibility of populations to local and global extinctions. Conservation Biology. 8: 60-71.

Bryant, M.D.; Caouette, J.P.; Wright, B.E. 2004. Evaluating stream habitat survey data and statistical power using an example from southeast Alaska. North American Journal of Fisheries Management. 24: 1353-1362.

Bryce, S.A.; Omernick, J.; Larsen, D. 1999. Ecoregions: a geographic framework to guide risk characterization and ecosystem management. Environmental Practice. 1: $141-153$.

Burton, T.A. 2005. Fish and stream habitat risks from uncharacteristic wildfire: observations from 17 years of fire-related disturbances on the Boise National Forest, Idaho. Forest Ecology and Management. 211(1-2): 140-149.

Chan, S.; Anderson, P.; Cissel, J.; Lateen, L.; Thompson, C. 2004. Variable density management in riparian reserves: lessons learned from an operational study in managed forests of western Oregon, USA. Forest Snow and Landscape Research. 78(1/2): 151-172.

Charnley, S., tech. coord. 2006. Northwest Forest Plan - the first 10 years (1994-2003): socioeconomic monitoring results. Gen. Tech. Rep. PNW-GTR-649. Portland, OR: U.S. Department of Agriculture, Forest Service, Pacific Northwest Research Station. 6 vol.

Clinton, W.J.; Gore, A., Jr. 1993. The forest plan for a sustainable economy and a sustainable environment. In: Tuchmann, E.T.; Connaughton, K.P.; Freedman, L.E.; Moriwaki, C.B. 1996. The Northwest Forest Plan: a report to the President and Congress. Portland, OR: U.S. Department of Agriculture, Forest Service, Pacific Northwest Research Station. Appendix A.

Cohen, W.B.; Yang, Z.; Kennedy, R. 2010. Detecting trends in forest disturbance and recovery using yearly Landsat time series 2. TimeSync - tools for calibration and validation. Remote Sensing of Environment. 114(12): 2911-2924. 
Daigle, P. 2010. A summary of the environmental impacts of roads, management responses, and research gaps: literature review. British Columbia Journal of Ecosystems and Management. 10(3): 65-89.

Dale, V.H.; Joyce, L.A.; McNulty, S.; Neilson, R.P.; Ayres, M.P.; Flannigan, M.D.; Hanson, P.J.; Irland, L.C.; Lugo, A.E.; Peterson, C.J.; Simberloff, D.; Swanson, F.J.; Stocks, B.J.; Michael Wotton, B. 2001. Climate change and forest disturbances. BioScience. 51(9): 723-734.

Davis, R.J.; Dugger, K.M.; Mohoric, S.; Evers, L.; Aney, W.C. 2011. Northwest Forest Plan—the first 15 years (1994-2008): status and trends of northern spotted owl populations and habitats. Gen. Tech. Rep. PNWGTR-850. Portland, OR: U.S. Department of Agriculture, Forest Service, Pacific Northwest Research Station. $147 \mathrm{p}$.

Dunham, J.; Gallo, K. 2008. Assessing the feasibility of native fish reintroductions: a framework and example applied to bull trout in the Clackamas River, Oregon. Open-File Report 2008-1007. Reston, VA: U.S. Geological Survey. 23 p.

Dunham, J.B.; Young, M.K.; Gresswell, R.E.; Rieman, B.E. 2003. Effects of fire on fish populations: landscape perspectives on persistence of native fishes and nonnative fish invasion. Forest Ecology and Management. 178(1-2): 183-196.

Dwyer, W.L. 1994. Seattle Audubon Society, et al. v. James Lyons, Assistant Secretary of Agriculture, et al. Order on motions for summary judgment RE 1994 Forest Plan. Seattle, WA: U.S. District Court, Western District of Washington.

Erkert, T. 2003. Personal communication. Road engineer, USDA Forest Service, Pacific Northwest Region, 333 SW First Ave., Portland, OR 97204.

\section{Forest Ecosystem Management Assessment Team}

[FEMAT]. 1993. Forest ecosystem management: an ecological, economic, and social assessment. Portland, OR: U.S. Department of Agriculture; U.S. Department of the Interior [et al.]. [Irregular pagination].
Franklin, J.F.; Dyrness, C.T. 1973. Natural vegetation of Oregon and Washington. Gen. Tech. Rep. PNW-8. Portland, OR: U.S. Department of Agriculture, Forest Service, Pacific Northwest Research Station. 417 p.

Frissell, C.A.; Liss, W.J.; Greswell, R.E.; Nawa, R.K.; Ebersole, J.L. 1997. A resource in crisis: changing the measure of salmon management. In: Strouder, D.J.; Bisson, P.A.; Naiman, R.J., eds. Pacific salmon and their ecosystems. New York: Chapman and Hall: 411-444.

Gallo, K.; Lanigan, S.H.; Eldred, P.; Gordon, S.N.; Moyer, C. 2005. Northwest Forest Plan-the first 10 years (1994-2003): preliminary assessment of the condition of watersheds. Gen. Tech. Rep. PNW-GTR647. Portland, OR: U.S. Department of Agriculture, Forest Service, Pacific Northwest Research Station. 133 p.

Gilbert, G.K. 1917. Hydraulic-mining debris in the Sierra Nevada. Professional Paper 105. Washington, DC: U.S. Department of the Interior, Geological Survey. 154 p.

Goodman, L.; Brong, E.M.; Blackwell, J.A.; Poole, M. 2002 (4 October). Letter to USDA Forest Service forest supervisors and USDI Bureau of Land Management district managers and field managers. Recommended monitoring interview agenda. BLM Information Bulletin No. OR 2003 003. http://www.reo.gov/library/iac/20012003/122002/tribal\%20monitor\%20agenda.rtf. (January 10, 2011).

Gordon, S.N.; Gallo, K. 2011. Structuring expert input for a knowledge-based approach to watershed condition assessment for the Northwest Forest Plan, USA. Environmental Monitoring and Assessment. 172(1): 643-661.

Grant, G.E.; Lewis, S.L.; Swanson, F.J.; Cissel, J.H.; Mcdonnell, J.J . 2008. Effects of forest practices on peak flows and consequent channel response: a stateof-science report for western Oregon and Washington. Gen. Tech. Rep. PNW-GTR-760. Portland, OR: U.S. Department of Agriculture, Forest Service, Pacific Northwest Research Station. 76 p. 
Gucinski, H.; Furniss, M.J.; Ziemer, R.R.; Brookes, M.H., eds. 2001. Forest roads: a synthesis of scientific information. Gen. Tech. Rep. PNW-GTR-509. Portland, OR: U.S. Department of Agriculture, Forest Service, Pacific Northwest Research Station. 103 p.

Haynes, R.W.; Bormann, B.T.; Lee, D.C.; Martin, J.R., tech. eds. 2006. Northwest Forest Plan-the first 10 years (1994-2003): synthesis of monitoring and research results. Gen. Tech. Rep. PNW-GTR-651. Portland, OR: U.S. Department of Agriculture, Forest Service, Pacific Northwest Research Station. 292 p.

Healey, S.; Cohen, W.; Spies, T.; Moeur, M.; Pflugmacher, D.; Whitley, M.; Lefsky, M. 2008. The relative impact of harvest and fire upon landscape-level dynamics of older forests: lessons from the Northwest Forest Plan. Ecosystems. 11(7): 1106-1119.

Hemstrom, M.; Spies, T.; Palmer, C.; Kiester, R.; Teply, J.; McDonald, P.; Warbington, R. 1998. Late-successional and old-growth forest effectiveness monitoring plan for the Northwest Forest Plan. Gen. Tech. Rep. PNW-GTR-438. Portland, OR: U.S. Department of Agriculture, Forest Service, Pacific Northwest Research Station. 37 p.

Henderson, J. 2009. Modeled potential natural vegetation zones of Washington and Oregon. http:/ecoshare.info/ category/gis-data-vegzones/. (January, 2010).

Herlihy, A. 2009. Development of an index of biotic integrity for forested Pacific Northwest stream macroinvertebrates. 17 p. Unpublished report. On file with: AREMP/RPM, USDA Forest Service Pacific Northwest Region, 333 SW First Ave, Portland, OR 97204.

Hilsenhoff, W.L. 1988. Rapid field assessment of organic pollution with a family level biotic index. The Journal of the North American Benthological Society. 7: 65-68.

Hubler, S. 2008. PREDATOR: development and use of RIVPACS-type macroinvertebrate models to assess the biotic condition of wadeable Oregon streams. Hillsboro, OR: Oregon Department of Environmental Quality, Laboratory and Environmental Assessment Division. 51 p.
Hubler, S.; Miller, S.; Merrick, L.; Leferink, R.; Borisenko, A. 2009. High level indicators of Oregon's forested streams. Hillsboro, OR: Oregon Department of Environmental Quality, Laboratory and Environmental Assessment Division. 76 p.

Huff, M.H.; Raphael, M.G.; Miller, S.L.; Nelson, S.K.; Baldwin, J., tech. coords. 2006. Northwest Forest Plan - the first 10 years (1994-2003): status and trends of populations and nesting habitat for the marbled murrelet. Gen. Tech. Rep. PNW-GTR-650. Portland, OR: U.S. Department of Agriculture, Forest Service, Pacific Northwest Research Station. 149 p.

Hughes, R.M.; Howlin, S.; Kaufmann, P.R. 2004. A biointegrity index (IBI) for coldwater streams of western Oregon and Washington. Transactions of the American Fisheries Society. 133(6): 1497-1515.

Karr, J.R.; Chu, E.W. 1999. Restoring life in running waters: better biological monitoring. Washington, DC: Island Press. 206 p.

Kaufmann, P.R.; Hughes, R.M. 2006. Geomorphic and anthropogenic influences on fish and amphibians in Pacific Northwest coastal streams. In: Hughes, R.M.; Wang, L.; Seelbach, P.W., eds. American Fisheries Society symposium: landscape influences on stream habitats and biological assemblages. Bethesda, MD: American Fisheries Society: 429-455.

Keeney, R.L.; Raiffa, H. 1976. Decisions with multiple objectives: preferences and value tradeoffs. New York: Wiley. 569 p.

Kennedy, R.E.; Cohen, W.B.; Schroeder, T.A. 2007. Trajectory-based change detection for automated characterization of forest disturbance dynamics. Remote Sensing of Environment. 110: 370-386.

Kennedy, R.E.; Yang, Z.; Cohen, W.B. 2010. Detecting trends in forest disturbance and recovery using yearly Landsat time series 1. LandTrendr-temporal segmentation algorithms. Remote Sensing of Environment. 114(12): 2897-2910. 
Knighton, A.D. 1999. Downstream variation in stream power. Geomorphology. 29: 293-306.

\section{Landscape Ecology, Modeling, Mapping and} Analysis Program [LEMMA]. 2010. GNN accuracy assessment report. Portland, OR: U.S. Department of Agriculture, Forest Service, PNW Research Station, Landscape Ecology, Modeling, Mapping and Analysis Program. http://www.fsl.orst.edu/ lemma/main.php?project $=$ common\&id $=$ mr\&model region=200\&ref=nwfp. $($ March 20, 2011).

Lanigan, S.H.; Moyer, C.; Gallo, K.; Gruendike, P. 2007. Aquatic and Riparian Effectiveness Monitoring Program. Interagency monitoring program-Northwest Forest Plan Area. Annual technical report. On file with: U.S. Department of Agriculture, Forest Service, Resource Planning and Monitoring, Pacific Northwest Region, 333 SW First Ave., Portland, OR 97208.

Lee, D.C.; Sedell, J.R.; Rieman, B.E.; Thurow, R.F.; Williams, J.E. 1997. Broadscale assessment of aquatic species and habitats. An assessment of ecosystem components in the interior Columbia Basin and portions of the Klamath and Great Basins. Gen. Tech. Rep. PNW-GTR-405. Portland, OR: U.S. Department of Agriculture, Forest Service, Pacific Northwest Research Station. Vol. 3, chapter 4.

Lint, J., tech. coord. 2005. Northwest Forest Plan-the first 10 years (1994-2003): status and trends of northern spotted owl populations and habitat. Gen. Tech. Rep. PNW-GTR-648. Portland, OR: U.S. Department of Agriculture, Forest Service, Pacific Northwest Research Station. 176 p.

Lint, J.; Noon, B.; Anthony, R.; Forsman, E.; Raphael, M.; Collopy, M.; Starkey, E. 1999. Northern spotted owl effectiveness monitoring plan for the Northwest Forest Plan. Gen. Tech. Rep. PNW-GTR-440. Portland, OR: U.S. Department of Agriculture, Forest Service, Pacific Northwest Research Station. 43 p.
Madej, M.A.; Ozaki, V. 1996. Channel response to sediment wave propagation and movement, Redwood Creek, California, USA. Earth Surface Processes and Landforms. 21: 911-927.

Madsen, S.; Evans, D.; Hamer, T.; Henson, P.; Miller, S.; Nelson, S.K.; Roby, D.; Stapanian, M. 1999. Marbled murrelet effectiveness monitoring plan for the Northwest Forest Plan. Gen. Tech. Rep. PNW-GTR-439. Portland, OR: U.S. Department of Agriculture, Forest Service, Pacific Northwest Research Station. 51 p.

Maindonald, J.; Braun, J. 2003. Data analysis and graphics using R: an example-based approach. New York: Cambridge University Press. 362 p.

Merritt, R.W.; Cummins, K.W., eds. 1996. An introduction to the aquatic insects of North America. Dubuque, IA: Kendall/Hunt Publishing Company. 862 p.

Miller, D.J. 2003. Programs for DEM analysis. In: Landscape dynamics and forest management. Gen. Tech. Rep. RMRS-GTR-101. [CD]. Fort Collins, CO: U.S. Department of Agriculture, Forest Service, Rocky Mountain Research Station.

Miller, D. 2006. Landslides in watershed condition assessments. 17 p. Unpublished report. On file with: U.S. Department of Agriculture, Forest Service, Pacific Northwest Region, RPM/AREMP, 333 SW First Ave, Portland, OR 97204.

Miller, D.J.; Burnett, K.M. 2007. Effects of forest cover, topography, and sampling extent on the measured density of shallow, translational landslides. Water Resources Research. 43: W03433.

Miller, D.J.; Burnett, K.M. 2008. Probabilistic model of debris-flow delivery to stream channels, demonstrated for the Coast Range of Oregon, USA. Geomorphology. 94: 184-205. 
Moeur, M.; Ohmann, J.L.; Kennedy, R.E.; Cohen, W.B.; Matthew, J. Gregory; Yang, Z.; Roberts, H.M.; Spies, T.A.; Fiorella, M. 2011. Northwest Forest Plan - the first 15 years (1994-2008): status and trends of late-successional and old-growth forests. Gen. Tech. Rep. PNW-GTR-853. Portland, OR: U.S. Department of Agriculture, Forest Service, Pacific Northwest Research Station. 48 p.

Moeur, M.; Spies, T.A.; Hemstrom, M.; Martin, J.R.; Alegria, J.; Browning, J.; Cissel, J.; Cohen, W.B.; Demeo, T.E.; Healey, S.; Warbington, R. 2005. Northwest Forest Plan — the first 10 years (1994-2003): status and trend of late-successional and old-growth forest. Gen. Tech. Rep. PNW-GTR-646. Portland, OR: U.S. Department of Agriculture, Forest Service, Pacific Northwest Research Station. 142 p.

Montgomery, D.R.; Schmidt, K.M.; Greenberg, H.M.; Dietrich, W.E. 2000. Forest clearing and regional landsliding. Geology. 28: 311-314.

Moore, K.; Jones, K.; Dambacher, J. 1999. Methods for stream habitat surveys. Corvallis, OR: Aquatic Habitat Inventory Project, Natural Production Program, Oregon Department of Fish and Wildlife. 59 p.

Moyer, C. 2010. Results of the Aquatic and Riparian Effectiveness Monitoring Program quality assurance program 2001-2008. Draft on file with: U.S. Department of Agriculture, Forest Service, Pacific Northwest Region, Resource Planning and Monitoring, 333 SW First Ave., Portland, OR 97208.

\section{Mulder, B.; Alegria, J.; Czaplewski, R.; Ringold, P.;}

Tolle, T. 1995. Effectiveness monitoring: an interagency program for the Northwest Forest Plan with an emphasis on late-successional forest, northern spotted owl, marbled murrelet, survey and manage, and riparian and aquatic. Portland, OR: Research and Monitoring Committee, Regional Ecosystem Office. 51 p.
Mulder, B.; Noon, B.; Spies, T.; Raphael, M.G., tech. coords. Palmer, C.J.; Olsen, A.R.; Reeves, G.H.; Welsh, H.H. 1999. The strategy and design of the effectiveness monitoring program for the Northwest Forest Plan. Gen. Tech. Rep. PNW-GTR-437. Portland, OR: U.S. Department of Agriculture, Forest Service, Pacific Northwest Research Station. 138 p.

Mulvey, M.; Leferink, R.; Borisenko, A. 2009. Willamette basin rivers and streams assessment. Hillsboro, OR: Oregon Department of Environmental Quality, Laboratory and Environmental Assessment Division. 68 p.

Naiman, R.J.; Beechie, T.J.; Benda, L.E.; Berg, D.R.; Bisson, P.A.; MacDonald, L.H.; O'Connor, M.D.; Olson, P.L.; Steel, E.A. 1992. Fundamental elements of healthy watersheds in the Pacific Northwest coastal ecoregion. In: Naiman, R.J., ed. Watershed management: balancing sustainability and environmental change. New York: Springer-Verlag: 127-188.

Noon, B.R.; Raphael, M.G.; Spies, T.A. 1999. Conceptual basis for designing an effectiveness monitoring program. In: Mulder, B.S.; Noon, B.R.; Spies, T.A.; Raphael, M.G.; Palmer, C.J.; Olsen, A.R.; Reeves, G.H.; Welsh, H.H., tech. coords. The strategy and design of the effectiveness monitoring program for the Northwest Forest Plan.

Gen. Tech. Rep. PNW-GTR-437. Portland, OR: U.S. Department of Agriculture, Forest Service, Pacific Northwest Research Station: 17-36.

Ohmann, J.L.; Gregory, M.J. 2002. Predictive mapping of forest composition and structure with direct gradient analysis and nearest-neighbor imputation in coastal Oregon, USA. Canadian Journal of Forest Research. 32: 725-741.

Ohmann, J.L.; Gregory, M.J.; Spies, T.A. 2007. Influence of environment, disturbance, and ownership on forest vegetation of coastal Oregon. Ecological Applications. 17(1): 18-33. 
Olson, D.H.; Anderson, P.D.; Frissell, C.A.; Welsh, H.H.; Bradford, D.F. 2007. Biodiversity management approaches for stream-riparian areas: perspectives for Pacific Northwest headwater forests, microclimates, and amphibians. Forest Ecology and Management. 246: 81-107.

Oregon Department of Environmental Quality. 2004. Oregon's 2004 water quality assessment section 305(b) report. Hillsboro, OR: Water Quality Division. 55 p.

Oreskes, N.; Shrader-Frechette, K.; Belitz, K. 1994. Verification, validation, and the confirmation of numerical models in the earth sciences. Science. 263: 641-646.

Pabst, R.J.; Spies, T.A. 1999. Structure and composition of unmanaged riparian forests in the coastal mountains of Oregon, U.S.A. Canadian Journal of Forest Resources. 29: $1557-1573$.

Peck, D.V.; Lazorchak, J.M.; Klemm, D.J., eds. 1999. Environmental monitoring and assessment program - surface waters: western pilot study field operations manual for wadeable streams. Unpublished draft. Washington, DC: U.S. Environmental Protection Agency. 226 p.

Pierce, K.B., Jr.; Ohmann, J.L.; Wimberly, M.C.; Gregory, M.J.; Fried, J.S. 2009. Mapping wildland fuels and forest structure for land management: a comparison of nearest-neighbor imputation and other methods. Canadian Journal of Forest Research. 39(10): 1901-1916.

Reeves, G.H.; Benda, L.E.; Burnett, K.M.; Bisson, P.A.; Sedell, J.R. 1995. A disturbance-based ecosystem approach to maintaining and restoring freshwater habitats of evolutionarily significant units of anadromous salmonids in the Pacific Northwest. In: Nielson, J.L.; Powers, D.A., eds. Evolution and the aquatic ecosystem: defining unique units in population conservation. Bethesda, MD: American Fisheries Society: 334-349.
Reeves, G.H.; Duncan, S. 2009. Ecological history vs. social expectations: managing aquatic ecosystems. Ecology and Society. 14(2): Article 8.

Reeves, G.H.; Hohler, D.B.; Larsen, D.P.; Busch, D.E.; Kratz, K.; Reynolds, K.; Stein, K.F.; Atzet, T.; Hays, P.; Tehan, M. 2004. Aquatic and riparian effectiveness monitoring plan for the Northwest Forest Plan. Gen. Tech. Rep. PNW-GTR-577. Portland, OR: U.S. Department of Agriculture, Forest Service, Pacific Northwest Research Station. 70 p.

Refsgaard, J.C.; van der Sluijs, J.P.; Højberg, A.L.; Vanrolleghem, P.A. 2007. Uncertainty in the environmental modelling process - a framework and guidance. Environmental Modelling and Software. 22(11): 1543-1556.

\section{Regional Interagency Executive Committee [RIEC].} 2006. Regional Interagency Executive Committee meeting notes for March 17, 2006. http:/www.reo.gov/ library/riec/2006/2192RIECnotes03172006revised.htm. (Oct. 21, 2010).

Reid, L.M. 1993. Research and cumulative watershed effects. Gen. Tech. Rep. PSW-GTR-141. Albany, CA: U.S. Department of Agriculture, Forest Service, Pacific Southwest Research Station. 118 p.

Reid, L.M.; Dunne T. 1984. Sediment production from forest road surfaces. Water Resources Research. 20(11): 1753-1761.

Reid, L.M.; Furniss, M.J. 1998. On the use of regional channel-based indicators for monitoring. Arcata, CA: USDA Forest Service, Redwood Sciences Laboratory. http://www.krisweb.com/kriskootenai/krisdb/html/ krisweb/biblio/reid/chbl4e 1.htm. (October 20, 2010).

Rieman, B.E.; Hessburg, P.F.; Lee, D.C.; Thurow, R.F.; Sedell, J.R. 2000. Toward an integrated classification of ecosystems: defining opportunities for managing fish and forest health. Environmental Management. 25(4): 425-444. 
Rieman, B.E.; Peterson, J.T.; Clayton, J.; Howell, P.; Thurow, R.; Thompson, W.; Lee, D. 2001. Evaluation of potential effects of federal land management alternatives on trends of salmonids and their habitats in the interior Columbia River basin. Forest Ecology and Management. 153(1-3): 43-62.

Roper, B.B.; Buffington, J.M.; Bennett, S.; Lanigan, S.H.; Archer, E.; Downie, S.T.; Faustini, J.; Hillman, T.W.; Hubler, S.; Jones, K.; Jordan, C.; Kaufmann, P.R.; Merritt, G.; Moyer, C.; Pleus, A. 2010. A comparison of the performance and compatibility of protocols used by seven monitoring groups to measure stream habitat in the Pacific Northwest. North American Journal of Fisheries Management. 30(2): 565-587.

Sedell, J.R.; Lee, D.C.; Rieman, B.E.; Thurow, R.F.; Williams, J.E. 1997. Effects of propsed alternatives on aquatic habitats and native fishes. In: Quigley, T.M.; Lee, K.M.; Arbelbide, S.J., eds. Evaluation of EIS alterantives by the science integration team. Portland, OR: U.S. Department of Agriculture, Forest Service, Pacific Northwest Research Station: 435-535.

Sheskin, D.J. 2004. Handbook of parametric and nonparametric statistical procedures. $3^{\text {rd }}$ ed. Boca Raton, FL: Chapman \& Hall/CRC. 706 p.

Standford, J.A. 1998. Rivers in the landscape: introduction to the special issue on riparian and groundwater ecology. Freshwater Biology. 40: 402-406.

Stevens, D.L., Jr.; Olsen, A.R. 2003. Variance estimation for spatially balanced samples of environmental resources. Environmetrics. 14: 593-610.

Stevens, D.L., Jr.; Olsen, A.R. 2004. Spatially-balanced sampling of natural resources. Journal of the American Statistical Association. 99: 262-278.

Stewart, C.; Martine, K., tech. eds. 2006. Northwest Forest Plan — the first 10 years (1994-2003): effectiveness of the federal-tribal relationship. Tech. Paper R6-RPM-TP-02-2006. Portland, OR: U.S. Department of Agriculture, Forest Service, Pacific Northwest Region. 51 p.
Swanson, F.J.; Dyrness, C.T. 1975. Impact of clear-cutting and road construction on soil erosion by landslides in the western Cascade Range, Oregon. Geology. 3(7): 393-396.

Tidwell, T. 2010. An all-lands approach to conservation. Speech to the Western States Land Commissioners Association, winter 2010 conference. Little Rock, AR. January 13, 2010. http://www.fs.fed.us/news/2010/ speeches/01/conservation.shtml. (February 21, 2011).

Trimble, S.W. 1983. A sediment budget for Coon Creek basin in the driftless area, Wisconsin, 1853-1977. American Journal of Science. 283: 454-474.

Tuchmann, E.T.; Connaughton, K.P.; Freedman, L.E.; Moriwaki, C.B. 1996. The Northwest Forest Plan: a report to the President and Congress. Portland, OR: U.S. Department of Agriculture, Forest Service, Pacific Northwest Research Station. 253 p.

Turban, E.; Aronson, J.E. 2001. Decision support systems and intelligent systems. Upper Saddle River, NJ: Prentice Hall. 867 p.

\section{U.S. Department of Agriculture, Forest Service [USDA} FS]. 1995. Inland native fish strategy environmental assessment decision notice and finding of no significant impact: interim strategies for managing fish-producing watersheds in eastern Oregon and Washington, Idaho, western Montana, and portions of Nevada [INFISH]. [Place of publication unknown]: Intermountain, Northern, and Pacific Northwest Regions. 39 p.

\section{U.S. Department of Agriculture, Forest Service [USDA} FS]. 1998. Stream condition inventory guidebook. Version 4.0. [Place of publication unknown]: Pacific Southwest Region. 57 p.

\section{U.S. Department of Agriculture, Forest Service [USDA} FS]. 2008. Aquatic and Riparian Conservation Strategy. Portland, OR: Pacific Northwest Region. 48 p. http:// www.fs.fed.us/r6/fish/documents/Final-ARCS-081308. doc. (June 10, 2011). 


\section{U.S. Department of Agriculture, Forest Service}

[USDA FS]. 2010a. FY 2009 legacy roads and trails, accomplishment report. Portland, OR: Pacific Northwest Region. 20 p.

\section{U.S. Department of Agriculture, Forest Service [USDA}

FS]. 2010b. Forest Service watershed condition classification technical guide. Washington, DC: U.S. Department of Agriculture, Forest Service. 24 p. http:// www.fs.fed.us/publications/watershed/watershed classification_guide.pdf. (June 10, 2011).

\section{U.S. Department of Agriculture, Forest Service;}

U.S. Department of the Interior, Bureau of Land Management [USDA and USDI]. 1994. Record of decision for amendments to Forest Service and Bureau of Land Management planning documents in the range of the northern spotted owl and standards and guidelines for management of habitat for late-successional and oldgrowth forest related species in the range of the northern spotted owl. [Place of publication unknown]. 74 p. [plus Attachment A: standards and guidelines].

\section{U.S. Department of Agriculture, Forest Service;}

U.S. Department of the Interior, Bureau of Land Management [USDA and USDI]. 1995. Decision notice/ decision record, FONSI, environmental assessment, and appendices for the implementation of interim strategies for managing anadromous fish-producing watersheds in eastern Oregon and Washington, Idaho, and portions of California [PACFISH]. [Place of publication unknown]. $305 \mathrm{p}$.

\section{U.S. Department of Agriculture Forest Service;} U.S. Department of the Interior, Bureau of Land Management [USDA and USDI]. 2003. Final supplemental environmental impact statement: clarification of language in the 1994 Record of Decision for the Northwest Forest Plan national forests and Bureau of Land Management districts within the range of the northern spotted owl. Proposal to amend wording about the aquatic conservation strategy. Portland, OR. http:// www.reo.gov/library/acs/. (Oct. 21, 2010).

van Wagtendonk, J.W.; Root, R.R.; Key, C.H. 2004. Comparison of AVIRIS and Landsat ETM+ detection capabilities for burn severity. Remote Sensing of Environment. 92: 397-408.

Whittier, T.R.; Hughes, R.M.; Lomnicky, G.A.; Peck D.V. 2007. Fish and amphibian tolerance values and an assemblage tolerance index for streams and rivers in the western USA. Transactions of the American Fisheries Society. 136: 254-271. 


\section{Appendix 1: Objectives of the Aquatic Conservation Strategy}

The Northwest Forest Plan aquatic conservation strategy (USDA and USDI 1994: B-11) states that the Forest Service and Bureau of Land Management-administered lands within the range of the northern spotted owl (Strix occidentalis caurina) will be managed to:

- Maintain and restore the distribution, diversity, and complexity of watershed and landscape-scale features to ensure protection of the aquatic systems to which species, populations, and communities are uniquely adapted.

- Maintain and restore spatial and temporal connectivity within and between watersheds. Lateral, longitudinal, and drainage network connections include flood plains, wetlands, upslope areas, headwater tributaries, and intact refugia. These network connections must provide chemically and physically unobstructed routes to areas critical to fulfilling life history requirements of aquatic and riparian-dependent species.

- Maintain and restore the physical integrity of the aquatic system, including shorelines, banks, and bottom configurations.

- Maintain and restore water quality necessary to support healthy riparian, aquatic, and wetland ecosystems. Water quality must remain within the range that maintains the biological, physical, and chemical integrity of the system and benefits survival, growth, reproduction, and migration of individuals composing aquatic and riparian communities.
- Maintain and restore the sediment regime under which aquatic ecosystems evolved. Elements of the sediment regime include the timing, volume, rate, and character of sediment input, storage, and transport.

- Maintain and restore instream flows sufficient to create and sustain riparian, aquatic, and wetland habitats and to retain patterns of sediment, nutrient, and wood routing. The timing, magnitude, duration, and spatial distribution of peak, high, and low flows must be protected.

- Maintain and restore the timing, variability, and duration of flood-plain inundation and water table elevation in meadows and wetlands.

- Maintain and restore the species composition and structural diversity of plant communities in riparian areas and wetlands to provide adequate summer and winter thermal regulation, nutrient filtering, appropriate rates of surface erosion, bank erosion, and channel migration and to supply amounts and distributions of coarse woody debris sufficient to sustain physical complexity and stability.

- Maintain and restore habitat to support well-distributed populations of native plant, invertebrate, and vertebrate riparian-dependent species. 
GENERAL TECHNICAL REPORT PNW-GTR-856 


\section{Appendix 2: Project-Scale Restoration Efforts}

Seven local unit watershed restoration projects are highlighted from throughout the Northwest Forest Plan area. Some of the projects may have had immediate effects, such as opening up habitat to fish by replacing poorly designed culverts that previously blocked fish passage. But most restoration projects should be viewed as a critical first step in restoring natural watershed processes. 


\section{Cummins and Tenmile Watershed, Siuslaw National Forest, Oregon}

\section{Land acquisition and conservation easement tools are being used for restoring watersheds and recovering \\ species-Land acquisitions and conservation} easements are a major component of the restoration strategy in the Cummins/Tenmile watershed. Although most of the watershed is managed by the Forest Service, a large number of the major fish-bearing streams were located on private land prior to implementation of the land acquisition program.

Working with the Trust for Public Lands and local landowners, the Forest Service, Audubon Society of Portland, and The Nature Conservancy have acquired 1,900 ac and $10 \mathrm{mi}$ of critical habitat for threatened coho salmon in the Cummins/Tenmile watershed. In addition, the Tenmile Conservation Program worked with the McKenzie River Trust and local landowners to complete a 500 -ac conservation easement package to protect habitat for multiple species dependent on older forest habitat, including an additional 2 $\mathrm{mi}$ of coho salmon streams. Funding for the land acquisitions and easements came from the Federal Land and Water Conservation Fund, Landowner Incentive Program; Oregon Watershed Enhancement Board; and Oregon State Parks.

The restoration strategy was recently extended into the Pacific Ocean adjacent to the Cummins/ Tenmile watershed with a proposal to make a marine reserve in Oregon's state waters. These ongoing efforts combined with the aquatic conservation strategy in the Northwest Forest Plan have protected ecologically significant habitat, and they have enabled implementation of a variety of restoration activities that work with natural processes to recover depleted and federally Endangered Species Act listed species.

Contact Jack Sleeper (jsleeper@fs.fed.us) for more information.

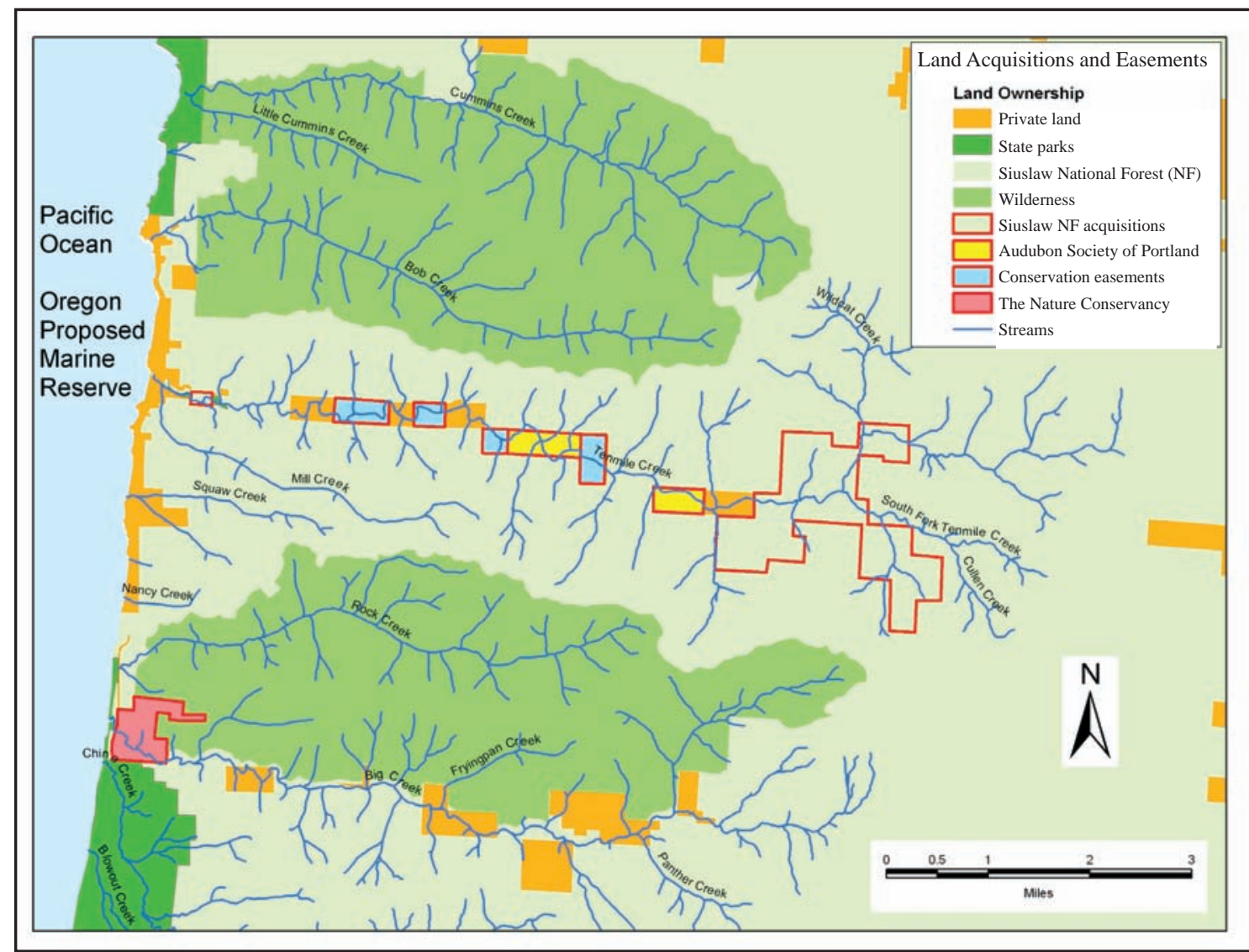




\section{Elkhorn Creek Watershed, Salem Bureau of Land Management District, Oregon}

\section{Natural disturbance and past management affected coho habitat-The Elkhorn Creek} watershed is the most productive salmon habitat in the Trask River drainage. However, these streams were lacking large wood partly because of a series of largescale fires collectively called the Tillamook Burn and the extensive salvage logging that followed in the late 1940s through the early 1960s. Many roads and skid trails were built for postfire logging that are still affecting hydrologic processes. Historical removal of large wood from streams also occurred on public and privately managed lands. The lack of large wood negatively affected many inchannel processes including creation of complex pools, sediment and nutrient storage, spawning gravel sorting and retention, and providing cover for fish during high winter streamflows. Preproject rapid bio-assessment (RBA) surveys had shown Elkhorn and Cruiser Creeks to have high summer rearing capacity but minimal capability to support juvenile salmonids during high winter flow regimes.

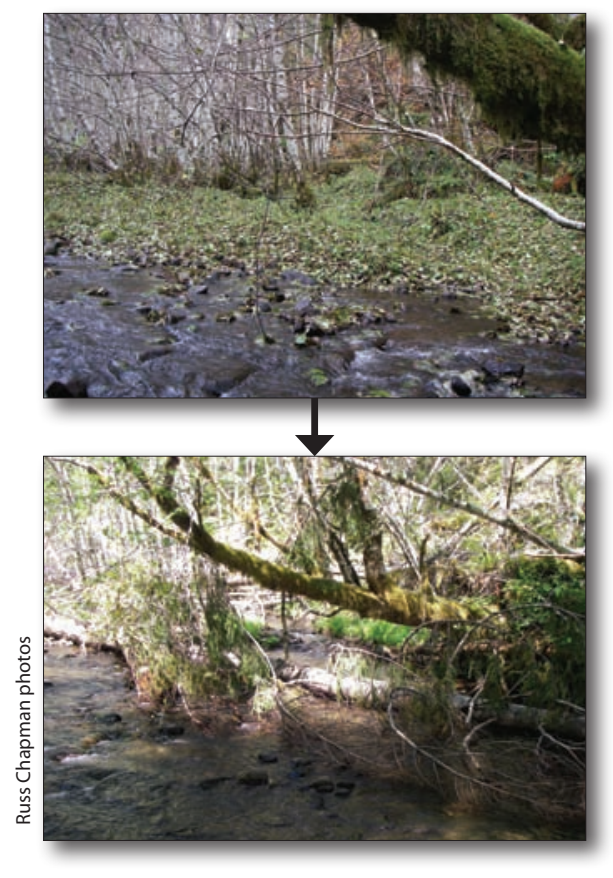

A-An old remnant channel (top photo) became active again with multiple braided flood-plain channels after wood was added (bottom photo).

\section{A diverse partnership is restoring the} watershed-Salem District Bureau of Land Management, Oregon Dept of Fish and Wildlife, Oregon Department of Forestry, U.S. Fish and Wildlife Service, Tillamook Estuaries Partnership, Tillamook Bay Watershed Council, Weyerhaeuser LLC, Tillamook Futures Council, Nestucca Valley High School, and Bio-Surveys LLC have all worked together to enhance summer rearing and overwinter habitat on a watershed scale by placing large wood and boulder structures in Cruiser Creek and Elkhorn Creek to increase stream complexity, improve pool/ riffle ratios, and retain more of the quality spawning gravels that were being washed out of these streams. Other restoration actions included riparian plantings, replacing culverts, and obliterating and decommissioning riparian roads.

Fish numbers are up!- The treated reaches have shown dramatic increases in complex pools, and retention of spawning gravels and increased stream complexity. The RBA surveys show that coho overwinter survival rates have gone from about 5 percent preproject for both Cruiser and Elkhorn Creeks, to a postproject high of 17.4 percent in Cruiser and 25 percent in Elkhorn! This represents significant production increases for Oregon Coast coho from these watersheds.
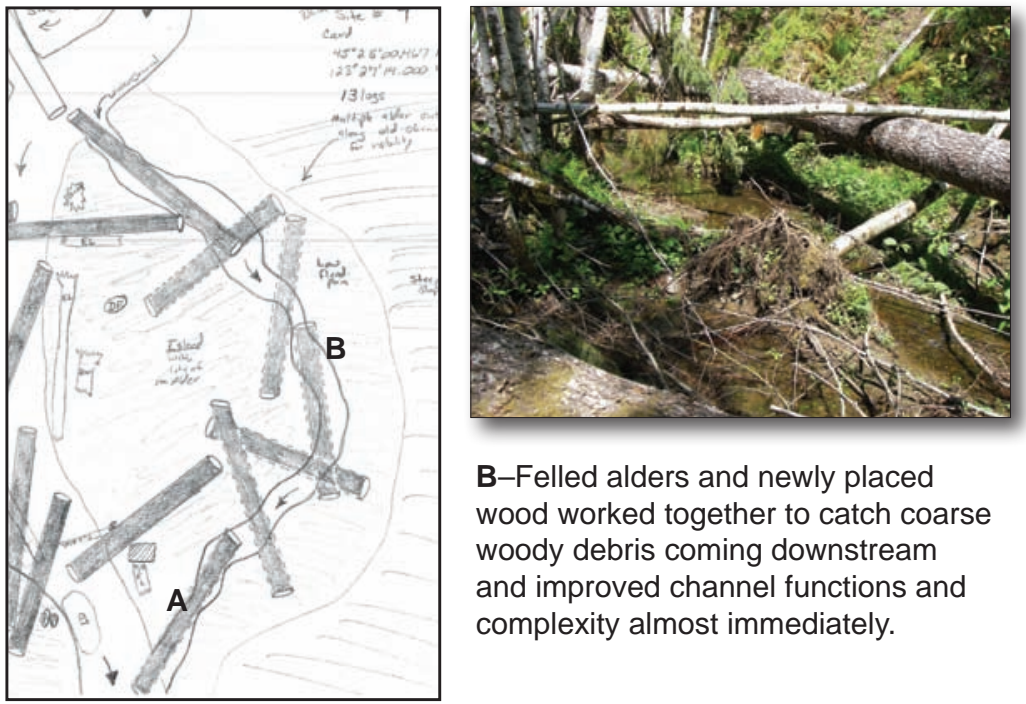

B-Felled alders and newly placed wood worked together to catch coarse woody debris coming downstream and improved channel functions and complexity almost immediately.

Contact Russ Chapman (rchapman@blm.gov) for more information. 


\section{Legacy Roads and Trails Program}

\section{Upgrading and maintaining needed forest roads and decommissioning unnecessary ones can maximize the many benefits they provide, while minimizing their risks to water quality and aquatic ecosystems-}

Roads provide many benefits to society, including access for recreation, forest management, fire management, and monitoring and research. Some road systems, however, can adversely impact water quality and the health of aquatic ecosystems in a variety of ways. These include increasing peak flows, erosion, and stream temperatures; constricting streams and decreasing their interactions with flood plains; and fragmenting habitats. Because the national forest transportation system is so vast, was largely built using older standards, and contains many aging components, road restoration has been a major part of implementing the Northwest Forest Plan aquatic conservation strategy and similar aquatic strategies on federal forests throughout the Pacific Northwest. Restoration treatments generally include relocating roads away from streams, riparian areas, and unstable terrains; upgrading and improving road drainage systems; replacing road-stream crossings to provide passage for fish and other biota; "storing" roads that are not currently being used but will be needed in the future; and decommissioning unneeded roads.

In recent years, Congress has placed greater emphasis on these activities and provided additional sources of funding. For example, between fiscal year (FY) 2008 and FY 2010, the U.S. Forest Service (FS) Pacific Northwest Region was allocated almost \$40 million in Legacy Roads and Trails funding to correct or reduce road and trail impacts and risks to watershed and aquatic resources. Given the importance of these activities

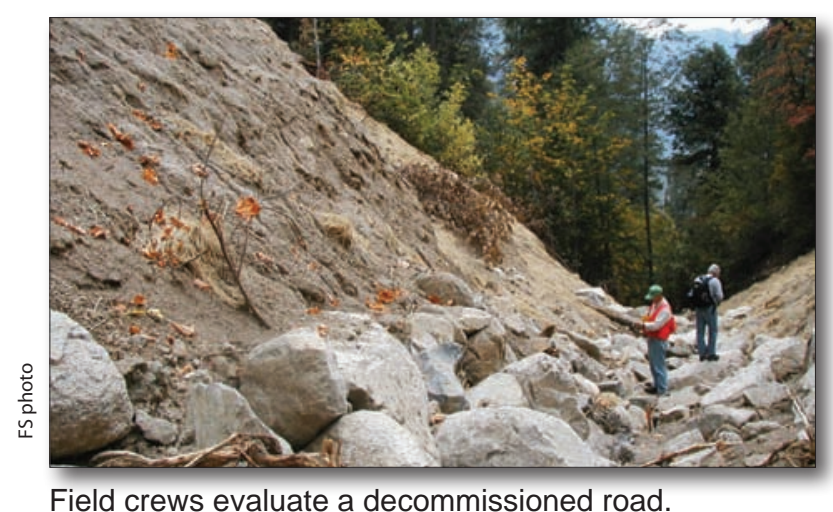

in protecting and restoring watersheds, the FS is implementing two regional-scale studies to evaluate their effectiveness, which are described below. These finer scale, more intensive effectiveness monitoring studies are intended to complement the coarser, broader scale status and trend monitoring being conducted by the Aquatic and Riparian Effectivness Monitoring Program.

\section{Hydrogeomorphic effectiveness}

monitoring - To evaluate the effectiveness of road treatments in reducing hydrologic and geomorphic impacts, the FS Rocky Mountain Research Station and Pacific Northwest Region are using detailed, field-based inventories and a suite of robust environmental models to develop and compare multiple road impact-risk metrics, before and after road treatments at treated and control sites (see photo). Each site also includes a final validation evaluation following a large storm event. To date, evaluations have been initiated or completed at 25 locales where road decommissioning, road storage, or road drainage improvements have been or will be implemented. Results from the one site where monitoring results have been fully analyzed indicate that some road treatments can significantly reduce road impacts and risks to aquatic ecosystems.

\section{Fish passage effectiveness monitoring-}

Since 2002, the Region has treated more than 200 crossings using the "stream simulation" technique. This is a design process intended to ensure that conditions within a culvert or bridge mimic the natural upstream and downstream conditions. Fish passage, sediment transport, and debris conveyance within the crossing are designed to function as they would in a natural channel. Given the considerable past and planned investments in removing fish barriers, the region initiated a pilot program in 2008 to develop and apply a cost-effective method for evaluating whether new crossings are providing fish passage and simulating natural stream channels.

Preliminary results suggest that passage was achieved at all of the 25 monitored crossings and that 19 of them "simulated" the natural stream channel conditions. The region is now working in partnership with the FS San Dimas Technology Center, the Pacific Northwest Research Station, and the U.S. Geological Survey as part of a national effort to further refine and apply the monitoring protocol.

Contact Brian Staab brianstaab@fs.fed.us) for more information. 


\section{Methow Valley Subbasin, Okanogan and Wenatchee National Forests, Washington}

\section{Improving stream connectivity for fluvial} bull trout in the Methow subbasin-The

Methow Valley subbasin is a core bull trout (Salvelinus confluentus) area in the upper Columbia River basin. Bull trout are listed in the Endangered Species Act as a threatened species. A key criterion in the bull trout recovery plan is removing artificial barriers to allow unimpeded access to these important life stage areas.

Historically, irrigation dams and road culverts throughout the Methow Valley contributed to the decline in bull trout in the subbasin by blocking migratory corridors and restricting connectivity to upstream spawning areas and downstream overwintering areas.

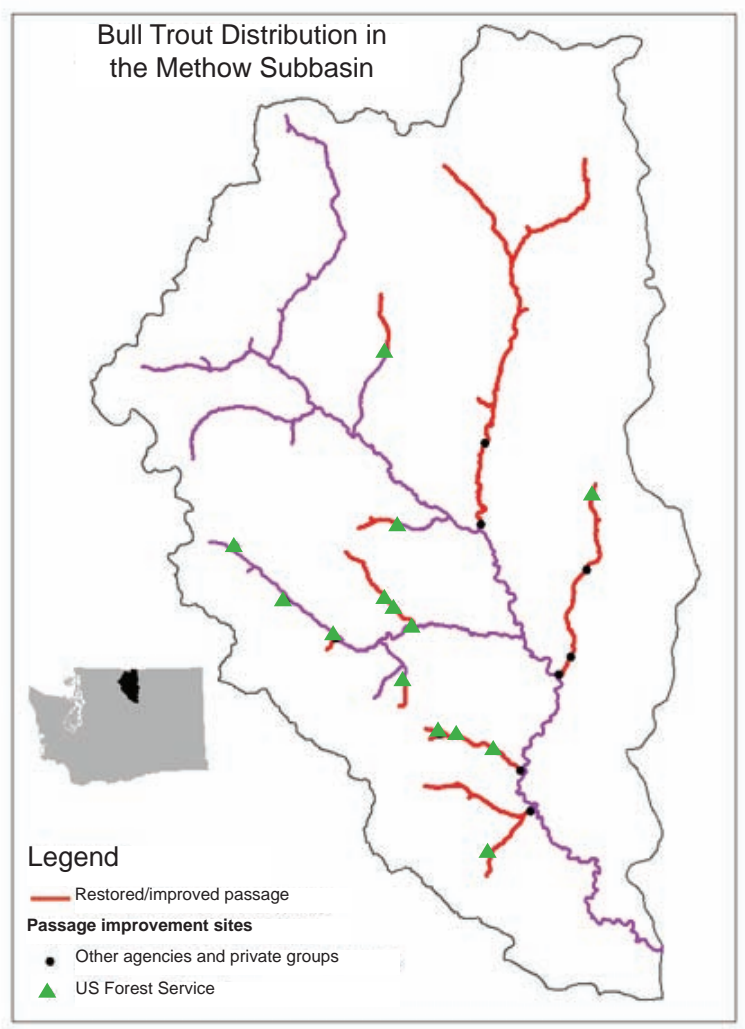

Bull trout distribution showing restored or improved habitat connectivity.

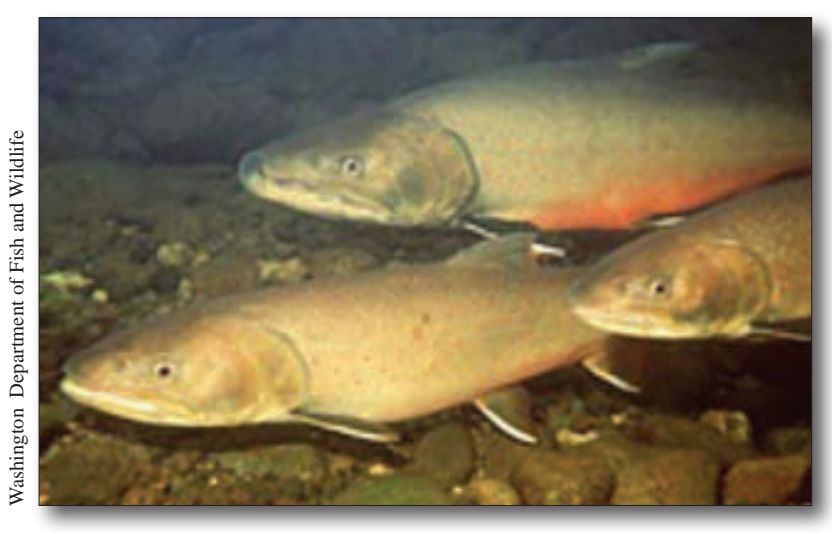

Recent radiotelemetry studies documented bull trout use in Goat Creek, Cold Creek, and Libby Creek, where access was previously blocked by artificial barriers.

Restoring migratory bull trout passage throughout the Methow was a large cooperative effort that included the Bureau of Reclamation, Washington Department Fish and Wildlife, Okanogan County, Washington Department of Transportation, Methow Salmon Recovery Foundation, Chewuch Basin Council, private landowners, and the Okanogan and Wenatchee National Forest. These efforts have greatly improved connectivity and migration corridors for bull trout in the Methow subbasin by restoring or improving migratory bull trout access to approximately $112 \mathrm{mi}$ of habitat within the Methow subbasin.

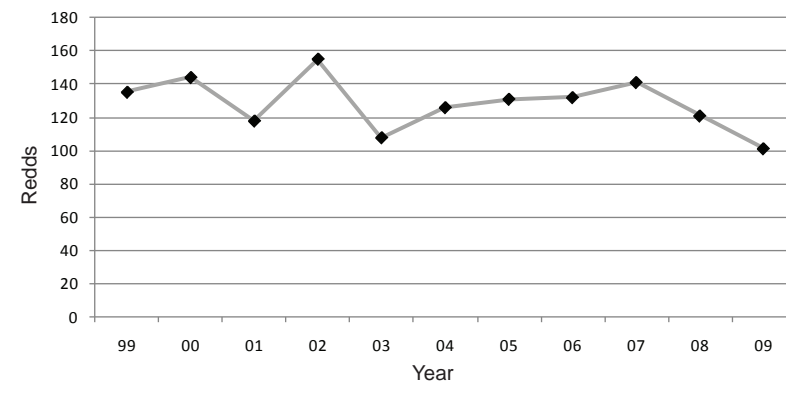

Fluvial bull trout redd numbers from six streams monitored since 1999. The data do not suggest a clear trend. From 1999 to 2003, the redd counts fluctuated downward then had a somewhat consistent increase until 2007. In 2008 and 2009, bull trout redd counts were down across the Methow. Although the data do not demonstrate any clear trends, we expect the improved access has improved production.

Contact Gene Shull (gshull@fs.fed.us) for more information. 


\section{Paradise Creek, Coos Bay Bureau of Land Mangement District, Oregon}

This creek needs help_-Paradise Creek, a tributary to the Umpqua River, was designated as a tier one key watershed under the Northwest Forest Plan. However, Oregon Department of Fish and Wildlife (ODFW) habitat inventories showed the majority of the fish-bearing habitat throughout the watershed was in poor to fair condition because instream habitat was dominated by bedrock with minimal structure or stream complexity.

\section{A partnership to the rescue-The Coos Bay}

District Bureau of Land Management (BLM) and partners Roseburg Resources Inc. (a private timber company), ODFW, the Partnership for Umpqua Rivers (watershed council) and private landowners (Paradise Creek Ranch) implemented a watershed-scale Paradise Creek restoration project during 2006-2007 affecting about 11 stream miles. It was apparent that achieving properly functioning conditions in the Paradise Creek watershed was not likely to occur within the foreseeable future without active intervention. Like the majority of forested lands managed by the Coos Bay District BLM, the Paradise Creek watershed has a legacy of logging and other land management activities that have degraded instream and

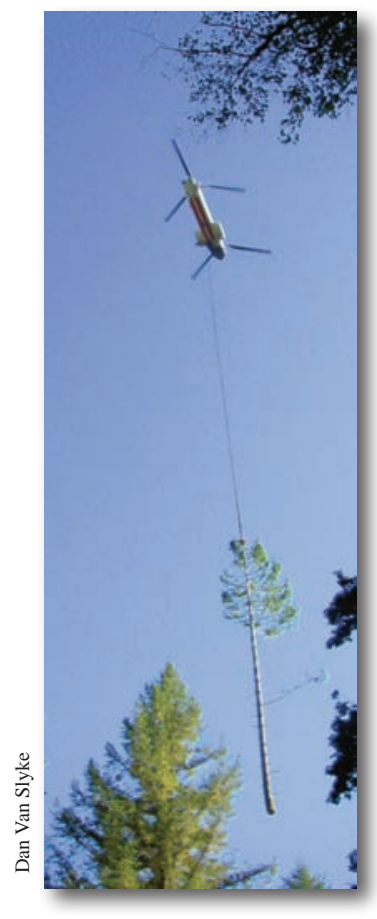
riparian habitats on both public and private lands. Roads now occupy a significant amount of historical flood plains, the conifers adjacent to stream channels have been reduced substantially, and logs and boulders were removed from virtually all stream reaches accessible by roads or logging systems.

\section{Immediate benefits-}

Adding large trees to the stream channel immediately benefited fish, amphibians, and crayfish because the logs and boulders provided a tremendous amount of cover habitat that did not exist previously. The structures also provided immediate low-velocity refuge during high flows, which is critical for overwintering juvenile salmonids. Postproject monitoring has shown that fine stream substrate is already being stored behind placed structures, and through time, stable gravel riffles will develop and provide quality spawning habitat. Spawning Chinook (Oncorhynchus tshawytscha) and coho salmon (O. kisutch) were observed in the boulder placement project reach in the first winter following placement.

\section{Contact Dan VanSlyke (dan_vanslyke@blm.gov) for more} information.

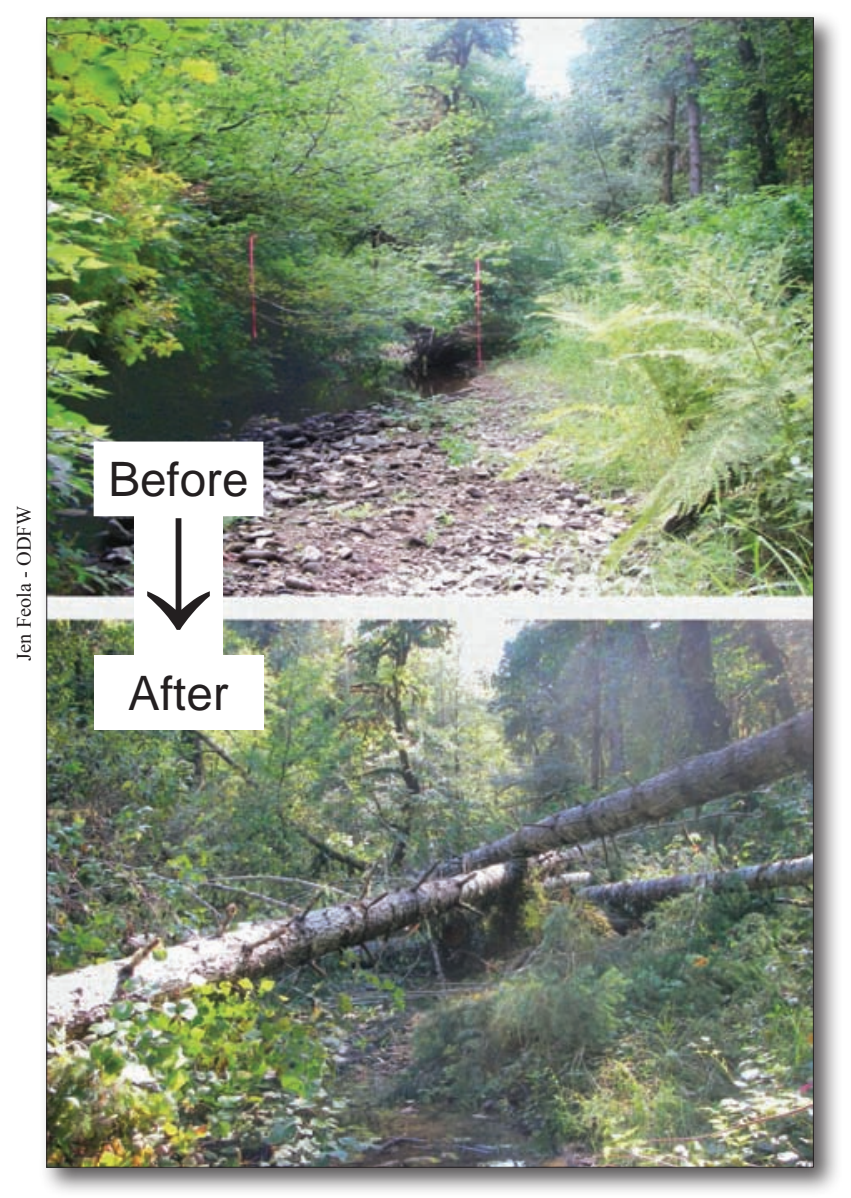

A helicopter, excavator, and cable yarding system were used to place over 900 conifer logs and hundreds of boulders throughout the watershed in 2006-2007 to provide quality spawning and rearing habitat for coho salmon (Oncorhynchus kisutch) (listed as threatened), Chinook salmon (0. tshawytscha), cutthroat trout (O. clarkii), steelhead trout (O. mykiss), and both resident and Pacific lamprey (Lampetra tridentata). An average of 82 logs were placed per stream mile. 


\section{Scott River, Klamath National Forest, California}

The 1.9-million-ac Klamath National Forest administers public lands that contain portions of the Klamath River and three of its significant tributaries: Scott, Salmon, and Shasta Rivers. A key beneficial use for these rivers is the coldwater salmonid fisheries for Chinook salmon (Oncorhynchus tshawytscha), coho salmon (O. kisutch), and steelhead (O. mykiss).

\section{Tributaries are considered impaired under the Clean Water Act-All of these rivers are} listed under the Clean Water Act as impaired for either nonpoint sources of temperature or sediment (303(d) listings). The advent of 303(d) listings and the subsequent development of Total Maximum Daily Loads (TMDLs) has placed a new urgency and focus on watershed restoration. Many TMDL requirements are consistent with past restoration efforts to disconnect the road network from the tributaries. For example:

- Unneeded roads were decommissioned. Old sedimentproducing roads were converted from having inboard ditches to being out-sloped and drained by rolling dips.

- The amount of fill on many stream crossings was greatly reduced, which eliminated the potential for the streams to flow down the road.

However, TMDLs also caused a shift in watershed focus from key watersheds identified by the Northwest Forest Plan to nonkey impaired watersheds. Also, the use of

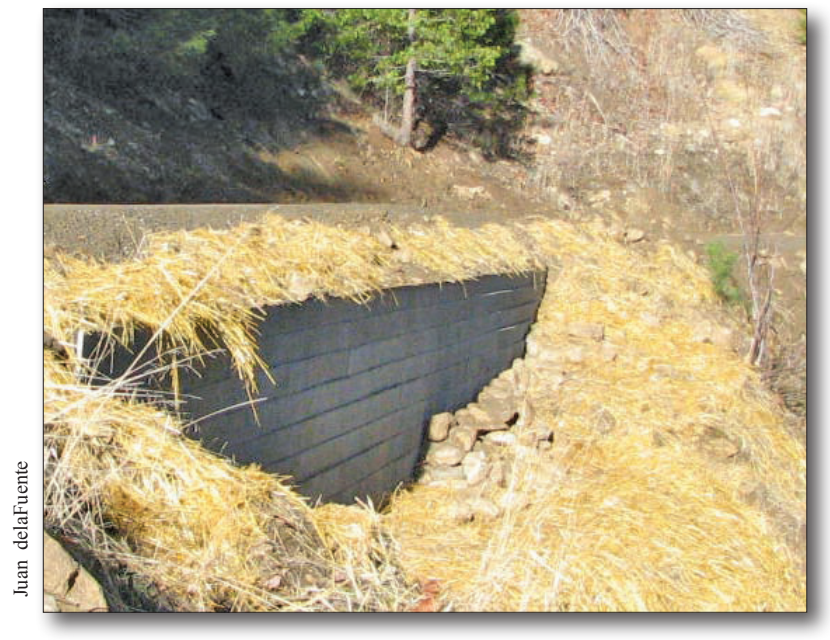

This retaining wall was installed on Bucher Road to stop sediment from a 2006 slide from entering the Scott River. anecdotal information for some 303(d) listings indicated a need for scientifically credible data to verify some listings and focus scarce funds on the truly impaired watersheds.

The forest leveraged the use of appropriated funds by partnering with state and federal agencies and nonprofit organizations to achieve much of this road work. For example, by "piggybacking" on earlier efforts, the forest received over $\$ 550,000$ of federal stimulus funds to stormproof $140 \mathrm{mi}$ of road.

Scott River TMDL_-The first TMDL was developed for the Scott River watershed (520,000 ac). The challenge for the forest is that it only administers 37 percent of this watershed. It also contains significant agricultural lands, industrial forest lands, and grazing lands. Portions of the Scott River tributaries were also turned literally upsidedown by gold dredging in the early $20^{\text {th }}$ century. The forest and the North Coast Water Quality Control Board are in the process of creating a bilateral memorandum of understanding (MOU) that will guide TMDL implementation compliance. One important requirement of the MOU is the already ongoing process of sediment source inventory, and prioritization, scheduling, and implementation of corrective actions. The model used for the Scott River may be applied in the future as an integrated and comprehensive forestwide approach to all TMDLs.

Integrated monitoring approach-Another new approach coming out of the Scott River TMDL is the development of an integrated monitoring approach, to be applied forestwide. The monitoring plan includes protocols for field collection of instream sediment data and stream shading. The plan also stratifies the forest's seventh-field watersheds into geologic (sandy, nonsandy, volcanic) and management categories (reference, over cumulative watershed effect threshold, sediment control, etc.) to facilitate analysis and interpretation of results. The monitoring plan objectives include:

- Track compliance with the TMDL.

- Conduct instream "best management practices" effectiveness monitoring.

- $\quad$ Ensure compliance of projects enrolled under categorical waiver(s).

- Create lines of evidence for the forest to use in proposing the delisting of unimpaired streams.

- Create data that can be used to calibrate and refine cumulative watershed effect models.

Contact John Schuyler (jschuyler@fs.fed.us) for more information. 


\section{Six Rivers National Forest, California}

Water quality problems-Most watersheds on the Six Rivers National Forest (NF) are listed as water quality impaired under section 303(d) of the Clean Water Act for sediment, temperature, nutrients, or dissolved oxygen. With the exception of sediment, these water quality concerns are primarily attributable to management activities outside of the forest boundary. On the Six Rivers NF, roads are the leading source of management-related sediment inputs. Where forest roads are located on steep terrain, mass soil movement is a common mechanism of erosion and sediment delivery. Most road-related erosion and sediment delivery is associated with large storm events that trigger culvert failures, stream diversions, and mass wasting. With the decline of road maintenance funding over the last 15 years, the risk of road failures and elevated sediment delivery is increasing, especially during large storm events.

Watershed restoration efforts, for the purpose of protecting important anadromous streams, began about 1990 and were focused on minimizing surface erosion from inner gorge landslides by using tree planting and other landslide stabilization techniques. However, these efforts proved costly and not very effective. When the Northwest Forest Plan was signed and subsequently incorporated into their forest plan in 1995, decommissioning of abandoned forest roads became the focus of restoration efforts on the Six Rivers NF.

Since 1994, the Six Rivers NF has secured over \$6.8 million for road decommissioning and stormproofing (primarily correcting stream crossing diversion potential). To date, $384 \mathrm{mi}$ have been decommissioned and 301 stream crossings have had diversion potential corrected. The forest received over $\$ 1$ million in 2009 for legacy road funding that will be spent on road-associated water quality improvements and road decommissioning.

\section{Tribal partnerships are a key for success-} Forming partnerships between the Six Rivers NF and the Karuk and Yurok Tribes has proven to be an effective method of garnering competitive grant funding to restore fisheries habitat through road decommissioning effects. As part of the cost-share partnership, each tribe contributes 30 to 35 percent of project costs. In addition to contributing funding, the tribes provide skilled restoration specialists to implement the work, thereby keeping jobs within local communities.

Contact Corrine Black (cblack@fs.fed.us) for more information.

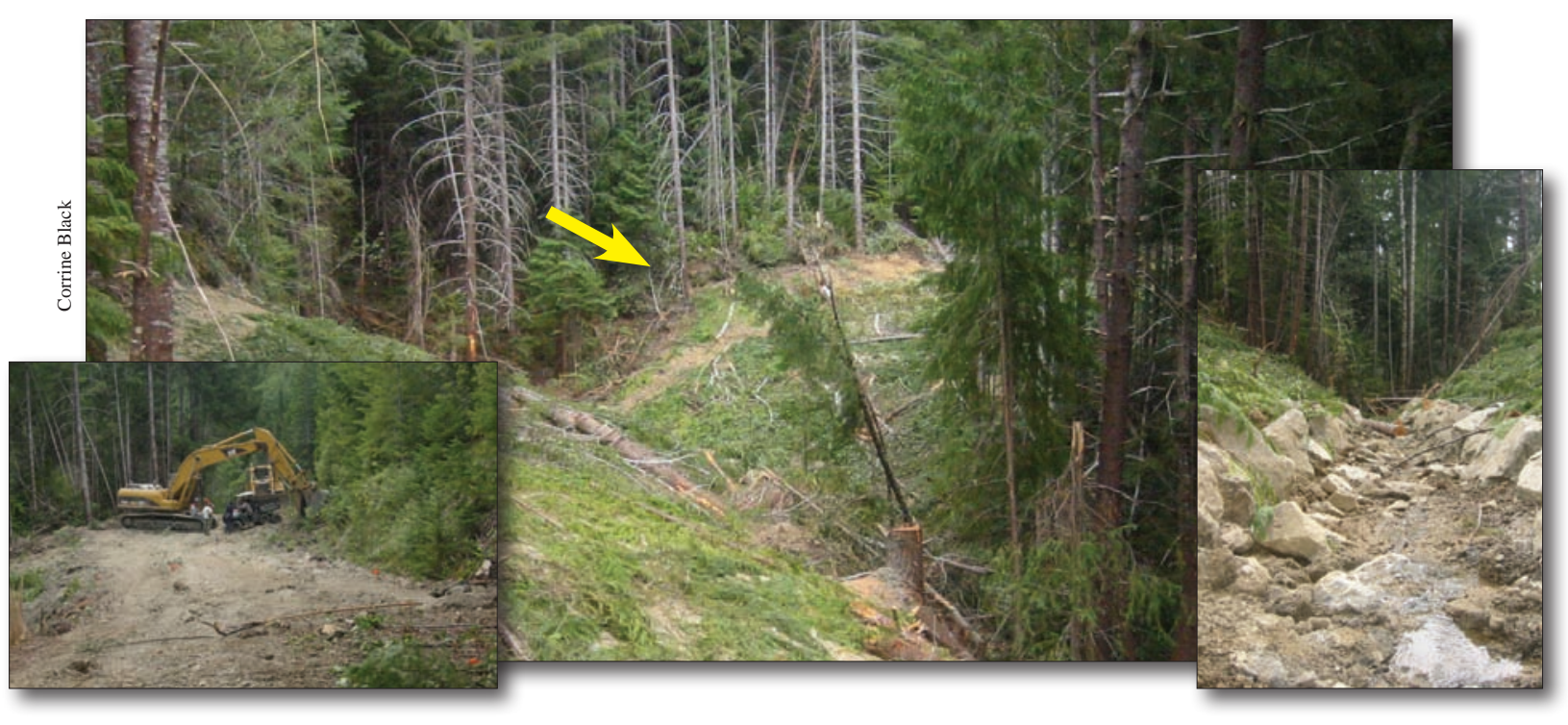

Left photo: Karuk Tribes restoration crews marked the limit of excavation and reviewed site plans prior to decommissioning this perennial stream crossing in the Bluff Creek watershed. Middle photo: View of completed work. The arrow marks the spot where the left photo was taken. Right photo: Closeup view of newly excavated stream channel. 


\section{Appendix 3: Watersheds Selected for Inchannel Monitoring}

The 250 watersheds shown in table 8 were randomly chosen as part of a panel design to determine the status and trend of inchannel processes. Approximately 25 to 30 watersheds have been sampled each year.

Table 8-The 250 subwatersheds randomly chosen to determine the status and trend of inchannel processes

\begin{tabular}{|c|c|c|c|c|c|c|}
\hline USGS HUC & Province & $\begin{array}{c}\text { Administrative } \\
\text { unit }\end{array}$ & $\begin{array}{l}\text { Watershed } \\
\text { name }\end{array}$ & $\begin{array}{c}\text { Subwatershed } \\
\text { name }\end{array}$ & $\begin{array}{c}\text { Year } \\
\text { surveyed }^{a}\end{array}$ & $\begin{array}{l}\text { Federal } \\
\text { land }\end{array}$ \\
\hline & & & & & & Percent \\
\hline 171003030503 & Oregon Coast & Coos Bay BLM & Lake Creek & $\begin{array}{l}\text { Upper Camp } \\
\text { Creek }\end{array}$ & 2003 & 90.13 \\
\hline 171003030401 & Oregon Coast & Coos Bay BLM & $\begin{array}{l}\text { Middle Umpqua } \\
\text { River }\end{array}$ & Paradise Creek & 2007 & 49.47 \\
\hline 171003050405 & Oregon Coast & Coos Bay BLM & $\begin{array}{l}\text { East Fork } \\
\text { Coquille }\end{array}$ & Elk Creek & 2008 & 36.25 \\
\hline 171003050404 & Oregon Coast & Coos Bay BLM & $\begin{array}{r}\text { East Fork } \\
\text { Coquille }\end{array}$ & Brewster Canyon & 2003 & 45.01 \\
\hline 171003050501 & Oregon Coast & Coos Bay BLM & $\begin{array}{l}\text { North Fork } \\
\text { Coquille }\end{array}$ & North Coquille & 2002 & 25.73 \\
\hline 171003030704 & Oregon Coast & Coos Bay BLM & $\begin{array}{l}\text { Lower Smith } \\
\text { River }\end{array}$ & $\begin{array}{l}\text { Upper Lower } \\
\text { Smith River }\end{array}$ & & 40.75 \\
\hline 180102030101 & High Cascades & Crater Lake NP & Wood River & E Fork Annie & 2002 & 100.00 \\
\hline 170703010207 & High Cascades & Deschutes NF & $\begin{array}{l}\text { Deschutes River/ } \\
\text { Browns Creek }\end{array}$ & Browns Creek & 2009 & 100.00 \\
\hline 170703010104 & High Cascades & Deschutes NF & $\begin{array}{l}\text { Deschutes River/ } \\
\text { Charleton Creek }\end{array}$ & Snow Creek & 2002 & 100.00 \\
\hline 170703020203 & High Cascades & Deschutes NF & Crescent Creek & Summit Lake & 2002 & 100.00 \\
\hline 170703020204 & High Cascades & Deschutes NF & Crescent Creek & Crescent Lake & & 100.00 \\
\hline 170703010803 & High Cascades & Deschutes NF & Squaw Creek & $\begin{array}{l}\text { Upper Trout } \\
\text { Creek }\end{array}$ & 2005 & 100.00 \\
\hline 170703010907 & High Cascades & Deschutes NF & $\begin{array}{l}\text { Upper Metolius } \\
\text { River }\end{array}$ & Canyon Creek & 2003 & 99.64 \\
\hline 171002060301 & Oregon Coast & Eugene BLM & Wildcat Creek & $\begin{array}{l}\text { Upper Wildcat } \\
\text { Creek }\end{array}$ & 2005 & 33.35 \\
\hline 170900060607 & Western Cascades & Eugene BLM & $\begin{array}{l}\text { South Santiam } \\
\text { River }\end{array}$ & Owl Creek & 2009 & 31.96 \\
\hline 170900020304 & Western Cascades & Eugene BLM & $\begin{array}{l}\text { Upper Coast Fork } \\
\text { Willamette River }\end{array}$ & $\begin{array}{l}\text { Cottage Grove } \\
\text { Reservoir }\end{array}$ & 2006 & 29.04 \\
\hline 170900020201 & Western Cascades & Eugene BLM & Mosby Creek & $\begin{array}{l}\text { Upper Mosby } \\
\text { Creek }\end{array}$ & 2005 & 30.29 \\
\hline 170701051004 & High Cascades & $\begin{array}{l}\text { Gifford Pinchot } \\
\text { NF }\end{array}$ & $\begin{array}{l}\text { Little White } \\
\text { Salmon River }\end{array}$ & $\begin{array}{l}\text { Middle Little } \\
\text { White Salmon } \\
\text { River }\end{array}$ & 2007 & 38.13 \\
\hline 170800020202 & Western Cascades & $\begin{array}{l}\text { Gifford Pinchot } \\
\text { NF }\end{array}$ & Muddy River & Clearwater Creek & 2008 & 100.00 \\
\hline 170800040402 & Western Cascades & $\begin{array}{l}\text { Gifford Pinchot } \\
\text { NF }\end{array}$ & $\begin{array}{l}\text { Upper Cispus } \\
\text { River }\end{array}$ & Walupt Creek & 2008 & 100.00 \\
\hline
\end{tabular}


Table 8 - The 250 subwatersheds randomly chosen to determine the status and trend of inchannel processes (continued)

\begin{tabular}{|c|c|c|c|c|c|c|}
\hline USGS HUC & Province & $\begin{array}{c}\text { Administrative } \\
\text { unit }\end{array}$ & $\begin{array}{l}\text { Watershed } \\
\text { name }\end{array}$ & $\begin{array}{l}\text { Subwatershed } \\
\text { name }\end{array}$ & $\begin{array}{c}\text { Year } \\
\text { surveyed }^{a}\end{array}$ & $\begin{array}{l}\text { Federal } \\
\text { land }\end{array}$ \\
\hline & & & & & & Percent \\
\hline 170800020503 & Western Cascades & $\begin{array}{l}\text { Gifford Pinchot } \\
\text { NF }\end{array}$ & $\begin{array}{l}\text { East Fork } \\
\text { Lewis River }\end{array}$ & Copper Creek & 2006 & 89.77 \\
\hline 170800040205 & Western Cascades & $\begin{array}{l}\text { Gifford Pinchot } \\
\text { NF }\end{array}$ & $\begin{array}{l}\text { Upper Cowlitz } \\
\text { River }\end{array}$ & Johnson Creek & 2006 & 99.03 \\
\hline 170800020203 & Western Cascades & $\begin{array}{l}\text { Gifford Pinchot } \\
\text { NF }\end{array}$ & Muddy River & Elk Creek & 2003 & 100.00 \\
\hline 170800020108 & Western Cascades & $\begin{array}{l}\text { Gifford Pinchot } \\
\text { NF }\end{array}$ & Upper Lewis River & Alec Creek & 2003 & 100.00 \\
\hline 170800020102 & Western Cascades & $\begin{array}{l}\text { Gifford Pinchot } \\
\text { NF }\end{array}$ & Upper Lewis River & Twin Falls Creek & 2003 & 100.00 \\
\hline 170800040307 & Western Cascades & $\begin{array}{l}\text { Gifford Pinchot } \\
\text { NF }\end{array}$ & $\begin{array}{l}\text { Cowlitz Valley } \\
\text { Frontal }\end{array}$ & Siler Creek & & 65.18 \\
\hline 171100150110 & Western Cascades & $\begin{array}{l}\text { Gifford Pinchot } \\
\text { NF }\end{array}$ & $\begin{array}{l}\text { Upper Nisqually } \\
\text { River }\end{array}$ & $\begin{array}{l}\text { Little Nisqually } \\
\text { River }\end{array}$ & 2005 & 88.38 \\
\hline 170800020401 & Western Cascades & $\begin{array}{l}\text { Gifford Pinchot } \\
\text { NF }\end{array}$ & Yale Reservoir & $\begin{array}{l}\text { Upper Siouxon } \\
\text { Creek }\end{array}$ & 2006 & 100.00 \\
\hline 170800020404 & Western Cascades & $\begin{array}{l}\text { Gifford Pinchot } \\
\text { NF }\end{array}$ & Yale Reservoir & Cougar Creek & & 43.73 \\
\hline 170800040409 & Western Cascades & $\begin{array}{l}\text { Gifford Pinchot } \\
\text { NF }\end{array}$ & $\begin{array}{l}\text { Upper Cispus } \\
\text { River }\end{array}$ & $\begin{array}{l}\text { Blue Lake/ } \\
\text { Cispus River }\end{array}$ & & 100.00 \\
\hline 170800040302 & Western Cascades & $\begin{array}{l}\text { Gifford Pinchot } \\
\text { NF }\end{array}$ & $\begin{array}{l}\text { Cowlitz Valley } \\
\text { Frontal }\end{array}$ & Willame Creek & 2002 & 98.96 \\
\hline 170701051002 & Western Cascades & $\begin{array}{l}\text { Gifford Pinchot } \\
\text { NF }\end{array}$ & $\begin{array}{l}\text { Little White } \\
\text { Salmon River }\end{array}$ & $\begin{array}{l}\text { Big Lava Bed } \\
\text { Frontal }\end{array}$ & 2002 & 89.29 \\
\hline 180102090203 & $\begin{array}{l}\text { Klamath- } \\
\text { Siskiyou }\end{array}$ & Klamath NF & Indian Creek & $\begin{array}{l}\text { East Fork } \\
\text { Indian Creek }\end{array}$ & 2005 & 96.22 \\
\hline 180102090303 & $\begin{array}{l}\text { Klamath- } \\
\text { Siskiyou }\end{array}$ & Klamath NF & Elk Creek & Lower Elk Creek & 2007 & 97.46 \\
\hline 180102090703 & $\begin{array}{l}\text { Klamath- } \\
\text { Siskiyou }\end{array}$ & Klamath NF & $\begin{array}{l}\text { Lower Salmon } \\
\text { River }\end{array}$ & Somes Creek & 2009 & 98.46 \\
\hline 180102100401 & $\begin{array}{l}\text { Klamath- } \\
\text { Siskiyou }\end{array}$ & Klamath NF & $\begin{array}{l}\text { Lower Salmon } \\
\text { River }\end{array}$ & Crapo Creek & & 97.08 \\
\hline 180102060802 & $\begin{array}{l}\text { Klamath- } \\
\text { Siskiyou }\end{array}$ & Klamath NF & Empire Creek & Humbug Creek & & 46.11 \\
\hline 180102060803 & $\begin{array}{l}\text { Klamath- } \\
\text { Siskiyou }\end{array}$ & Klamath NF & Empire Creek & Vesa Creek & & 60.73 \\
\hline 180102080103 & $\begin{array}{l}\text { Klamath- } \\
\text { Siskiyou }\end{array}$ & Klamath NF & $\begin{array}{l}\text { East Fork Scott } \\
\text { River }\end{array}$ & Noyes Valley & 2008 & 38.94 \\
\hline 180102090204 & $\begin{array}{l}\text { Klamath- } \\
\text { Siskiyou }\end{array}$ & Klamath NF & Indian Creek & $\begin{array}{l}\text { South Fork Indian } \\
\text { Creek }\end{array}$ & 2009 & 97.91 \\
\hline 180102080402 & $\begin{array}{l}\text { Klamath- } \\
\text { Siskiyou }\end{array}$ & Klamath NF & Moffett Creek & Indian Creek & & 46.20 \\
\hline 180102050102 & $\begin{array}{l}\text { Klamath- } \\
\text { Siskiyou }\end{array}$ & Klamath NF & $\begin{array}{l}\text { Mount Shasta } \\
\text { Woods }\end{array}$ & Horsethief Creek & & 48.05 \\
\hline
\end{tabular}


Table 8 - The 250 subwatersheds randomly chosen to determine the status and trend of inchannel processes (continued)

\begin{tabular}{|c|c|c|c|c|c|c|}
\hline USGS HUC & Province & $\begin{array}{c}\text { Administrative } \\
\text { unit }\end{array}$ & $\begin{array}{l}\text { Watershed } \\
\text { name }\end{array}$ & $\begin{array}{c}\text { Subwatershed } \\
\text { name }\end{array}$ & $\begin{array}{c}\text { Year } \\
\text { surveyed }^{a}\end{array}$ & $\begin{array}{l}\text { Federal } \\
\text { land }\end{array}$ \\
\hline & & & & & & Percent \\
\hline 180102090501 & $\begin{array}{l}\text { Klamath- } \\
\text { Siskiyou }\end{array}$ & Klamath NF & Ukonom Creek & Oak Flat Creek & 2006 & 98.06 \\
\hline 180102090402 & $\begin{array}{l}\text { Klamath- } \\
\text { Siskiyou }\end{array}$ & Klamath NF & Clear Creek & Tenmile Creek & 2003 & 100.00 \\
\hline 180102080203 & $\begin{array}{l}\text { Klamath- } \\
\text { Siskiyou }\end{array}$ & Klamath NF & $\begin{array}{l}\text { South Fork Scott } \\
\text { River }\end{array}$ & Haynes Lake Creek & 2003 & 27.77 \\
\hline 180102100102 & $\begin{array}{l}\text { Klamath- } \\
\text { Siskiyou }\end{array}$ & Klamath NF & $\begin{array}{l}\text { South Fork Salmon } \\
\text { River }\end{array}$ & Summerville & 2002 & 98.42 \\
\hline 180102100106 & $\begin{array}{l}\text { Klamath- } \\
\text { Siskiyou }\end{array}$ & Klamath NF & $\begin{array}{l}\text { South Fork Salmon } \\
\text { River }\end{array}$ & Crawford Creek & 2003 & 97.23 \\
\hline 180102060903 & $\begin{array}{l}\text { Klamath- } \\
\text { Siskiyou }\end{array}$ & Klamath NF & West Fork Beaver & Bear Creek & 2007 & 43.88 \\
\hline 180102080601 & $\begin{array}{l}\text { Klamath- } \\
\text { Siskiyou }\end{array}$ & Klamath NF & Bridge Flat & Emigrant Creek & & 35.78 \\
\hline 180102080101 & $\begin{array}{l}\text { Klamath- } \\
\text { Siskiyou }\end{array}$ & Klamath NF & $\begin{array}{l}\text { East Fork } \\
\text { Scott River }\end{array}$ & $\begin{array}{l}\text { Upper East Fork } \\
\text { Scott River }\end{array}$ & 2006 & 30.82 \\
\hline 180102090302 & $\begin{array}{l}\text { Klamath- } \\
\text { Siskiyou }\end{array}$ & Klamath NF & Elk Creek & Upper Elk Creek & 2006 & 100.00 \\
\hline 180102090603 & $\begin{array}{l}\text { Klamath- } \\
\text { Siskiyou }\end{array}$ & Klamath NF & Dillon Creek & Jackass Creek & 2009 & 100.00 \\
\hline 180102060502 & High Cascades & Medford BLM & $\begin{array}{l}\text { Klamath River/ } \\
\text { Iron Gate }\end{array}$ & Scotch Creek & 2004 & 56.22 \\
\hline 180102060405 & High Cascades & Medford BLM & Jenny Creek & Keene Creek & & 44.55 \\
\hline 171003090203 & $\begin{array}{l}\text { Klamath- } \\
\text { Siskiyou }\end{array}$ & Medford BLM & $\begin{array}{l}\text { Applegate River/ } \\
\text { Mckee Bridge }\end{array}$ & $\begin{array}{l}\text { Applegate River/ } \\
\text { Star Gulch }\end{array}$ & 2004 & 71.56 \\
\hline 171003020804 & $\begin{array}{l}\text { Klamath- } \\
\text { Siskiyou }\end{array}$ & Medford BLM & $\begin{array}{l}\text { West Fork } \\
\text { Cow Creek }\end{array}$ & $\begin{array}{l}\text { West Fork Cow } \\
\text { Creek/Bear Creek }\end{array}$ & 2003 & 50.43 \\
\hline 171003020603 & $\begin{array}{l}\text { Klamath- } \\
\text { Siskiyou }\end{array}$ & Medford BLM & Upper Cow Creek & $\begin{array}{l}\text { Upper Cow Creek/ } \\
\text { Galesville }\end{array}$ & 2002 & 45.64 \\
\hline 171003110502 & $\begin{array}{l}\text { Klamath- } \\
\text { Siskiyou }\end{array}$ & Medford BLM & Deer Creek & Middle Deer Creek & & 33.50 \\
\hline 171003100403 & $\begin{array}{l}\text { Klamath- } \\
\text { Siskiyou }\end{array}$ & Medford BLM & $\begin{array}{l}\text { Rogue River/ } \\
\text { Horseshoe Bend }\end{array}$ & $\begin{array}{l}\text { Rogue River/Big } \\
\text { Windy Creek }\end{array}$ & 2003 & 95.39 \\
\hline 171003080301 & $\begin{array}{l}\text { Klamath- } \\
\text { Siskiyou }\end{array}$ & Medford BLM & Evans Creek & Upper Evans Creek & 2005 & 30.46 \\
\hline 171003020801 & Oregon Coast & Medford BLM & $\begin{array}{l}\text { West Fork } \\
\text { Cow Creek }\end{array}$ & $\begin{array}{l}\text { Upper West Fork } \\
\text { Cow Creek }\end{array}$ & 2002 & 44.44 \\
\hline 171003070602 & $\begin{array}{l}\text { Western } \\
\text { Cascades }\end{array}$ & Medford BLM & Trail Creek & $\begin{array}{l}\text { West Fork } \\
\text { Trail Creek }\end{array}$ & 2003 & 42.84 \\
\hline 171003110504 & $\begin{array}{l}\text { Klamath- } \\
\text { Siskiyou }\end{array}$ & Medford NF & Deer Creek & McMullin Creek & 2009 & 30.27 \\
\hline 171003100405 & $\begin{array}{l}\text { Klamath- } \\
\text { Siskiyou }\end{array}$ & Medford NF & $\begin{array}{l}\text { Rogue River/ } \\
\text { Horseshoe Bend }\end{array}$ & Kelsey Creek & 2006 & 96.0 \\
\hline
\end{tabular}


Table 8 - The 250 subwatersheds randomly chosen to determine the status and trend of inchannel processes (continued)

\begin{tabular}{|c|c|c|c|c|c|c|}
\hline USGS HUC & Province & $\begin{array}{c}\text { Administrative } \\
\text { unit }\end{array}$ & $\begin{array}{l}\text { Watershed } \\
\text { name }\end{array}$ & $\begin{array}{l}\text { Subwatershed } \\
\text { name }\end{array}$ & $\begin{array}{c}\text { Year } \\
\text { surveyed }^{a}\end{array}$ & $\begin{array}{l}\text { Federal } \\
\text { land }\end{array}$ \\
\hline & & & & & & Percent \\
\hline 171003070809 & $\begin{array}{l}\text { Klamath- } \\
\text { Siskiyou }\end{array}$ & Medford NF & Little Butte Creek & Little Butte/Lick & 2009 & 36.45 \\
\hline 171003070802 & $\begin{array}{l}\text { Klamath- } \\
\text { Siskiyou }\end{array}$ & Medford NF & Little Butte Creek & $\begin{array}{l}\text { Lower North Fork } \\
\text { Little Butte Creek }\end{array}$ & 2006 & 28.87 \\
\hline 171003110304 & $\begin{array}{l}\text { Klamath- } \\
\text { Siskiyou }\end{array}$ & Medford NF & Sucker Creek & Lower Sucker Creek & 2006 & 35.11 \\
\hline 171003090403 & $\begin{array}{l}\text { Klamath- } \\
\text { Siskiyou }\end{array}$ & Medford NF & $\begin{array}{l}\text { Middle Applegate } \\
\text { River }\end{array}$ & $\begin{array}{l}\text { Applegate River/ } \\
\text { Humbug Creek }\end{array}$ & 2008 & 36.78 \\
\hline 171003020803 & Oregon Coast & Medford NF & $\begin{array}{l}\text { West Fork } \\
\text { Cow Creek }\end{array}$ & $\begin{array}{l}\text { West Fork Cow } \\
\text { Creek/Elk } \\
\text { Valley Creek }\end{array}$ & 2007 & 53.56 \\
\hline 171003070504 & $\begin{array}{l}\text { Western } \\
\text { Cascades }\end{array}$ & Medford NF & $\begin{array}{l}\text { Elk Creek/ } \\
\text { Rogue River }\end{array}$ & $\begin{array}{l}\text { Elk Creek/ } \\
\text { Flat Creek }\end{array}$ & 2007 & 28.38 \\
\hline 180101030202 & Franciscan & Mendocino NF & Rice Fork & Lower Rice Fork & & 80.46 \\
\hline 180201160202 & Franciscan & Mendocino NF & $\begin{array}{l}\text { North Fork } \\
\text { Cache Creek }\end{array}$ & Bartlett Crek & & 57.20 \\
\hline 180101030105 & $\begin{array}{l}\text { Klamath- } \\
\text { Siskiyou }\end{array}$ & Mendocino NF & Lake Pillsbury & Anderson Creek & & 88.78 \\
\hline 180101040201 & $\begin{array}{l}\text { Klamath- } \\
\text { Siskiyou }\end{array}$ & Mendocino NF & Black Butte River & $\begin{array}{l}\text { Upper Black } \\
\text { Butte River }\end{array}$ & 2002 & 78.15 \\
\hline 180101040204 & $\begin{array}{l}\text { Klamath- } \\
\text { Siskiyou }\end{array}$ & Mendocino NF & Black Butte River & $\begin{array}{l}\text { Lower Black } \\
\text { Butte River }\end{array}$ & & 66.81 \\
\hline 180101040106 & $\begin{array}{l}\text { Klamath- } \\
\text { Siskiyou }\end{array}$ & Mendocino NF & Wilderness & Howard Creek & 2005 & 93.23 \\
\hline 180101040103 & $\begin{array}{l}\text { Klamath- } \\
\text { Siskiyou }\end{array}$ & Mendocino NF & Wilderness & $\begin{array}{l}\text { Balm of Gilead } \\
\text { Creek }\end{array}$ & & 100.00 \\
\hline 171100050805 & North Cascades & $\begin{array}{l}\text { Mount Baker- } \\
\text { Snoqualmie NF }\end{array}$ & Baker River & Lower Baker Lake & 2009 & 98.29 \\
\hline 171100060101 & North Cascades & $\begin{array}{l}\text { Mount Baker- } \\
\text { Snoqualmie NF }\end{array}$ & $\begin{array}{l}\text { Upper Sauk } \\
\text { River }\end{array}$ & Sloan Creek & 2006 & 100.00 \\
\hline 171100040301 & North Cascades & $\begin{array}{l}\text { Mount Baker- } \\
\text { Snoqualmie NF }\end{array}$ & $\begin{array}{l}\text { South Fork } \\
\text { Nooksack River }\end{array}$ & $\begin{array}{l}\text { Upper South Fork } \\
\text { Nooksack River }\end{array}$ & 2006 & 93.34 \\
\hline 171100050604 & North Cascades & $\begin{array}{l}\text { Mount Baker- } \\
\text { Snoqualmie NF }\end{array}$ & Cascade River & $\begin{array}{l}\text { Middle Cascade } \\
\text { River }\end{array}$ & 2009 & 99.97 \\
\hline 171100090201 & North Cascades & $\begin{array}{l}\text { Mount Baker- } \\
\text { Snoqualmie NF }\end{array}$ & $\begin{array}{l}\text { Skykomish River } \\
\text { Forks }\end{array}$ & $\begin{array}{l}\text { Upper North Fork } \\
\text { Skykomish River }\end{array}$ & 2004 & 100.00 \\
\hline 171100060106 & North Cascades & $\begin{array}{l}\text { Mount Baker- } \\
\text { Snoqualmie NF }\end{array}$ & Upper Sauk River & $\begin{array}{l}\text { Lower White } \\
\text { Chuck River }\end{array}$ & 2003 & 100.00 \\
\hline 171100050702 & North Cascades & $\begin{array}{l}\text { Mount Baker- } \\
\text { Snoqualmie NF }\end{array}$ & $\begin{array}{l}\text { Skagit River/ } \\
\text { Illabot Creek }\end{array}$ & $\begin{array}{l}\text { Skagit River } \\
\text { at Corkindale }\end{array}$ & & 63.17 \\
\hline 171100050806 & North Cascades & $\begin{array}{l}\text { Mount Baker- } \\
\text { Snoqualmie NF }\end{array}$ & Baker River & $\begin{array}{l}\text { Lower Baker River/ } \\
\text { Lake Shannon }\end{array}$ & 2007 & 49.84 \\
\hline 171100100102 & North Cascades & $\begin{array}{l}\text { Mount Baker- } \\
\text { Snoqualmie NF }\end{array}$ & $\begin{array}{l}\text { North Fork } \\
\text { Snoqualmie River }\end{array}$ & $\begin{array}{l}\text { North Fork } \\
\text { Snoqualmie River/ } \\
\text { Sunday Creek }\end{array}$ & & 55.70 \\
\hline
\end{tabular}


Table 8-The 250 subwatersheds randomly chosen to determine the status and trend of inchannel processes (continued)

\begin{tabular}{|c|c|c|c|c|c|c|}
\hline USGS HUC & Province & $\begin{array}{c}\text { Administrative } \\
\text { unit }\end{array}$ & $\begin{array}{l}\text { Watershed } \\
\text { name }\end{array}$ & $\begin{array}{l}\text { Subwatershed } \\
\text { name }\end{array}$ & $\begin{array}{c}\text { Year } \\
\text { surveyed }^{a}\end{array}$ & $\begin{array}{l}\text { Federal } \\
\text { land }\end{array}$ \\
\hline & & & & & & Percent \\
\hline 171100080102 & North Cascades & $\begin{array}{l}\text { Mount Baker- } \\
\text { Snoqualmie NF }\end{array}$ & $\begin{array}{l}\text { North Fork } \\
\text { Stillaguamish } \\
\text { River }\end{array}$ & $\begin{array}{l}\text { North Fork } \\
\text { Stillaguamish River } \\
\text { at Squire Creek }\end{array}$ & 2005 & 27.96 \\
\hline 171100090206 & North Cascades & $\begin{array}{l}\text { Mount Baker- } \\
\text { Snoqualmie NF }\end{array}$ & $\begin{array}{l}\text { Skykomish } \\
\text { River Forks }\end{array}$ & $\begin{array}{l}\text { Skykomish River } \\
\text { Lower South Fork }\end{array}$ & 2007 & 65.23 \\
\hline 171100040104 & North Cascades & $\begin{array}{l}\text { Mount Baker- } \\
\text { Snoqualmie NF }\end{array}$ & $\begin{array}{l}\text { Upper North } \\
\text { Fork Nooksack } \\
\text { River }\end{array}$ & Glacier Creek & 2005 & 78.04 \\
\hline 171100100303 & North Cascades & $\begin{array}{l}\text { Mount Baker- } \\
\text { Snoqualmie NF }\end{array}$ & $\begin{array}{l}\text { Middle Fork } \\
\text { Snoqualmie } \\
\text { River }\end{array}$ & Taylor River & & 97.91 \\
\hline 171100090107 & North Cascades & $\begin{array}{l}\text { Mount Baker- } \\
\text { Snoqualmie NF }\end{array}$ & $\begin{array}{l}\text { Tye and } \\
\text { Beckler Rivers }\end{array}$ & $\begin{array}{l}\text { Lower Beckler } \\
\text { River }\end{array}$ & 2007 & 74.45 \\
\hline 171100090104 & North Cascades & $\begin{array}{l}\text { Mount Baker- } \\
\text { Snoqualmie NF }\end{array}$ & $\begin{array}{l}\text { Tye and } \\
\text { Beckler Rivers }\end{array}$ & Lower Tye River & & 72.25 \\
\hline 171100130104 & Western Cascades & $\begin{array}{l}\text { Mount Baker- } \\
\text { Snoqualmie NF }\end{array}$ & Upper Green River & $\begin{array}{l}\text { Upper Green River/ } \\
\text { Twin Camp Creek }\end{array}$ & 2009 & 48.41 \\
\hline 171100140202 & Western Cascades & $\begin{array}{l}\text { Mount Baker- } \\
\text { Snoqualmie NF }\end{array}$ & $\begin{array}{l}\text { Lower White } \\
\text { River }\end{array}$ & Clearwater River & 2003 & 43.18 \\
\hline 171100140105 & Western Cascades & $\begin{array}{l}\text { Mount Baker- } \\
\text { Snoqualmie NF }\end{array}$ & Upper White River & $\begin{array}{l}\text { Upper Greenwater } \\
\text { River }\end{array}$ & 2007 & 100.00 \\
\hline 171100140104 & Western Cascades & Mount Baker-River & Upper White River & $\begin{array}{l}\text { Upper White River/ } \\
\text { Silver Creek }\end{array}$ & 2002 & 86.09 \\
\hline 171100130101 & Western Cascades & $\begin{array}{l}\text { Mount Baker- } \\
\text { Snoqualmie NF }\end{array}$ & $\begin{array}{l}\text { Upper Green River } \\
\text { Headwaters }\end{array}$ & Green River & 2005 & 43.80 \\
\hline 170701050601 & High Cascades & Mount Hood NF & $\begin{array}{l}\text { East Fork } \\
\text { Hood River }\end{array}$ & $\begin{array}{l}\text { Upper East Fork } \\
\text { Hood River }\end{array}$ & 2008 & 100.00 \\
\hline 170701050201 & High Cascades & Mount Hood NF & Fifteenmile Creek & $\begin{array}{l}\text { Headwaters } \\
\text { Fifteenmile Creek }\end{array}$ & 2003 & 49.81 \\
\hline 170703060901 & High Cascades & Mount Hood NF & Tygh Creek & Upper Badger Creek & 2005 & 96.99 \\
\hline 170900110101 & Western Cascades & Mount Hood NF & Collawash River & $\begin{array}{l}\text { Upper Hot Springs } \\
\text { Fork Collawash }\end{array}$ & 2007 & 100.00 \\
\hline 170800010102 & Western Cascades & Mount Hood NF & Salmon River & Draw Creek & 2003 & 100.00 \\
\hline 170900110304 & Western Cascades & Mount Hood NF & $\begin{array}{l}\text { Oak Grove Fork } \\
\text { Clackamas River }\end{array}$ & High Rock Creek & 2006 & 100.00 \\
\hline 170900110401 & Western Cascades & Mount Hood NF & $\begin{array}{l}\text { Upper Clackamas } \\
\text { River }\end{array}$ & Pot Creek & 2009 & 99.35 \\
\hline 170800010201 & Western Cascades & Mount Hood NF & Zigzag River & Still Creek & 2002 & 98.23 \\
\hline 170800010504 & Western Cascades & Mount Hood NF & Bull Run River & Cedar Creek & 2003 & 96.22 \\
\hline 170900110201 & Western Cascades & Mount Hood NF & $\begin{array}{l}\text { Upper Clackamas } \\
\text { River }\end{array}$ & Cub Creek & 2005 & 100.00 \\
\hline 170800010501 & Western Cascades & Mount Hood NF & Bull Run River & Blazed Alder Creek & 2008 & 99.16 \\
\hline 170900110301 & Western Cascades & Mount Hood NF & $\begin{array}{l}\text { Oak Grove Fork } \\
\text { Clackamas River }\end{array}$ & $\begin{array}{l}\text { Upper Oak Grove } \\
\text { Fork Clackamas } \\
\text { River }\end{array}$ & & 42.05 \\
\hline
\end{tabular}


Table 8 - The 250 subwatersheds randomly chosen to determine the status and trend of inchannel processes (continued)

\begin{tabular}{|c|c|c|c|c|c|c|}
\hline USGS HUC & Province & $\begin{array}{c}\text { Administrative } \\
\text { unit }\end{array}$ & $\begin{array}{l}\text { Watershed } \\
\text { name }\end{array}$ & $\begin{array}{l}\text { Subwatershed } \\
\text { name }\end{array}$ & $\begin{array}{c}\text { Year } \\
\text { surveyed }^{a}\end{array}$ & $\begin{array}{l}\text { Federal } \\
\text { land }\end{array}$ \\
\hline & & & & & & Percent \\
\hline 170800010506 & Western Cascades & Mount Hood NF & Bull Run River & $\begin{array}{l}\text { Middle Bull Run } \\
\text { River }\end{array}$ & 2009 & 100.00 \\
\hline 171100150101 & Western Cascades & Mount Rainer NP & $\begin{array}{l}\text { Upper Nisqually } \\
\text { River }\end{array}$ & $\begin{array}{l}\text { Nisqually } \\
\text { Headwaters }\end{array}$ & 2006 & 98.24 \\
\hline 171100050401 & North Cascades & North Cascades NP & $\begin{array}{l}\text { Skagit River/ } \\
\text { Gorge Lake }\end{array}$ & Fisher Creek & 2002 & 97.54 \\
\hline 170200090111 & North Cascades & North Cascades NP & Stehekin & Boulder Creek & 2003 & 98.87 \\
\hline 170200080203 & North Cascades & Okanogan NF & $\begin{array}{l}\text { Upper Methow } \\
\text { River }\end{array}$ & Rattlesnake Creek & & 89.01 \\
\hline 170200080703 & North Cascades & Okanogan NF & $\begin{array}{l}\text { Lower Methow } \\
\text { River }\end{array}$ & $\begin{array}{l}\text { Mainstem Lower } \\
\text { Methow River }\end{array}$ & 2003 & 93.15 \\
\hline 170200080204 & North Cascades & Okanogan NF & $\begin{array}{l}\text { Upper Methow } \\
\text { River }\end{array}$ & Cedar Creek & & 100.00 \\
\hline 170200080102 & North Cascades & Okanogan NF & Lost River & $\begin{array}{l}\text { South Fork Lost } \\
\text { River }\end{array}$ & & 100.00 \\
\hline 170200080103 & North Cascades & Okanogan NF & Lost River & Lower Lost River & & 99.54 \\
\hline 170200080502 & North Cascades & Okanogan NF & Twisp River & South Creek & & 99.10 \\
\hline 171100180601 & $\begin{array}{l}\text { Olympic } \\
\text { Peninsula }\end{array}$ & Olympic NF & Big Quilcene River & $\begin{array}{l}\text { Upper Big Quilcene } \\
\text { River }\end{array}$ & 2004 & 99.78 \\
\hline 171100180302 & $\begin{array}{l}\text { Olympic } \\
\text { Peninsula }\end{array}$ & Olympic NF & $\begin{array}{l}\text { Hamma Hamma } \\
\text { River }\end{array}$ & $\begin{array}{l}\text { Hamma Hamma } \\
\text { River }\end{array}$ & 2002 & 75.08 \\
\hline 171001010501 & $\begin{array}{l}\text { Olympic } \\
\text { Peninsula }\end{array}$ & Olympic NF & Calawah River & $\begin{array}{l}\text { North Fork Calawah } \\
\text { River }\end{array}$ & & 52.00 \\
\hline 171001020107 & $\begin{array}{l}\text { Olympic } \\
\text { Peninsula }\end{array}$ & Olympic NF & Queets River & Salmon River & 2005 & 29.27 \\
\hline 171100200304 & $\begin{array}{l}\text { Olympic } \\
\text { Peninsula }\end{array}$ & Olympic NF & Dungeness River & $\begin{array}{l}\text { Lower Gray } \\
\text { Wolf River }\end{array}$ & 2007 & 99.30 \\
\hline 171100180701 & $\begin{array}{l}\text { Olympic } \\
\text { Peninsula }\end{array}$ & Olympic NF & $\begin{array}{l}\text { Upper West Hood } \\
\text { Canal Frontal }\end{array}$ & $\begin{array}{l}\text { Spencer/Marple } \\
\text { Creek }\end{array}$ & & 36.59 \\
\hline 171001020104 & $\begin{array}{l}\text { Olympic } \\
\text { Peninsula }\end{array}$ & Olympic NF & Queets River & Sams River & & 98.36 \\
\hline 171001010602 & $\begin{array}{l}\text { Olympic } \\
\text { Peninsula }\end{array}$ & Olympic NP & Bogachiel River & $\begin{array}{l}\text { Middle Bogachiel } \\
\text { River }\end{array}$ & & 100.00 \\
\hline 171001010402 & $\begin{array}{l}\text { Olympic } \\
\text { Peninsula }\end{array}$ & Olympic NP & Sol Duc River & $\begin{array}{l}\text { Headwaters Sol } \\
\text { Duc River }\end{array}$ & 2008 & 99.70 \\
\hline 171001010401 & $\begin{array}{l}\text { Olympic } \\
\text { Peninsula }\end{array}$ & Olympic NP & Sol Duc River & $\begin{array}{l}\text { North Fork Sol } \\
\text { Duc River }\end{array}$ & 2007 & 100.00 \\
\hline 171001020402 & $\begin{array}{l}\text { Olympic } \\
\text { Peninsula }\end{array}$ & Olympic NP & $\begin{array}{l}\text { Upper Quinalt } \\
\text { River }\end{array}$ & Graves Creek & 2009 & 100.00 \\
\hline 180102110603 & $\begin{array}{l}\text { Klamath- } \\
\text { Siskiyou }\end{array}$ & Redding BLM & Weaver/Rush & $\begin{array}{l}\text { Grass Valley } \\
\text { Creek }\end{array}$ & 2007 & 59.75 \\
\hline 180102110604 & $\begin{array}{l}\text { Klamath- } \\
\text { Siskiyou }\end{array}$ & Redding BLM & Weaver/Rush & Indian Creek & & 33.83 \\
\hline
\end{tabular}


Table 8 - The 250 subwatersheds randomly chosen to determine the status and trend of inchannel processes (continued)

\begin{tabular}{|c|c|c|c|c|c|c|}
\hline USGS HUC & Province & $\begin{array}{c}\text { Administrative } \\
\text { unit }\end{array}$ & $\begin{array}{l}\text { Watershed } \\
\text { name }\end{array}$ & $\begin{array}{c}\text { Subwatershed } \\
\text { name }\end{array}$ & $\begin{array}{c}\text { Year } \\
\text { surveyed }^{a}\end{array}$ & $\begin{array}{c}\text { Federal } \\
\text { land }\end{array}$ \\
\hline & & & & & & Percent \\
\hline 171003100601 & Franciscan & $\begin{array}{l}\text { Rogue River- } \\
\text { Siskiyou NF }\end{array}$ & $\begin{array}{r}\text { Rogue River/ } \\
\text { Illahe Creek }\end{array}$ & $\begin{array}{l}\text { Shasta Costa } \\
\text { Creek }\end{array}$ & 2004 & 99.67 \\
\hline 171003120106 & Franciscan & $\begin{array}{l}\text { Rogue River- } \\
\text { Siskiyou NF }\end{array}$ & Chetco River & Boulder Creek & 2004 & 100.00 \\
\hline 171003100801 & Franciscan & $\begin{array}{l}\text { Rogue River- } \\
\text { Siskiyou NF }\end{array}$ & $\begin{array}{r}\text { Rogue River/ } \\
\text { Illahe Creek }\end{array}$ & Rogue/Illahe & 2009 & 92.28 \\
\hline 171003111101 & Franciscan & $\begin{array}{l}\text { Rogue River- } \\
\text { Siskiyou NF }\end{array}$ & $\begin{array}{l}\text { Illinois River/ } \\
\text { Lawson Creek }\end{array}$ & Lawson Creek & & 98.27 \\
\hline 171003110804 & Franciscan & $\begin{array}{l}\text { Rogue River- } \\
\text { Siskiyou NF }\end{array}$ & $\begin{array}{l}\text { Illinois River/ } \\
\text { Klondike Creek }\end{array}$ & Florence Creek & 2009 & 100.00 \\
\hline 171003120501 & Franciscan & $\begin{array}{l}\text { Rogue River- } \\
\text { Siskiyou NF }\end{array}$ & Hunter Creek & $\begin{array}{l}\text { Upper Hunter } \\
\text { Creek }\end{array}$ & 2007 & 74.58 \\
\hline 171003070402 & High Cascades & $\begin{array}{l}\text { Rogue River- } \\
\text { Siskiyou NF }\end{array}$ & Big Butte Creek & $\begin{array}{l}\text { Clarks Fork Creek/ } \\
\text { Fourbit Creek }\end{array}$ & 2004 & 79.00 \\
\hline 171003070403 & High Cascades & $\begin{array}{l}\text { Rogue River- } \\
\text { Siskiyou NF }\end{array}$ & Big Butte Creek & Willow Creek & 2006 & 60.27 \\
\hline 171003070203 & High Cascades & $\begin{array}{l}\text { Rogue River- } \\
\text { Siskiyou NF }\end{array}$ & $\begin{array}{l}\text { South Fork } \\
\text { Rogue River }\end{array}$ & $\begin{array}{l}\text { Upper Middle Fork } \\
\text { Rogue River }\end{array}$ & 2005 & 97.55 \\
\hline 171003070105 & High Cascades & $\begin{array}{l}\text { Rogue River- } \\
\text { Siskiyou NF }\end{array}$ & $\begin{array}{l}\text { Upper Rogue } \\
\text { River }\end{array}$ & $\begin{array}{l}\text { Rogue River/ } \\
\text { Foster Creek }\end{array}$ & 2008 & 100.00 \\
\hline 171003070803 & High Cascades & $\begin{array}{l}\text { Rogue River- } \\
\text { Siskiyou NF }\end{array}$ & $\begin{array}{l}\text { Little Butte } \\
\text { Creek }\end{array}$ & $\begin{array}{l}\text { Upper South Fork } \\
\text { Little Butte Creek }\end{array}$ & 2005 & 100.00 \\
\hline 171003070113 & High Cascades & $\begin{array}{l}\text { Rogue River- } \\
\text { Siskiyou NF }\end{array}$ & $\begin{array}{l}\text { Upper Rogue } \\
\text { River }\end{array}$ & $\begin{array}{l}\text { Rogue River/ } \\
\text { Barr Creek }\end{array}$ & & 40.19 \\
\hline 171003070112 & High Cascades & $\begin{array}{l}\text { Rogue River- } \\
\text { Siskiyou NF }\end{array}$ & $\begin{array}{l}\text { Upper Rogue } \\
\text { River }\end{array}$ & Mill Creek & 2004 & 84.50 \\
\hline 171003070110 & High Cascades & $\begin{array}{l}\text { Rogue River- } \\
\text { Siskiyou NF }\end{array}$ & $\begin{array}{l}\text { Upper Rogue } \\
\text { River }\end{array}$ & Abbott Creek & & 97.03 \\
\hline 171003110603 & $\begin{array}{l}\text { Klamath- } \\
\text { Siskiyou }\end{array}$ & $\begin{array}{l}\text { Rogue River- } \\
\text { Siskiyou NF }\end{array}$ & $\begin{array}{l}\text { Illinois River/ } \\
\text { Josephine Creek }\end{array}$ & Sixmile Creek & 2003 & 97.44 \\
\hline 171003110102 & $\begin{array}{l}\text { Klamath- } \\
\text { Siskiyou }\end{array}$ & $\begin{array}{l}\text { Rogue River- } \\
\text { Siskiyou NF }\end{array}$ & $\begin{array}{l}\text { East Fork Illinois } \\
\text { River }\end{array}$ & Dunn Creek & 2009 & 96.45 \\
\hline 171003110303 & $\begin{array}{l}\text { Klamath- } \\
\text { Siskiyou }\end{array}$ & $\begin{array}{l}\text { Rogue River- } \\
\text { Siskiyou NF }\end{array}$ & Sucker Creek & Grayback Creek & 2007 & 79.80 \\
\hline 171003090107 & $\begin{array}{l}\text { Klamath- } \\
\text { Siskiyou }\end{array}$ & $\begin{array}{l}\text { Rogue River- } \\
\text { Siskiyou NF }\end{array}$ & $\begin{array}{l}\text { Upper Applegate } \\
\text { River }\end{array}$ & Lower Carberry & 2005 & 71.94 \\
\hline 171003090106 & $\begin{array}{l}\text { Klamath- } \\
\text { Siskiyou }\end{array}$ & $\begin{array}{l}\text { Rogue River- } \\
\text { Siskiyou NF }\end{array}$ & $\begin{array}{l}\text { Upper Applegate } \\
\text { River }\end{array}$ & $\begin{array}{l}\text { Steve Fork } \\
\text { Carberry Creek }\end{array}$ & 2002 & 93.72 \\
\hline 171003110604 & $\begin{array}{l}\text { Klamath- } \\
\text { Siskiyou }\end{array}$ & $\begin{array}{l}\text { Rogue River- } \\
\text { Siskiyou NF }\end{array}$ & $\begin{array}{l}\text { Illinois River/ } \\
\text { Josephine Creek }\end{array}$ & Baker Creek & 2005 & 97.94 \\
\hline 171003080106 & $\begin{array}{l}\text { Klamath- } \\
\text { Siskiyou }\end{array}$ & $\begin{array}{l}\text { Rogue River- } \\
\text { Siskiyou NF }\end{array}$ & Bear Creek & Ashland Creek & 2003 & 73.08 \\
\hline 171003090103 & $\begin{array}{l}\text { Klamath- } \\
\text { Siskiyou }\end{array}$ & $\begin{array}{l}\text { Rogue River- } \\
\text { Siskiyou NF }\end{array}$ & $\begin{array}{l}\text { Upper Applegate } \\
\text { River }\end{array}$ & $\begin{array}{l}\text { Elliott Creek/ } \\
\text { Dutch Creek }\end{array}$ & 2008 & 67.21 \\
\hline
\end{tabular}


Table 8-The 250 subwatersheds randomly chosen to determine the status and trend of inchannel processes (continued)

\begin{tabular}{|c|c|c|c|c|c|c|}
\hline USGS HUC & Province & $\begin{array}{c}\text { Administrative } \\
\text { unit }\end{array}$ & $\begin{array}{l}\text { Watershed } \\
\text { name }\end{array}$ & $\begin{array}{l}\text { Subwatershed } \\
\text { name }\end{array}$ & $\begin{array}{c}\text { Year } \\
\text { surveyed }^{a}\end{array}$ & $\begin{array}{l}\text { Federal } \\
\text { land }\end{array}$ \\
\hline & & & & & & Percent \\
\hline 171003110104 & $\begin{array}{l}\text { Klamath- } \\
\text { Siskiyou }\end{array}$ & $\begin{array}{l}\text { Rogue River- } \\
\text { Siskiyou NF }\end{array}$ & $\begin{array}{l}\text { East Fork } \\
\text { Illinois River }\end{array}$ & $\begin{array}{l}\text { Lower East Fork } \\
\text { Illinois River }\end{array}$ & 2003 & 34.59 \\
\hline 171003050101 & $\begin{array}{l}\text { Oregon } \\
\text { Coast }\end{array}$ & $\begin{array}{l}\text { Rogue River- } \\
\text { Siskiyou NF }\end{array}$ & $\begin{array}{l}\text { Coquille South, } \\
\text { Fork Lower }\end{array}$ & $\begin{array}{l}\text { Headwaters South } \\
\text { Fork Coquille } \\
\text { River }\end{array}$ & 2002 & 72.23 \\
\hline 171003050104 & $\begin{array}{c}\text { Oregon } \\
\text { Coast }\end{array}$ & $\begin{array}{l}\text { Rogue River- } \\
\text { Siskiyou NF }\end{array}$ & $\begin{array}{l}\text { Coquille South, } \\
\text { Fork Lower }\end{array}$ & Elk Creek & 2009 & 48.09 \\
\hline 171003020504 & $\begin{array}{l}\text { Klamath- } \\
\text { Siskiyou }\end{array}$ & Roseburg BLM & $\begin{array}{l}\text { South Umpqua } \\
\text { River }\end{array}$ & Stouts Creek & 2009 & 50.20 \\
\hline 171003020506 & $\begin{array}{l}\text { Klamath- } \\
\text { Siskiyou }\end{array}$ & Roseburg BLM & $\begin{array}{l}\text { South Umpqua } \\
\text { River }\end{array}$ & $\begin{array}{l}\text { Upper Shively } \\
\text { Oshea }\end{array}$ & 2005 & 30.27 \\
\hline 171003020901 & $\begin{array}{l}\text { Klamath- } \\
\text { Siskiyou }\end{array}$ & Roseburg BLM & $\begin{array}{l}\text { Lower Cow } \\
\text { Creek }\end{array}$ & Middle Creek & 2004 & 32.96 \\
\hline 171003030106 & $\begin{array}{l}\text { Oregon } \\
\text { Coast }\end{array}$ & Roseburg BLM & $\begin{array}{l}\text { Upper Umpqua } \\
\text { River }\end{array}$ & Yellow Creek & 2008 & 40.98 \\
\hline 171003010903 & $\begin{array}{l}\text { Western } \\
\text { Cascades }\end{array}$ & Roseburg BLM & Canton Creek & Pass Creek & 2009 & 79.59 \\
\hline 171002050104 & $\begin{array}{l}\text { Oregon } \\
\text { Coast }\end{array}$ & Salem BLM & $\begin{array}{l}\text { Upper Alsea } \\
\text { River }\end{array}$ & $\begin{array}{l}\text { Upper South } \\
\text { Fork Alsea River }\end{array}$ & 2009 & 66.90 \\
\hline 171002030201 & Oregon Coast & Salem BLM & Nestucca River & Upper Nestucca River & & 52.81 \\
\hline 171002040402 & Oregon Coast & Salem BLM & Upper Siletz River & $\begin{array}{l}\text { Lower North Fork } \\
\text { Siletz River }\end{array}$ & 2008 & 36.05 \\
\hline 170900090503 & $\begin{array}{l}\text { Western } \\
\text { Cascades }\end{array}$ & Salem BLM & $\begin{array}{l}\text { Upper Molalla } \\
\text { River }\end{array}$ & $\begin{array}{l}\text { Molalla River/ } \\
\text { Pine Creek }\end{array}$ & 2002 & 41.96 \\
\hline 170900110601 & $\begin{array}{l}\text { Western } \\
\text { Cascades }\end{array}$ & Salem BLM & $\begin{array}{l}\text { Lower Clackamas } \\
\text { River }\end{array}$ & $\begin{array}{l}\text { Upper Clear } \\
\text { Creek }\end{array}$ & & 25.18 \\
\hline 180102120406 & $\begin{array}{l}\text { Klamath- } \\
\text { Siskiyou }\end{array}$ & $\begin{array}{l}\text { Shasta-Trinity } \\
\text { NF }\end{array}$ & $\begin{array}{l}\text { Lower Hayfork } \\
\text { Creek }\end{array}$ & $\begin{array}{l}\text { Grassy Flat } \\
\text { Creek }\end{array}$ & 2007 & 94.31 \\
\hline 180102120302 & $\begin{array}{l}\text { Klamath- } \\
\text { Siskiyou }\end{array}$ & $\begin{array}{l}\text { Shasta-Trinity } \\
\text { NF }\end{array}$ & $\begin{array}{l}\text { Upper Hayfork } \\
\text { Creek }\end{array}$ & $\begin{array}{l}\text { North Fork } \\
\text { Hayfork Creek }\end{array}$ & & 46.29 \\
\hline 180200040106 & $\begin{array}{l}\text { Klamath- } \\
\text { Siskiyou }\end{array}$ & $\begin{array}{l}\text { Shasta-Trinity } \\
\text { NF }\end{array}$ & Ash Creek & Lower Ash Creek & 2008 & 90.03 \\
\hline 180102120304 & $\begin{array}{l}\text { Klamath- } \\
\text { Siskiyou }\end{array}$ & $\begin{array}{l}\text { Shasta-Trinity } \\
\text { NF }\end{array}$ & $\begin{array}{l}\text { Upper Hayfork } \\
\text { Creek }\end{array}$ & Gurley Gulch & 2009 & 87.50 \\
\hline 180200031103 & $\begin{array}{l}\text { Klamath- } \\
\text { Siskiyou }\end{array}$ & $\begin{array}{l}\text { Shasta-Trinity } \\
\text { NF }\end{array}$ & Squaw Creek & $\begin{array}{l}\text { Lower Squaw } \\
\text { Creek }\end{array}$ & & 88.51 \\
\hline 180102120402 & $\begin{array}{l}\text { Klamath- } \\
\text { Siskiyou }\end{array}$ & $\begin{array}{l}\text { Shasta-Trinity } \\
\text { NF }\end{array}$ & $\begin{array}{l}\text { Lower Hayfork } \\
\text { Creek }\end{array}$ & Philpot Creek & 2003 & 67.70 \\
\hline 180102110403 & $\begin{array}{l}\text { Klamath- } \\
\text { Siskiyou }\end{array}$ & $\begin{array}{l}\text { Shasta-Trinity } \\
\text { NF }\end{array}$ & Stuart Fork & Stoney Creek & 2004 & 71.90 \\
\hline 180102110605 & $\begin{array}{l}\text { Klamath- } \\
\text { Siskiyou }\end{array}$ & $\begin{array}{l}\text { Shasta-Trinity } \\
\text { NF }\end{array}$ & Weaver/Rush & Weaver Creek & 2008 & 49.81 \\
\hline 180102120204 & $\begin{array}{l}\text { Klamath- } \\
\text { Siskiyou }\end{array}$ & $\begin{array}{l}\text { Shasta-Trinity } \\
\text { NF }\end{array}$ & $\begin{array}{l}\text { Middle South } \\
\text { Fork Trinity River }\end{array}$ & Indian Valley Creek & 2005 & 96.82 \\
\hline
\end{tabular}


Table 8 - The 250 subwatersheds randomly chosen to determine the status and trend of inchannel processes (continued)

\begin{tabular}{|c|c|c|c|c|c|c|}
\hline USGS HUC & Province & $\begin{array}{c}\text { Administrative } \\
\text { unit }\end{array}$ & $\begin{array}{l}\text { Watershed } \\
\text { name }\end{array}$ & $\begin{array}{c}\text { Subwatershed } \\
\text { name }\end{array}$ & $\begin{array}{c}\text { Year } \\
\text { surveyed }^{a}\end{array}$ & $\begin{array}{c}\text { Federal } \\
\text { land }\end{array}$ \\
\hline & & & & & & Percent \\
\hline 180200040102 & $\begin{array}{l}\text { Klamath- } \\
\text { Siskiyou }\end{array}$ & $\begin{array}{l}\text { Shasta-Trinity } \\
\text { NF }\end{array}$ & Ash Creek & Upper Ash Creek & & 64.97 \\
\hline 180102120103 & $\begin{array}{l}\text { Klamath- } \\
\text { Siskiyou }\end{array}$ & $\begin{array}{l}\text { Shasta-Trinity } \\
\text { NF }\end{array}$ & $\begin{array}{l}\text { Upper South Fork } \\
\text { Trinity River }\end{array}$ & $\begin{array}{l}\text { Upper South Fork } \\
\text { Trinity River }\end{array}$ & & 94.98 \\
\hline 180200040303 & $\begin{array}{l}\text { Klamath- } \\
\text { Siskiyou }\end{array}$ & $\begin{array}{l}\text { Shasta-Trinity } \\
\text { NF }\end{array}$ & $\begin{array}{l}\text { Squaw Valley } \\
\text { Creek }\end{array}$ & Panther Creek & 2007 & 40.11 \\
\hline 180102110301 & $\begin{array}{c}\text { Klamath- } \\
\text { Siskiyou }\end{array}$ & $\begin{array}{l}\text { Shasta-Trinity } \\
\text { NF }\end{array}$ & $\begin{array}{l}\text { East Fork } \\
\text { Trinity River }\end{array}$ & $\begin{array}{l}\text { Upper East Fork } \\
\text { Trinity River }\end{array}$ & & 30.89 \\
\hline 180200040103 & $\begin{array}{c}\text { Klamath- } \\
\text { Siskiyou }\end{array}$ & $\begin{array}{l}\text { Shasta-Trinity } \\
\text { NF }\end{array}$ & Ash Creek & Horse Creek & & 28.03 \\
\hline 180102110102 & $\begin{array}{l}\text { Klamath- } \\
\text { Siskiyou }\end{array}$ & $\begin{array}{l}\text { Shasta-Trinity } \\
\text { NF }\end{array}$ & $\begin{array}{l}\text { Main Trinity } \\
\text { River }\end{array}$ & Little Trinity River & 2004 & 55.33 \\
\hline 180102111102 & $\begin{array}{l}\text { Klamath- } \\
\text { Siskiyou }\end{array}$ & $\begin{array}{l}\text { Shasta-Trinity } \\
\text { NF }\end{array}$ & Lower Trinity River & Little French Creek & & 95.83 \\
\hline 180200050401 & $\begin{array}{l}\text { Klamath- } \\
\text { Siskiyou }\end{array}$ & $\begin{array}{l}\text { Shasta-Trinity } \\
\text { NF }\end{array}$ & $\begin{array}{l}\text { Sacramento Arm } \\
\text { Shasta Lake }\end{array}$ & Middle Salt Creek & & 41.67 \\
\hline 180102111101 & $\begin{array}{l}\text { Klamath- } \\
\text { Siskiyou }\end{array}$ & $\begin{array}{l}\text { Shasta-Trinity } \\
\text { NF }\end{array}$ & $\begin{array}{l}\text { Lower Trinity } \\
\text { River }\end{array}$ & Sailor Bar Creek & & 94.16 \\
\hline 180200050103 & $\begin{array}{l}\text { Klamath- } \\
\text { Siskiyou }\end{array}$ & $\begin{array}{l}\text { Shasta-Trinity } \\
\text { NF }\end{array}$ & Box Canyon & $\begin{array}{l}\text { South Fork } \\
\text { Sacramento River }\end{array}$ & & 74.26 \\
\hline 180102110503 & $\begin{array}{l}\text { Klamath- } \\
\text { Siskiyou }\end{array}$ & $\begin{array}{l}\text { Shasta-Trinity } \\
\text { NF }\end{array}$ & $\begin{array}{l}\text { Trinity } \\
\text { Reservoir }\end{array}$ & $\begin{array}{l}\text { Lower Trinity } \\
\text { Reservoir }\end{array}$ & & 74.37 \\
\hline 180102111103 & $\begin{array}{l}\text { Klamath- } \\
\text { Siskiyou }\end{array}$ & $\begin{array}{l}\text { Shasta-Trinity } \\
\text { NF }\end{array}$ & $\begin{array}{l}\text { Lower Trinity } \\
\text { River }\end{array}$ & $\begin{array}{l}\text { Big French } \\
\text { Creek }\end{array}$ & 2007 & 100.00 \\
\hline 180200031202 & $\begin{array}{l}\text { Klamath- } \\
\text { Siskiyou }\end{array}$ & $\begin{array}{l}\text { Shasta-Trinity } \\
\text { NF }\end{array}$ & $\begin{array}{l}\text { Pit Arm Shasta } \\
\text { Lake }\end{array}$ & Potem Creek & 2009 & 65.56 \\
\hline 171002050405 & $\begin{array}{l}\text { Oregon } \\
\text { Coast }\end{array}$ & Siuslaw NF & Lower Alsea River & $\begin{array}{l}\text { Alsea River/ } \\
\text { Eckman Creek }\end{array}$ & 2008 & 31.35 \\
\hline 171002050302 & $\begin{array}{l}\text { Oregon } \\
\text { Coast }\end{array}$ & Siuslaw NF & Drift Creek & $\begin{array}{l}\text { Middle Drift Creek/ } \\
\text { Alsea River }\end{array}$ & & 36.59 \\
\hline 171002060501 & $\begin{array}{c}\text { Oregon } \\
\text { Coast }\end{array}$ & Siuslaw NF & Deadwood Creek & $\begin{array}{l}\text { Upper Deadwood } \\
\text { Creek }\end{array}$ & 2006 & 55.43 \\
\hline 171002050704 & $\begin{array}{l}\text { Oregon } \\
\text { Coast }\end{array}$ & Siuslaw NF & $\begin{array}{l}\text { Cummins Creek/ } \\
\text { Tenmile Creek/ } \\
\text { Mercer Lake } \\
\text { Frontal }\end{array}$ & Mercer Lake & & 58.62 \\
\hline 171002030204 & $\begin{array}{c}\text { Oregon } \\
\text { Coast }\end{array}$ & Siuslaw NF & Nestucca River & $\begin{array}{l}\text { Nestucca River/ } \\
\text { Niagara Creek }\end{array}$ & 2005 & 75.74 \\
\hline 171003030706 & $\begin{array}{c}\text { Oregon } \\
\text { Coast }\end{array}$ & Siuslaw NF & $\begin{array}{l}\text { Lower Smith } \\
\text { River }\end{array}$ & $\begin{array}{l}\text { Lower North } \\
\text { Fork Smith River }\end{array}$ & & 32.91 \\
\hline 171002050202 & $\begin{array}{c}\text { Oregon } \\
\text { Coast }\end{array}$ & Siuslaw NF & $\begin{array}{l}\text { Five Rivers/ } \\
\text { Lobster Creek }\end{array}$ & Upper Five Rivers & 2003 & 77.30 \\
\hline 171002060602 & $\begin{array}{c}\text { Oregon } \\
\text { Coast }\end{array}$ & Siuslaw NF & $\begin{array}{l}\text { Indian Creek/ } \\
\text { Lake Creek }\end{array}$ & $\begin{array}{l}\text { Lower Indian } \\
\text { Creek }\end{array}$ & 2005 & 53.66 \\
\hline
\end{tabular}


Table 8-The 250 subwatersheds randomly chosen to determine the status and trend of inchannel processes (continued)

\begin{tabular}{|c|c|c|c|c|c|c|}
\hline USGS HUC & Province & $\begin{array}{c}\text { Administrative } \\
\text { unit }\end{array}$ & $\begin{array}{c}\text { Watershed } \\
\text { name }\end{array}$ & $\begin{array}{l}\text { Subwatershed } \\
\text { name }\end{array}$ & $\begin{array}{c}\text { Year } \\
\text { surveyed }^{a}\end{array}$ & $\begin{array}{l}\text { Federal } \\
\text { land }\end{array}$ \\
\hline & & & & & & Percent \\
\hline 180101050201 & Franciscan & Six Rivers NF & $\begin{array}{l}\text { Upper North } \\
\text { Fork Eel River }\end{array}$ & $\begin{array}{l}\text { Headwaters North } \\
\text { Fork Eel River }\end{array}$ & 2002 & 84.57 \\
\hline 180101010301 & $\begin{array}{l}\text { Klamath- } \\
\text { Siskiyou }\end{array}$ & Six Rivers NF & $\begin{array}{l}\text { South Fork } \\
\text { Smith River }\end{array}$ & Prescott Fork & & 99.02 \\
\hline 180101010104 & $\begin{array}{l}\text { Klamath- } \\
\text { Siskiyou }\end{array}$ & Six Rivers NF & $\begin{array}{l}\text { North Fork } \\
\text { Smith River }\end{array}$ & Peridotite Canyon & & 95.84 \\
\hline 180102120505 & $\begin{array}{l}\text { Klamath- } \\
\text { Siskiyou }\end{array}$ & Six Rivers NF & Grouse/Madden & $\begin{array}{l}\text { Lower South Fork } \\
\text { Trintity River }\end{array}$ & & 88.43 \\
\hline 180101010204 & $\begin{array}{l}\text { Klamath- } \\
\text { Siskiyou }\end{array}$ & Six Rivers NF & $\begin{array}{l}\text { Middle Fork } \\
\text { Smith River }\end{array}$ & Shelley Creek & 2002 & 87.71 \\
\hline 180102090801 & $\begin{array}{l}\text { Klamath- } \\
\text { Siskiyou }\end{array}$ & Six Rivers NF & Bluff Creek & Cedar Creek & 2008 & 94.91 \\
\hline 180102091005 & $\begin{array}{l}\text { Klamath- } \\
\text { Siskiyou }\end{array}$ & Six Rivers NF & Blue Creek & $\begin{array}{l}\text { Lower Blue } \\
\text { Creek }\end{array}$ & & 35.56 \\
\hline 180102111203 & $\begin{array}{l}\text { Klamath- } \\
\text { Siskiyou }\end{array}$ & Six Rivers NF & $\begin{array}{l}\text { Trinity/South Fork } \\
\text { to Tish Tang }\end{array}$ & Horse Linto Creek & 2005 & 96.80 \\
\hline 180201160503 & Franciscan & Ukiah BLM & Lakeport & Lower Scotts Creek & & 34.01 \\
\hline 171003010402 & High Cascades & Umpqua NF & Clearwater & Bear Creek & 2004 & 100.00 \\
\hline 171003010103 & High Cascades & Umpqua NF & Diamond Lake & Diamond Lake & & 100.00 \\
\hline 171003010301 & High Cascades & Umpqua NF & $\begin{array}{l}\text { Upper North } \\
\text { Umpqua }\end{array}$ & $\begin{array}{l}\text { Warm Springs } \\
\text { Creek }\end{array}$ & 2005 & 100.00 \\
\hline 171003010708 & $\begin{array}{l}\text { Western } \\
\text { Cascades }\end{array}$ & Umpqua NF & $\begin{array}{l}\text { Middle North } \\
\text { Umpqua }\end{array}$ & Blitzen Facial & 2009 & 99.52 \\
\hline 171003020203 & $\begin{array}{l}\text { Western } \\
\text { Cascades }\end{array}$ & Umpqua NF & Jackson Creek & Squaw Creek & 2006 & 100.00 \\
\hline 171003020302 & $\begin{array}{l}\text { Western } \\
\text { Cascades }\end{array}$ & Umpqua NF & $\begin{array}{l}\text { Middle South } \\
\text { Umpqua River }\end{array}$ & Dumont Creek & 2002 & 100.00 \\
\hline 171003010801 & $\begin{array}{l}\text { Western } \\
\text { Cascades }\end{array}$ & Umpqua NF & Steamboat Creek & $\begin{array}{l}\text { Steamboat } \\
\text { Headwaters }\end{array}$ & 2004 & 96.86 \\
\hline 171003011104 & $\begin{array}{l}\text { Western } \\
\text { Cascades }\end{array}$ & Umpqua NF & Little River & Emile Creek & 2004 & 82.88 \\
\hline 171003011106 & $\begin{array}{l}\text { Western } \\
\text { Cascades }\end{array}$ & Umpqua NF & Little River & $\begin{array}{l}\text { Upper Cavitt } \\
\text { Creek }\end{array}$ & 2007 & 100.00 \\
\hline 171003020403 & $\begin{array}{l}\text { Western } \\
\text { Cascades }\end{array}$ & Umpqua NF & $\begin{array}{l}\text { Elk Creek/ } \\
\text { South Umpqua }\end{array}$ & Drew Creek & 2005 & 92.57 \\
\hline 170900020101 & $\begin{array}{l}\text { Western } \\
\text { Cascades }\end{array}$ & Umpqua NF & Row River & Layng Creek & 2004 & 88.76 \\
\hline 171003011101 & $\begin{array}{l}\text { Western } \\
\text { Cascades }\end{array}$ & Umpqua NF & Little River & $\begin{array}{l}\text { Little River } \\
\text { Headwaters }\end{array}$ & 2003 & 98.59 \\
\hline 171003010501 & $\begin{array}{l}\text { Western } \\
\text { Cascades }\end{array}$ & Umpqua NF & Fish Creek & $\begin{array}{l}\text { Fish Creek } \\
\text { Headwaters }\end{array}$ & 2008 & 100.00 \\
\hline 170200090203 & $\begin{array}{l}\text { North } \\
\text { Cascades }\end{array}$ & Wenatchee NF & Upper Chelan & Fish Creek & 2004 & 98.95 \\
\hline
\end{tabular}


Table 8 - The 250 subwatersheds randomly chosen to determine the status and trend of inchannel processes (continued)

\begin{tabular}{|c|c|c|c|c|c|c|}
\hline USGS HUC & Province & $\begin{array}{c}\text { Administrative } \\
\text { unit }\end{array}$ & $\begin{array}{c}\text { Watershed } \\
\text { name }\end{array}$ & $\begin{array}{l}\text { Subwatershed } \\
\text { name }\end{array}$ & $\begin{array}{c}\text { Year } \\
\text { surveyed }^{a}\end{array}$ & $\begin{array}{l}\text { Federal } \\
\text { land }\end{array}$ \\
\hline & & & & & & Percent \\
\hline 170300010301 & $\begin{array}{l}\text { North } \\
\text { Cascades }\end{array}$ & Wenatchee NF & $\begin{array}{l}\text { Middle Upper } \\
\text { Yakima River }\end{array}$ & Swauk Creek & 2002 & 74.68 \\
\hline 170200110303 & $\begin{array}{l}\text { North } \\
\text { Cascades }\end{array}$ & Wenatchee NF & Nason/Tumwater & $\begin{array}{l}\text { Chiwaukum } \\
\text { Creek }\end{array}$ & 2008 & 89.97 \\
\hline 170200110302 & $\begin{array}{l}\text { North } \\
\text { Cascades }\end{array}$ & Wenatchee NF & Nason/Tumwater & $\begin{array}{l}\text { Upper Nason } \\
\text { Creek }\end{array}$ & 2009 & 90.14 \\
\hline 170200110404 & $\begin{array}{l}\text { North } \\
\text { Cascades }\end{array}$ & Wenatchee NF & Icicle/Chumstick & Chumstick Creek & & 45.30 \\
\hline 170200110202 & $\begin{array}{l}\text { North } \\
\text { Cascades }\end{array}$ & Wenatchee NF & Chiawa River & $\begin{array}{l}\text { Middle Chiawa } \\
\text { River }\end{array}$ & & 100.00 \\
\hline 170200110203 & $\begin{array}{l}\text { North } \\
\text { Cascades }\end{array}$ & Wenatchee NF & Chiawa River & $\begin{array}{l}\text { Lower Chiawa } \\
\text { River }\end{array}$ & 2008 & 87.36 \\
\hline 170300020303 & $\begin{array}{l}\text { North } \\
\text { Cascades }\end{array}$ & Wenatchee NF & $\begin{array}{l}\text { Naches River/ } \\
\text { Tieton River }\end{array}$ & $\begin{array}{l}\text { North Fork } \\
\text { Tieton River }\end{array}$ & 2009 & 100.00 \\
\hline 170900040501 & $\begin{array}{l}\text { Western } \\
\text { Cascades }\end{array}$ & Willamette NF & $\begin{array}{l}\text { Mckenzie River/ } \\
\text { Quartz Creek }\end{array}$ & Quartz Creek & 2003 & 31.71 \\
\hline 170900040201 & $\begin{array}{l}\text { Western } \\
\text { Cascades }\end{array}$ & Willamette NF & Horse Creek & $\begin{array}{l}\text { Upper Separation } \\
\text { Creek }\end{array}$ & 2004 & 100.00 \\
\hline 170900060401 & $\begin{array}{l}\text { Western } \\
\text { Cascades }\end{array}$ & Willamette NF & Quartzville Creek & $\begin{array}{l}\text { Upper Quartzville } \\
\text { Creek }\end{array}$ & 2002 & 100.00 \\
\hline 170900050301 & $\begin{array}{l}\text { Western } \\
\text { Cascades }\end{array}$ & Willamette NF & $\begin{array}{l}\text { Detroit Reservoir/ } \\
\text { Blowout Divide } \\
\text { Creek }\end{array}$ & $\begin{array}{l}\text { Upper Blowout } \\
\text { Creek }\end{array}$ & 2008 & 99.81 \\
\hline 170900050304 & $\begin{array}{l}\text { Western } \\
\text { Cascades }\end{array}$ & Willamette NF & $\begin{array}{l}\text { Detroit Reservoir/ } \\
\text { Blowout Divide } \\
\text { Creek }\end{array}$ & $\begin{array}{l}\text { Detroit Reservoir/ } \\
\text { Kinney Creek }\end{array}$ & 2009 & 39.79 \\
\hline 170900010603 & $\begin{array}{l}\text { Western } \\
\text { Cascades }\end{array}$ & Willamette NF & $\begin{array}{l}\text { North Fork of } \\
\text { Middle Fork } \\
\text { Willamette River }\end{array}$ & $\begin{array}{l}\text { North Fork of } \\
\text { Middle Fork } \\
\text { Willamette River/ } \\
\text { Fisher Creek }\end{array}$ & 2003 & 100.00 \\
\hline 170900050202 & $\begin{array}{l}\text { Western } \\
\text { Cascades }\end{array}$ & Willamette NF & $\begin{array}{l}\text { North Fork } \\
\text { Breitenbush } \\
\text { River }\end{array}$ & $\begin{array}{l}\text { North Fork } \\
\text { Breitenbush } \\
\text { River }\end{array}$ & 2006 & 94.39 \\
\hline 170900050203 & $\begin{array}{l}\text { Western } \\
\text { Cascades }\end{array}$ & Willamette NF & $\begin{array}{l}\text { North Fork } \\
\text { Breitenbush } \\
\text { River }\end{array}$ & Humbug Creek & 2006 & 100.00 \\
\hline 170900010303 & $\begin{array}{l}\text { Western } \\
\text { Cascades }\end{array}$ & Willamette NF & $\begin{array}{l}\text { Salt Creek/ } \\
\text { Willamette } \\
\text { River }\end{array}$ & $\begin{array}{l}\text { Lower Salt } \\
\text { Creek }\end{array}$ & 2005 & 100.00 \\
\hline 170900010902 & $\begin{array}{l}\text { Western } \\
\text { Cascades }\end{array}$ & Willamette NF & Fall Creek & $\begin{array}{l}\text { Fall Creek/ } \\
\text { Hehe Creek }\end{array}$ & 2004 & 97.09 \\
\hline 170900040302 & $\begin{array}{l}\text { Western } \\
\text { Cascades }\end{array}$ & Willamette NF & $\begin{array}{l}\text { South Fork } \\
\text { Mckenzie River }\end{array}$ & $\begin{array}{l}\text { South Fork } \\
\text { Mckenzie River/ } \\
\text { Elk Creek }\end{array}$ & 2009 & 100.00 \\
\hline
\end{tabular}


Table 8 - The 250 subwatersheds randomly chosen to determine the status and trend of inchannel processes (continued)

\begin{tabular}{|c|c|c|c|c|c|c|}
\hline USGS HUC & Province & $\begin{array}{c}\text { Administrative } \\
\text { unit }\end{array}$ & $\begin{array}{c}\text { Watershed } \\
\text { name }\end{array}$ & $\begin{array}{l}\text { Subwatershed } \\
\text { name }\end{array}$ & $\begin{array}{c}\text { Year } \\
\text { surveyed }^{a}\end{array}$ & $\begin{array}{l}\text { Federal } \\
\text { land }\end{array}$ \\
\hline & & & & & & Percent \\
\hline 170900010504 & $\begin{array}{l}\text { Western } \\
\text { Cascades }\end{array}$ & Willamette NF & $\begin{array}{c}\text { Hills Creek } \\
\text { Reservoir }\end{array}$ & $\begin{array}{l}\text { Middle Fork } \\
\text { Willamette River/ } \\
\text { Larison Creek }\end{array}$ & 2003 & 95.90 \\
\hline 170900040102 & $\begin{array}{l}\text { Western } \\
\text { Cascades }\end{array}$ & Willamette NF & $\begin{array}{l}\text { Upper Mckenzie } \\
\text { River }\end{array}$ & $\begin{array}{l}\text { Hackleman } \\
\text { Creek }\end{array}$ & 2004 & 94.34 \\
\hline 170900040307 & $\begin{array}{l}\text { Western } \\
\text { Cascades }\end{array}$ & Willamette NF & $\begin{array}{l}\text { South Fork } \\
\text { Mckenzie River }\end{array}$ & $\begin{array}{l}\text { South Fork } \\
\text { Mckenzie River/ } \\
\text { Cougar Reservoir }\end{array}$ & 2008 & 90.40 \\
\hline 170900060503 & $\begin{array}{l}\text { Western } \\
\text { Cascades }\end{array}$ & Willamette NF & $\begin{array}{l}\text { Middle Santiam } \\
\text { River }\end{array}$ & Donaca Creek & 2002 & 86.19 \\
\hline 170900050503 & $\begin{array}{l}\text { Western } \\
\text { Cascades }\end{array}$ & Willamette NF & $\begin{array}{l}\text { Little North } \\
\text { Santiam River }\end{array}$ & Gold Creek & 2005 & 100.00 \\
\hline 170900050107 & $\begin{array}{l}\text { Western } \\
\text { Cascades }\end{array}$ & Willamette NF & $\begin{array}{l}\text { Upper North } \\
\text { Santiam River }\end{array}$ & $\begin{array}{l}\text { Boulder Creek/ } \\
\text { Marys Creek }\end{array}$ & 2005 & 64.15 \\
\hline 170900010702 & $\begin{array}{l}\text { Western } \\
\text { Cascades }\end{array}$ & Willamette NF & $\begin{array}{l}\text { Middle Fork } \\
\text { Willamette/ } \\
\text { Lookout Point }\end{array}$ & $\begin{array}{l}\text { Lookout Point } \\
\text { Reservoir }\end{array}$ & 2007 & 71.64 \\
\hline 170900010106 & $\begin{array}{l}\text { Western } \\
\text { Cascades }\end{array}$ & Willamette NF & $\begin{array}{l}\text { Upper Middle } \\
\text { Fork Willamette } \\
\text { River }\end{array}$ & $\begin{array}{l}\text { Lower Middle } \\
\text { Fork Willamette } \\
\text { River }\end{array}$ & 2003 & 65.59 \\
\hline 170900060604 & $\begin{array}{l}\text { Western } \\
\text { Cascades }\end{array}$ & Willamette NF & $\begin{array}{l}\text { South Santiam } \\
\text { River }\end{array}$ & Trout Creek & 2006 & 92.03 \\
\hline 170900040107 & $\begin{array}{l}\text { Western } \\
\text { Cascades }\end{array}$ & Willamette NF & $\begin{array}{l}\text { Upper Mckenzie } \\
\text { River }\end{array}$ & White Branch & 2006 & 100.00 \\
\hline 170900010202 & $\begin{array}{l}\text { Western } \\
\text { Cascades }\end{array}$ & Willamette NF & Hills Creek & $\begin{array}{l}\text { Upper Hills } \\
\text { Creek }\end{array}$ & 2009 & 100.00 \\
\hline 180102030201 & $\begin{array}{l}\text { High } \\
\text { Cascades }\end{array}$ & Winema NF & Klamath Lake & Threemile & 2003 & 90.59 \\
\hline
\end{tabular}

Includes the U.S. Geological Survey hydrologic unit code (USGS HUC), the aquatic province, the national forest (NF), Bureau of Land Management (BLM) unit, or national park (NP) that manages the land, the fifth-field watershed name, the sixth-field subwatershed name, and the percentage of the total subwatershed area that is federally owned.

${ }^{a}$ No date is listed for "year surveyed" if the watershed was not surveyed. 


\section{Appendix 4: Model Structures, Evaluation Criteria, and Status and Trend Maps for Each of the Provincial Decision-Support Models}

The model structure, evaluation criteria, and watershed condition status and trend maps are shown for each aquatic province within the Northwest Forest Plan (NWFP) area.

\section{Model Structures}

The NWFP Aquatic and Riparian Effectiveness Monitoring Program (AREMP) team worked with local experts from each province to develop evaluation models for upslope/ riparian and inchannel data. These models hierarchically aggregate a number of attributes into broader indexes of inchannel and watershed condition. A graphical depiction of the model structures for each province is contained in this appendix (figs. 48 through 53). Some model sections were "turned off" in this iteration because the corresponding data were not available. These unused portions of the models are indicated by gray text.

\section{Attribute-Level Scoring}

A model begins by reading in a set of data observations, which we call “attributes,” for a watershed. These attributes are the rightmost nodes in the model structure diagrams. For example, attributes for the High Cascades province (fig. 48) watershed condition model includes "watershed road density.” Details about the attributes for each provincial model are shown in table 9 (watershed condition) and table 10 (inchannel condition). The "Attribute and measure" column contains the attribute name, units of measure, and qualifiers if any, (e.g., temperature is evaluated differently in watersheds depending on whether bull trout, Salvelinus confluentus, are present).

As part of the model-building process, the provincial experts developed evaluation criteria for each attribute. These evaluation criteria determine how any particular data value is scored on a common scale from +1 to -1 according to its relationship to watershed condition. As the attribute data for each watershed are read into the model, they are each compared to their respective evaluation criteria to produce an evaluation score for each between +1 and -1 .
For the Olympic Peninsula province, if there are no riparian roads (density $=0$ ), then the evaluated score would be +1 ; if road density was $0.1 \mathrm{mi} / \mathrm{mi}^{2}$ of riparian area or greater, the score would be - 1 ; and if the density falls between 0 and $0.1 \mathrm{mi} / \mathrm{mi}^{2}$, the attribute receives a score that is a linear interpolation between +1 and -1 (e.g., $0.05 \mathrm{mi} / \mathrm{mi}^{2}$ would evaluate to 0). Note that there is an important difference between a data value of "zero" and "no data." Data values of zero (e.g., riparian roads example above) are compared to their evaluation curve the same as all other data values. However, if data for a particular attribute are lacking in a particular watershed, then that attribute is given an evaluated score of zero, representing a neutral value that does not indicate either good or poor condition. The "Data value" and "Evaluated score" columns show how the raw data values correspond to evaluated scores, and the "Curve shape” column gives a graphical depiction of this (generally linear) function, with data values represented on the $\mathrm{x}$-axis and corresponding evaluation scores on the y-axis. The "Source" column gives the basis on which the curve was constructed, most often the professional judgment of workshop participants but also including data sets and published reports or standards.

\section{Aggregation of Attribute Scores}

After each attribute datum is evaluated, the model begins to aggregate these scores together in a hierarchical fashion. The combined score is passed up to the next level in the model hierarchy, where it is combined again with results from other parts of the model. The modeling software enables a number of different aggregation functions, but we limited choice to the three simplest:

- $\quad$ MIN: take the minimum score from those being aggregated.

- AVE: take the average of the aggregated scores.

- MAX: take the maximum score from those being aggregated. 
These functions determine whether the situation is of a "limiting factor" type, where the worst condition score determines the combined score, a "partially compensatory" situation, where scores are all counted equally, or a "fully compensatory" situation, where the best score determines the combined score.

In addition to operators, each node in the model can also be assigned a weight. These weights are listed on the model structure diagrams. For example, the North Cascades model (fig. 50) weighted riparian tree size at 0.7 and watershed-wide vegetation at 0.3 , so the overall vegetation score comes 70 percent from riparian value and 30 percent from the watershed value. These weights are only relevant under the AVE operator.

Status and trend maps for each province follow (figs. 54 through 68). 


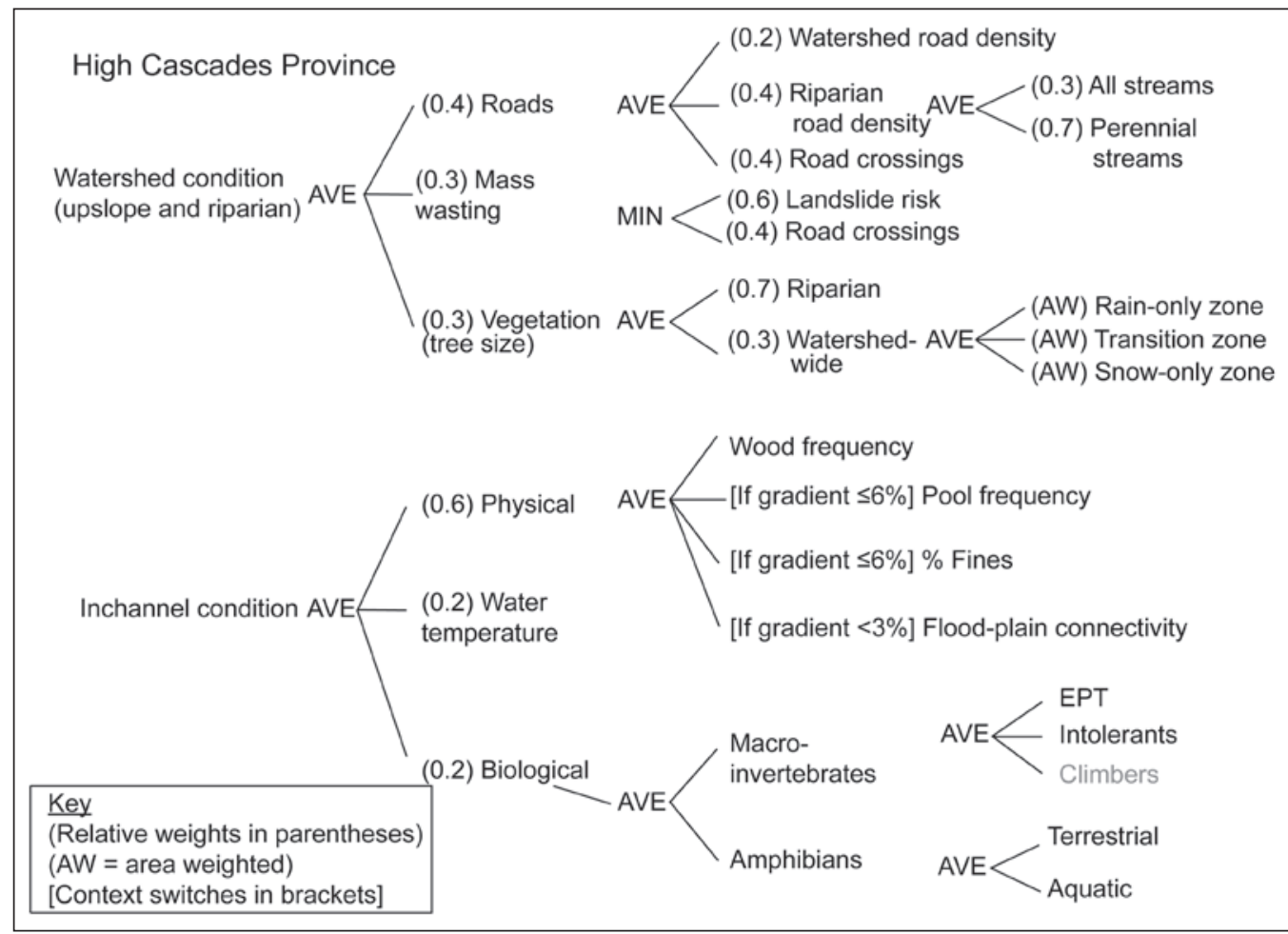

Figure 48-High Cascades province evaluation model structures for watershed and inchannel conditions $(\mathrm{EPT}=$ percentage of taxa in Ephemeroptera, Plecoptera, and Tricoptera AVE = average of the aggregated score, MIN = minimum score from those being aggregated). [] = use the indicator if context switch is true. Gray indicator was not used because of unavailable data.

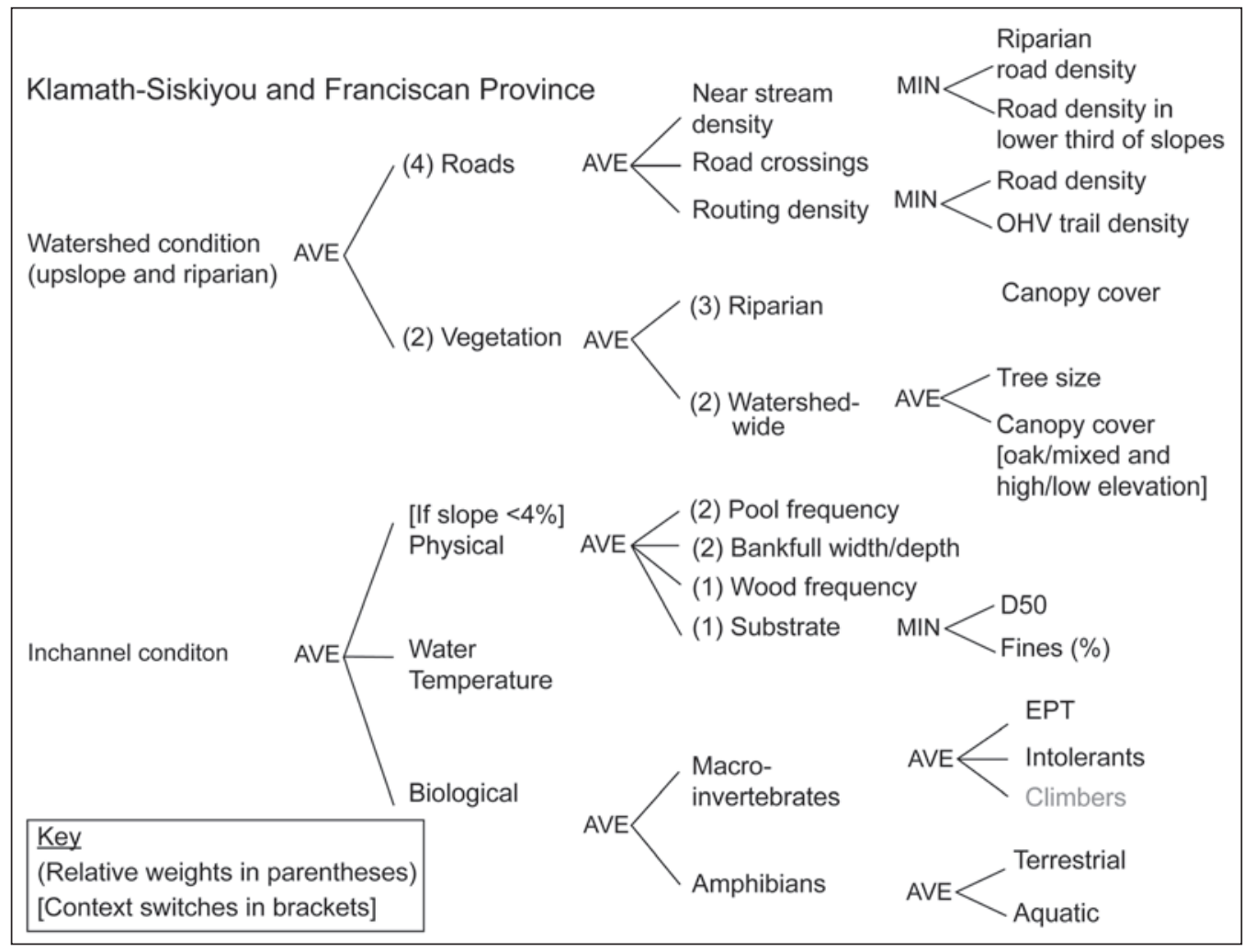

Figure 49-Klamath-Siskiyou and Franciscan province evaluation model structures for watershed and inchannel conditions $(\mathrm{EPT}=$ percentage of taxa in Ephemeroptera, Plecoptera, and Tricoptera; D50 = median particle size; $\mathrm{OHV}=$ off-highway vehicle, AVE $=$ average of the aggregated scores, MIN = Minimum score from those being aggregated scores). [] = use the indicator if context switch is true. Gray indicators were not used because of unavailable data. 


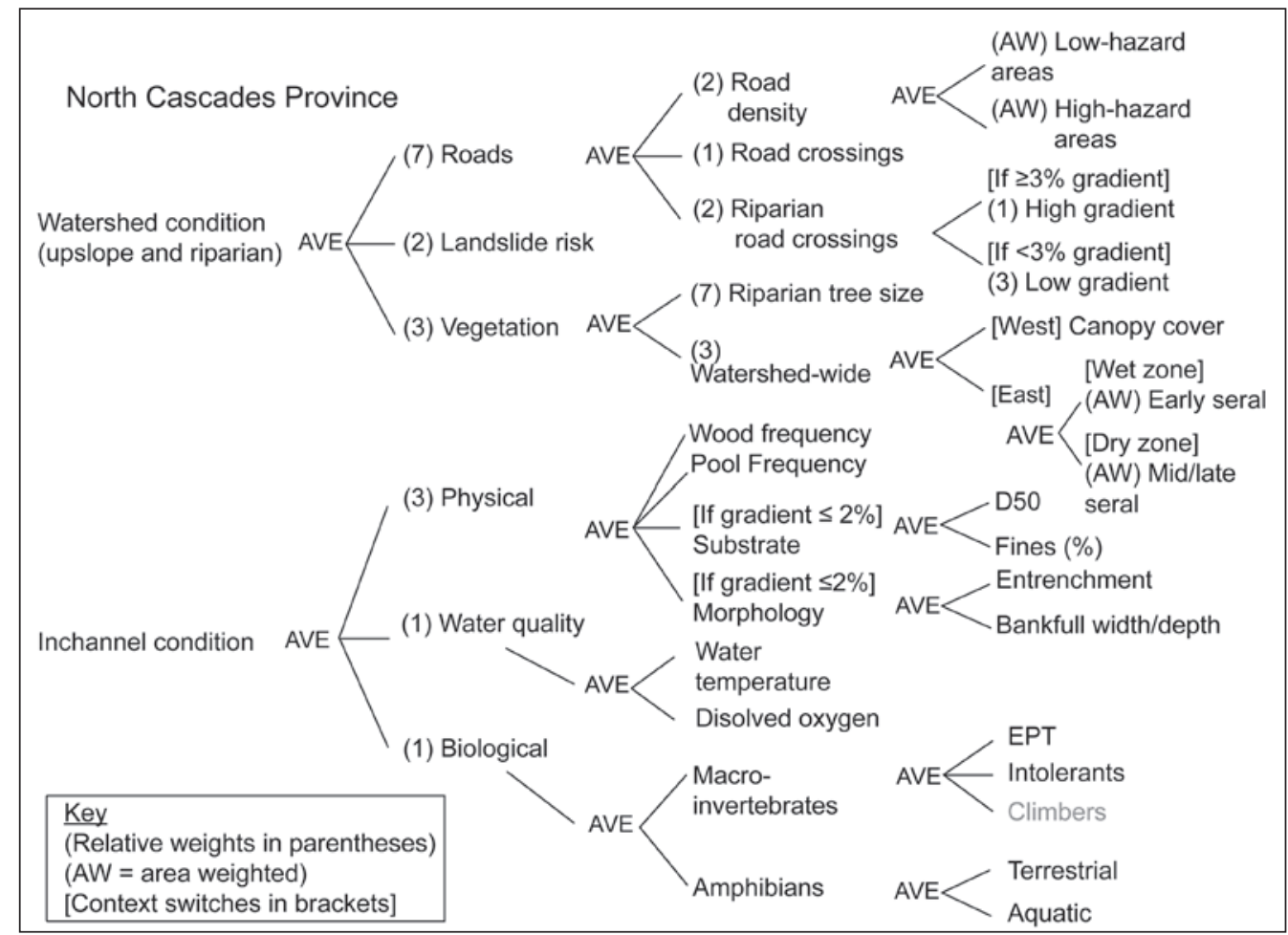

Figure 50-North Cascades province evaluation model structures for watershed and inchannel conditions $(\mathrm{EPT}=$ percentage of taxa in Ephemeroptera, Plecoptera, and Tricoptera, AVE = average of the aggregated scores, D50 = median particle size). [] = use the indicator if context switch is true. Gray indicator was not used because of unavailable data.

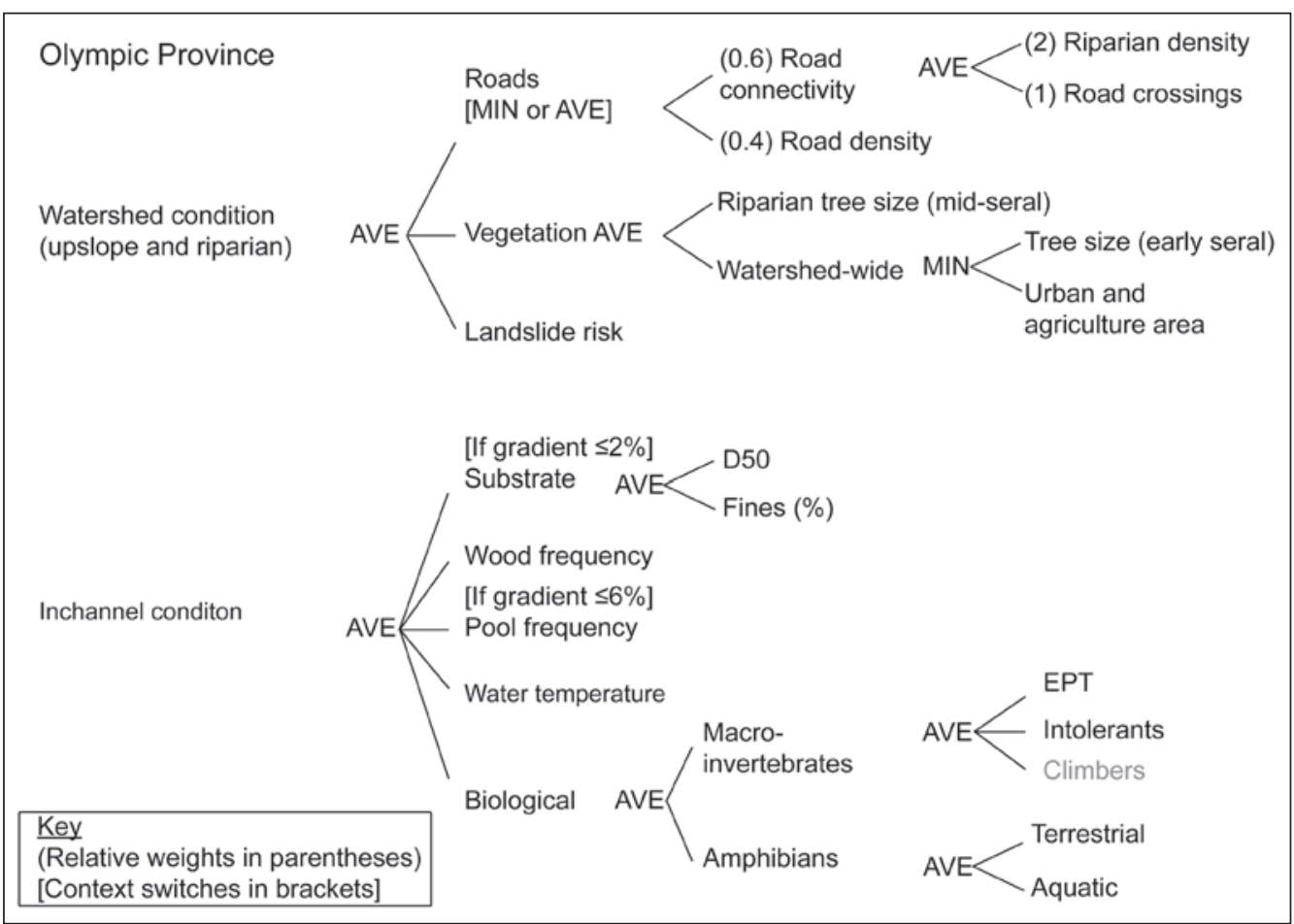

Figure 51-Olympic Peninsula province evaluation model structures for watershed and inchannel conditions $(\mathrm{EPT}=$ percentage of taxa in Ephemeroptera, Plecoptera, and Tricoptera, AVE = average, $\mathrm{MIN}=$ minimum score from those being aggregated, D50 = median particle size). [] = use the indicator if context switch is true. Gray indicators were not used because of unavailable data. 


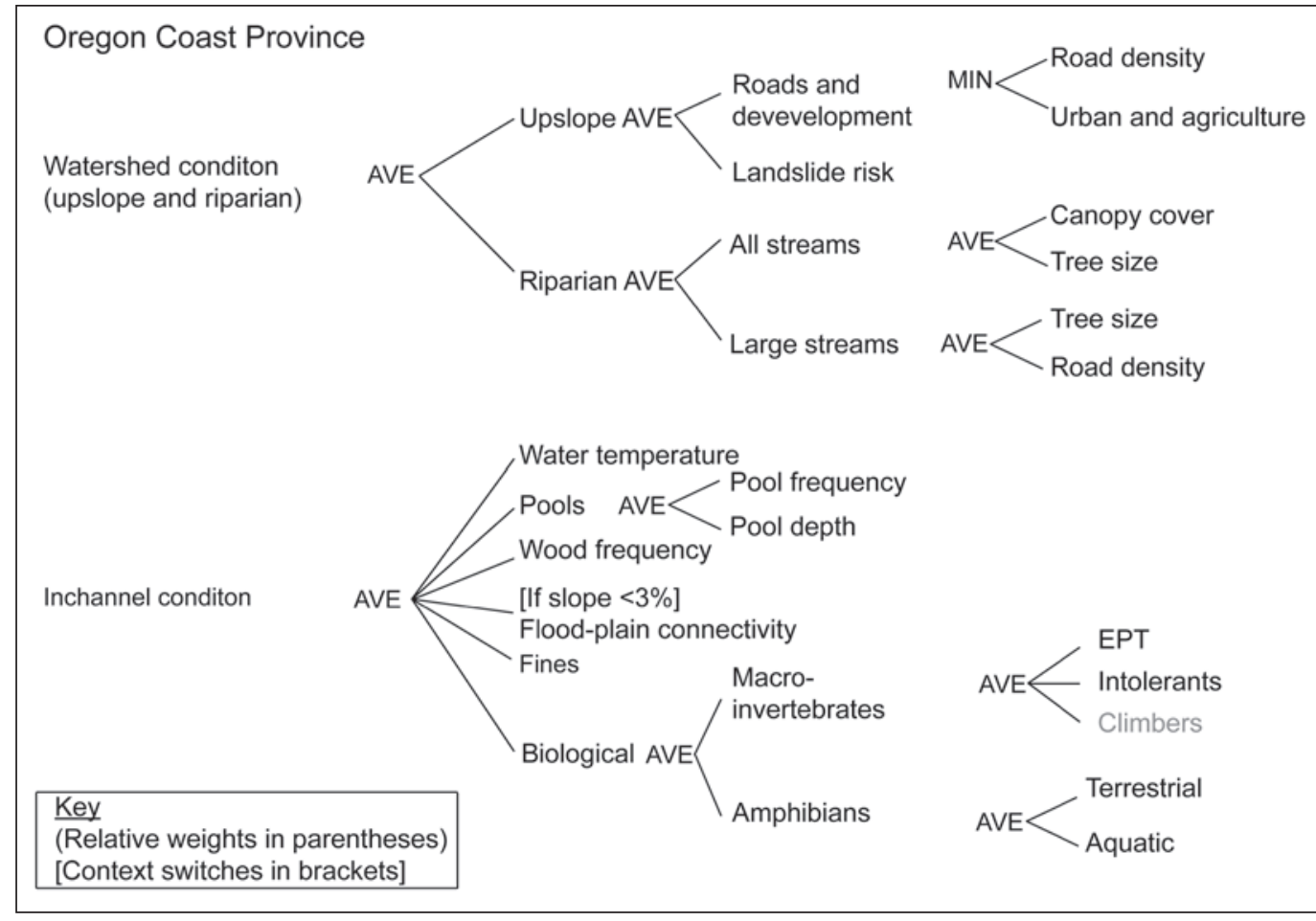

Figure 52-Oregon Coast province evaluation model structures for watershed and inchannel conditions (EPT = percentage of taxa in Ephemeroptera, Plecoptera, and Tricoptera, AVE = average of the aggregated scores, $\mathrm{MIN}=$ minimum score from those being aggregated). [] = use the indicator if context switch is true. Gray indicator was not used because of unavailable data.

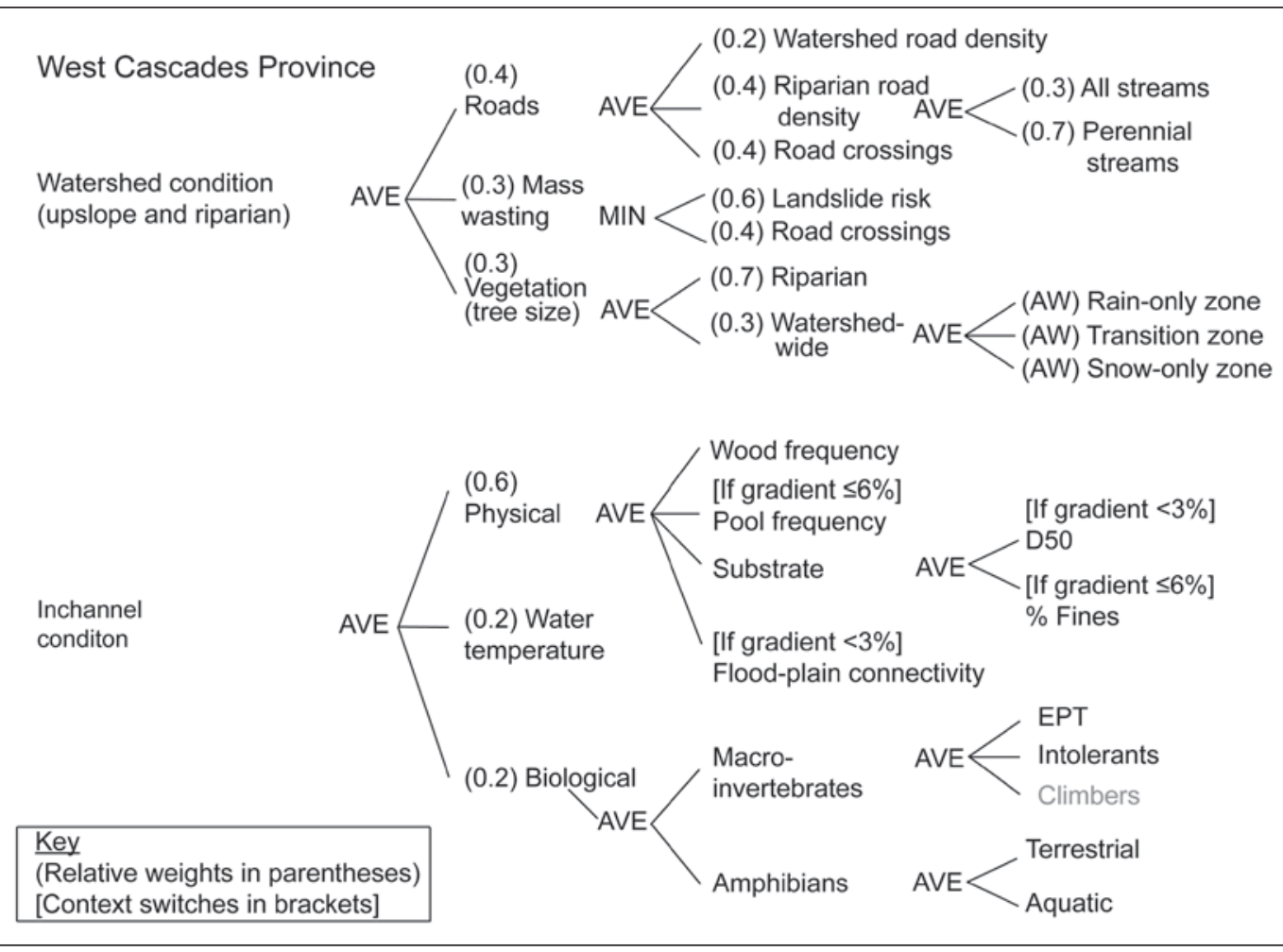

Figure 53-West Cascades province evaluation model structures for watershed and inchannel conditions $(\mathrm{EPT}=$ percentage of taxa in Ephemeroptera, Plecoptera, and Tricoptera, D50 = median particle size, AVE = average of the aggregated scores, $\mathrm{MIN}=$ minimum score from those being aggregated). [] = use the indicator if context switch is true. Gray indicator was not used because of unavailable data. 
Table 9-Evaluation criteria used in watershed-level decision-support models for each aquatic province

\begin{tabular}{|c|c|c|c|c|}
\hline Attribute and measure & $\begin{array}{l}\text { Data } \\
\text { value }\end{array}$ & $\begin{array}{l}\text { Evaluated } \\
\text { score }\end{array}$ & $\begin{array}{l}\text { Curve } \\
\text { shape }\end{array}$ & Source \\
\hline \multicolumn{5}{|l|}{ High Cascades province } \\
\hline \multirow{3}{*}{$\begin{array}{l}\text { Roads-watershed road density } \\
\quad \text { (road mi/watershed area } \mathrm{mi}^{2} \text { ) }\end{array}$} & 0.5 & +1 & & \multirow{3}{*}{$\begin{array}{l}\text { Aquatic and Riparian Effectiveness } \\
\text { Monitoring Program (AREMP) } \\
\text { workshop 4/15-17/2008 }\end{array}$} \\
\hline & 2 & 0 & & \\
\hline & 4 & -1 & & \\
\hline \multirow{2}{*}{$\begin{array}{l}\text { Roads-riparian-all streams, } \\
\text { 120-ft buffer (road mi/stream } \\
\text { mi) }\end{array}$} & 0.01 & +1 & & \multirow{2}{*}{ AREMP workshop 9/16/2009 } \\
\hline & 0.1 & -1 & & \\
\hline \multirow{2}{*}{$\begin{array}{l}\text { Roads-riparian-perennial } \\
\text { streams, 180-ft buffer (road } \\
\text { mi/perennial stream mi) } \\
\end{array}$} & 0.01 & +1 & & \multirow{2}{*}{ AREMP workshop 4/15-17/2008 } \\
\hline & 0.1 & -1 & & \\
\hline \multirow{2}{*}{$\begin{array}{l}\text { Roads-crossings } \\
\text { (number/stream mi) }\end{array}$} & 0.01 & +1 & & \multirow[b]{2}{*}{ AREMP workshop 4/15-17/2008 } \\
\hline & 1.25 & -1 & & \\
\hline \multirow{2}{*}{$\begin{array}{l}\text { Mass wasting-landslide risk } \\
\text { (change in average landslide } \\
\text { density [per km²] from an } \\
\text { optimum forested, unroaded } \\
\text { state) }\end{array}$} & 0.1 & +1 & & \multirow[b]{2}{*}{ AREMP workshop 4/15-17/2008 } \\
\hline & 0.3 & -1 & & \\
\hline \multirow{2}{*}{$\begin{array}{l}\text { Mass wasting-road crossings in } \\
\text { high-risk areas } \\
\text { (number/stream mi) }\end{array}$} & 0.01 & +1 & & \multirow{2}{*}{ AREMP workshop 9/16/2009 } \\
\hline & 0.3 & -1 & & \\
\hline \multirow{3}{*}{$\begin{array}{l}\text { Vegetation-riparian, } \\
\text { QMD }^{a} \geq 8 \text { - or } 14 \text {-in } \\
\text { (lodgepole/other) and canopy } \\
\text { cover } \geq 40 \% \text {, all species, } 160 \text { - } \\
\text { ft buffer }\left(\mathrm{mi}^{2} / \text { riparian forest- }\right. \\
\text { capable } \mathrm{mi}^{2} \text { ) }\end{array}$} & 0.3 & -1 & & \multirow[b]{3}{*}{ AREMP workshop 4/15-17/2008 } \\
\hline & 0.5 & 0 & & \\
\hline & 0.7 & +1 & & \\
\hline \multirow{2}{*}{$\begin{array}{l}\text { Vegetation-watershed-rain-on- } \\
\text { snow band QMD } \geq 8 \text {-in and } \\
\text { cover } \geq 40 / 70 \% \text { (dry/wet } \\
\text { zone) }\left(\mathrm{mi}^{2} / \text { watershed forest- }\right. \\
\left.\text { capable } \mathrm{mi}^{2}\right)\end{array}$} & 0.35 & -1 & & \multirow{2}{*}{$\begin{array}{l}\text { AREMP workshop 4/15-17/2008 } \\
\text { Grant et al. (2008) }\end{array}$} \\
\hline & 0.85 & +1 & & \\
\hline \multirow{2}{*}{$\begin{array}{l}\text { Vegetation-watershed-rain- } \\
\text { only and snow-only bands, } \\
\text { QMD } \geq 8 \text {-inch and cover } \geq \\
40 / 70 \% \text { (dry/wet zone) } \\
{\text { ( } \mathrm{mi}^{2} / \text { watershed forest- }}_{\text {capable } \mathrm{mi}^{2} \text { ) }}\end{array}$} & 0.1 & -1 & & \multirow{2}{*}{$\begin{array}{l}\text { AREMP workshop 4/15-17/2008 } \\
\text { Grant et al. (2008) }\end{array}$} \\
\hline & 0.45 & +1 & & \\
\hline
\end{tabular}

Klamath-Siskiyou and Franciscan province

\begin{tabular}{l|c|c|c|c}
\hline \multirow{2}{*}{$\begin{array}{c}\text { Roads-crossings } \\
\text { (number/stream mi) }\end{array}$} & 0.5 & +1 & -1 & AREMP workshop 2003 \\
\cline { 2 - 3 } $\begin{array}{c}\text { Roads-riparian, 160-ft buffer } \\
\left(\text { road mi/riparian area mi }{ }^{2}\right)\end{array}$ & 1 & -1 & +1 & AREMP workshop 10/14/2009 \\
\cline { 2 - 3 } $\begin{array}{c}\text { Roads-lower 1/3 of slope } \\
\left(\text { road mi/lower } 1 / 3 \text { slope } \mathrm{mi}^{2}\right)\end{array}$ & 2 & -1 & & AREMP workshop 2003
\end{tabular}


Table 9-Evaluation criteria used in watershed-level decision-support models for each aquatic province (continued)

\begin{tabular}{|c|c|c|c|c|}
\hline Attribute and measure & $\begin{array}{l}\text { Data } \\
\text { value }\end{array}$ & $\begin{array}{l}\text { Evaluated } \\
\text { score }\end{array}$ & $\begin{array}{l}\text { Curve } \\
\text { shape }\end{array}$ & Source \\
\hline \multirow{3}{*}{$\begin{array}{l}\text { Roads-watershed, designated } \\
\text { motorized off-highway } \\
\text { vehicle trail (trail } \\
\text { mi/watershed area } \mathrm{mi}^{2} \text { ) } \\
\end{array}$} & 0.5 & +1 & & \multirow{3}{*}{ AREMP workshop 3/18/2008 } \\
\hline & 1.25 & 0 & & \\
\hline & 2 & -1 & & \\
\hline \multirow{3}{*}{$\begin{array}{l}\text { Roads-watershed (road } \\
\text { mi/watershed area mi²) }\end{array}$} & 1 & +1 & & \multirow{3}{*}{ AREMP workshop 2003} \\
\hline & 2.5 & 0 & & \\
\hline & 4 & -1 & & \\
\hline \multirow{2}{*}{$\begin{array}{l}\text { Vegetation-riparian cover- } \\
\text { mixed species, } 160 \text {-ft buffer } \\
\text { (average canopy cover [\%]) }\end{array}$} & 40 & -1 & & \multirow[b]{2}{*}{ AREMP workshop 10/14/2009 } \\
\hline & 60 & +1 & & \\
\hline \multirow{2}{*}{$\begin{array}{l}\text { Vegetation-riparian cover- } \\
\text { oak woodlands } 160-\mathrm{ft} \text { buffer } \\
\text { (average canopy cover [\%]) }\end{array}$} & 20 & -1 & & \multirow[b]{2}{*}{ AREMP analysis } \\
\hline & 50 & +1 & & \\
\hline \multirow{2}{*}{$\begin{array}{l}\text { Vegetation-watershed-early } \\
\text { seral, QMD }<5 \text {-in } \\
\left(\mathrm{mi}^{2} / \text { watershed forest-capable }\right. \\
\left.\mathrm{mi}^{2}\right)\end{array}$} & 0.05 & +1 & & \multirow[b]{2}{*}{ AREMP workshop 3/18/2008 } \\
\hline & 0.25 & -1 & & \\
\hline \multirow{2}{*}{$\begin{array}{l}\text { Vegetation-watershed- } \\
<7,000 \mathrm{ft} \text { elevation-mixed } \\
\text { species (average canopy } \\
\text { cover [\%]) }\end{array}$} & 40 & -1 & & \multirow[b]{2}{*}{ AREMP workshop 10/14/2009 } \\
\hline & 70 & +1 & & \\
\hline \multirow{2}{*}{$\begin{array}{l}\text { Vegetation-watershed- } \\
<7,000 \text {-ft elevation-oak } \\
\text { woodlands } \\
\text { (average canopy cover [\%]) }\end{array}$} & 10 & -1 & & \multirow[b]{2}{*}{ AREMP workshop 10/14/2009 } \\
\hline & 40 & +1 & & \\
\hline \multirow{2}{*}{$\begin{array}{l}\text { Vegetation-watershed- }-\geq 7,000 \\
\text { ft elevation-mixed species } \\
\text { (average canopy cover [\%]) }\end{array}$} & 20 & -1 & & \multirow[b]{2}{*}{ AREMP workshop 10/14/2009 } \\
\hline & 40 & +1 & & \\
\hline \multirow{2}{*}{$\begin{array}{l}\text { Vegetation-watershed- }-\geq 7,000 \\
\text { ft elevation-oak woodlands } \\
\text { (average canopy cover [\%]) }\end{array}$} & 40 & -1 & & \multirow[b]{2}{*}{ AREMP workshop 10/14/2009 } \\
\hline & 70 & +1 & & \\
\hline \multicolumn{5}{|l|}{ North Cascades province } \\
\hline \multirow{2}{*}{$\begin{array}{l}\text { Landslide risk-roads and } \\
\text { vegetation (change in average } \\
\text { landslide density [per } \mathrm{km}^{2} \text { ] } \\
\text { from an optimum forested, } \\
\text { unroaded state) }\end{array}$} & 0.1 & +1 & & \multirow[b]{2}{*}{ AREMP analysis } \\
\hline & 0.3 & -1 & & \\
\hline \multirow{2}{*}{$\begin{array}{l}\text { Roads-crossings (No. } \\
\text { crossings/stream mi) }\end{array}$} & 0 & +1 & & \multirow{2}{*}{ AREMP workshop 9/19/2008 } \\
\hline & 1.25 & -1 & & \\
\hline \multirow{2}{*}{$\begin{array}{l}\text { Roads-riparian-<3 \% gradient } \\
\text { 30-m (100-ft) buffer } \\
\text { (proportion of stream mi } \\
\text { w/road in buffer) }\end{array}$} & 0 & +1 & & \multirow[b]{2}{*}{ AREMP workshop 9/19/2008 } \\
\hline & 0.05 & -1 & & \\
\hline \multirow{2}{*}{$\begin{array}{l}\text { Roads-riparian- } \geq 3 \% \text { gradient, } \\
\text { 100-m (328-ft) buffer } \\
\text { (proportion of stream mi } \\
\text { w/road in buffer) }\end{array}$} & 0 & +1 & & \multirow[b]{2}{*}{ AREMP workshop 9/19/2008 } \\
\hline & 0.05 & -1 & & \\
\hline
\end{tabular}


Table 9-Evaluation criteria used in watershed-level decision-support models for each aquatic province (continued)

\begin{tabular}{|c|c|c|c|c|}
\hline Attribute and measure & $\begin{array}{l}\text { Data } \\
\text { value }\end{array}$ & $\begin{array}{c}\text { Evaluated } \\
\text { score }\end{array}$ & $\begin{array}{l}\text { Curve } \\
\text { shape }\end{array}$ & Source \\
\hline \multirow{2}{*}{$\begin{array}{l}\text { Road density-high-hazard } \\
\text { areas (road mi/watershed area } \\
\mathrm{mi}^{2} \text { ) }\end{array}$} & 0 & +1 & & \multirow{2}{*}{ AREMP workshop 9/19/2008 } \\
\hline & 1.2 & -1 & & \\
\hline \multirow{2}{*}{ 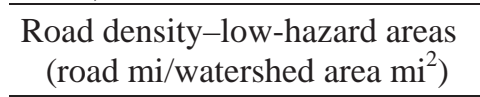 } & 0.7 & +1 & & \multirow{2}{*}{ AREMP workshop 9/19/2008 } \\
\hline & 2.4 & -1 & & \\
\hline \multirow{4}{*}{$\begin{array}{l}\text { Vegetation-riparian east, } \\
\text { QMD } \geq 12 \text {-in, all species, } \\
\text { 100-ft buffer }\left(\mathrm{mi}^{2} / \text { riparian }\right. \\
\left.\text { forest-capable } \mathrm{mi}^{2}\right)\end{array}$} & 0.3 & -1 & & \multirow{4}{*}{ AREMP workshop 9/19/2008 } \\
\hline & 0.5 & +1 & & \\
\hline & 0.8 & +1 & & \\
\hline & 1 & 0 & & \\
\hline \multirow{2}{*}{$\begin{array}{l}\text { Vegetation-riparian west, } \\
\text { QMD } \geq 16 \text {-in, all species, } \\
\text { 160-ft buffer }\left(\mathrm{mi}^{2} / \text { riparian }\right. \\
\text { forest-capable } \mathrm{mi}^{2} \text { ) } \\
\end{array}$} & 0.3 & -1 & & \multirow[b]{2}{*}{ AREMP workshop 9/19/2008 } \\
\hline & 0.6 & +1 & & \\
\hline \multirow{2}{*}{$\begin{array}{l}\text { Vegetation-watershed east, wet } \\
\text { zone, QMD }<5 \text {-in, all species } \\
\left(\mathrm{mi}^{2} / \text { watershed forest capable }\right. \\
\left.\mathrm{mi}^{2}\right)\end{array}$} & 0.2 & +1 & & \multirow[b]{2}{*}{ AREMP workshop 2003} \\
\hline & 0.3 & -1 & & \\
\hline \multirow{2}{*}{$\begin{array}{l}\text { Vegetation-watershed, east, } \\
\text { dry zone, } \mathrm{QMD} \geq 20 \text {-in, } \\
\text { conifers }\left(\mathrm{mi}^{2} / \text { watershed }\right. \\
\left.\text { forest-capable } \mathrm{mi}^{2}\right) \\
\end{array}$} & 0.3 & -1 & & \multirow[b]{2}{*}{ AREMP workshop 9/19/2008 } \\
\hline & 0.6 & +1 & & \\
\hline \multirow{2}{*}{$\begin{array}{l}\text { Vegetation-watershed west, } \\
\geq 70 \% \text { cover, conifers } \\
\left(\mathrm{mi}^{2} / \text { watershed forest }\right. \\
\left.\text { capable } \mathrm{mi}^{2}\right) \\
\end{array}$} & 0.65 & -1 & & \multirow[b]{2}{*}{ AREMP workshop 2003} \\
\hline & 0.88 & +1 & & \\
\hline \multicolumn{5}{|l|}{ Olympic Peninsula province } \\
\hline \multirow{2}{*}{$\begin{array}{l}\text { Landslide risk-roads and } \\
\text { vegetation (change in average } \\
\text { landslide density [per } \mathrm{km}^{2} \text { ] } \\
\text { from an optimum forested, } \\
\text { unroaded state) } \\
\end{array}$} & 0.1 & +1 & & \\
\hline & 0.3 & -1 & & AREMP analysis \\
\hline \multirow{2}{*}{$\begin{array}{l}\text { Roads-crossings } \\
\text { (number/stream mi) }\end{array}$} & 0.25 & +1 & & \multirow[b]{2}{*}{ AREMP workshop followup 2003} \\
\hline & 1 & -1 & & \\
\hline \multirow{2}{*}{$\begin{array}{l}\text { Roads-riparian, 160-ft buffer } \\
\text { (road mi/stream mi) }\end{array}$} & 0 & +1 & & \multirow{2}{*}{ AREMP workshop 4/10/08 } \\
\hline & 0.1 & -1 & & \\
\hline \multirow{2}{*}{$\begin{array}{l}\text { Roads-watershed (road } \\
\text { mi/watershed area } \mathrm{mi}^{2} \text { ) }\end{array}$} & 1 & +1 & & \multirow{2}{*}{ AREMP workshop 4/10/08 } \\
\hline & 3 & -1 & & \\
\hline \multirow{2}{*}{$\begin{array}{l}\text { Vegetation-riparian, } \\
\text { QMD } \geq 20 \text {-in (wet zone) } \\
\text { QMD } \geq 12 \text {-in (dry zone) } \\
160 \text {-ft buffer ( } \mathrm{mi}^{2} / \text { riparian } \\
\text { forest-capable } \mathrm{mi}^{2} \text { ) }\end{array}$} & 0.25 & -1 & & \multirow[b]{2}{*}{ AREMP workshop 4/10/08 } \\
\hline & 0.65 & +1 & & \\
\hline \multirow{2}{*}{$\begin{array}{l}\text { Vegetation-urban/agriculture } \\
\left(\mathrm{mi}^{2} / \text { watershed area } \mathrm{mi}^{2}\right)\end{array}$} & 0.2 & +1 & & \multirow{2}{*}{ AREMP workshop 4/10/08 } \\
\hline & 0.4 & -1 & & \\
\hline \multirow{2}{*}{$\begin{array}{l}\text { Vegetation-watershed, QMD } \\
<5 \text {-in }\left(\mathrm{mi}^{2} / \text { watershed forest- }\right. \\
\left.\text { capable } \mathrm{mi}^{2}\right)\end{array}$} & 0.05 & +1 & & \multirow{2}{*}{ AREMP workshop 6/16/2009 } \\
\hline & 0.25 & -1 & & \\
\hline
\end{tabular}


Table 9-Evaluation criteria used in watershed-level decision-support models for each aquatic province (continued)

\begin{tabular}{|c|c|c|c|c|}
\hline Attribute and measure & $\begin{array}{l}\text { Data } \\
\text { value }\end{array}$ & $\begin{array}{c}\text { Evaluated } \\
\text { score }\end{array}$ & $\begin{array}{l}\text { Curve } \\
\text { shape }\end{array}$ & Source \\
\hline \multicolumn{5}{|l|}{ Oregon Coast province } \\
\hline \multirow{2}{*}{$\begin{array}{l}\text { Upslope-road density (road } \\
\text { mi/watershed area } \mathrm{mi}^{2} \text { ) }\end{array}$} & 2.2 & +1 & & \multirow{2}{*}{ Kaufman and Hughes 2006} \\
\hline & 4.2 & -1 & & \\
\hline \multirow{2}{*}{$\begin{array}{c}\text { Upslope-urban/agriculture } \\
\left(\mathrm{mi}^{2} / \text { watershed area } \mathrm{mi}^{2}\right)\end{array}$} & 0.2 & +1 & & \multirow{2}{*}{ AREMP workshop 2003} \\
\hline & 0.4 & -1 & & \\
\hline \multirow{2}{*}{$\begin{array}{l}\text { Upslope-landslide risk } \\
\text { (difference in average } \\
\text { landslide density [per } \mathrm{km}^{2} \text { ] } \\
\text { from an optimum forested, } \\
\text { unroaded state) }\end{array}$} & 0.1 & +1 & & \multirow[b]{2}{*}{ AREMP analysis } \\
\hline & 0.3 & -1 & & \\
\hline \multirow{2}{*}{$\begin{array}{l}\text { Riparian-all streams-canopy } \\
\text { cover, 160-ft buffer, all } \\
\text { species (average cover [\%]) }\end{array}$} & 0.55 & -1 & & \multirow{2}{*}{ AREMP analysis } \\
\hline & 0.7 & +1 & & \\
\hline \multirow{2}{*}{$\begin{array}{l}\text { Riparian-all streams-conifers } \\
\geq 20 \text {-in QMD, 160-ft buffer } \\
\left(\mathrm{mi}^{2} / \text { riparian forest-capable }\right. \\
\left.\mathrm{mi}^{2}\right)\end{array}$} & 0.25 & -1 & & \multirow[b]{2}{*}{ AREMP workshop 2003} \\
\hline & 0.5 & +1 & & \\
\hline \multirow{2}{*}{$\begin{array}{l}\text { Riparian-perennial streams- } \\
\text { QMD conifers } \geq 20 \text {-in, } \\
\text { 300-ft buffer }\left(\mathrm{mi}^{2} / \text { riparian }\right. \\
\left.\text { forest capable } \mathrm{mi}^{2}\right)\end{array}$} & 0.25 & -1 & & \multirow[b]{2}{*}{ AREMP workshop 3/4/2008 } \\
\hline & 0.5 & +1 & & \\
\hline \multirow{2}{*}{$\begin{array}{l}\text { Riparian-perennial streams- } \\
\text { road density, 300-ft buffer } \\
\text { (road mi/stream mi) }\end{array}$} & 0.075 & +1 & & \multirow[b]{2}{*}{ AREMP workshop 3/4/2008 } \\
\hline & 0.4 & -1 & & \\
\hline \multicolumn{5}{|l|}{ Western Cascades province } \\
\hline \multirow{3}{*}{$\begin{array}{l}\text { Roads-watershed road density } \\
\text { (road mi/watershed area mi²) }\end{array}$} & 0.5 & +1 & & \multirow{3}{*}{ AREMP workshop 4/15-17/2008 } \\
\hline & 2 & 0 & & \\
\hline & 4 & -1 & & \\
\hline \multirow{2}{*}{$\begin{array}{l}\text { Roads-riparian-all streams, } \\
\text { 120-ft buffer (road mi/ } \\
\text { stream mi) }\end{array}$} & 0.01 & +1 & & \multirow[b]{2}{*}{ AREMP workshop 9/16/2009 } \\
\hline & 0.1 & -1 & & \\
\hline \multirow{2}{*}{$\begin{array}{l}\text { Roads-riparian-perennial } \\
\text { streams, 180-ft buffer (road } \\
\text { mi/perennial stream mi) }\end{array}$} & 0.01 & +1 & & \multirow{2}{*}{ AREMP workshop 4/15-17/2008 } \\
\hline & 0.1 & -1 & & \\
\hline \multirow{2}{*}{$\begin{array}{l}\text { Roads-crossings } \\
\text { (number/stream mi) }\end{array}$} & 0.01 & +1 & & \multirow{2}{*}{ AREMP workshop 4/15-17/2008 } \\
\hline & 1.25 & -1 & & \\
\hline \multirow{2}{*}{$\begin{array}{l}\text { Mass wasting-landslide risk } \\
\text { (change in average landslide } \\
\text { density [per km²] from an } \\
\text { optimum forested, unroaded } \\
\text { state) }\end{array}$} & 0.1 & +1 & & \multirow[t]{2}{*}{ AREMP analysis } \\
\hline & 0.3 & -1 & & \\
\hline \multirow{2}{*}{$\begin{array}{l}\text { Mass wasting-road crossings in } \\
\text { high-risk areas } \\
\text { (number/stream mi) }\end{array}$} & 0.01 & +1 & & \multirow{2}{*}{ AREMP workshop 9/16/2009 } \\
\hline & 0.3 & -1 & & \\
\hline
\end{tabular}


Table 9-Evaluation criteria used in watershed-level decision-support models for each aquatic province (continued)

\begin{tabular}{|c|c|c|c|c|}
\hline Attribute and measure & $\begin{array}{c}\text { Data } \\
\text { value }\end{array}$ & $\begin{array}{c}\text { Evaluated } \\
\text { score } \\
\end{array}$ & $\begin{array}{l}\text { Curve } \\
\text { shape }\end{array}$ & Source \\
\hline \multirow{2}{*}{$\begin{array}{l}\text { Vegetation-riparian, QMD } \geq 8 \text { - } \\
\text { or } 14 \text {-in (lodgepole/ } \\
\text { other) and canopy closure } \\
\geq 40 \% \text {, all species, } 160 \text {-ft } \\
\text { buffer }\left(\mathrm{mi}^{2} / \text { riparian forest }\right. \\
\text { capable } \mathrm{mi}^{2} \text { ) }\end{array}$} & 0.5 & -1 & & \multirow[t]{2}{*}{ AREMP workshop 4/15-17/2008 } \\
\hline & 0.7 & +1 & & \\
\hline \multirow{2}{*}{$\begin{array}{l}\text { Vegetation-watershed-rain on- } \\
\text { snow band, QMD } \geq 8 \text {-in and } \\
\text { cover } \geq 70 \% \\
\left(\mathrm{mi}^{2} / \text { watershed forest-capable }\right. \\
\left.\mathrm{mi}^{2}\right)\end{array}$} & 0.35 & -1 & & \multirow{2}{*}{$\begin{array}{l}\text { AREMP workshop 4/15-17/2008 } \\
\text { Grant et al. (2008) }\end{array}$} \\
\hline & 0.85 & +1 & & \\
\hline \multirow{2}{*}{$\begin{array}{l}\text { Vegetation-watershed-rain- } \\
\text { only and snow-only bands, } \\
\text { QMD } \geq 8 \text {-in and cover } \geq 70 \% \\
\left(\mathrm{mi}^{2} / \text { watershed forest- }\right. \\
\left.\text { capable } \mathrm{mi}^{2}\right)\end{array}$} & 0.1 & -1 & & \multirow{2}{*}{$\begin{array}{l}\text { AREMP workshop 4/15-17/2008 } \\
\text { Grant et al. (2008) }\end{array}$} \\
\hline & 0.45 & +1 & & \\
\hline
\end{tabular}

${ }^{a} \mathrm{QMD}=$ quadratic mean diameter of all dominant and codominant trees. 
Table 10-Evaluation criteria used in inchannel-level decision-support models for each aquatic province

\begin{tabular}{|c|c|c|c|c|}
\hline Attribute and measure & $\begin{array}{c}\text { Data } \\
\text { value }\end{array}$ & $\begin{array}{c}\text { Evaluated } \\
\text { score }\end{array}$ & $\begin{array}{l}\text { Curve } \\
\text { shape }\end{array}$ & Source \\
\hline \multicolumn{5}{|l|}{ High Cascades province } \\
\hline \multirow[b]{2}{*}{$\begin{array}{l}\text { Amphibians (aquatic and } \\
\text { terrestrial index) }\end{array}$} & 33 & 0 & & \multirow[b]{2}{*}{$\begin{array}{l}\text { Aquatic and Riparian Effectiveness } \\
\text { Monitoring Program (AREMP) } \\
\text { analysis }\end{array}$} \\
\hline & 100 & +1 & & \\
\hline \multirow{4}{*}{$\begin{array}{l}\text { Fines, } \\
<3 \% \text { gradient (percentage } \\
\text { of fines) }\end{array}$} & 0 & -1 & & \multirow{4}{*}{ AREMP workshop 2003} \\
\hline & 10 & +1 & & \\
\hline & 20 & +1 & & \\
\hline & 30 & -1 & & \\
\hline \multirow{2}{*}{$\begin{array}{l}\text { Fines, } \\
3 \text { to } 6 \% \text { gradient } \\
\text { (percentage of fines) }\end{array}$} & 20 & +1 & & \multirow[b]{2}{*}{ AREMP workshop 2003} \\
\hline & 35 & -1 & & \\
\hline \multirow{5}{*}{$\begin{array}{l}\text { Flood-plain connectivity, } \\
\text { <3\% gradient: } \\
\text { (No side channels } \\
\text { No side channels visible } \\
\text { Indeterminate } \\
\text { Probably side channels } \\
\text { visible } \\
\text { Side channels obviously } \\
\text { connected }\end{array}$} & & -1 & & \multirow{5}{*}{ AREMP workshop 2008} \\
\hline & & -0.5 & & \\
\hline & & 0 & & \\
\hline & & 0.5 & & \\
\hline & & +1 & & \\
\hline \multirow{2}{*}{$\begin{array}{l}\text { Macroinvertebrates-EPT } \\
\text { (percentage of taxa in } \\
\text { Ephemeroptera, } \\
\text { Plecoptera, and } \\
\text { Tripcoptera [EPT]) }\end{array}$} & 61 & -1 & & \multirow[b]{2}{*}{$\begin{array}{l}\text { Herlihy (2009) analysis of reference } \\
\text { sites }\end{array}$} \\
\hline & 72 & +1 & & \\
\hline \multirow{2}{*}{$\begin{array}{l}\text { Macroinvertebrates- } \\
\text { intolerant (percentage of } \\
\text { taxa) }\end{array}$} & 35 & -1 & & \multirow{2}{*}{$\begin{array}{l}\text { Herlihy (2009) analysis of reference } \\
\text { sites }\end{array}$} \\
\hline & 50 & +1 & & \\
\hline \multirow{2}{*}{$\begin{array}{l}\text { Pool frequency, } \\
<3 \% \text { gradient (bankfull } \\
\text { widths per pool) }\end{array}$} & 5 & +1 & & \multirow[b]{2}{*}{ AREMP workshop 2003} \\
\hline & 7 & -1 & & \\
\hline \multirow{2}{*}{$\begin{array}{l}\text { Pool frequency, } \\
3 \text { to } 6 \% \text { gradient (bankfull } \\
\text { widths per pool) }\end{array}$} & 2 & +1 & & \multirow[b]{2}{*}{ AREMP workshop 2003} \\
\hline & 6 & -1 & & \\
\hline \multirow{3}{*}{$\begin{array}{l}\text { Water temperature, } \\
\text { bull trout are not present } \\
\left({ }^{\circ} \mathrm{C}\right)\end{array}$} & 16 & +1 & & \multirow{3}{*}{ AREMP workshop 2008} \\
\hline & 18 & 0 & & \\
\hline & 23 & -1 & & \\
\hline \multirow{3}{*}{$\begin{array}{l}\text { Water temperature, } \\
\text { bull trout are present } \\
\left({ }^{\circ} \mathrm{C}\right)\end{array}$} & 9 & +1 & & \multirow{3}{*}{ AREMP workshop 2008} \\
\hline & 12 & 0 & & \\
\hline & 13 & -1 & & \\
\hline
\end{tabular}


Table 10-Evaluation criteria used in inchannel-level decision-support models for each aquatic province (continued)

\begin{tabular}{|c|c|c|c|c|}
\hline Attribute and measure & $\begin{array}{l}\text { Data } \\
\text { value }\end{array}$ & $\begin{array}{c}\text { Evaluated } \\
\text { score }\end{array}$ & $\begin{array}{l}\text { Curve } \\
\text { shape }\end{array}$ & Source \\
\hline \multirow{2}{*}{$\begin{array}{l}\text { Wood frequency-North, } \\
\text { min } 12 \text {-in diameter by 25- } \\
\mathrm{ft} \text { length (pieces } / 100 \mathrm{~m} \\
\text { [pieces } / 328 \mathrm{ft} \text { ) }\end{array}$} & 1 & -1 & & \multirow[b]{2}{*}{ AREMP workshop 2008} \\
\hline & 4 & +1 & & \\
\hline \multirow{2}{*}{$\begin{array}{l}\text { Wood frequency-South, min } \\
\text { 18-in diameter x } 25-\mathrm{ft} \\
\text { length (pieces } / 100 \mathrm{~m} \\
\text { [pieces/328 ft]) }\end{array}$} & 1 & -1 & & \multirow[b]{2}{*}{ AREMP workshop 2008} \\
\hline & 4 & +1 & & \\
\hline \multicolumn{5}{|c|}{ Klamath-Siskiyou and Franciscan Province } \\
\hline \multirow{2}{*}{$\begin{array}{l}\text { Amphibians (aquatic and } \\
\text { terrestrial index) }\end{array}$} & 33 & 0 & & \multirow[b]{2}{*}{ AREMP analysis } \\
\hline & 100 & +1 & & \\
\hline \multirow[b]{2}{*}{$\begin{array}{l}\text { Bankfull width:depth, } \\
\text { <4\% gradient (ratio) }\end{array}$} & 15 & +1 & & \multirow{2}{*}{ AREMP workshop 3/2008 } \\
\hline & 35 & -1 & & \\
\hline \multirow{4}{*}{$\begin{array}{l}\text { Median particle size (D50) } \\
<4 \% \text { gradient }(\mathrm{mm})\end{array}$} & 2 & -1 & & \multirow{4}{*}{ AREMP workshop 3/2008 } \\
\hline & 45 & +1 & & \\
\hline & 200 & +1 & & \\
\hline & 350 & -1 & & \\
\hline \multirow{2}{*}{$\begin{array}{l}\text { Fines } \\
<4 \% \text { gradient } \\
\text { (percentage of fines) }\end{array}$} & 30 & -1 & & \multirow{2}{*}{ AREMP workshop 3/2008 } \\
\hline & 10 & +1 & & \\
\hline \multirow{2}{*}{$\begin{array}{l}\text { Macroinvertebrates-EPT } \\
\text { (percentage of taxa in } \\
\text { Ephemeroptera, } \\
\text { Plecoptera, and } \\
\text { Tripcoptera [EPT]) }\end{array}$} & 61 & -1 & & \multirow[b]{2}{*}{$\begin{array}{l}\text { Herlihy (2009) analysis of reference } \\
\text { sites }\end{array}$} \\
\hline & 72 & +1 & & \\
\hline \multirow{2}{*}{$\begin{array}{l}\text { Macroinvertebrates- } \\
\text { intolerant (percentage of } \\
\text { taxa) }\end{array}$} & 35 & -1 & & \multirow{2}{*}{$\begin{array}{l}\text { Herlihy (2009) analysis of reference } \\
\text { sites }\end{array}$} \\
\hline & 50 & +1 & & \\
\hline \multirow{2}{*}{$\begin{array}{l}\text { Pool frequency, } \\
<4 \% \text { gradient and within } \\
\text { unconfined valley type } \\
\text { (bankfull widths per pool) }\end{array}$} & 5 & +1 & & \multirow[b]{2}{*}{ AREMP workshop 2003} \\
\hline & 12 & -1 & & \\
\hline \multirow{4}{*}{ Water temperature $\left({ }^{\circ} \mathrm{C}\right)$} & 18 & 1 & & \multirow{4}{*}{ AREMP workshop 3/2008 } \\
\hline & 20 & 0.8 & & \\
\hline & 21 & 0 & & \\
\hline & 24 & -1 & & \\
\hline \multirow{2}{*}{$\begin{array}{l}\text { Wood frequency, } \\
\text { min } 12 \text {-in diameter by 25- } \\
\mathrm{ft} \text { length (pieces } / 100 \mathrm{~m} \\
\text { [pieces } / 328 \mathrm{ft}] \text { ) }\end{array}$} & 1 & -1 & & \multirow[b]{2}{*}{ AREMP workshop 3/2008 } \\
\hline & 3 & +1 & & \\
\hline
\end{tabular}


Table 10-Evaluation criteria used in inchannel-level decision-support models for each aquatic province (continued)

\begin{tabular}{|c|c|c|c|c|}
\hline Attribute and measure & $\begin{array}{l}\text { Data } \\
\text { value }\end{array}$ & $\begin{array}{c}\text { Evaluated } \\
\text { score }\end{array}$ & $\begin{array}{l}\text { Curve } \\
\text { shape }\end{array}$ & Source \\
\hline \multirow{2}{*}{$\begin{array}{l}\text { Wood frequency, } \\
\text { min } 24 \text {-in diameter } \\
\text { (small end) by } 50-\mathrm{ft} \\
\text { length (pieces/100 m } \\
\text { [pieces/328ft]) }\end{array}$} & 0 & -1 & & \multirow[b]{2}{*}{ AREMP workshop 3/2008 } \\
\hline & 0.1 & +1 & & \\
\hline \multicolumn{5}{|l|}{ North Cascades Province } \\
\hline \multirow{2}{*}{$\begin{array}{l}\text { Amphibians (aquatic and } \\
\text { terrestrial index) }\end{array}$} & 33 & 0 & & \multirow[b]{2}{*}{ AREMP analysis } \\
\hline & 100 & +1 & & \\
\hline \multirow{2}{*}{$\begin{array}{l}\text { Bankfull width:depth, } \\
\leq 2 \% \text { gradient, nonglacial } \\
\text { (ratio) }\end{array}$} & $<40$ & +1 & & \multirow[b]{2}{*}{ AREMP workshop 4/28/03 } \\
\hline & $\geq 40$ & -1 & & \\
\hline \multirow{4}{*}{$\begin{array}{l}\text { Mean particle size }(\mathrm{D} 50) \\
\leq 2 \% \text { gradient, nonglacial } \\
(\mathrm{mm})\end{array}$} & 20 & -1 & & \multirow{4}{*}{ AREMP workshop 4/28/03 } \\
\hline & 30 & +1 & & \\
\hline & 100 & +1 & & \\
\hline & 500 & -1 & & \\
\hline \multirow[b]{2}{*}{ Dissolved oxygen (mg/L) } & 5 & -1 & & \multirow[b]{2}{*}{ AREMP workshop 4/28/03 } \\
\hline & 10 & +1 & & \\
\hline \multirow{2}{*}{$\begin{array}{l}\text { Entrenchment, eastside } \\
\leq 2 \% \text { gradient, nonglacial } \\
\text { (ratio) }\end{array}$} & 1.4 & -1 & & \multirow[b]{2}{*}{ AREMP workshop 4/28/03 } \\
\hline & 1.5 & +1 & & \\
\hline \multirow{2}{*}{$\begin{array}{l}\text { Entrenchment, westside } \\
\leq 2 \% \text { gradient, nonglacial } \\
\text { (ratio) }\end{array}$} & 1.2 & -1 & & \multirow[b]{2}{*}{ AREMP workshop 4/28/03 } \\
\hline & 1.3 & +1 & & \\
\hline \multirow{2}{*}{$\begin{array}{l}\text { Fines } \\
\leq 2 \% \text { gradient, nonglacial } \\
\text { (percent) }\end{array}$} & 11 & +1 & & \multirow[b]{2}{*}{ AREMP workshop 4/28/03 } \\
\hline & 17 & -1 & & \\
\hline \multirow{2}{*}{$\begin{array}{l}\text { Macroinvertebrates-EPT } \\
\text { (percentage of taxa in } \\
\text { Ephemeroptera, } \\
\text { Plecoptera, and } \\
\text { Tripcoptera [EPT]) }\end{array}$} & 61 & -1 & & \multirow[b]{2}{*}{$\begin{array}{l}\text { Herlihy (2009) analysis of reference } \\
\text { sites }\end{array}$} \\
\hline & 72 & +1 & & \\
\hline \multirow{2}{*}{$\begin{array}{l}\text { Macroinvertebrates- } \\
\text { intolerant (percentage } \\
\text { of taxa) }\end{array}$} & 35 & -1 & & \multirow{2}{*}{$\begin{array}{l}\text { Herlihy (2009) analysis of reference } \\
\text { sites }\end{array}$} \\
\hline & 50 & +1 & & \\
\hline \multirow{4}{*}{$\begin{array}{l}\text { Pool frequency, eastside, } \\
\text { >2\% gradient (bankfull } \\
\text { widths per pool) }\end{array}$} & 0.9 & +1 & & \multirow{4}{*}{ AREMP workshop 2004} \\
\hline & 1 & 0 & & \\
\hline & 4 & 0 & & \\
\hline & 4.1 & -1 & & \\
\hline \multirow{4}{*}{$\begin{array}{l}\text { Pool frequency, westside, } \\
\leq 2 \% \text { gradient (bankfull } \\
\text { widths per pool) }\end{array}$} & $<5$ & +1 & & \multirow{4}{*}{ AREMP workshop 2004} \\
\hline & 5 & 0 & & \\
\hline & 7 & 0 & & \\
\hline & $>7$ & -1 & & \\
\hline
\end{tabular}


Table 10-Evaluation criteria used in inchannel-level decision-support models for each aquatic province (continued)

\begin{tabular}{|c|c|c|c|c|}
\hline Attribute and measure & $\begin{array}{l}\text { Data } \\
\text { value }\end{array}$ & $\begin{array}{c}\text { Evaluated } \\
\text { score }\end{array}$ & $\begin{array}{l}\text { Curve } \\
\text { shape }\end{array}$ & Source \\
\hline \multirow{4}{*}{$\begin{array}{l}\text { Pool frequency, westside, } \\
\text { (bankfull widths per pool) }\end{array}$} & 4 & +1 & & \multirow{4}{*}{ AREMP workshop 2004} \\
\hline & 5 & 0 & & \\
\hline & 14 & 0 & & \\
\hline & 18 & -1 & & \\
\hline \multirow{4}{*}{$\begin{array}{l}\text { Water temperature, } \\
\text { bull trout are present }\left({ }^{\circ} \mathrm{C}\right)\end{array}$} & 3 & -1 & & \multirow{4}{*}{ AREMP workshop 2004} \\
\hline & 6 & +1 & & \\
\hline & 9 & +1 & & \\
\hline & 13 & -1 & & \\
\hline \multirow{4}{*}{$\begin{array}{l}\text { Water temperature, } \\
\text { bull trout are not present } \\
\left({ }^{\circ} \mathrm{C}\right)\end{array}$} & 4 & -1 & & \multirow{4}{*}{ AREMP workshop 2004} \\
\hline & 6 & +1 & & \\
\hline & 15 & +1 & & \\
\hline & 18 & -1 & & \\
\hline \multirow{3}{*}{$\begin{array}{l}\text { Wood frequency, eastside, } \\
\text { wetter subsections } \\
\text { min } 12 \text {-in diameter by } \\
25-\mathrm{ft} \text { length (pieces/100 m } \\
\text { [pieces/328 ft]) }\end{array}$} & 1.6 & -1 & & \multirow{3}{*}{ AREMP workshop 2004} \\
\hline & 3.1 & 0 & & \\
\hline & 4.5 & +1 & & \\
\hline \multirow{3}{*}{$\begin{array}{l}\text { Wood frequency, eastside, } \\
\text { drier subsections } \\
\text { min } 12 \text {-in diameter by } \\
\text { 25-ft length, (pieces/100 m } \\
\text { [pieces/328 ft]) }\end{array}$} & 0.9 & -1 & & \multirow{3}{*}{ AREMP workshop 2004} \\
\hline & 1.9 & 0 & & \\
\hline & 2.8 & +1 & & \\
\hline \multirow{3}{*}{$\begin{array}{l}\text { Wood frequency, westside, } \\
\text { min 12-in diameter (small } \\
\text { end) by 25-ft length, >2\% } \\
\text { gradient (pieces/100 m } \\
\text { [pieces/328 ft]) }\end{array}$} & 0.5 & -1 & & \multirow{3}{*}{ AREMP workshop 2004} \\
\hline & 1 & 0 & & \\
\hline & 5 & +1 & & \\
\hline \multirow{3}{*}{$\begin{array}{l}\text { Wood frequency, westside, } \\
\text { min } 12 \text {-in diameter (small } \\
\text { end) by } 25 \text {-ft length, } \leq 2 \% \\
\text { gradient (pieces/100 m } \\
\text { [pieces/328 ft]) }\end{array}$} & 0.5 & -1 & & \multirow{3}{*}{ AREMP workshop 2004} \\
\hline & 2.5 & 0 & & \\
\hline & 7.5 & +1 & & \\
\hline
\end{tabular}

Olympic Peninsula province

\begin{tabular}{|c|c|c|c|}
\hline \multirow{2}{*}{$\begin{array}{l}\text { Amphibians (aquatic and } \\
\text { terrestrial index) }\end{array}$} & 33 & 0 & \multirow{2}{*}{ AREMP analysis 2009} \\
\hline & 100 & +1 & \\
\hline \multirow{4}{*}{$\begin{array}{l}\text { Mean particle size (D50) } \\
\leq 2 \% \text { gradient, } \\
\text { unconstrained (mm) }\end{array}$} & 45 & -1 & \multirow{4}{*}{ AREMP workshop 2003} \\
\hline & 65 & +1 & \\
\hline & 95 & +1 & \\
\hline & 128 & -1 & \\
\hline \multirow[b]{2}{*}{$\begin{array}{l}\text { Fines, } \\
\leq 2 \% \text { gradient, } \\
\text { unconstrained (percent) }\end{array}$} & 11 & +1 & \multirow[b]{2}{*}{ AREMP workshop 2003} \\
\hline & 17 & -1 & \\
\hline \multirow{2}{*}{$\begin{array}{l}\text { Macroinvertebrates-EPT } \\
\text { (percentage of taxa in } \\
\text { Ephemeroptera, } \\
\text { Plecoptera, and } \\
\text { Tripcoptera [EPT]) }\end{array}$} & 61 & -1 & \multirow[b]{2}{*}{$\begin{array}{l}\text { Herlihy (2009) analysis of reference } \\
\text { sites }\end{array}$} \\
\hline & 72 & +1 & \\
\hline
\end{tabular}


Table 10 -Evaluation criteria used in inchannel-level decision-support models for each aquatic province (continued)

\begin{tabular}{|c|c|c|c|c|}
\hline Attribute and measure & $\begin{array}{l}\text { Data } \\
\text { value }\end{array}$ & $\begin{array}{l}\text { Evaluated } \\
\text { score }\end{array}$ & $\begin{array}{l}\text { Curve } \\
\text { shape }\end{array}$ & Source \\
\hline \multirow{2}{*}{$\begin{array}{l}\text { Macroinvertebrates- } \\
\text { intolerant (percentage } \\
\text { of taxa) }\end{array}$} & 35 & -1 & & \multirow{2}{*}{$\begin{array}{l}\text { Herlihy (2009) analysis of reference } \\
\text { sites }\end{array}$} \\
\hline & 50 & +1 & & \\
\hline \multirow{2}{*}{$\begin{array}{l}\text { Pool frequency (bankfull } \\
\text { widths/pool) }\end{array}$} & 8 & +1 & & \multirow{2}{*}{$\begin{array}{l}\text { Oregon Department of Fish and } \\
\text { Wildlife benchmarks }\end{array}$} \\
\hline & 20 & -1 & & \\
\hline \multirow{3}{*}{$\begin{array}{l}\text { Water temperature, } \\
\text { bull trout are not present } \\
\left({ }^{\circ} \mathrm{C}\right)\end{array}$} & 16 & +1 & & \multirow{3}{*}{ AREMP workshop 2008} \\
\hline & 18 & +1 & & \\
\hline & 23 & -1 & & \\
\hline \multirow{3}{*}{$\begin{array}{l}\text { Water temperature, } \\
\text { bull trout are present } \\
\left({ }^{\circ} \mathrm{C}\right)\end{array}$} & 9 & +1 & & \multirow{3}{*}{ AREMP workshop 2008} \\
\hline & 12 & 0 & & \\
\hline & 13 & -1 & & \\
\hline \multirow{3}{*}{$\begin{array}{l}\text { Wood frequency, } \\
\text { min 12-in diameter (small } \\
\text { end) by } 25 \text {-ft length, >2\% } \\
\text { gradient (pieces/100 m } \\
\text { [pieces/328 ft]) }\end{array}$} & 0.5 & -1 & & \multirow{3}{*}{ AREMP workshop 2008} \\
\hline & 1 & 0 & & \\
\hline & 5 & +1 & & \\
\hline \multirow{3}{*}{$\begin{array}{l}\text { Wood frequency, } \\
\text { min } 12 \text {-in diameter (small } \\
\text { end) by } 25 \text {-ft length, } \leq 2 \% \\
\text { gradient (pieces/100 m } \\
\text { [pieces/328 ft]) }\end{array}$} & 0.5 & -1 & & \multirow{3}{*}{ AREMP workshop 2008} \\
\hline & 2.5 & 0 & & \\
\hline & 7.5 & +1 & & \\
\hline \multicolumn{5}{|l|}{ Oregon Coast province } \\
\hline \multirow{2}{*}{$\begin{array}{l}\text { Amphibians (aquatic and } \\
\text { terrestrial index) }\end{array}$} & 33 & 0 & & \multirow[b]{2}{*}{ AREMP analysis 2009} \\
\hline & 100 & +1 & & \\
\hline \multirow{2}{*}{ Fines (percent) } & 11 & +1 & & \multirow{2}{*}{ AREMP workshop 2003} \\
\hline & 17 & -1 & & \\
\hline \multirow{5}{*}{$\begin{array}{l}\text { Flood-plain connectivity, } \\
\text { <3\% gradient: } \\
\text { No side channels } \\
\text { No side channels visible } \\
\text { Indeterminate } \\
\text { Probably side channels } \\
\text { visible } \\
\text { Side channels obviously } \\
\text { connected } \\
\end{array}$} & & -1 & & \multirow{5}{*}{ AREMP workshop 2008} \\
\hline & & -0.5 & & \\
\hline & & 0 & & \\
\hline & & 0.5 & & \\
\hline & & +1 & & \\
\hline \multirow{2}{*}{$\begin{array}{l}\text { Macroinvertebrates-EPT } \\
\text { (percentage of taxa in } \\
\text { Ephemeroptera, } \\
\text { Plecoptera, and } \\
\text { Tripcoptera [EPT]) }\end{array}$} & 61 & -1 & & \multirow[b]{2}{*}{$\begin{array}{l}\text { Herlihy (2009) analysis of reference } \\
\text { sites }\end{array}$} \\
\hline & 72 & +1 & & \\
\hline \multirow{2}{*}{$\begin{array}{l}\text { Macroinvertebrates- } \\
\text { intolerant (percentage } \\
\text { of taxa) }\end{array}$} & 35 & -1 & & \multirow{2}{*}{$\begin{array}{l}\text { Herlihy (2009) analysis of reference } \\
\text { sites }\end{array}$} \\
\hline & 50 & +1 & & \\
\hline \multirow{2}{*}{ Pool depth (m) } & 0.35 & -1 & & \multirow{2}{*}{ AREMP workshop 2003} \\
\hline & 0.75 & +1 & & \\
\hline
\end{tabular}


Table 10-Evaluation criteria used in inchannel-level decision-support models for each aquatic province (continued)

\begin{tabular}{|c|c|c|c|c|}
\hline Attribute and measure & $\begin{array}{c}\text { Data } \\
\text { value }\end{array}$ & $\begin{array}{l}\text { Evaluated } \\
\text { score }\end{array}$ & $\begin{array}{l}\text { Curve } \\
\text { shape }\end{array}$ & Source \\
\hline \multirow{2}{*}{$\begin{array}{l}\text { Pool frequency (bankfull } \\
\text { widths per pool) }\end{array}$} & 8 & +1 & & \multirow[b]{2}{*}{ AREMP workshop 2003} \\
\hline & 20 & -1 & & \\
\hline \multirow{2}{*}{$\begin{array}{l}\text { Water temperature, } \\
\text { maximum 7-day average } \\
\left({ }^{\circ} \mathrm{C}\right)\end{array}$} & 16 & 1 & & \multirow{2}{*}{ AREMP workshop 2003} \\
\hline & 23 & -1 & & \\
\hline \multirow{2}{*}{$\begin{array}{l}\text { Wood frequency, } \\
\text { min 24-in diameter (small } \\
\text { end) by 33-ft length } \\
\text { (pieces } / 100 \mathrm{~m} \\
\text { [pieces } / 328 \mathrm{ft} \text { ) } \\
\end{array}$} & 1 & -1 & & \multirow[b]{2}{*}{$\begin{array}{l}\text { Oregon Department of Fish and } \\
\text { Wildlife standard }\end{array}$} \\
\hline & 3 & +1 & & \\
\hline \multicolumn{5}{|l|}{ Western Cascades province } \\
\hline \multirow{2}{*}{$\begin{array}{l}\text { Amphibians (aquatic and } \\
\text { terrestrial index) }\end{array}$} & 33 & 0 & & \multirow[b]{2}{*}{ AREMP analysis } \\
\hline & 100 & +1 & & \\
\hline \multirow{4}{*}{$\begin{array}{l}\text { Mean particle size (D50) } \\
<3 \% \text { gradient (mm) }\end{array}$} & 40 & -1 & & \multirow{4}{*}{ AREMP workshop 2003} \\
\hline & 60 & +1 & & \\
\hline & 140 & +1 & & \\
\hline & 200 & -1 & & \\
\hline \multirow{4}{*}{$\begin{array}{l}\text { Fines, } \\
<3 \% \text { gradient (percentage } \\
\text { of fines) }\end{array}$} & 0 & -1 & & \multirow{4}{*}{ AREMP workshop 2003} \\
\hline & 10 & +1 & & \\
\hline & 20 & +1 & & \\
\hline & 30 & -1 & & \\
\hline \multirow{2}{*}{$\begin{array}{l}\text { Fines, } \\
3 \text { to } 6 \% \text { gradient } \\
\text { (percentage of fines) }\end{array}$} & 15 & +1 & & \multirow[b]{2}{*}{ AREMP workshop 2003} \\
\hline & 30 & -1 & & \\
\hline \multirow{5}{*}{$\begin{array}{l}\text { Flood-plain connectivity, } \\
\text { <3\% gradient: } \\
\text { No side channels } \\
\text { No side channels visible } \\
\text { Indeterminate } \\
\text { Probably side channels } \\
\text { visible } \\
\text { Side channels obviously } \\
\text { connected } \\
\end{array}$} & & -1 & & \multirow{5}{*}{ AREMP workshop 2008} \\
\hline & & -0.5 & & \\
\hline & & 0 & & \\
\hline & & 0.5 & & \\
\hline & & +1 & & \\
\hline \multirow{2}{*}{$\begin{array}{l}\text { Macroinvertebrates-EPT } \\
\text { (percentage of taxa in } \\
\text { Ephemeroptera, } \\
\text { Plecoptera, and } \\
\text { Tripcoptera [EPT]) } \\
\end{array}$} & 61 & -1 & & \multirow[b]{2}{*}{$\begin{array}{l}\text { Herlihy (2009) analysis of reference } \\
\text { sites }\end{array}$} \\
\hline & 72 & +1 & & \\
\hline \multirow{2}{*}{$\begin{array}{l}\text { Macroinvertebrates- } \\
\text { intolerant (percentage } \\
\text { of taxa) }\end{array}$} & 35 & -1 & & \multirow{2}{*}{$\begin{array}{l}\text { Herlihy (2009) analysis of reference } \\
\text { sites }\end{array}$} \\
\hline & 50 & +1 & & \\
\hline \multirow{2}{*}{$\begin{array}{l}\text { Pool frequency, } \\
<3 \% \text { gradient (bankfull } \\
\text { widths per pool) }\end{array}$} & 5 & +1 & & \multirow{2}{*}{ AREMP workshop 2003} \\
\hline & 7 & -1 & & \\
\hline
\end{tabular}


Table 10-Evaluation criteria used in inchannel-level decision-support models for each aquatic province (continued)

\begin{tabular}{|c|c|c|c|c|}
\hline Attribute and measure & $\begin{array}{l}\text { Data } \\
\text { value }\end{array}$ & $\begin{array}{c}\text { Evaluated } \\
\text { score }\end{array}$ & $\begin{array}{l}\text { Curve } \\
\text { shape }\end{array}$ & Source \\
\hline \multirow{2}{*}{$\begin{array}{l}\text { Pool frequency, } \\
3 \text { to } 6 \% \text { gradient (bankfull } \\
\text { widths per pool) }\end{array}$} & 2 & +1 & & \multirow{2}{*}{ AREMP workshop 2003} \\
\hline & 6 & -1 & & \\
\hline \multirow{3}{*}{$\begin{array}{l}\text { Water temperature, } \\
\text { bull trout are not present } \\
\left({ }^{\circ} \mathrm{C}\right)\end{array}$} & 16 & +1 & & \multirow{3}{*}{ AREMP workshop 2008} \\
\hline & 18 & +1 & & \\
\hline & 23 & -1 & & \\
\hline \multirow{3}{*}{$\begin{array}{l}\text { Water temperature, } \\
\text { bull trout are present } \\
\left({ }^{\circ} \mathrm{C}\right)\end{array}$} & 9 & +1 & & \multirow{3}{*}{ AREMP workshop 2008} \\
\hline & 12 & 0 & & \\
\hline & 13 & -1 & & \\
\hline $\begin{array}{l}\text { Wood frequency, } \\
\text { 24-in diameter at breast } \\
\text { height by } 50-\mathrm{ft} \\
\text { (pieces } / 100 \mathrm{~m} \\
\text { [pieces } / 328 \mathrm{ft} \text { ]) }\end{array}$ & 1 & -1 & & AREMP workshop 2008 \\
\hline
\end{tabular}




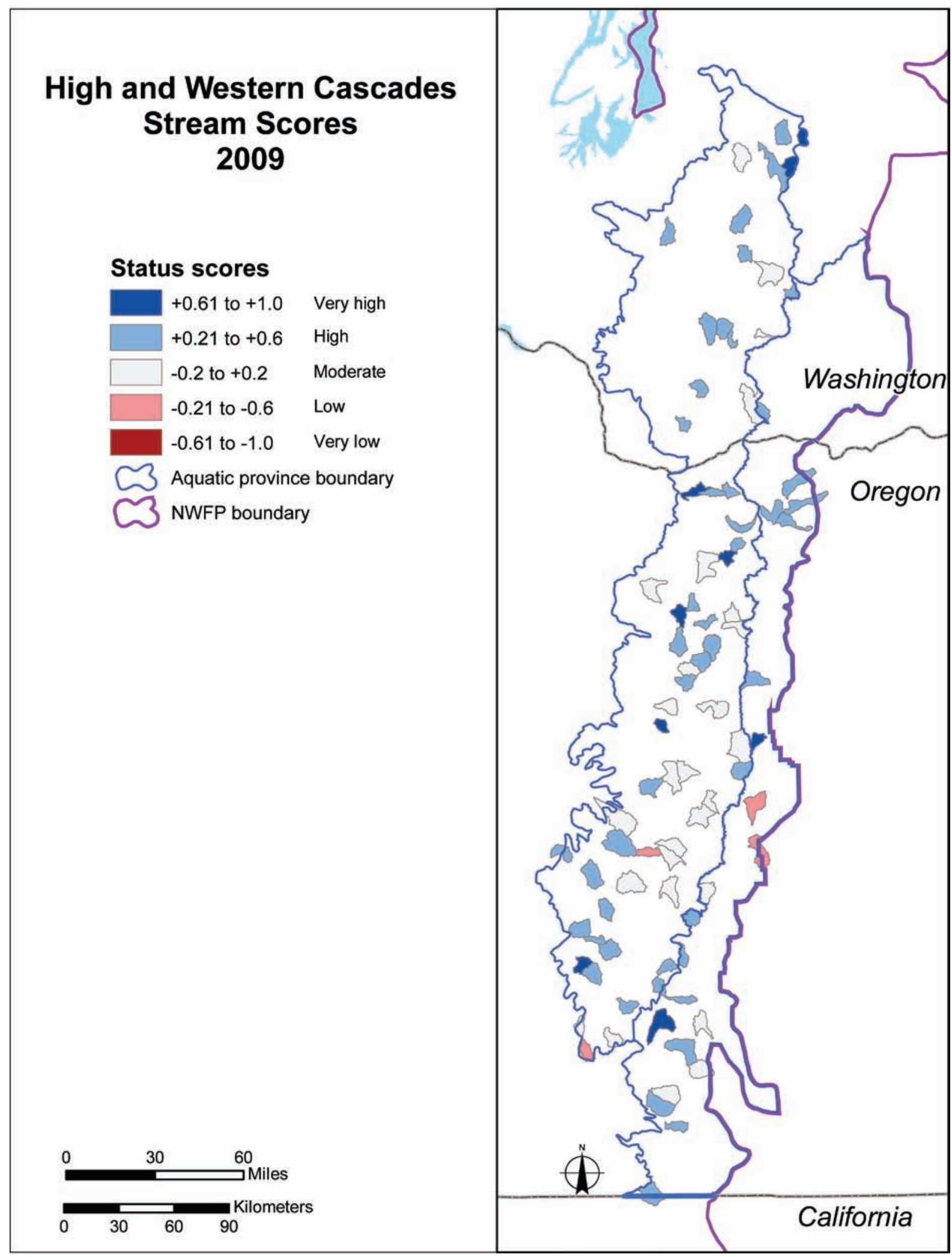

Figure 54-Distribution of inchannel condition scores for the randomly selected watersheds in the High Cascade and West Cascade provinces in the Northwest Forest Plan (NWFP) area that have been sampled for inchannel attributes as of 2009. 


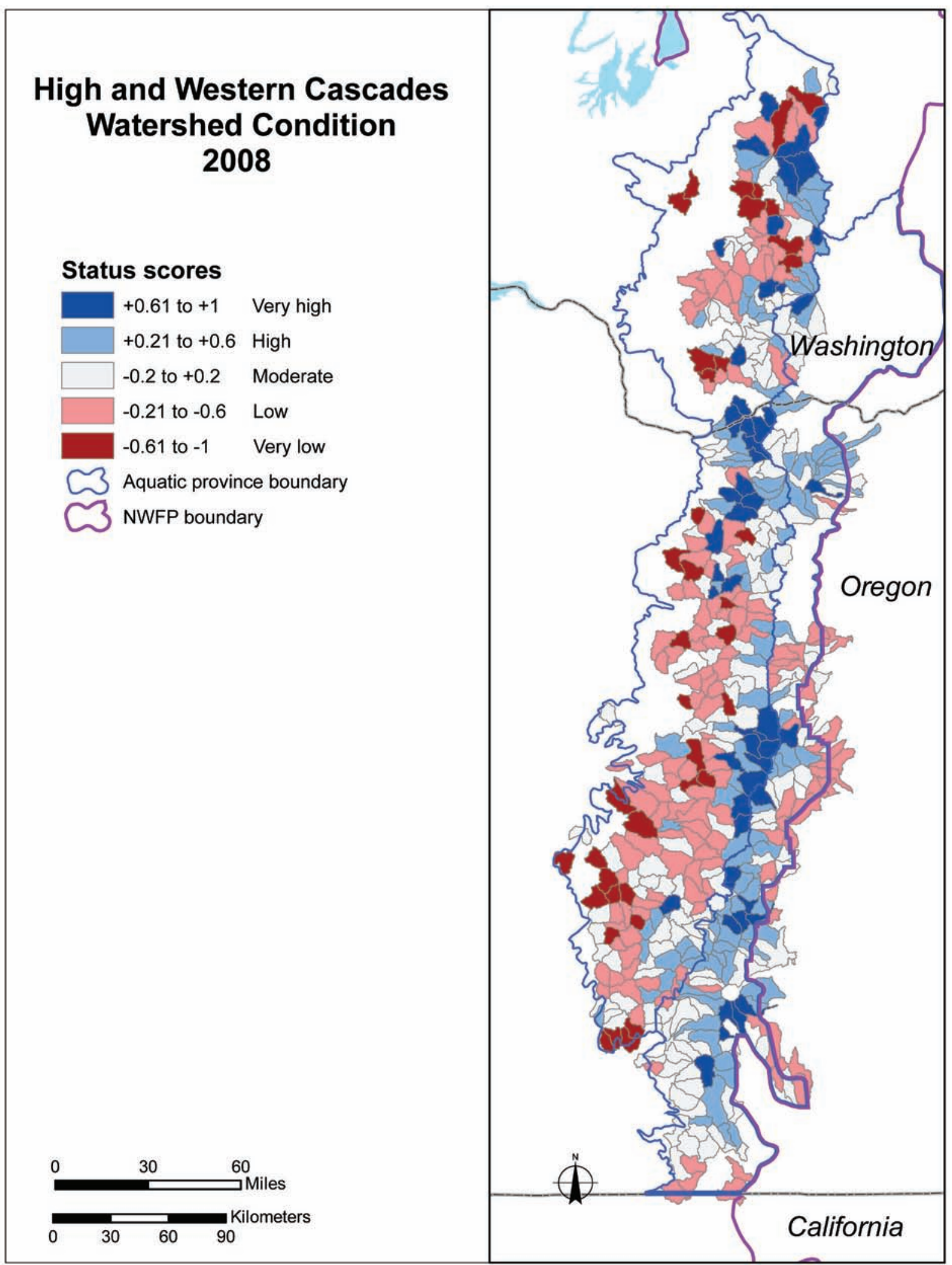

Figure 55-Watershed condition status scores (2008) for the High Cascade and West Cascade provinces in the Northwest Forest Plan (NWFP) area. 


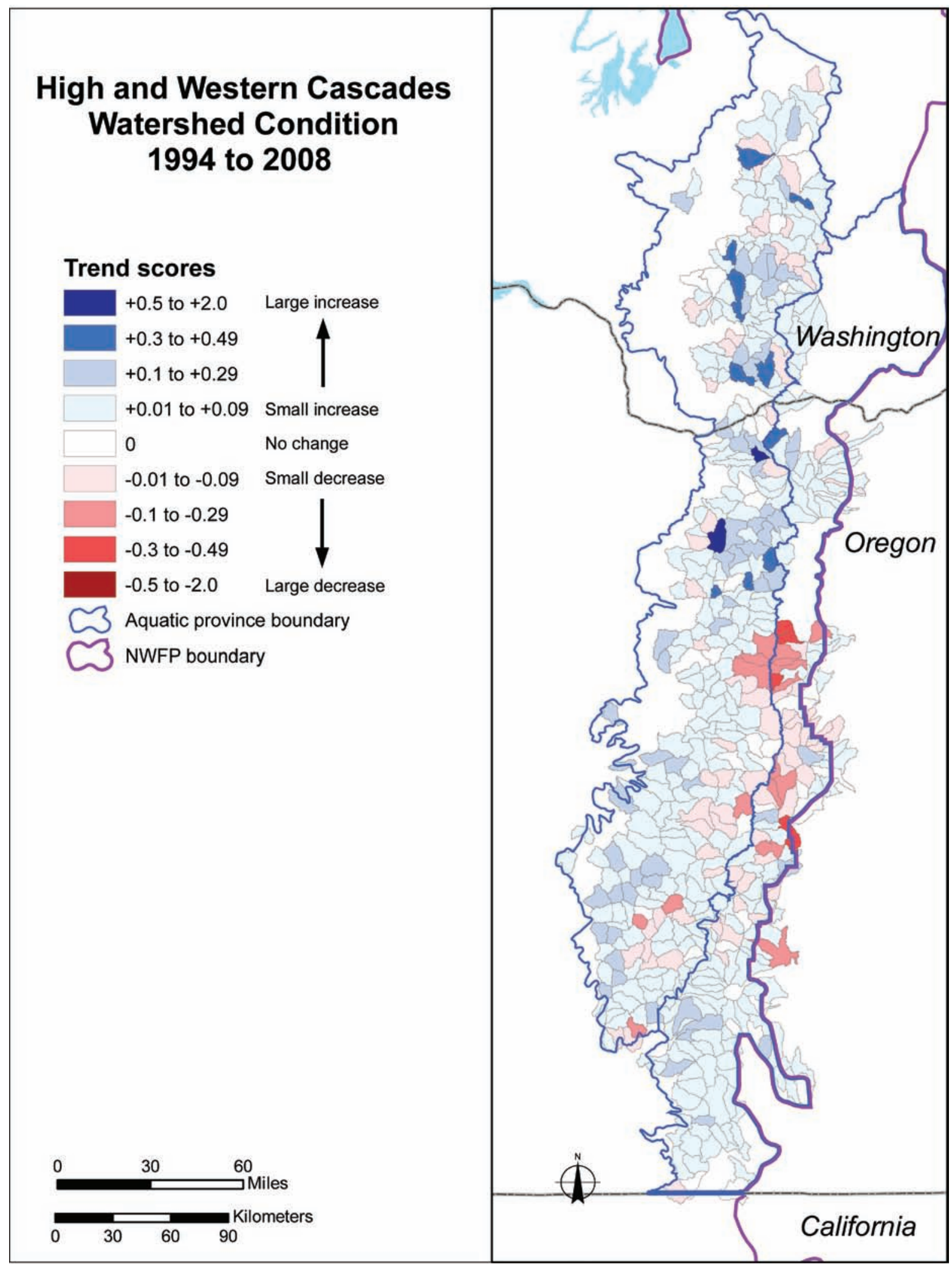

Figure 56-Watershed condition trend scores (1994 to 2008) for the High Cascade and West Cascade provinces in the Northwest Forest Plan (NWFP) area. 


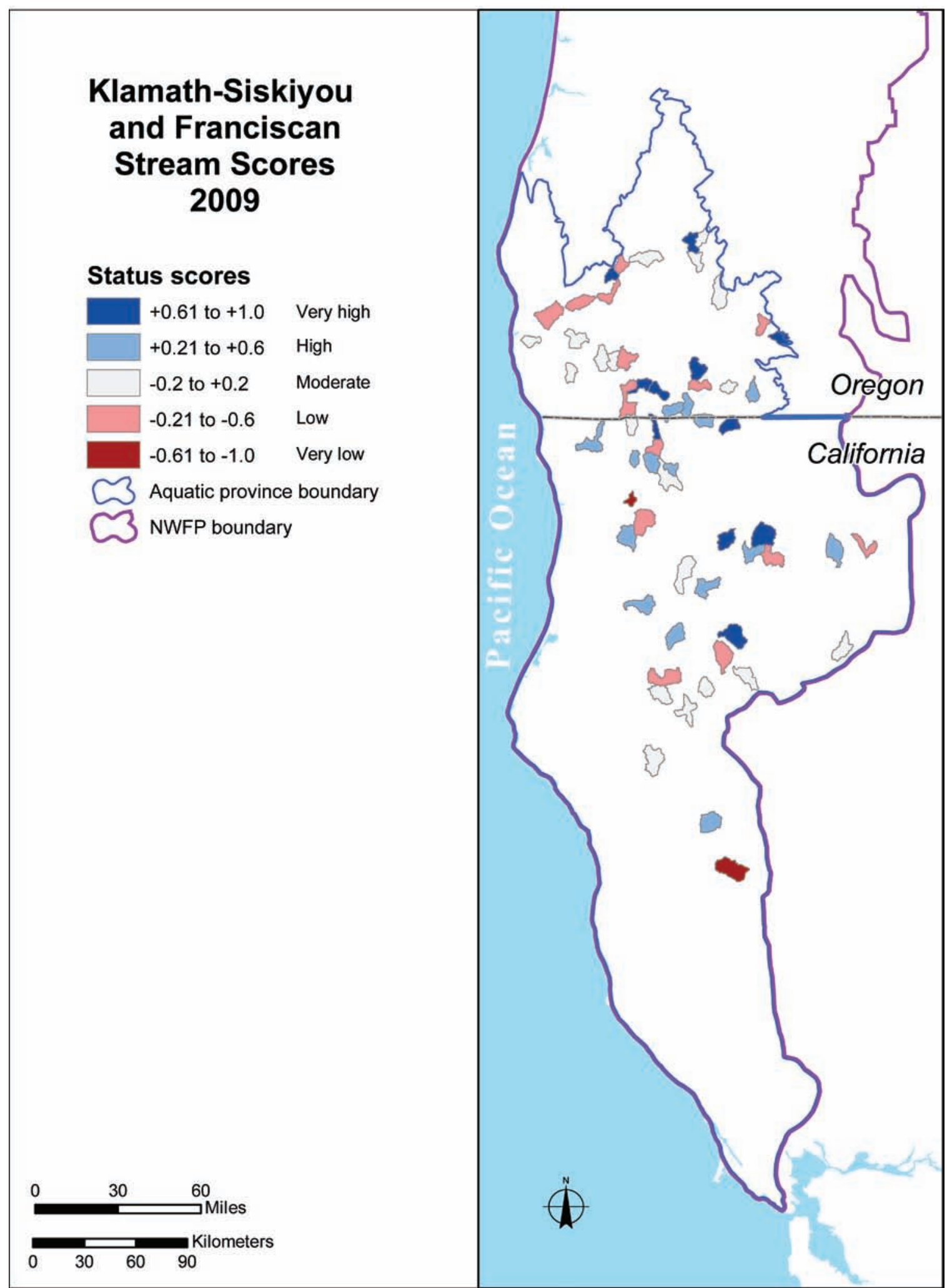

Figure 57-Distribution of inchannel condition scores for the randomly selected watersheds in the Klamath-Siskiyou and Franciscan provinces in the Northwest Forest Plan (NWFP) area that have been sampled for inchannel attributes as of 2009. 


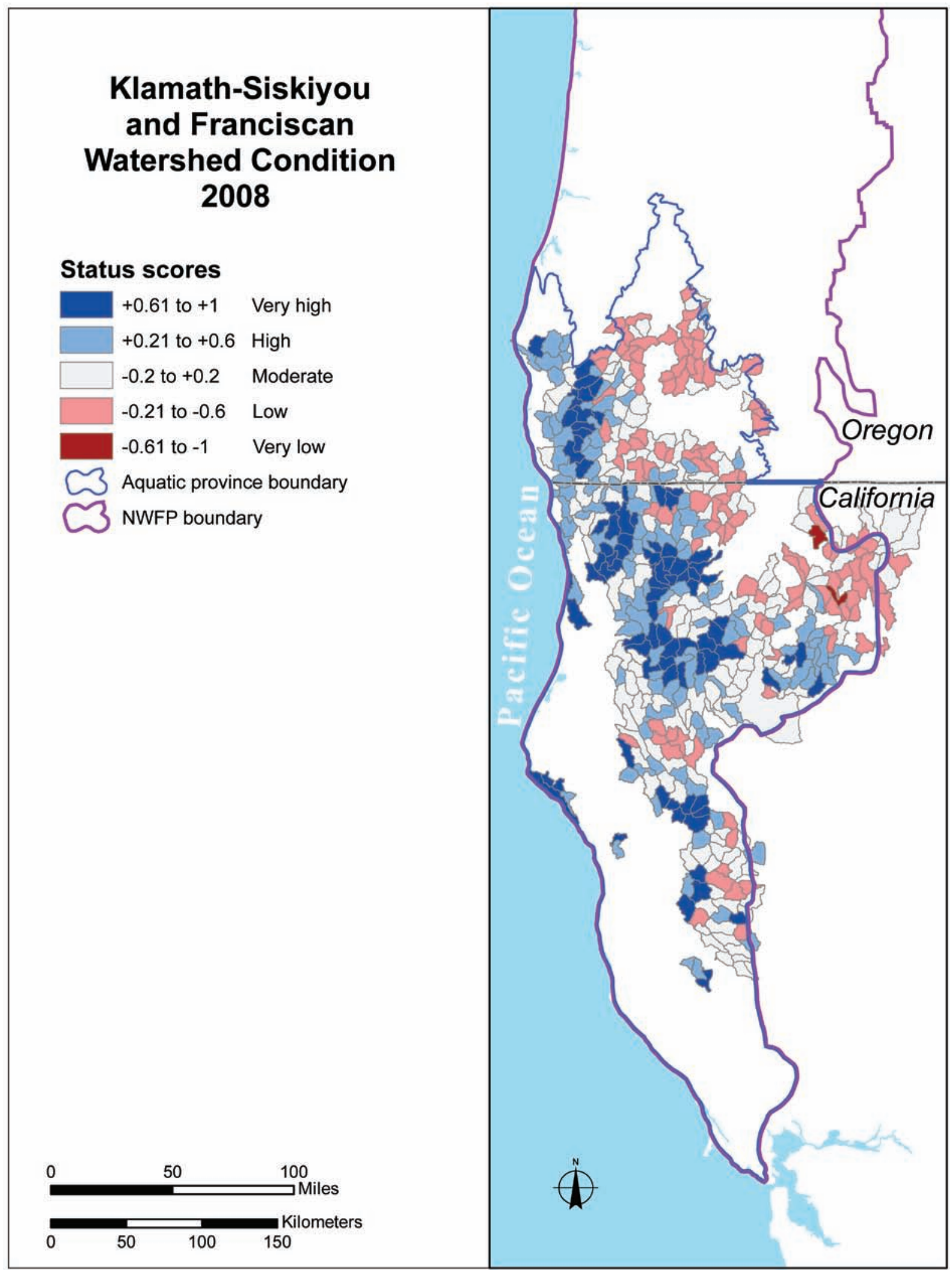

Figure 58-Watershed condition status scores (2008) for the Klamath-Siskiyou and Franciscan provinces in the Northwest Forest Plan (NWFP) area. 


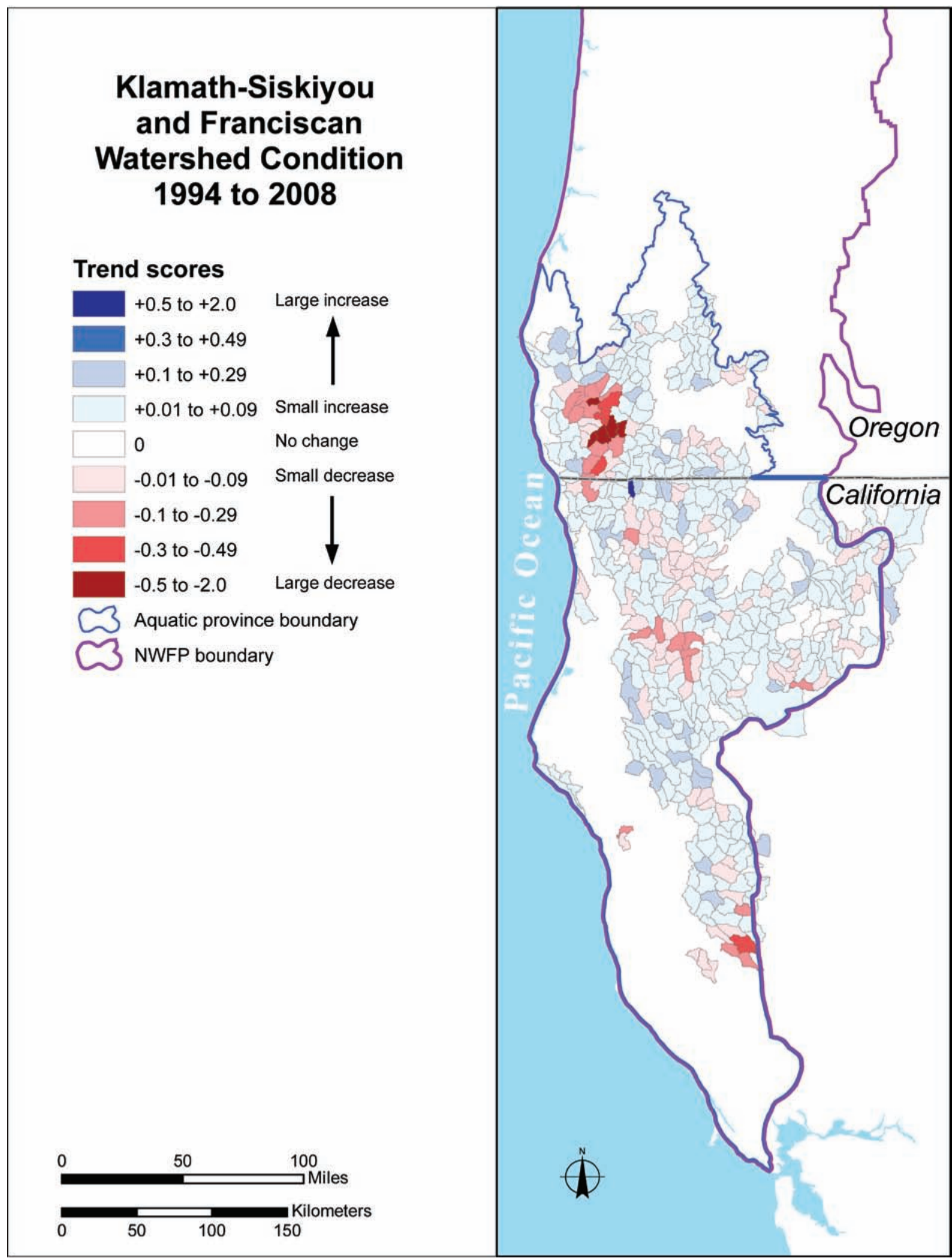

Figure 59-Watershed condition trend scores (1994 to 2008) for the Klamath-Siskiyou and Franciscan provinces in the Northwest Forest Plan (NWFP) area. 


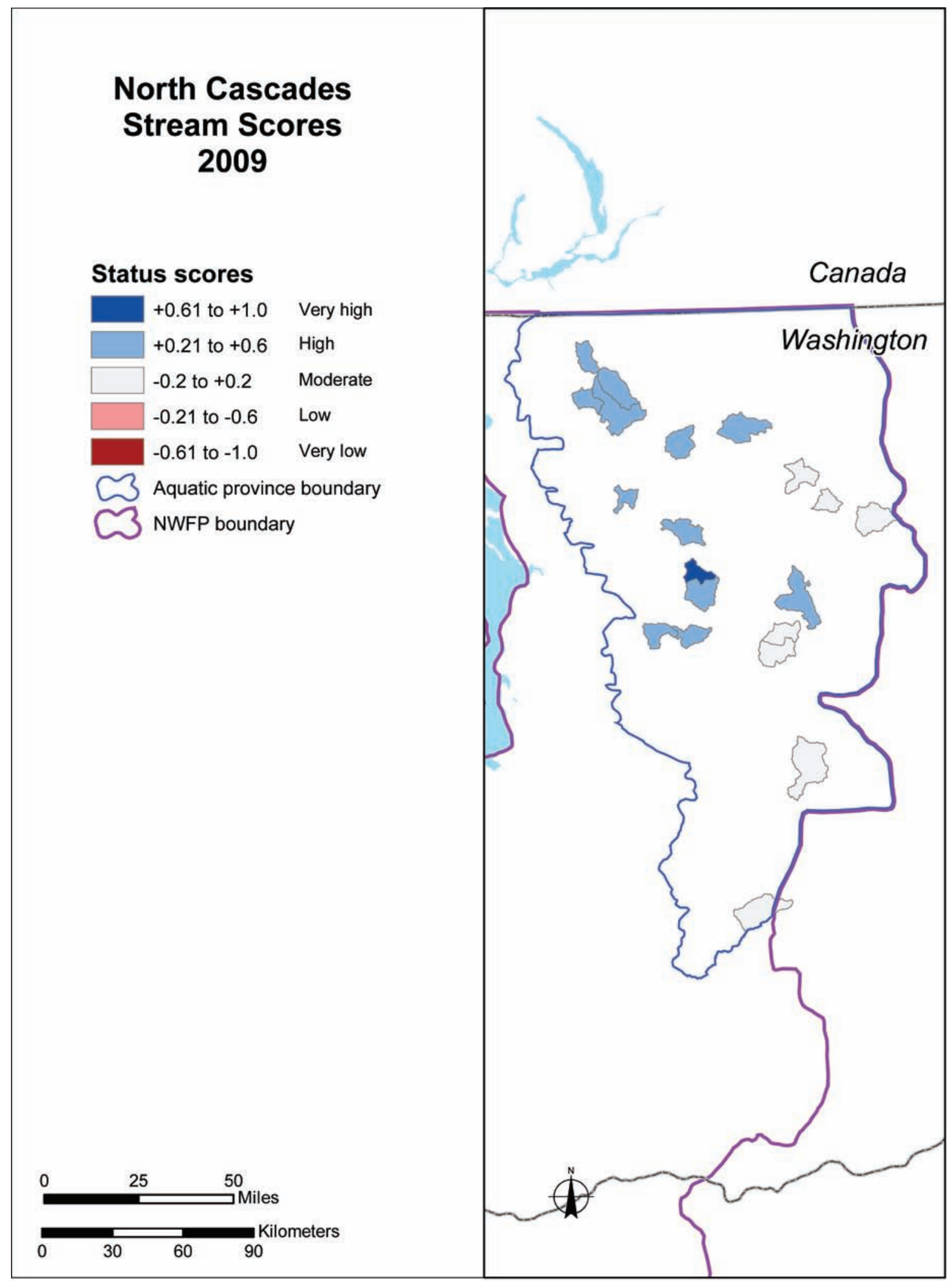

Figure 60-Distribution of inchannel condition scores for the randomly selected watersheds in the North Cascades province in the Northwest Forest Plan (NWFP) area that have been sampled for inchannel attributes as of 2009. 


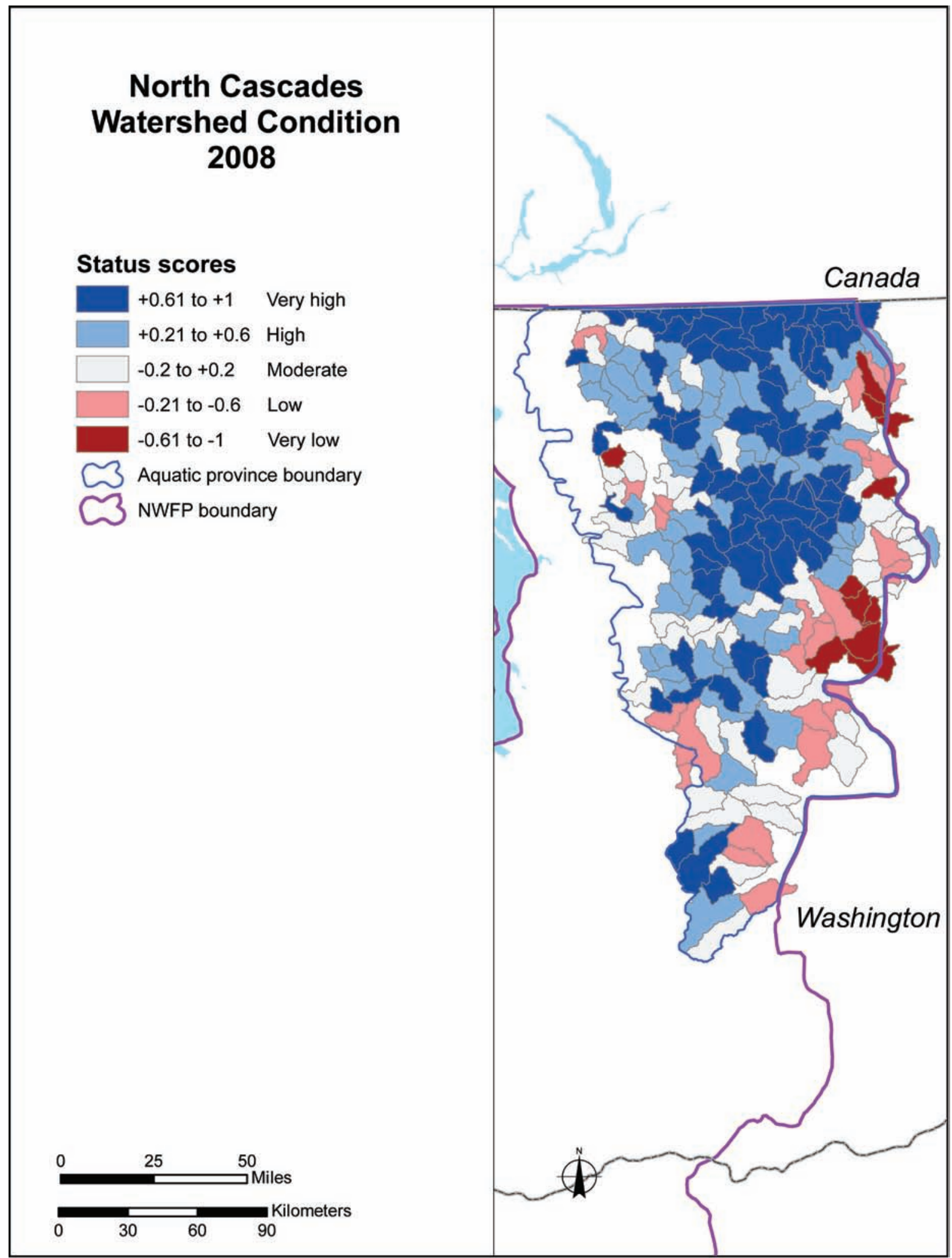

Figure 61-Watershed condition status scores (2008) for the North Cascades province in the Northwest Forest Plan (NWFP) area. 


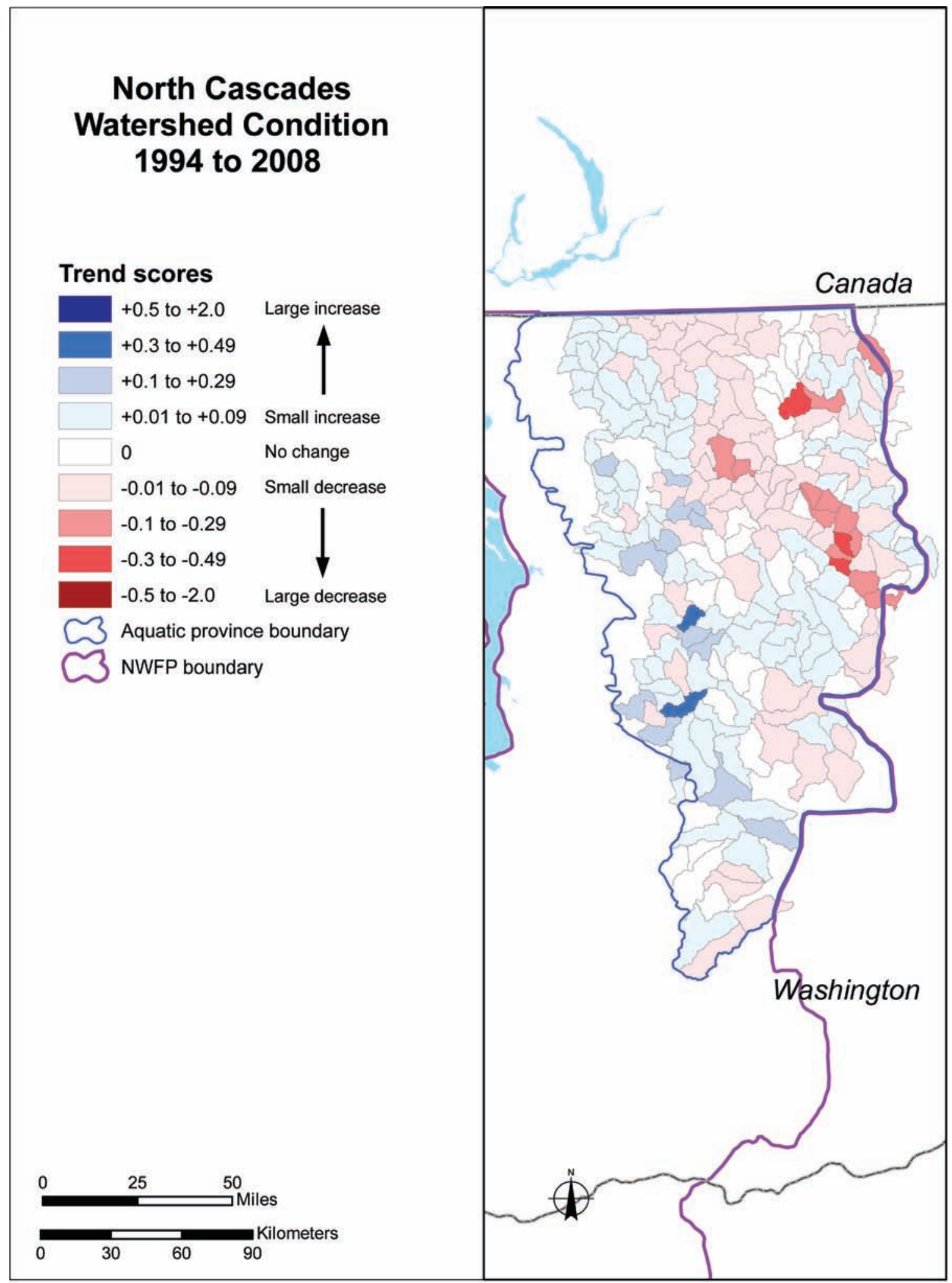

Figure 62-Watershed condition trend scores (1994 to 2008) for the North Cascades province in the Northwest Forest Plan (NWFP) area. 


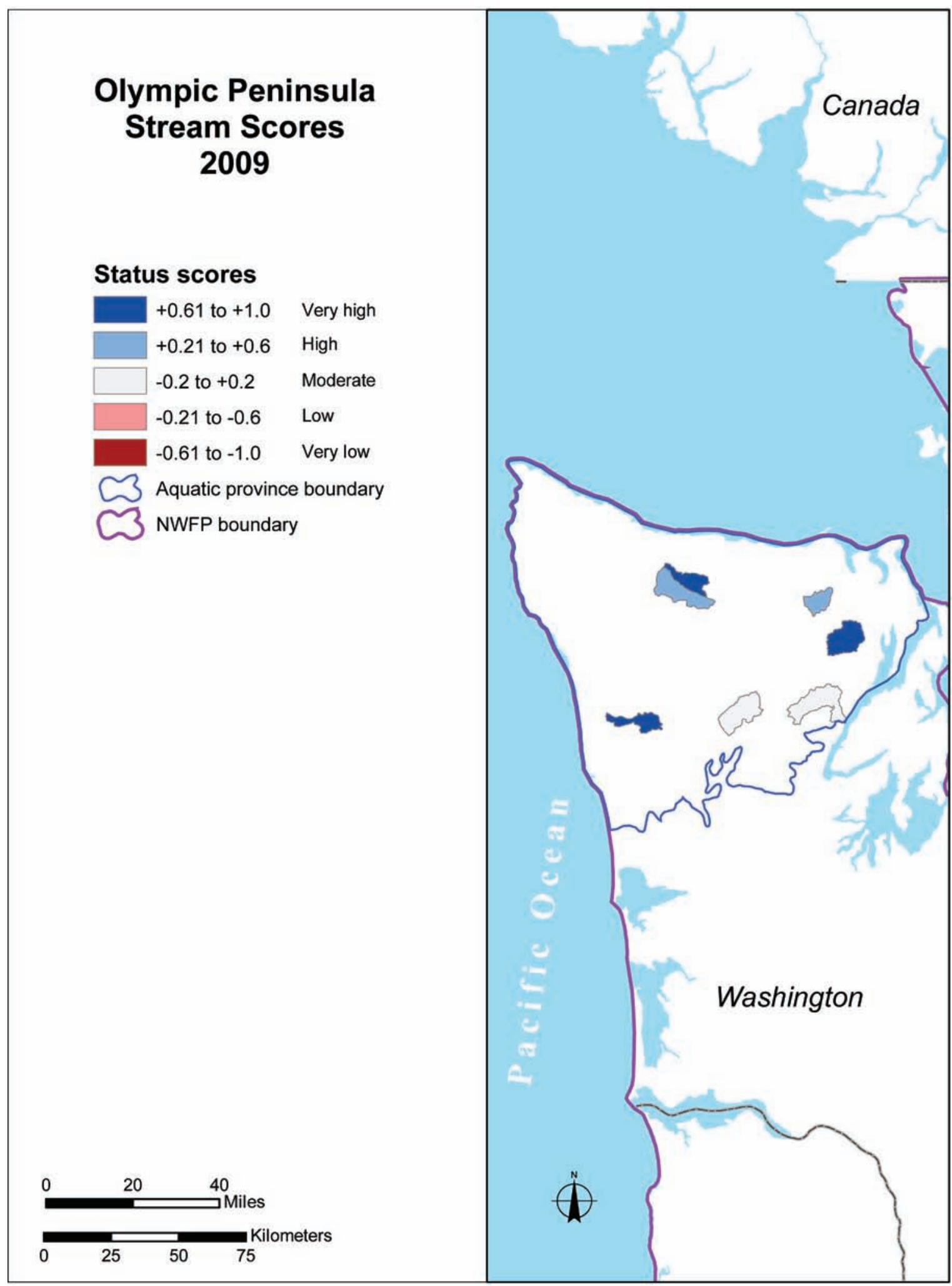

Figure 63-Distribution of inchannel condition scores for the randomly selected watersheds in the Olympic Peninsula province in the Northwest Forest Plan (NWFP) area that have been sampled for inchannel attributes as of 2009. 


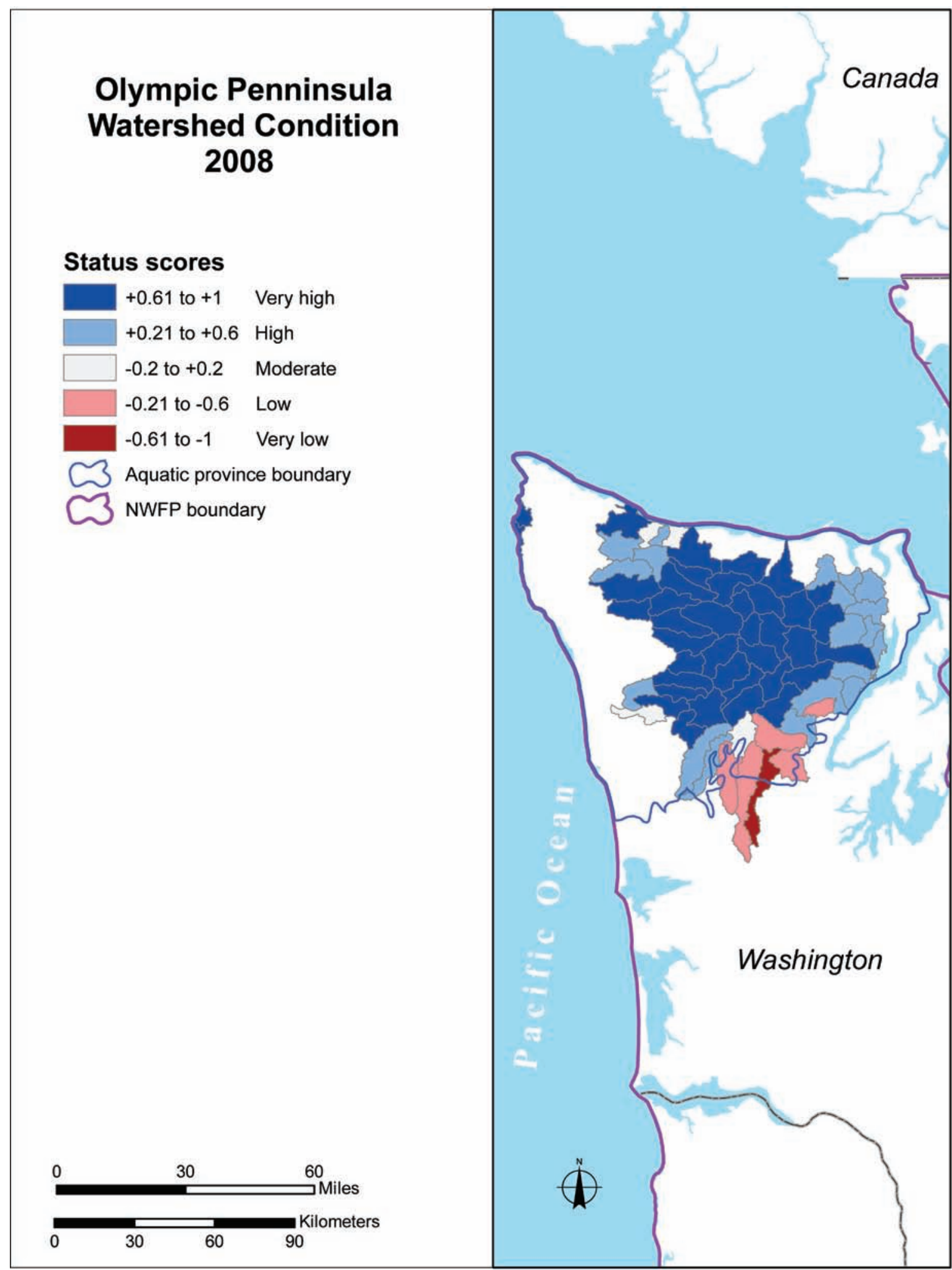

Figure 64-Watershed condition status scores (2008) for the Olympic Peninsula province in the Northwest Forest Plan (NWFP) area. 


\section{Olympic Penninsula Watershed Condition 1994 to 2008}

Trend scores

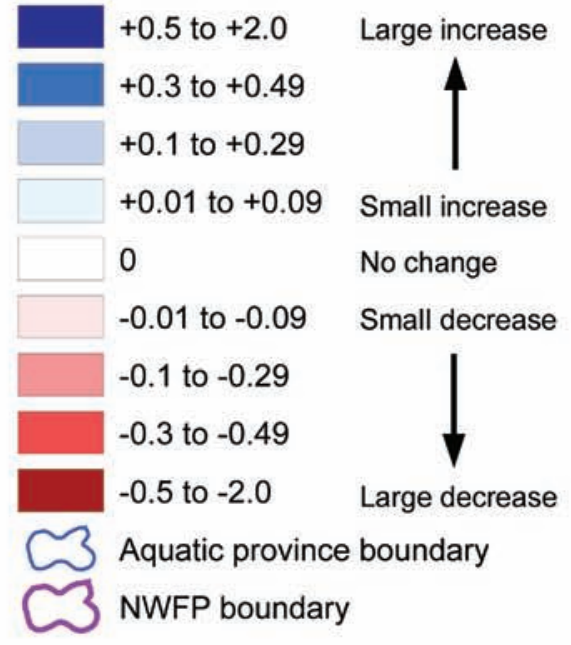
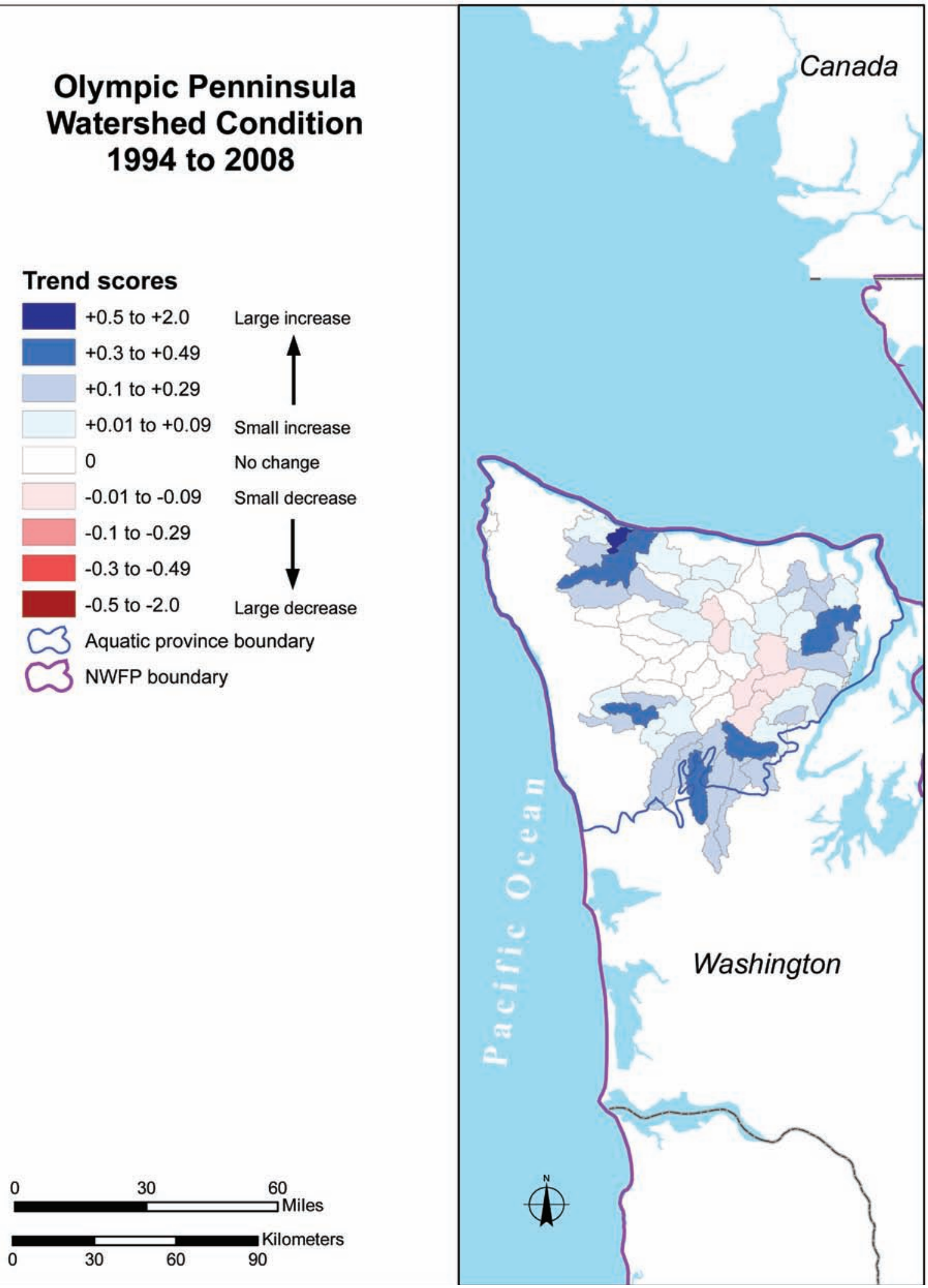

Figure 65-Watershed condition trend scores (1994 to 2008) for the Olympic Peninsula province in the Northwest Forest Plan (NWFP) area. 


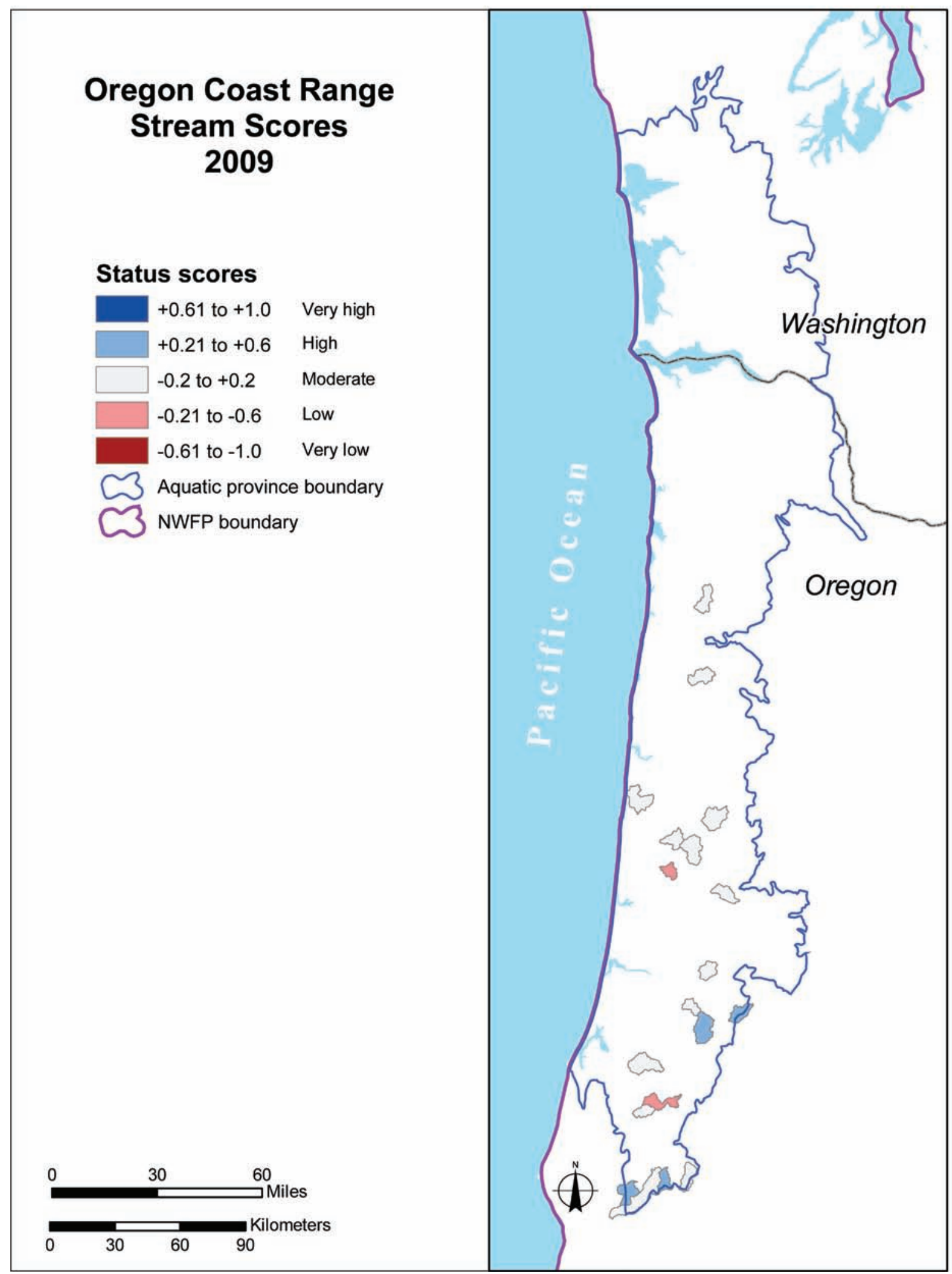

Figure 66-Distribution of inchannel condition scores for the randomly selected watersheds in the Oregon Coast province in the Northwest Forest Plan (NWFP) area that have been sampled for inchannel attributes as of 2009. 


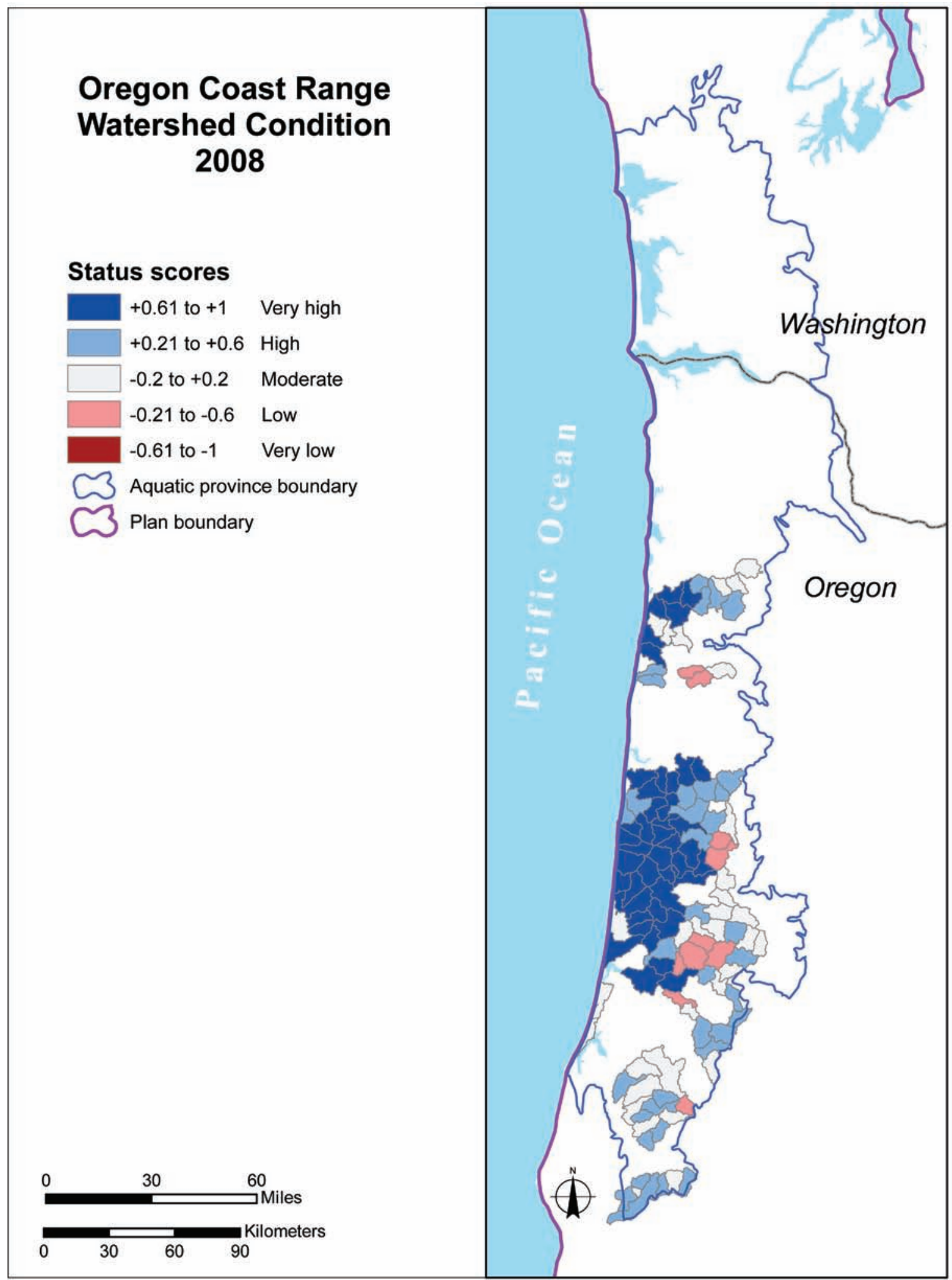

Figure 67-Watershed condition status scores (2008) for the Oregon Coast province in the Northwest Forest Plan (NWFP) area. 


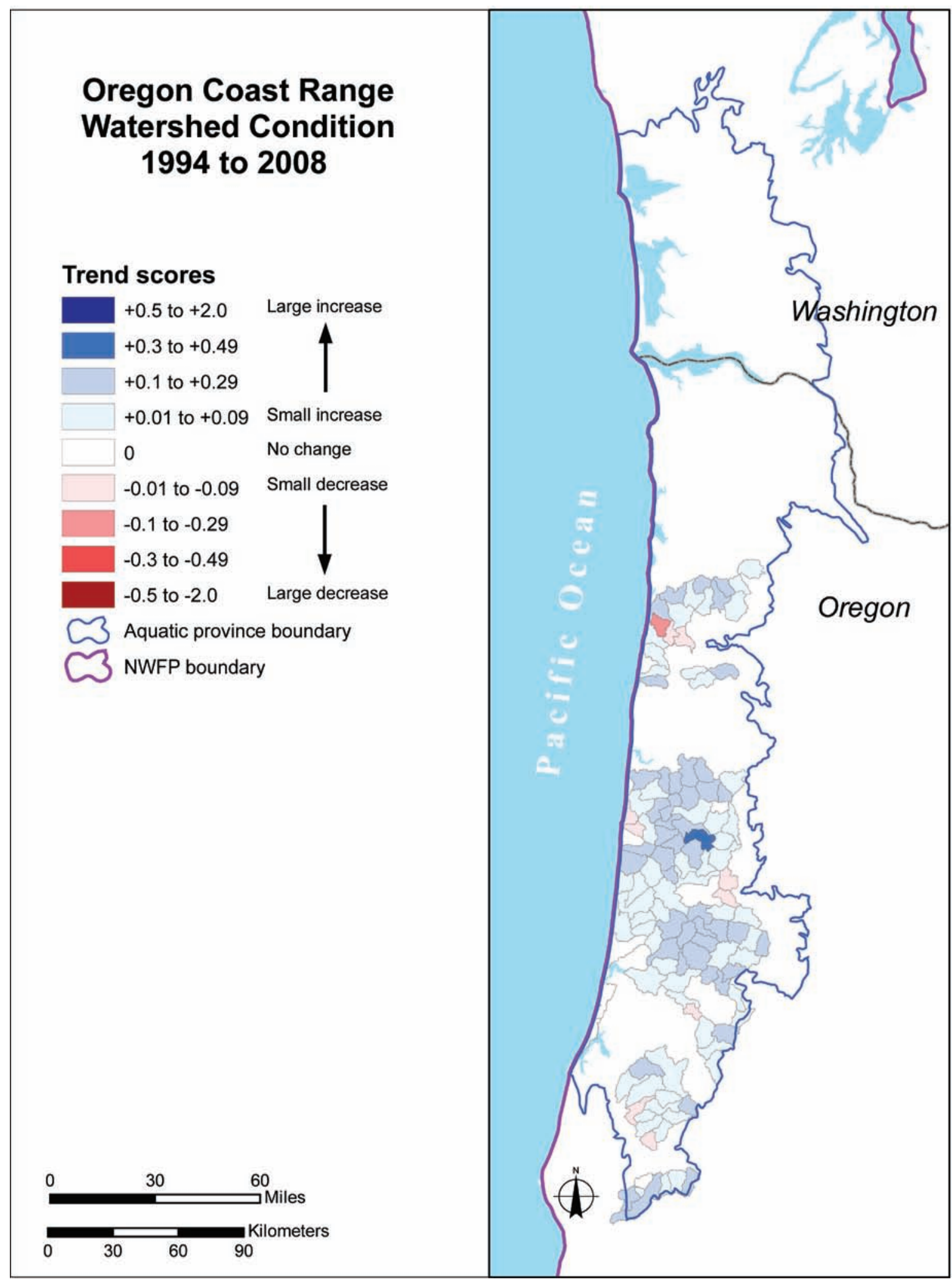

Figure 68-Watershed condition trend scores (1994 to 2008) for the Oregon Coast province in the Northwest Forest Plan (NWFP) area. 


\section{Appendix 5: Additional Information on Inchannel, Upslope, and Riparian Data}

\section{Inchannel Data}

\section{Watershed Selection}

The study design identified 250 randomly selected watersheds (see app. 3) from the 1,379 watersheds in the sixthfield watershed coverage (version 1.1, dated 2002) in the Northwest Forest Plan (NWFP) area, where more than 25 percent of the total stream length was located on federal land. We excluded watersheds from sampling if any of the following conditions were met:

1. A minimum of sampling four stream reaches could not be completed within 6 days (the length of time available each sampling trip) because of time constraints, accessibility issues, or stream reach constraints (see below).

2. Watersheds that did not have at least four sites that met the site selection criteria.

Sampling of some watersheds has been delayed because of disturbances that prevented field crew access, including (1) watersheds deemed dangerous for a survey crew to be working in the area (i.e., law enforcement personnel identified a watershed as currently having prevalent drug-growing operations) and (2) fire activity that blocked or limited road/ trail access to the watershed or had potential to spread, endangering the crew while working in the stream.

\section{Inchannel Site Selection}

Given the list of randomly selected sites, crews sampled individual sites until an 8-day sampling period expired. In each watershed, sites were sampled in the order they were selected. The number of sites sampled was typically a function of access (i.e., more sites were sampled in areas that were easily accessed). We excluded individual stream reaches from sampling if:

1. The stream reach was not safely accessible; i.e., it could not be reached without putting the crew in danger. (A long hike into a steep canyon did not qualify as a dangerous situation for the crew.)

2. The stream reach was not wadeable because of depth or current.
3. Travel time (round trip) from road camp or wilderness camp was over 4 hours (the wilderness camp cannot be more than a day hike from the trailhead).

4. The geographic positioning system (GPS) point (used to identify the beginning of a stream reach) was located on private land.

5. The GPS point for a stream reach was located in a lake, a wetland or marsh, or on a dam or glacier.

6. The stream reach was an artificial stream or irrigation canal.

\section{Upslope/Riparian Data}

Common Geographic Information System (GIS) Layers Used for All Provinces

\section{Watershed boundaries -}

The boundaries used were from the first draft of the sixthfield hydrologic unit code (HUC) boundaries developed by the Regional Ecosystem Office dated 2002. The first draft (version 1.1) was used because it was the version available when the 250 watersheds were selected.

\section{Streams and lakes-}

The Oregon and Washington streams and water bodies were taken from the USDI Bureau of Land Management (BLM) 1:24,000 stream geodatabase. The BLM created regional geodatabases by joining the Pacific Northwest hydrography framework (HUC) watershed data, so the line work is identical to the northwest hydrography framework layer. This stream layer has highly variable densification, but most of our metrics are calculated per stream mile and so are relatively insensitive to stream density (e.g., more road crossings would be mapped on a denser stream layer but the per-stream-mile metric would not necessarily be higher). The California layer was pieced together by the USDA Forest Service (FS) Pacific Southwest Region remote sensing laboratory from a combination of FS, BLM, and cartographic feature file data. The resulting layer also had varying stream density depending on the source. Some attributes were applied only to perennial streams, which excluded streams coded as unknown or null. 


\section{Riparian areas/stream buffers -}

Riparian areas differed by province, and different riparian buffer widths were sometimes used for road-stream interactions and vegetation. Buffer widths are expressed here as one-sided distance from the stream, so a 50-m (154-ft) buffer creates a riparian area that is $100 \mathrm{~m}$ (328 ft) wide. Riparian areas were created by buffering the stream lines by the prescribed width. Lakes were removed from the final buffered layer.

\section{Digital elevation models -}

Thirty-meter (98-ft) digital elevation models (DEMs) were obtained in 2001 from the National Elevation Data set (NED) compiled by the U.S. Geological Survey (USGS).

\section{Average precipitation-}

Average annual precipitation from 1961 to 1990 downloaded from the Oregon State University PRISM Climate Group (http://www.prism.oregonstate.edu/products/).

\section{Roads-}

Road layers used in Oregon and Washington were a combination of FS road layers with the BLM ground transportation layer (GTRN). The FS layers were obtained from each of the national forests in the NWFP area. The FS layers included attributes from the Infrastructure (INFRA) application attached to the road segments. The road layers were clipped to the ownership boundary of the forest. The FS ownership areas were removed from the BLM layer, and the FS road layers were pasted in using a "cookie cutter" process. No edge matching was done. The BLM and FS layers are from 2008. The decommissioning and year-built attributes were used to determine the change in the road system since 1994. The FS Pacific Southwest Region remote sensing laboratory constructed the California road layer.

\section{Vegetation-}

Detailed attributes of forest composition and structure were mapped for all forests in the NWFP area for two "bookend" dates using gradient nearest neighbor (GNN) imputation
(Ohmann and Gregory 2002). The bookend dates were 1996 and 2006 in Washington and Oregon, and 1994 and 2007 in California. The vegetation mapping for NWFP monitoring marks the first application of GNN imputation to multiple imagery dates. The primary challenge was to develop GNN model-based maps for the two bookend dates that were temporally consistent with each other and with maps of forest disturbance. A full description of the GNN bookends methodology can be found in Moeur et al. (2011).

Gradient nearest neighbor is one of many variations of nearest neighbor imputation methods. The GNN method was developed in the Pacific Northwest and has been applied to broad-scale vegetation mapping across a wide range of forest ecosystems (Ohmann et al. 2007, Pierce et al. 2009). In GNN, forest attributes from regional inventory plots are assigned to map pixels where data are missing on the basis of a modeled relationship between the detailed forest attributes from plots and a combination of spatial predictor variables derived from Landsat satellite imagery, climate variables, topographic variables, and soil parent materials. The assigned plot data allow generation of thematic maps for any detailed attribute (or combination of attributes) of forest composition or structure measured on the plots. Ground data for GNN models were basal area by tree species and size class from Forest Inventory and Analysis (FIA) periodic inventories on nonfederal lands, FIA annual inventory on all ownerships, and current vegetation survey inventories on FS and BLM lands. The assumption behind GNN methods is that two locations with similar combined spatial "signatures" should also have similar forest structure and composition.

For the bookends analysis, the GNN models used Landsat imagery that had been geometrically rectified and radiometrically normalized through time using the LandTrendr algorithms (Kennedy et al. 2007). The goal was to minimize differences in forest characteristics between the GNN bookend models that were caused by differences in the imagery that did not reflect real changes on the ground. 


\section{Vegetation disturbance-}

A new approach to monitoring landscape change was implemented to map forest disturbance in the NWFP. Landsatbased detection of trends in disturbance and recovery (LandTrendr) produces yearly maps of forest disturbance using new analysis of annual Landsat Thematic Mapper satellite imagery. The LandTrendr approach improves the temporal frequency of disturbance maps, better separates subtle change from background noise, and can detect phenomena that cannot be captured by older technologies that compare only two images at a time (Kennedy et al. 2010). A full description of the LandTrendr methodology can be found in Moeur et al. (2011).

In LandTrendr, annual time series of Landsat imagery were assembled for the entire NWFP area and then processed using basic atmospheric correction, cloud screening, and radiometric normalization. After image preparation, the time series of the normalized burn ratio (NBR) (van Wagtendonk et al. 2004) for each 30-m (98-ft) pixel was extracted, and temporal segmentation algorithms were used to identify periods of both stability and change in each pixel's NBR trajectory (Kennedy et al. 2007).

Maps were created by evaluating each pixel's NBR segmentation results. Disturbance segments were identified as those experiencing declines in NBR over time, and pre- and postdisturbance percentage of vegetation cover was predicted using a statistical model of cover developed from photo-interpreted plots (Cohen et al. 2010). Relative cover loss was calculated as the change in cover divided by predisturbance cover. Pixels with less than 15 percent relative vegetation loss over 1 year were removed, and groups of remaining adjacent pixels with the same disturbance year and larger than about 1 ha (2.5 ac, 11 pixels) were retained as disturbance patches. Each pixel remaining in a patch was labeled with the magnitude of change (relative cover), duration of the loss process (in years), year of disturbance onset, and likely cause of the disturbance (fire, insect, or harvest). Allowing for slight mismatch in timing of segmentation (typically \pm 1 year for harvest and fire), the LandTrendr segmentation algorithms were found to capture and correctly time 90 and 86 percent of the high-intensity harvest and fire events, respectively. Medium-intensity fire and harvest were also captured with high accuracy (about 75 percent), and only lost significant sensitivity at low intensity-level.

\section{Areas excluded from vegetation analysis-}

Subalpine areas, along with nonforested areas, were excluded from the vegetation analysis. Nonforested areas were based on a mask defined by the Landscape Ecology, Modeling, Mapping and analysis group (http://www.fsl.orst. edu/lemma) for the Interagency Mapping and Assessment Project (IMAP) data in Oregon and Washington, and a nonforested mask developed by the northern spotted owl (Strix occidentalis caurina) and marbled murrelet (Brachyramphus marmoratus) NWFP habitat groups (Davis et al. 2011). Subalpine areas were defined as from zones 29 to 33 in the 2009 version of the modeled potential natural vegetation zones for Washington and Oregon (Henderson 2009). For California, the subalpine layer developed by the NWFP northern spotted owl group was used (Davis et al. 2011).

\section{Landslide risk-}

Landslide risk was estimated using a model developed by the Earth Systems Institute (Miller 2003). The model was calibrated for the NWFP area using landslide data derived from aerial photographs in 14 Aquatic and Riparian Effectiveness Monitoring Program (AREMP) sixth-field watersheds (Miller 2006). The model calculated a topographic risk factor, based on characteristics such as slope and concavity, from a 10-m (33-ft) DEM. This baseline susceptibility was multiplied by the calibrated vegetation and road risk factors. The vegetation multiplier was based on the quadratic mean diameter of all dominant and codominant trees (QMDA_DOM) in the plot assigned to the map pixel: greater than 4 in $=$ multiply by 0.5 , less than 4 in $=$ multiply by 1.48 . A road proximity multiplier of 2.73 was applied to all pixels within $50 \mathrm{~m}(164 \mathrm{ft})$ of a road. 


\section{Additional Details on Provincial Models}

This section provides additional attribute details not covered by the generic descriptions above and the attribute tables in appendix 4.

\section{High Cascades Province}

- Road crossings in high-landslide-hazard areas: High-hazard areas were defined by topographic landslide risk scores greater than 0.28 from the landslide model. The value of 0.28 was determined by using an existing map of hazard roads from the Olympic province. A 20-m (66-ft) buffer was applied to the Olympic hazard roads, and this was overlaid on the Miller (2006) topographic landslide risk layer. Eighty percent of these hazard road buffers were captured by a topographic risk threshold of 0.28 . This risk factor was applied to the High and West Cascades provinces after finding that their distributions of risk values were similar.

- Vegetation — riparian: Map pixels were classified as either lodgepole pine (Pinus contorta Dougl. Ex Loud.) or nonlodgepole, based on dominant species. A lower minimum qualifying diameter threshold was applied to lodgepole stands ( 8 in) than to nonlodgepole stands (14 in) for determining the percentage of the riparian area meeting the criteria.

- Vegetation-watershed: Different minimum qualifying canopy cover thresholds were applied to the wetter (70 percent) and drier (40 percent) areas of the province, as defined by the 40 -in precipitation contour from the PRISM average precipitation data. Watersheds in the rain-on-snow hydrologic zones are considered to be more sensitive to increases in peak flow from harvest and road building (Grant et al. 2008), so different evaluation criteria were applied to these zones. Zones were defined using a combination of the rain and snow bands from the BLM Western Oregon Plan revisions in Oregon and elevation classes in Washington. The elevation classes are less that $457 \mathrm{~m}$ (1,500 ft) for rain, 457 to $1219 \mathrm{~m}(1,500$ to $4,000 \mathrm{ft})$ for rain on snow, and greater than $1219 \mathrm{~m}(4,000 \mathrm{ft})$ for snow on snow.

\section{Klamath-Siskiyou and Franciscan Provinces}

- Road density on the lowest one-third of slope: The lowest one-third of the slope was determined by running a slope position Arc Macro Language (AML) script that uses DEMs and creates a grid with the slope numbered from 1 to 100, with 1 being the bottom and 100 the top. The numbers 1 to 33 were used to define the lower one-third of the slope. The lower one-third area was turned into a polygon layer and intersected with the roads.

- $\quad$ Off-road vehicle (OHV) trail density: The officially designated OHV trails were extracted from the FS INFRA layer and the BLM GTRN layer and miles summed by watershed.

- Vegetation - riparian and watershed-oak woodlands: Map pixels were classified as either oak (Quercus spp.) or nonoak, based on dominant species. Lower canopy cover evaluation criteria were applied to oak woodlands.

\section{North Cascades Province}

- $\quad$ Road density in hazard areas: Hazard areas were defined as having a topographic landslide risk value of greater than 1.02. The value of 1.02 was derived by comparing the current landslide model results with hazard areas determined in the AREMP 2004 report using the Shalstab model and land type associations (Gallo et al. 2005).

- Vegetation - east/west: Different vegetation metrics and evaluation criteria were applied on the east and west sides of the province, based on the Cascade crest (incorporating the Pickett crest).

- Vegetation — watershed - east, dry/wet areas: Different metrics were used for the wet and dry areas on the eastern side of the Cascades. Map pixels were assigned to dry areas using the following plant 
association groups: all ponderosa pine and Douglasfir plant association groups or zones, grand fir-pinegrass, grand fir-pinegrass-lupine, grand fir-pinemat manzanita, grand fir-oceanspray-pinegrass, grand fir-mountain snowberry, grand fir-spirea-bracken fern, grand fir-snowberry-pinegrass, shrub-steppe.

\section{Olympic Peninsula}

- Vegetation-riparian: Different metrics were applied to the wetter (southwest) and drier (northeast) zones of the province as defined by the 110-in precipitation contour in the PRISM average precipitation data. In the wetter zone, the metric was percentage of area where tree quadratic mean diameter was $\geq 20$ in or stand age was $\geq 100$ years. In the drier zone, the metric was percentage of area where tree quadratic mean diameter was $\geq 12$ in or stand age was $\geq 100$ years. Riparian area was defined as $160-\mathrm{ft}$ buffer around streams for both zones.

- Vegetation-urban/agriculture: The percentage of watershed covered by urban and agricultural land was calculated from the designations in the base vegetation data set (Moeur et al. 2011).

\section{Oregon Coast}

- Vegetation - urban/agriculture: The percentage of watershed covered by urban and agricultural land was calculated from the designations in the base vegetation data set (Moeur et al. 2011).

\section{West Cascades}

- Road crossings in high-landslide-hazard areas:

High-hazard areas were defined by topographic landslide risk scores greater than 0.28 from the landslide model. The value of 0.28 was determined using an existing map of hazard roads from the Olympic province. A $20-\mathrm{m}$ (66-ft) buffer was applied to the Olympic hazard roads, and this was overlaid on the Miller (2006) topographic landslide risk layer. Eighty percent of these hazard roads buffers were captured by a topographic risk threshold of 0.28. This risk factor was applied to the High and West Cascades provinces after finding that their distributions of risk values were similar.

- Vegetation-riparian: Map pixels were classified as either lodgepole pine or nonlodgepole, based on dominant species. A lower minimum qualifying diameter threshold was applied to lodgepole stands ( 8 in) than to nonlodgepole stands (14 in) for determining the percentage of the riparian area meeting the criteria.

- Vegetation-watershed: Different minimum qualifying canopy cover thresholds were applied to the wetter (70 percent) and drier ( 40 percent) areas of the province, as defined by the 40 -in precipitation contour from the PRISM average precipitation data. Watersheds in the rain-on-snow hydrologic zone are considered to be more sensitive to increases in peak flow from harvest and road building (Grant et al. 2008), so different evaluation criteria were applied to these zones. Zones were defined using a combination of the rain and snow bands from the BLM Western Oregon Plan revisions in Oregon and elevation classes in Washington. The elevation classes are less that $457 \mathrm{~m}(1,500 \mathrm{ft})$ for rain, 457 to $1219 \mathrm{~m}$ $(1,500$ to $4,000 \mathrm{ft})$ for rain on snow, and greater than $1219 \mathrm{~m}(4,000 \mathrm{ft})$ for snow on snow. 
GENERAL TECHNICAL REPORT PNW-GTR-856 


\section{Appendix 6: Quality Assessment of Upslope/Riparian and Inchannel Data}

\section{Land Use Categories}

Each subwatershed was categorized according to a Northwest Forest Plan (NWFP) land use allocation and a key/nonkey designation based on the categories covering the largest share of its land area. Table 11 provides summary statistics on the percentage of watershed area actually falling within its assigned category.

\section{Upslope and Riparian Attributes}

\section{Roads}

The 10-year Aquatic and Riparian Effectiveness Monitoring Program (AREMP) report (Gallo et al. 2005) assessed the accuracy of the corporate roads geographic information system (GIS) layer by comparing it to roads digitized from digital aerial photography data for 38 watersheds. Because the creation of a roads layer from aerial photography is resource intensive, and we have not heard of any major changes to the corporate GIS roads layer, we relied on a reanalysis of this past data set for assessing road attribute accuracy for the current report. Our reanalysis reduced the scope from all lands to federal lands only and changed the road crossings metric from a per-road-mile to a per-streammile measure. Summary statistics for the three primary road attributes used are presented in table 12.

\section{Vegetation}

The accuracy of the vegetation attributes used in the AREMP watershed assessment models are reported in LEMMA (2010) in terms of correlation coefficients (R) and root mean squared error (RMSE) by modeling region. We have summarized the range of each accuracy metric across all the regions in table 13

\section{Landslide Risk}

No error assessment has been done for the landslide risk attribute.

\section{Inchannel Attributes}

\section{Methods}

The AREMP implemented a quality assurance (QA) plan to ensure that all data collected were scientifically sound and of known quality and includes activities such as training field crews, capturing errors in data collection procedures, and conducting secondary surveys at randomly selected sites. Analysis of the remeasured subset of sample sites (generally referred to as the paired set of initial-survey and secondary-survey data) was conducted to determine the consistency of the sample data (table 14). These paired survey results were examined to distinguish between environmental and measurement effects. Environmental effects are the differences that occur naturally between watersheds and between sites in watersheds; these effects are considered uncontrollable. Measurement effects include differences in measurements between crews and unexplained error; these effects are considered controllable through training, refinements in field protocols (to reduce subjectivity), and improvement in equipment.

\section{Results}

Highlights of a 2010 review of 9 years of the QA program (Moyer 2010) and changes we are making in response to the review include the following:

- Additional training time is needed to ensure crews fully understand how to implement field protocols.

- An additional week of training was added during the 2010 field season.

- We should continue to develop and implement automated data checking processes such as data entry forms and data validation rules using the latest technology for efficiency.

- New applications for our data loggers to ensure accurate data entry were added during the 2010 field season. 
Table 11-Accuracy of land use category assignments to individual subwatersheds

\begin{tabular}{lcccc}
\hline Land use category & Mean & $\begin{array}{c}\text { Standard } \\
\text { deviation }\end{array}$ & Minimum & Maximum \\
\hline & \multicolumn{5}{c}{ Percent } \\
Congressionally reserved & 82 & 18 & 38 & 100 \\
Late-successional reserves & 76 & 18 & 35 & 100 \\
Matrix & 77 & 1 & 35 & 100 \\
\hline
\end{tabular}

Table 12-Difference in aerial photography-based road attributes compared to corporate geographic information system road attributes

\begin{tabular}{lccc}
\hline Attribute & Mean & $\begin{array}{c}\text { Standard } \\
\text { deviation }\end{array}$ & Range \\
\hline $\begin{array}{l}\text { Upslope road density } \\
\text { (road mi/upslope } \mathrm{mi}^{2} \text { ) }\end{array}$ & 14 & 13.5 & 0 to 57 \\
$\begin{array}{l}\text { Riparian road density } \\
\text { (road mi/riparian } \mathrm{mi}^{2} \text { ) }\end{array}$ & 18 & 20 & 0 to 80 \\
$\begin{array}{l}\text { Road crossings } \\
\text { (crossings/stream mi) }\end{array}$ & 28 & 38 & 0 to 150 \\
\hline
\end{tabular}

Table 13-Summary of vegetation attribute accuracy assessment metric ranges

\begin{tabular}{lcc}
\hline Attribute & $\mathbf{R}^{\boldsymbol{a}}$ & $\mathbf{N R M S E}^{\boldsymbol{b}}$ \\
\hline $\begin{array}{l}\text { Quadratic mean diameter of all dominant } \\
\text { and codominant trees }\end{array}$ & $0.44-0.78$ & $0.41-0.55$ \\
Quadratic mean diameter of all dominant & & \\
$\quad$ and codominant conifers & $0.42-0.72$ & $0.45-0.7$ \\
Canopy cover of all live trees & $0.7-0.8$ & $0.2-0.31$ \\
Canopy cover of all conifers & $0.65-0.82$ & $0.22-0.49$ \\
\hline
\end{tabular}

${ }^{a}$ Coefficient of correlation.

${ }^{b}$ Normalized root mean squared error. 
Table 14-Field attributes evaluated in the Quality Assurance Program report

\begin{tabular}{llcr}
\hline Attribute type & Attribute & Environment & Observer \\
\hline \multirow{2}{*}{$\begin{array}{l}\text { Channel } \\
\text { morphology }\end{array}$} & Percent & \\
& Site length & 75 & 17 \\
& Average bankfull width & 95 & 4 \\
& Average bankfull depth & 36 & 54 \\
& Average bankfull width:depth & 84 & 1 \\
& Bedload gradient & 96 & 2 \\
Physical habitat & Stream channel sinuosity & 5 & 87 \\
& Median particle size (D50) & 20 & 80 \\
& D50 without bedrock & 97 & 0 \\
& Pool tail crest fines & 42 & 2 \\
& Wood frequency & 85 & 8 \\
& Pool frequency & 57 & 19 \\
Water chemistry & Pool depth & 45 & 50 \\
Biological & Dissolved oxygen & 29 & 12 \\
& Specific conductance & 74 & 25 \\
& EPT ${ }^{a}$ richness & 26 & 0 \\
& Intolerant taxa richness & 15 & 37 \\
& Terrestrial amphibian Simpson's & 55 & 16 \\
& index & & \\
\hline
\end{tabular}

The environment column represents the percentage of total variation in the data owing to the differences between watersheds plus the differences between sites within watersheds. The observer column represents the percentage of the total variation in the data owing to measurement by crews and unexplained error. The two columns do not total 100 percent because other terms related to time (differences through time) account for the remainder of the total variation.

${ }^{a}$ Ephemeroptera, Plecoptera, and Trichoptera taxa.

- Annually review the training program and evaluate all aspects for possible improvement.

- Changes in our 2010 field season included adding more laser training and more practice reaches.

- Continue surveying some watersheds a second time during the same year as the initial survey to determine the between-crew variability.

- Eight watersheds will have reaches resampled by independent crews in 2010 to determine between-crew variability.

- The variation in measurement by survey crews across all years was low for average bankfull width, average bankfull width:depth, gradient, the median particle size $\left(\mathrm{D}_{50}\right)$ without bedrock, pool tail crest fines, DSM (decision-support model) wood pieces and frequency, and EPT (Ephemeroptera, Plecoptera, Trichoptera) richness (table 14). This indicates these field measurements are more consistent (more accurately measured) than the other field attributes. No change is recommended for protocols associated with these attributes.

- The variation in measurement across all years in average bankfull depth, stream channel sinuosity, median particle size $\left(D_{50}\right)$, number of pools, pool frequency, average residual pool depth, dissolved oxygen, specific conductance, intolerant richness, and terrestrial amphibian Simpson's index is high relative to the environmental variation (table 14). Further examination of how the protocols are being implemented is warranted. 
- On an annual basis, some field attributes such as the frequency of DSM wood pieces and pool frequencies show marked improvement in performance (measurement accuracy) after 2004, which corresponds to when an overhaul of the training program occurred (i.e., new training sites, development of standardized lesson plans, and an overall training document as a component of the QA program) and the standardization of field protocols with the PACFISH/INFISH Biological Opinion Effectiveness Monitoring Program.
- Data completeness (the proportion of sites with measurements present for all attributes) was 92, 92, and 86 percent for channel morphology, physical habitat, and water chemistry attributes, respectively.

The amount of effort invested in conducting secondary surveys of sites as part of the QA program was equivalent to about 2 years of work spread across the 9 years examined. Indepth findings and recommendations resulting from examining all years of data collected by the program will be posted at http://www.reo.gov/monitoring/reports/watershedreports-publications.shtml. 


\section{Appendix 7: Contact Information}

\section{Want to know more? Please contact:}

Steve Lanigan, team leader

Sean Gordon, research associate

Peter Eldred, Geographic Information

System (GIS) analyst

Chris Moyer, fisheries biologist

Mark Isley, database manager

Steve Wilcox, GIS cartographer

Heidi Andersen, fisheries biologist
503.808 .2261

503.808 .2698

541.750 .7078

541.750 .7122

541.750 .7067 slanigan@fs.fed.us

seangordon@fs.fed.us

peldred@fs.fed.us

cmoyer@fs.fed.us

markisley@fs.fed.us

sewilcox@fs.fed.us

hvandersen@fs.fed.us

Please visit our Web site for more information on publications, presentations, reports, and summer employment: http://www.reo.gov/monitoring/watershed-overview.shtml. 


\begin{tabular}{|ll|}
\hline \multicolumn{2}{|c|}{ Pacific Northwest Research Station } \\
Web site & http://www.fs.fed.us/pnw \\
Telephone & $(503) 808-2592$ \\
Publication requests & $(503) 808-2138$ \\
FAX & $(503) 808-2130$ \\
E-mail & pnw_pnwpubs@fs.fed.us \\
Mailing address & Publications Distribution \\
& Pacific Northwest Research Station \\
& P.O. Box 3890 \\
& Portland, OR 97208-3890 \\
\hline
\end{tabular}




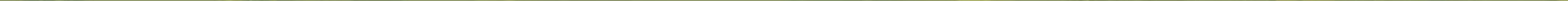

